Aus der Abteilung Neurologie

(Prof. Dr. med. M. Bähr)

im Zentrum Neurologische Medizin

der Medizinischen Fakultät der Universität Göttingen

\title{
Neuroprotektion durch BAG1 in Modellen des idiopathischen Parkinson-Syndroms
}

\author{
INAUGURAL-DISSERTATION \\ zur Erlangung des Doktorgrades \\ der Medizinischen Fakultät \\ der Georg-August-Universität zu Göttingen \\ vorgelegt von \\ Anja Friederike Baumann \\ aus \\ Hamburg
}

Göttingen 2010 
Dekan:

1. Berichterstatter: $\quad$ Prof. Dr. med. P. Kermer

2. Berichterstatterin: Prof. Dr. med. J. Gärtner

Tag der mündlichen Prüfung: 19.01.2011 


\section{INHALTSVERZEICHNIS}

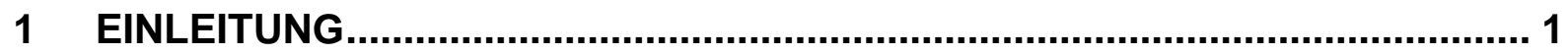

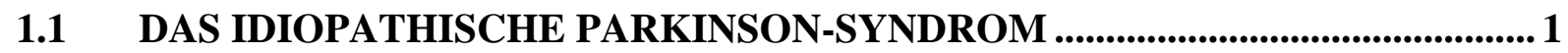

1.1.1 Epidemiologische Daten und Symptomatik ...................................................... 1

1.1.2 Pathomorphologischer Hintergrund des IPS .............................................. 1

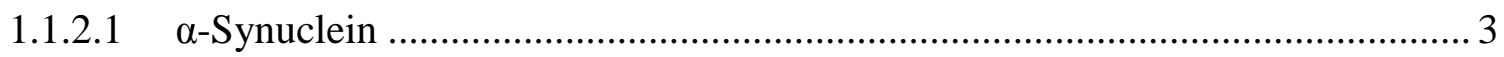

1.1.2.1.1 Struktur und Funktion ..................................................................... 3

1.1.2.1.2 Mutationen und Phänotypen.................................................................... 4

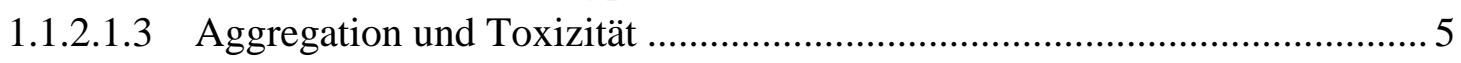

1.1.2.1.4 Posttranslationale Modifikation ............................................................... 7

1.1.2.1.5 Übertragbarkeit von krankheitspezifischem $\alpha$-Syn .................................... 7

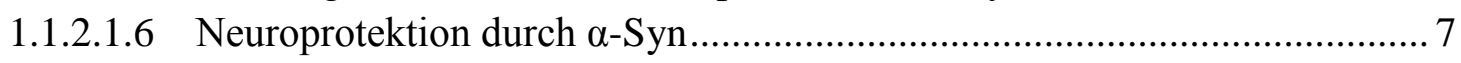

1.1.2.2 Umwelteinflüsse und Toxine ...................................................................... 8

1.1.2.3 Das Alter als Risikofaktor für das IPS ..................................................... 9

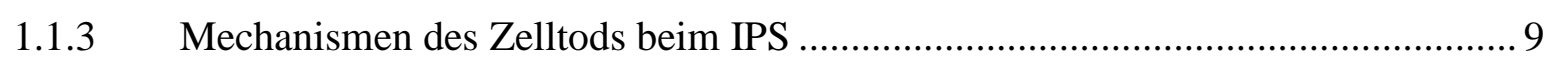

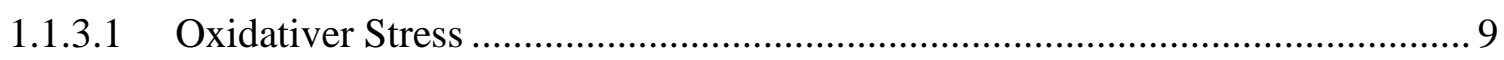

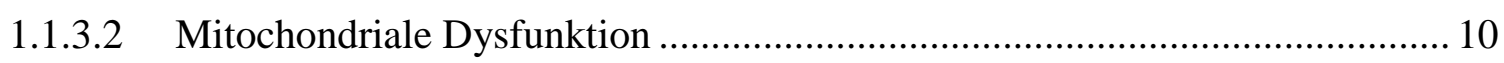

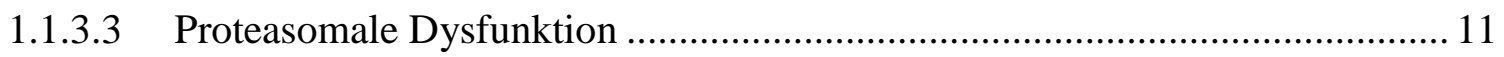

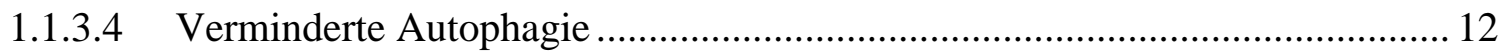

1.1.4 Modelle des Morbus Parkinson ....................................................................... 13

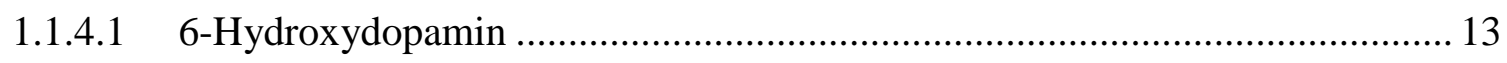

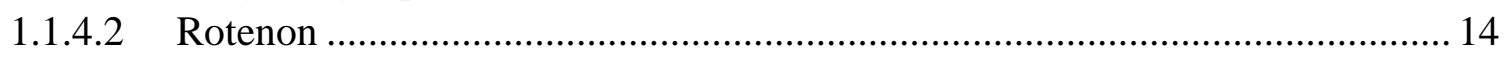

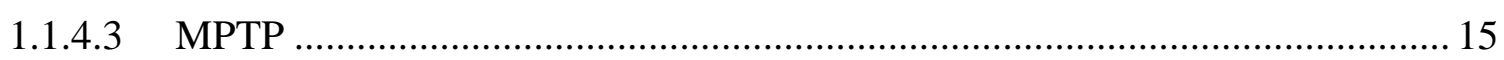

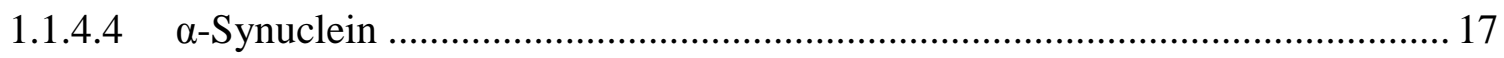

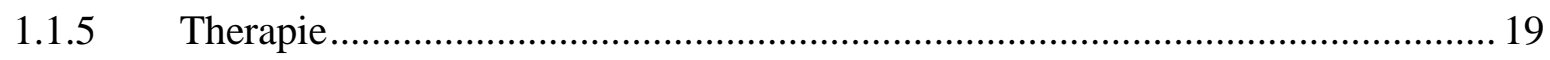

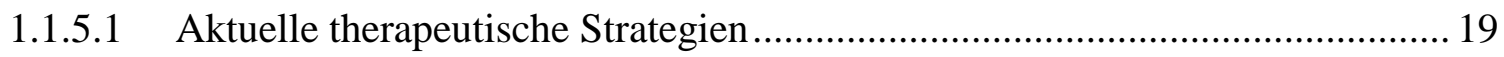

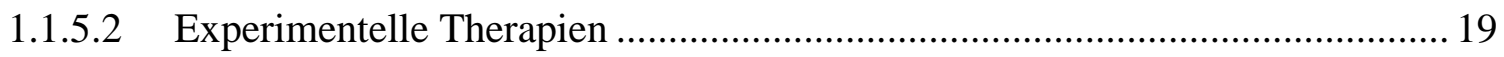

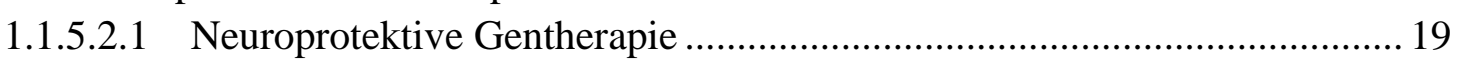

1.1.5.2.2 AAV-Vektoren als Werkzeuge der Gentherapie..................................... 20

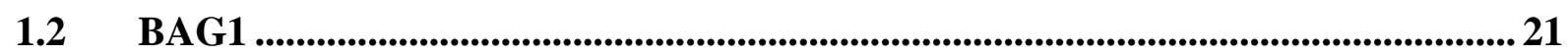

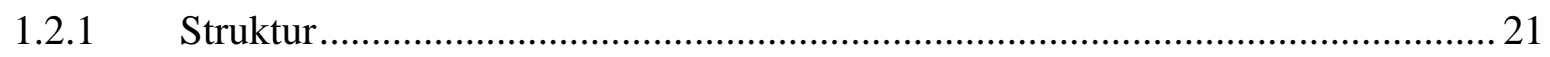

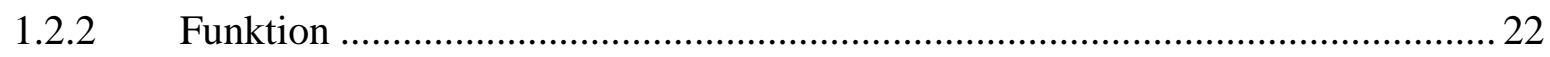

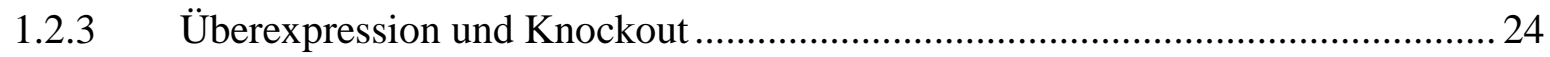

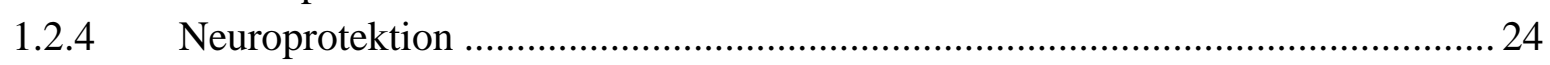

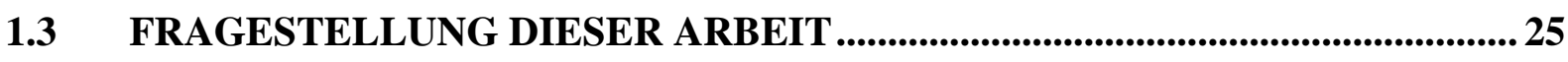

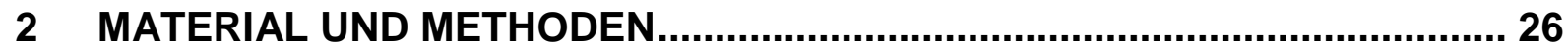




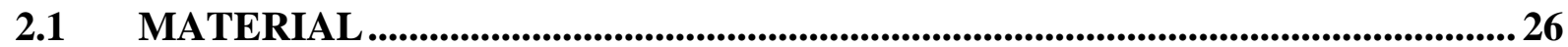

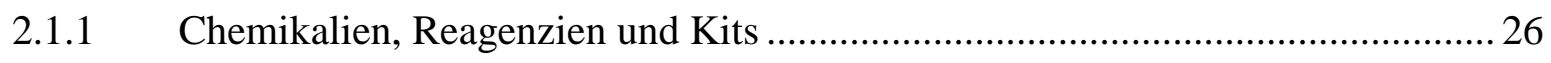

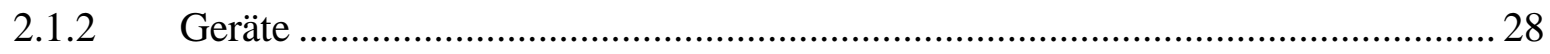

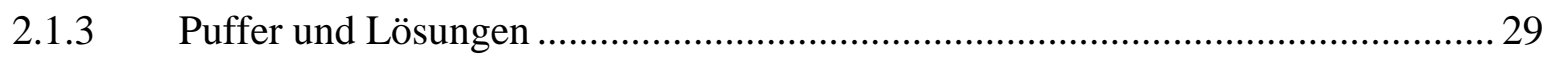

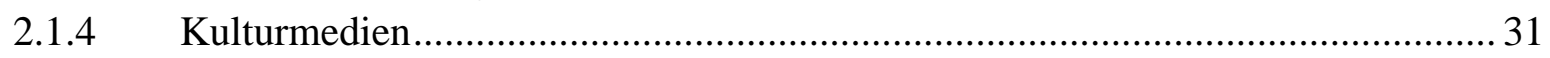

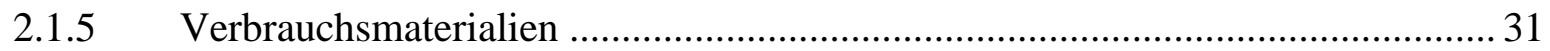

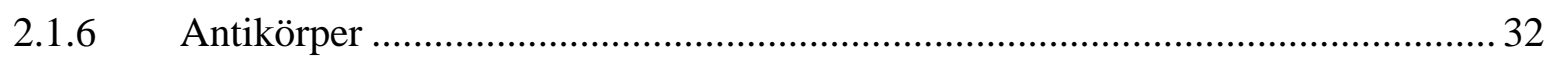

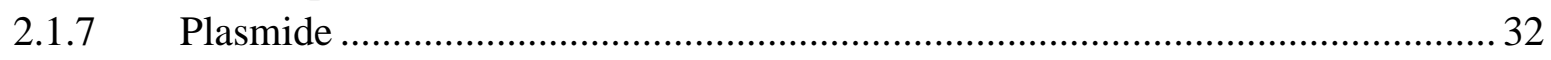

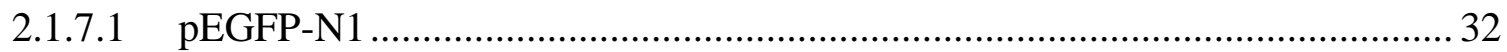

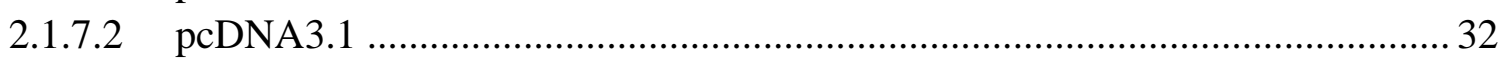

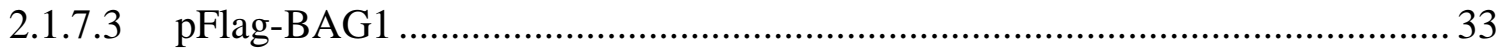

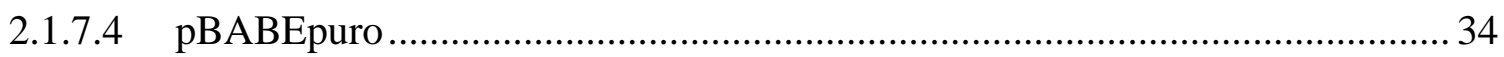

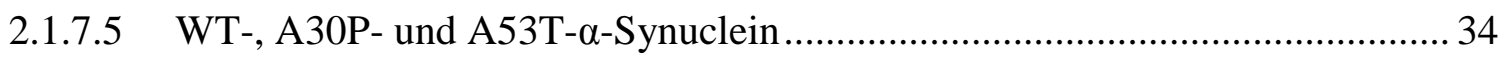

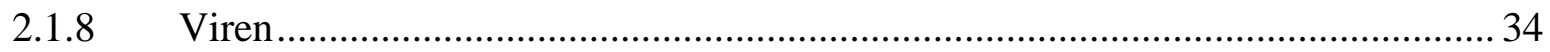

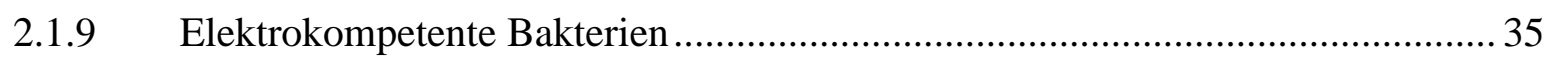

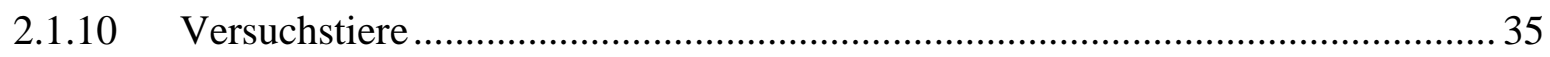

2.2 HERSTELLUNG UND AMPLIFIKATION DER PLASMIDE........................... 35

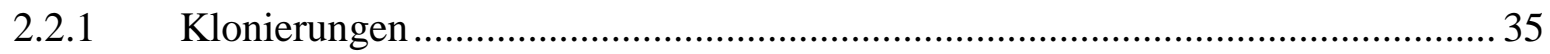

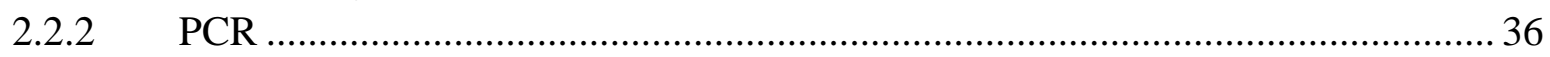

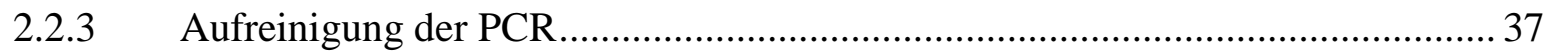

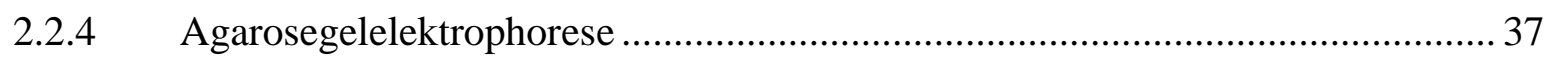

2.2.5 Aufreinigung der Agarosegelelektrophoreseprodukte .................................... 38

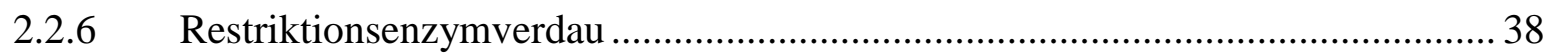

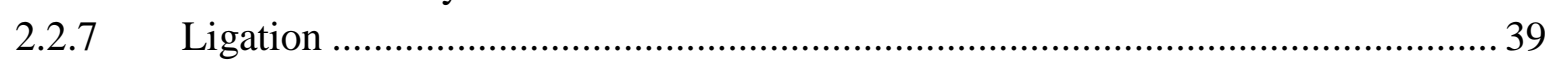

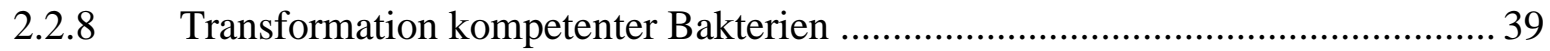

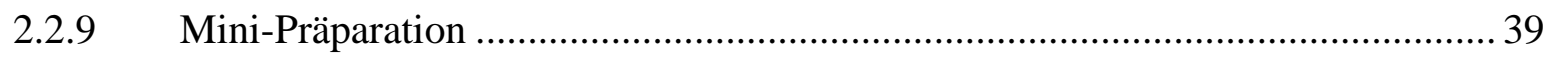

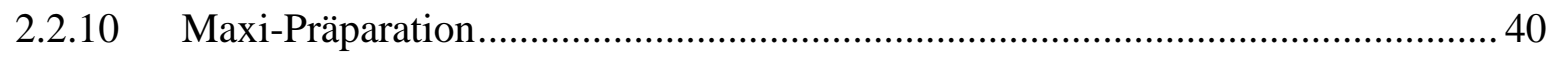

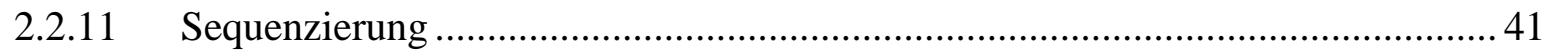

$2.3 \quad$ ZELLKULTUR ................................................................................................ 41

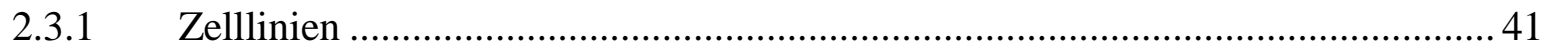

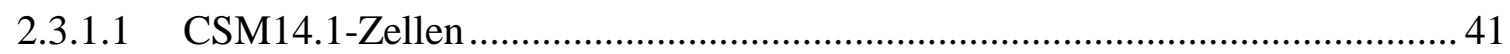

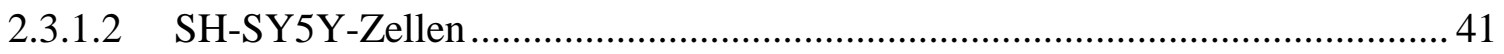

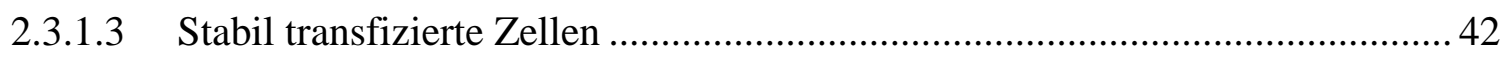

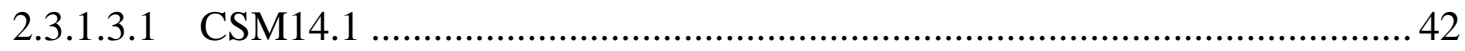

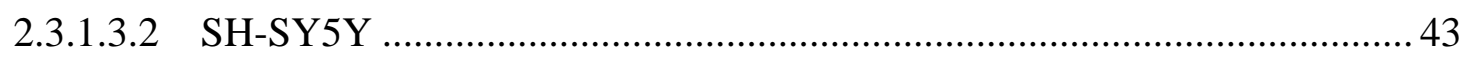

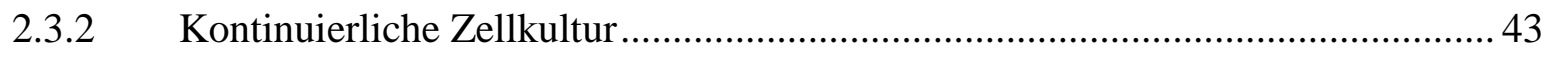

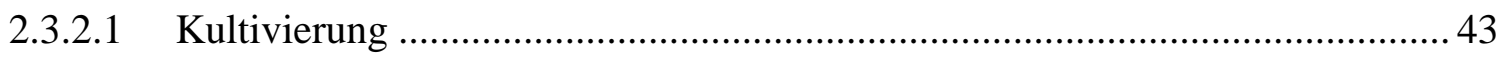

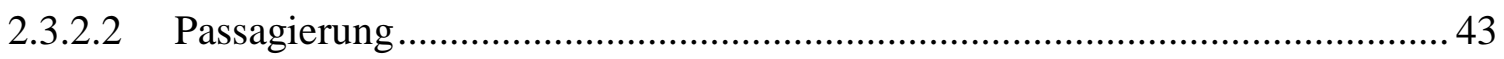

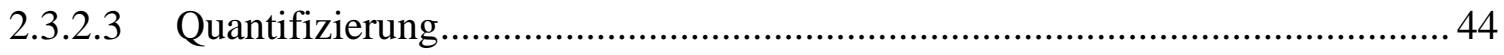

2.3.2.4 Einfrieren der Zellen ................................................................................. 44

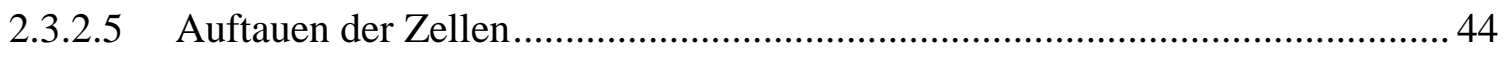

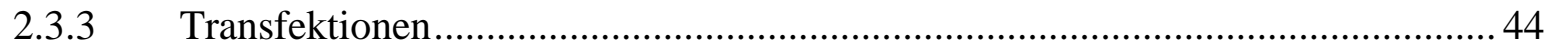

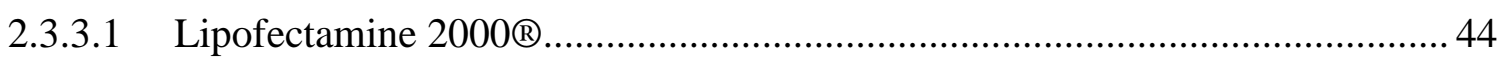

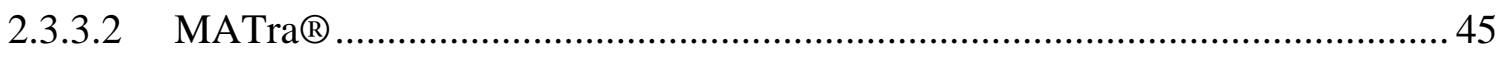




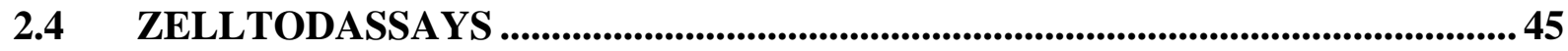

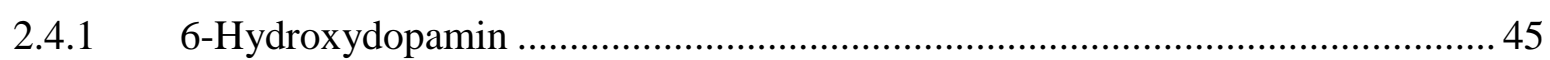

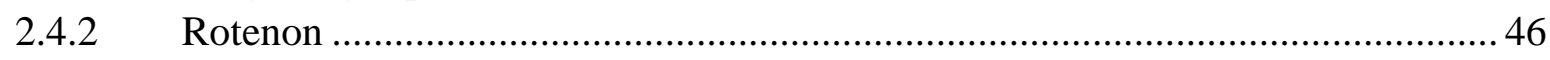

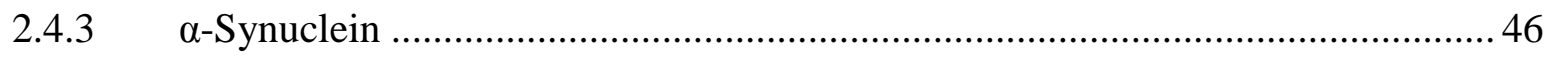

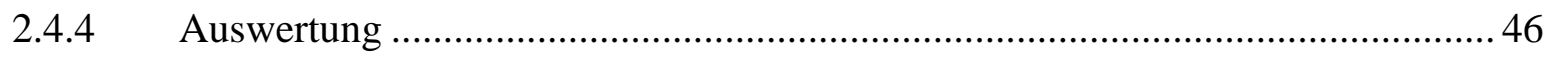

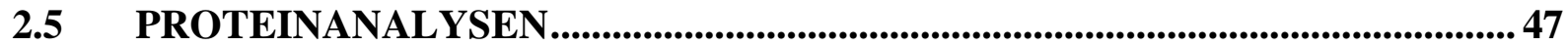

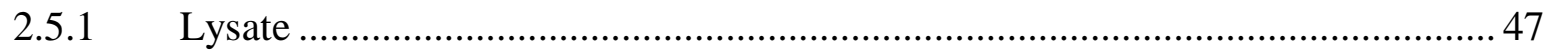

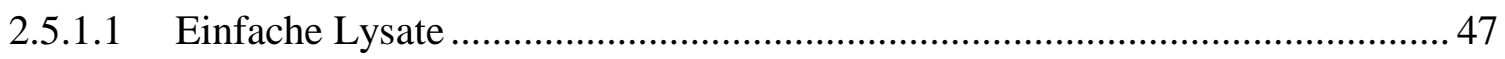

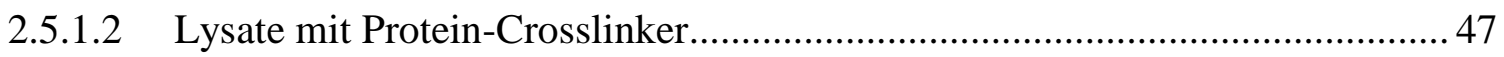

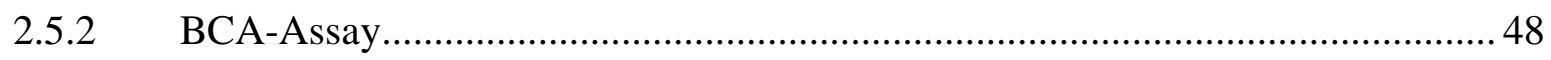

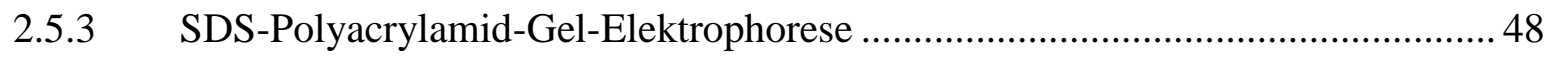

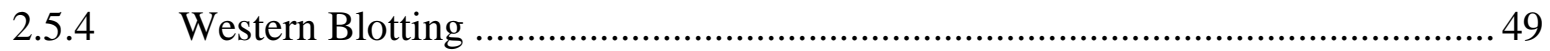

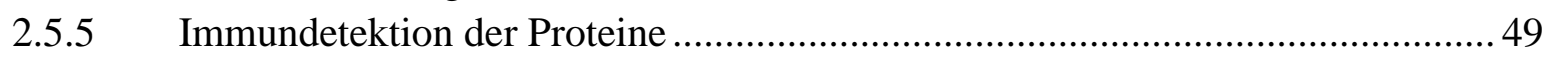

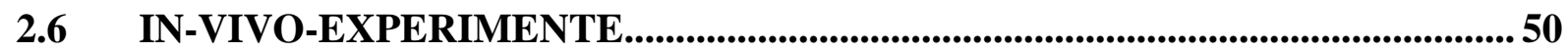

2.6.1 Stereotaktische Virusinjektion in das Mausgehirn ............................................ 50

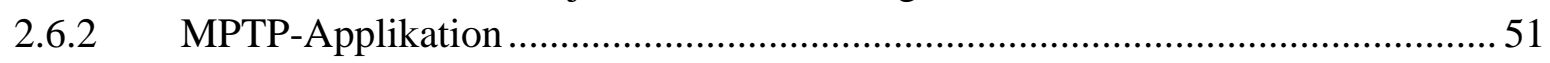

2.6.3 Transkardiale Perfusion und Weiterverarbeitung der Hirne ................................ 51

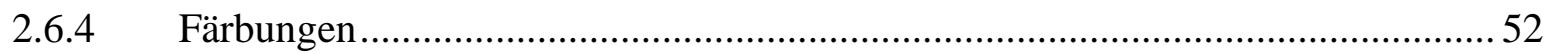

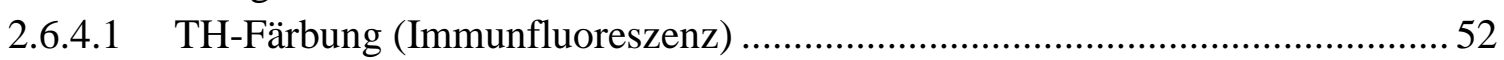

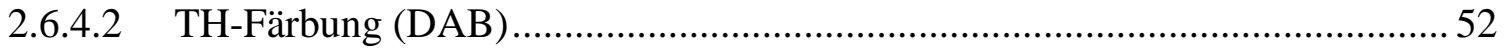

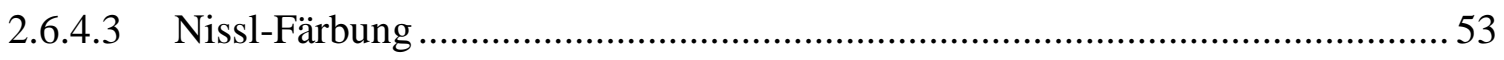

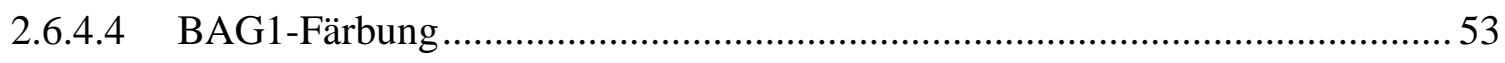

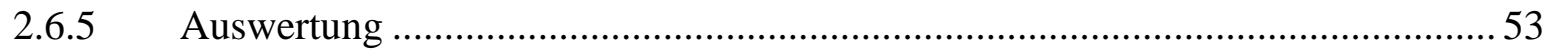

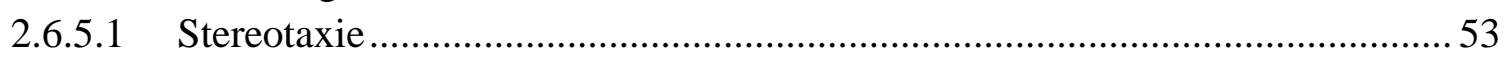

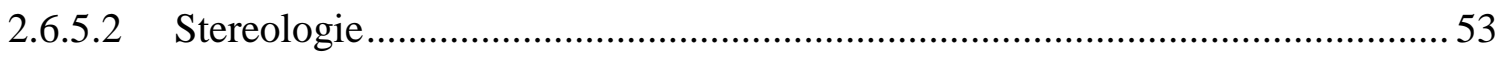

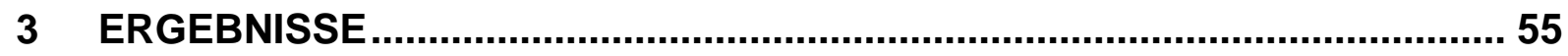

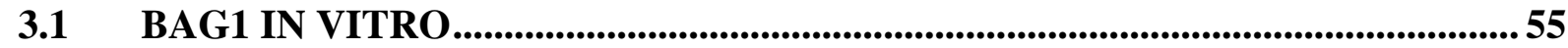

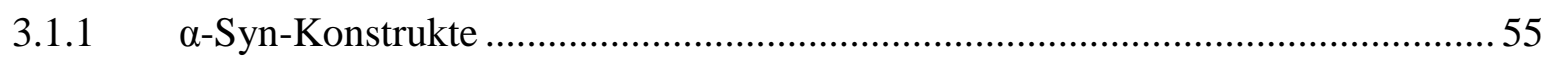

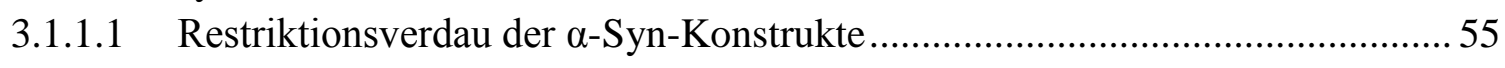

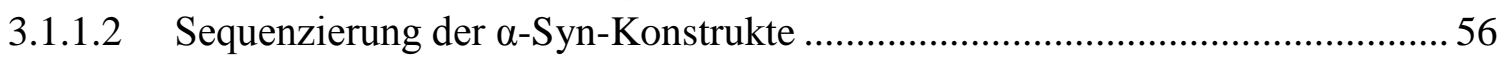

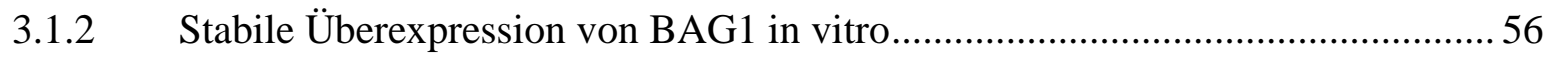

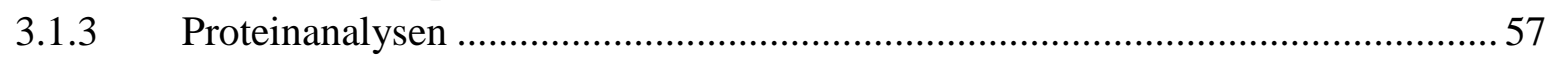

3.1.3.1 Keine Aggregation von $\alpha$-Syn detektierbar bei einfachen Lysaten ..................57

3.1.3.2 Auswirkungen von BAG1 auf die Aggregationsneigung von $\alpha-S y n . . . \ldots \ldots \ldots \ldots . . . . .58$

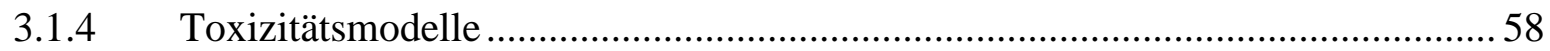

3.1.4.1 BAG1 ist nicht protektiv im 6-OHDA-Zellkultur-Modell ................................5

3.1.4.2 BAG1 ist protektiv gegen geringe Konzentrationen von Rotenon .................. 59

3.1.4.3 BAG1 ist protektiv im $\alpha$-Syn-Zellkultur-Modell ........................................... 60

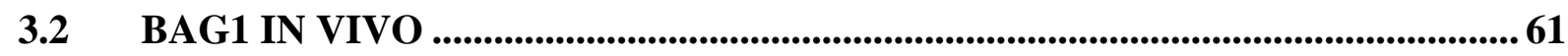

3.2.1 AAV-BAG1-EGFP und AAV-EGFP transduzieren dopaminerge Neurone ....... 61

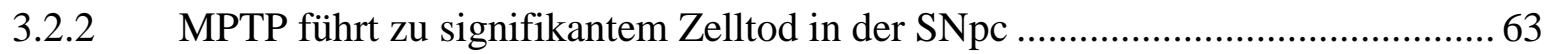


3.2.3 Virus-Injektionen führen nicht zu signifikantem Zelltod in der SNpc................ 64

3.2.4 Kein protektiver Effekt durch BAG1 gegenüber der Kontroll-SNpc ..................66

3.2.5 Protektiver Effekt durch BAG1 gegenüber dem Kontrollvirus .............................. 67

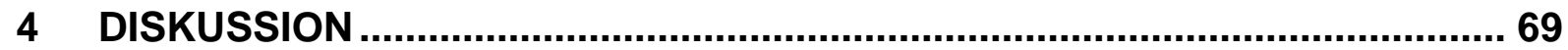

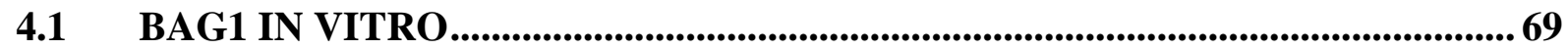

4.1.1 Toxin-assoziierte Modelle: 6-Hydroxydopamin und Rotenon.............................69

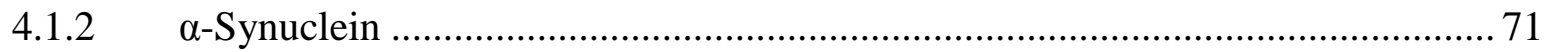

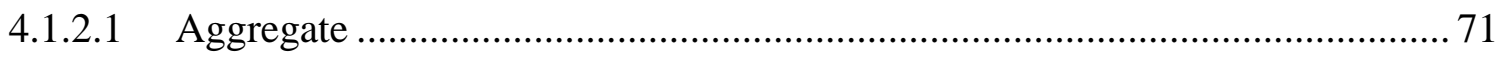

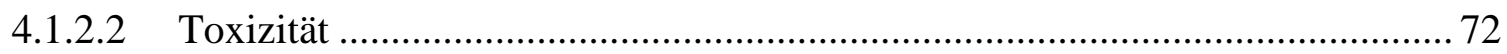

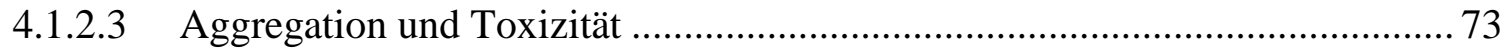

4.1.3 Generelle Probleme der in-vitro-Modelle ........................................................ 75

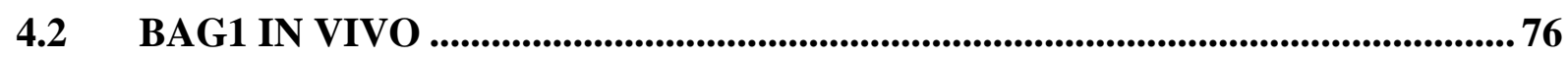

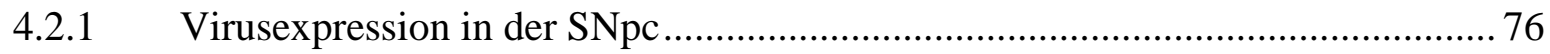

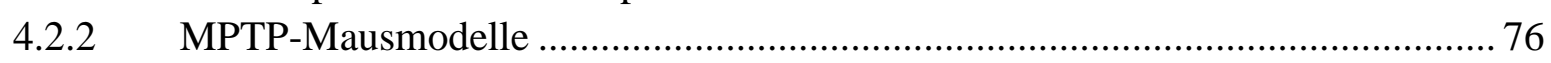

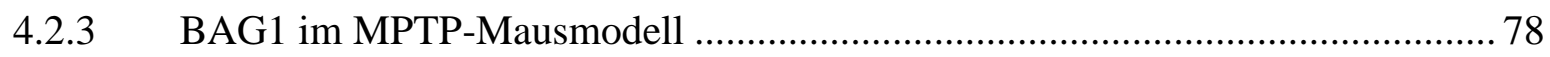

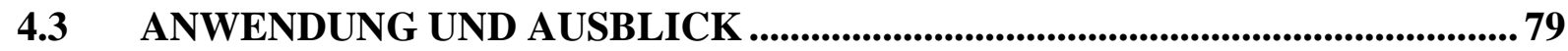

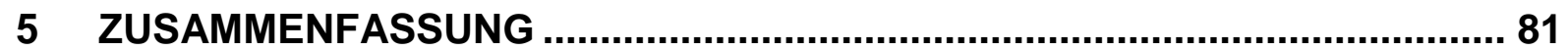

6 LITERATURVERZEICHNIS ..................................................................... 82 


\section{ABKÜRZUNGSVERZEICHNIS}

\begin{tabular}{|c|c|}
\hline AAV & Adeno-assoziierte Viren \\
\hline $\mathrm{ADP}$ & Adenosindiphosphat \\
\hline AIF & Apoptose induzierender Faktor \\
\hline ALS & Amyotrophe Lateralsklerose \\
\hline$\alpha-\operatorname{Syn}$ & $\alpha-S y n u c l e i n$ \\
\hline ATP & Adenosintriphosphat \\
\hline BAG1 & Bcl-2-assoziiertes Athanogen-1 \\
\hline $\operatorname{Bax}$ & Bcl-2-assoziiertes X-Protein \\
\hline $\mathrm{BCA}$ & Bicinchoninsäure \\
\hline $\mathrm{Bcl}-\mathrm{X}_{\mathrm{L}}$ & B-cell-lymphoma-Protein bei Xenopus laevis \\
\hline Bcl-2 & B-cell-lymphoma-2-Protein \\
\hline BDNF & Brain derived neurotrophic factor \\
\hline bGH & Bovines Wachstumshormon \\
\hline BSA & Bovines Serumalbumin \\
\hline CHIP & Carboxyl-Terminus von Hsp70 interagierendes Protein \\
\hline cJNKs & c-Jun N-terminale Kinasen \\
\hline CMV & Zytomegalievirus \\
\hline $\mathrm{CSP} \alpha 1$ & Cystein-String-Protein $\alpha 1$ \\
\hline CVA & Chaperon-vermittelte Autophagie \\
\hline $\mathrm{Cy} 3$ & Cyanin 3 \\
\hline Cyt. c & Cytochrom C \\
\hline $\mathrm{DAB}$ & 3,3'-Diaminobenzidin \\
\hline DAPI & 4',6-Diamidin-2'-Phenylindoldihydrochlorid \\
\hline DAT & Dopamintransporter \\
\hline DAQ & Dopaminquinon \\
\hline ddNTPs & Didesoxyribonucleinsäuretriphosphate \\
\hline DMEM & Dulbecco's modified eagle medium \\
\hline DMSO & Dimethylsulfoxid \\
\hline DNA & Desoxyribonukleinsäure \\
\hline DNTPs & Desoxyribonucleinsäuretriphosphate \\
\hline DSS & Disuccimidylsuberat \\
\hline
\end{tabular}


DTT Dithiothreitol

ECL Enhanced Chemiluminescence

EDTA Ethylendiamintetraessigsäure

EGFP Enhanced green fluorescent protein

FCS Fötales Rinderserum

GDNF Glial cell derived neurotrophic factor

GFP Green fluorescent protein

GSH Glutathion

G418 Geneticin

HEPES 2-(4-(2-Hydroxyethyl)-1-Piperazinyl)-Ethansulfonsäure

HRP Meerrettich-Peroxidase

Hsc70 Hitzeschockcognatprotein 70

Hsp70 Hitzeschockprotein 70

hSyn1 Humaner Synapsin-1-Promotor

Int. Intron

i.p. Intraperitoneal

IPS Idiopathisches Parkinson-Syndrom

ITRs Invertierte terminale Repeats

i.u. Infective units

KG Körpergewicht

LB Luria-Bertani

L-DOPA Levodopa

LK Lewy-Körperchen

MAO Monoaminooxidase

$\mathrm{MPP}^{+} \quad$ 1-Methyl-4-phenylpyridinium

MPPP 1-Methyl-4-phenyl-propion-oxy-piperidin

MPTP 1-Methyl-4-phenyl-1,2,3,6-tetrahydropyridin

NBIA Neurodegenerative Erkrankung mit Eisenablagerung im Gehirn

NET Norepinephrin-Transporter

NGS Natürliches Ziegenserum

NSE Neuronenspezifische Enolase

6-OHDA 6-Hydroxydopamin

ORF Open reading frame 
p53

PARP

PBS

PCR

PFA

PS

Raf-1

ROS

SDS

SDS-PAGE

Siah1

SNARE

SNCA

$\mathrm{SNpc}$

SOB

SOC

SV-40

TB

TBE

TBS

TBS-T

TEMED

$\mathrm{TH}$

U

ULD

UPS

UV

VMAT2

WPRE

WT

ZNS
Protein 53

Poly-ADP-Ribose-Polymerase

Phosphatgepufferte physiologische Kochsalzlösung

Polymerasekettenreaktion

Paraformaldehyd

Parkinson-Syndrom

V-Raf-1 murine leucemia viral oncogene homolog 1

Reaktive Sauerstoffmetaboliten

Natriumdodecylsulfat

SDS-Polyacrylamidgelelektrophorese

Seven in absentia Homolog 1

Soluble N-Ethylmaleimide sensitive factor attachment protein receptor für $\alpha$-Syn codierendes Gen

Substantia nigra pars compacta

Super optimal Broth

SOB mit Glucose

Affen-Virus-40

Transkriptions-Blocker

Tris-Borsäure-EDTA-Puffer

Tris-gepufferte Salzlösung

Tris-gepufferte Salzlösung mit Tween

Tetramethylethylendiamin

Tyrosinhydroxylase

Units

Ubiquitin-ähnliche Domäne

Ubiquitin-Proteasom-System

Ultraviolett

Vesikulärer Monoamin-Transporter-2

Murmeltier-Hepatitis-Virus posttranslationales regulatorisches Element

Wildtyp bzw. Leervektor

Zentrales Nervensystem 


\section{EINLEITUNG}

\subsection{DAS IDIOPATHISCHE PARKINSON-SYNDROM}

\subsubsection{Epidemiologische Daten und Symptomatik}

Das idiopathische Parkinson-Syndrom (IPS) wurde erstmals im Jahre 1817 vom britischen Arzt James Parkinson in seinem Essay „An Essay on the Shaking Palsy“ beschrieben (Parkinson 2002). Heutzutage ist das IPS die zweithäufigste neurodegenerative Erkrankung nach dem Morbus Alzheimer mit einer durchschnittlichen jährlichen Inzidenzrate von 121/100.000 (Driver et al. 2009) und einer Prävalenz von 1,8 \% bei der Bevölkerung über 65 Jahre und von sogar 2,6 \% bei den über 85-Jährigen (de Rijk et al. 2000). In Deutschland gab es im Jahr 2005 geschätzte 110.000 Fälle (Dorsey et al. 2007). Typischerweise erkranken die Patienten ab dem 60. Lebensjahr, wobei die Erkrankungswahrscheinlichkeit mit dem Alter zunimmt (Driver et al. 2009). Beim IPS degenerieren Neurone, unter anderem die dopaminergen Neurone in der Substantia nigra pars compacta (SNpc). Dies führt zur typischen Symptomtrias, bestehend aus Rigor, Tremor und Akinese bzw. Bradykinese (Blaszczyk 1998, Fearnley und Lees 1991, Parkinson 2002). Dazu kommen die posturale Instabilität mit Störung der Halte- und Stellreflexe (Bloem et al. 1992) und auch nichtmotorische Symptome (Chaudhuri und Schapira 2009), wie Obstipation, Blasenentleerungsstörungen oder erektile Dysfunktion. Weiterhin sind sensorische Symptome wie Dysästhesien und Schmerzen in Muskeln und Gelenken typisch. Auch psychische Veränderungen wie Demenzen und Depressionen treten im Rahmen des IPS auf. Außerdem können das olfaktorische (Herting et al. 2008) und das visuelle System (Bodis-Wollner und Tagliati 1993) im Rahmen des Untergangs dopaminerger Neurone beeinträchtigt sein.

\subsubsection{Pathomorphologischer Hintergrund des IPS}

Trotz der frühen Beschreibung des IPS und der extensiven Forschung sind die führenden Pathomechanismen der Erkrankung nur teilweise verstanden (Dauer und Przedborski 2003). Diskutiert werden oxidativer Stress, mitochondriale Dysfunktion, proteasomale Dysfunkion und verminderte Autophagie (1.1.3).

Bereits im Frühstadium des IPS ist eine ganze Reihe unterschiedlicher Hirnregionen betroffen. $\mathrm{Zu}$ nennen sind hier die ventrale tegmentale Area, der noradrenerge Locus coeruleus, die serotonergen Raphe-Kerne, die Kerne des retikulären Systems, die vorderen olfaktorischen Strukturen (Braak et al. 2006) sowie das visuelle System (Bodis-Wollner und 
Tagliati 1993). Kennzeichnend für das IPS ist aber der Untergang dopaminerger Neurone in der SNpc und eine Degeneration der nigrostriatalen Projektionen, wodurch die Dopaminkonzentration im Striatum signifikant reduziert wird (Dauer und Przedborski 2003). Dieser Dopaminmangel ist verantwortlich für einen Großteil der Symptome der Patienten. Biochemische Messungen und Bildgebungen geben allerdings Hinweise, dass ein Zellverlust von fast $70 \%$ vorliegen muss, bis sich die ersten klinischen Symptome entwickeln (Brooks 1998).

Einige wenige Patienten mit Parkinson-Symptomen weisen einen monogenen Erbgang auf (Bossy-Wetzel et al. 2004). Seit 1997 konnten 16 Genloci identifiziert werden, deren Genprodukte in 12 der Fälle bekannt sind (Tabelle 1). Das familiäre Parkinson-Syndrom (PS) zeigt oftmals atypische Merkmale wie frühes Erkrankungsalter, Dystonien, früh-auftretende Demenz und fehlende Aggregat-Ablagerungen in histologischen Präparaten (Gasser 2001). Der Zusammenhang zwischen diesen Genen und dem häufigen IPS ist unklar. Es ist aber zu vermuten, dass die monogen-determinierten Formen einer ähnlichen Pathogenese unterliegen wie die sporadische Form (Thomas und Beal 2007). Wahrscheinlich ist hier eine multifaktorielle Genese, bestimmt durch genetische und umweltbedingte Faktoren (Braak und Del Tredici 2008, Wider und Wszolek 2008). Es ist deshalb Gegenstand intensiver Forschungen die Pathogenese der einzelnen genetischen PS aufzudecken.

Tabelle 1: Genetische Parkinson-Syndrome

\begin{tabular}{|c|c|c|c|c|c|}
\hline Genort & Gen & Chromosom & Vererbung & Proteinfunktion / Vorkommen & Referenz \\
\hline $\begin{array}{l}\text { PARK1 / } \\
\text { PARK4 }\end{array}$ & $\alpha$-Synuclein & $4 q 21$ & $\mathrm{AD}$ & $\begin{array}{l}\text { Präsynaptisches Protein, } \\
\text { Lewy-Körperchen-Bestandteil }\end{array}$ & $\begin{array}{l}\text { (Polymeropoulos et al. } \\
\text { 1997, Singleton et al. 2003) }\end{array}$ \\
\hline PARK2 & Parkin & $6 q 25.2-27$ & AR & Ubiquitin-E3-Ligase & (Kitada et al. 1998) \\
\hline PARK3 & unbekannt & $2 \mathrm{p} 13$ & $\mathrm{AD}$ & unbekannt & (Gasser 2001) \\
\hline PARK5 & UCH-L1 & $4 \mathrm{p} 14$ & $\mathrm{AD}$ & Ubiqitin- Hydrolase & (Leroy et al. 1998) \\
\hline PARK6 & PINK1 & $1 \mathrm{p} 35-36$ & AR & Mitochondriale Kinase & (Valente et al. 2004) \\
\hline PARK7 & DJ-1 & $1 \mathrm{p} 36$ & AR & Chaperon, Antioxidant & (Bonifati et al. 2003) \\
\hline PARK8 & LRRK2 & $12 \mathrm{p} 11.2$ & $\mathrm{AD}$ & Kinase & $\begin{array}{l}\text { (Paisan-Ruiz et al. 2004, } \\
\text { Zimprich et al. 2004) }\end{array}$ \\
\hline PARK9 & ATP13A2 & $1 \mathrm{p} 36$ & AR & ATPase & (Ramirez et al. 2006) \\
\hline PARK10 & unbekannt & $1 \mathrm{p} 32$ & $\mathrm{AD}$ & unbekannt & (Hicks et al. 2002) \\
\hline PARK11 & GIGYF2 & $2 q 36-37$ & $\mathrm{AD}$ & $\begin{array}{l}\text { Regulation von Tyrosinkinase- } \\
\text { Rezeptorsignalwegen }\end{array}$ & (Lautier et al. 2008) \\
\hline PARK12 & unbekannt & Xq21-q25 & unbekannt & unbekannt & (Pankratz et al. 2003) \\
\hline PARK13 & HTRA2 & $2 \mathrm{p} 12$ & unbekannt & Mitochondriale Serin-Protease & (Strauss et al. 2005) \\
\hline PARK14 & PLA2G6 & $22 q 13.1$ & $\mathrm{AR}$ & Phospholipase A2 & (Paisan-Ruiz et al. 2009) \\
\hline PARK15 & FBXO7 & $22 q 12-q 13$ & AR & $\begin{array}{l}\text { F-Box Protein, Untereinheit } \\
\text { einer Ubiquitin Protein Ligase }\end{array}$ & (Di Fonzo et al. 2009) \\
\hline PARK16 & unbekannt & $1 \mathrm{q} 32$ & unbekannt & unbekannt & (Satake et al. 2009) \\
\hline
\end{tabular}




\subsubsection{1 $\quad \alpha-S y n u c l e i n$}

Mutationen, Duplikationen und Triplikationen im Gen des $\alpha$-Synucleins ( $\alpha$-Syn), sowie Promotorpolymorphismen führen $\mathrm{zu}$ einem familiären PS (1.1.2.1.2). Außerdem ist dieses Protein Bestandteil der Lewy-Körperchen (LK). Dabei handelt es sich um eosinophile, intrazytoplasmatische Einschlusskörperchen, die unter anderem bei Patienten mit IPS gefunden werden (Spillantini et al. 1997).

\subsection{Struktur und Funktion}

a-Syn ist ein etwa $14 \mathrm{kDa}$ schweres, 140 Aminosäuren langes zytoplasmatisches Protein, das neben $\beta$ - und $\gamma$-Synuclein der Familie der Synucleine angehört. Synucleine konnten bisher nur in Vertebraten beschrieben werden. Das humane $\alpha$-Syn befindet sich auf dem Chromosom 4q21.3-q22 und besteht aus 7 Exons, von denen 5 proteincodierend sind. Allen Synucleinen gemeinsam ist ein hochkonserviertes helikales Amino-Ende und ein weniger konserviertes saures Carboxyl-Ende (George 2002). Anders als andere Proteine dieser Größe liegt es nativ zum Teil in einer löslichen, ungefalteten Form vor (Conway et al. 1998). Weiterhin scheint es, membrangebunden, auch in $\alpha$-helikaler Form vorzuliegen und zeigt eine Tendenz zur Oligomerisierung unter Ausbildung von B-Faltblattstrukturen (Cookson 2009). $\alpha$-Syn wird nahezu überall im menschlichen Körper, so auch im Gehirn, exprimiert. Die Expression im Gehirn ist insbesondere in Neokortex, Hippokampus, Striatum, Thalamus und Cerebellum hoch (George 2002). Besonders angereichert findet sich $\alpha$-Syn in den präsynaptischen Axonterminalen, sodass eine Rolle in präsynaptischen Membran-assoziierten Prozessen, anzunehmen ist (George 2002). Es spielt wohl eine Rolle bei der synaptischen Plastizität und beim Aufbau des für Membranfusionen notwendigen Soluble N-Ethylmaleimide sensitive factor attachment protein receptor (SNARE)-Komplexes (Chandra et al. 2005). In Kulturen mit primären hippokampalen Neuronen konnte gezeigt werden, dass $\alpha$-Syn erst nach der Synapsenformation exprimiert wird, sodass es hier keine bemerkenswerte Rolle zu spielen scheint (Murphy et al. 2000). Weiterhin wird durch Verminderung der $\alpha$-Syn-Expression von außen der Pool an distal lokalisierten synaptischen Vesikeln vermindert, sodass anzunehmen ist, dass $\alpha$-Syn die Größe der unterschiedlichen Pools an synaptischen Vesikeln reguliert (Murphy et al. 2000). Daneben scheint eine Funktion von $\alpha$-Syn die Repression der Aktivität des Dopamin-Transporters (DAT) zu sein, wodurch es zu einer geringeren Aufnahme von Dopamin in die Zelle kommt (Wersinger und Sidhu 2003). $\alpha$-Syn-Knockout-Mäuse sind lebensfähig und fertil, sie zeigen eine intakte Architektur des Gehirns und eine normale Anzahl an dopaminergen Zellkörpern, Fasern und Synapsen. Nigrostriatale Terminalen der Knockout-Mäuse weisen eine normale Ausschüttung und Wiederaufnahme von Dopamin als 
Antwort auf elektrische Reize auf. Allerdings führen Doppelreize bzw. erhöhtes Calcium zu einer vermehrten Freisetzung. Im Gegensatz dazu weisen diese Mäuse aber eine Reduktion in striatalem Dopamin und eine Abschwächung der Dopamin-abhängigen Bewegungsreaktion als Antwort auf Amphetamine auf. Dies führt zu der Annahme, dass $\alpha$-Syn als negativer Regulator der dopaminergen Neurotransmission fungiert (Abeliovich et al. 2000). Mäuse, die humanes Wildtyp (WT) $\alpha$-Syn überexprimieren, weisen dagegen IPS-ähnliche Defizite auf und entwickeln neuronale Einschlusskörperchen, die aber im Gegensatz zu denen beim Menschen nicht fibrillärer Natur sind (Masliah et al. 2000).

\subsection{Mutationen und Phänotypen}

Das SNCA-Gen (PARK 1 / PARK 4), welches für $\alpha$-Syn codiert, wurde von Polymeropoulos 1997 als erster Genlocus des familiären PS identifiziert (Polymeropoulos et al. 1997). Neben der von ihm beschriebenen A53T-Mutation bedingen noch zwei weitere N-terminale Punktmutationen, A30P (Krüger et al. 1998) und E46K (Zarranz et al. 2004), ein familiäres PS. Diese Punktmutationen sind jedoch rar. Die in ca. 30 Familien beobachtete A53TMutation konnte auf einen initialen Überträger griechisch-italienischen Ursprungs zurückgeführt werden, die A30P- und die E46K-Mutation trat jeweils nur in einer einzigen Familie auf. Kürzlich ist eine weitere schwedische Familie entdeckt worden, die eine denovo-A53T-Mutation aufweist (Puschmann et al. 2009). Nichtsdestotrotz sind die Mutationen extrem selten (Berg et al. 2005). Interessanterweise führen gleiche Mutationen in ein und derselben Familie zu unterschiedlichen Phänotypen. So sind die Patienten unterschiedlich stark von Tremor betroffen und es besteht eine hohe Varianz des Erkrankungsalters. Auch das Ansprechen auf eine Therapie mit Levodopa (L-DOPA) variiert stark (Golbe et al. 1996, Puschmann et al. 2009). Die postmortalen Untersuchungen von A53T-Gehirnen zeigten nigrale Degenerationen mit nur sehr geringer LK-Pathologie, dafür aber umso prominenterer Lewy-Neuriten-Pathologie (Kotzbauer et al. 2004). Gehirne von Patienten mit der E46KMutation zeigten kortikale und subkortikale LK (Zarranz et al. 2004). Zur A30P-Mutation existieren bis jetzt keine histopathologischen Daten. Kürzlich konnte dargelegt werden, dass auch die Duplikation bzw. Triplikation des Genlocus zum autosomal-dominant vererbten PS führen (Chartier-Harlin et al. 2004, Singleton et al. 2003), was vermuten lässt, dass neben der strukturellen Abänderung des Proteins durch Mutationen auch Gen-Dosis-Effekte an der Pathogenese der Erkrankung beteiligt sind. Diese Vermutung wird bestärkt durch die Tatsache, dass Promotor-Polymorphismen im SNCA-Gen ein Risikofaktor für das IPS sind (Tan et al. 2003) und außerdem das durchschnittliche Erkrankungsalter herabsetzen (Hadjigeorgiou et al. 2006). 


\subsection{Aggregation und Toxizität}

$\alpha$-Syn findet sich in den zyoplasmatischen ubiquitinilierten Proteinaggregaten (Spillantini et al. 1997) und in den dystrophen Neuriten (Takeda et al. 1998), LK und Lewy-Neuriten genannt, der Gehirne von IPS-Patienten. LK werden außerdem in Fällen von Lewy-BodyDemenzen, bei der Multisystematrophie, dem Morbus Alzheimer, dem Parkinson-DemenzKomplex von Guan und der neurodegenerativen Erkrankung mit Eisenablagerung im Gehirn (NBIA; früher: Hallervorden-Spatz-Erkrankung) gefunden. Dies könnte zu der Annahme verleiten, die LK selbst seien die toxische Spezies, die den Untergang der Neurone auslöst (George 2002). Dies ist aber höchstwahrscheinlich nicht der Fall. Die Transformation des $\alpha$ Syn von seiner nativen, ungefalteten, löslichen Form hin zur fibrillären Form, wie sie in den LK gefunden werden kann, geht mit Änderungen in der Konformation des Proteins einher. So nimmt das Protein vermehrt eine $\beta$-Faltblatt-Struktur an, die als Monomer aber nicht stabil ist und durch Chaperone, Proteine, die die Aufgabe haben, fehlgefaltete Proteine wieder in ihre ursprüngliche Form zu bringen, schnell wieder aufgelöst werden kann (Dohm et al. 2008, Goldberg und Lansbury 2000). Erst die Änderung der Quartärstruktur, die Zusammenlagerung zu Oligomeren und die darauf folgende Fibrillenbildung scheinen eine Stabilität zu induzieren (Conway et al. 1998). Dabei bilden sich zuerst kleine sphärische Oligomere, die sich dann zu kritischen Oligomeren mit stark ß-Faltblatt-haltiger Konformation umwandeln. Die ß-Faltblattstruktur bewirkt eine Polarisierung innerhalb des Moleküls, sodass die Form der Protofibrillen linear angeordnet ist. Die Protofibrillen werden dann in der letzten Stufe der Aggregatbildung zu Wasser-unlöslichen Fibrillen konvertiert, wie sie in den LK gefunden werden (Modler et al. 2003). Es gibt Hinweise darauf, dass nicht das Endprodukt, die Fibrillen in den LK, die toxische Spezies sind, sondern die Zwischenprodukte auf dem Weg zur Fibrillenbildung - genauer gesagt die Oligomere oder Protofibrillen (Goldberg und Lansbury 2000). Gestützt wird diese Annahme durch Untersuchungen an den $\alpha$-Syn-Mutanten A30P und A53T. Während die A53T-Mutante, ebenso wie auch eine stark erhöhte Konzentration an WT- $\alpha-S y n$, eine stark beschleunigte Fibrillenbildung zeigt, inhibiert die A30P-Mutante die Fibrillenbildung sogar. Beiden Mutanten gemeinsam ist die erhöhte Rate an Oligomerisierung. Die A30P-Mutation, bei der die Konversion von Protofibrillen zu Fibrillen gehemmt ist, lässt damit sogar stark vermehrt Oligomere auftreten (Conway et al. 2000). Dies lässt vermuten, dass es sich bei den Oligomeren um die eigentlich toxische Spezies handelt (Abb. 1). In einer kürzlich publizierten Studie konnte sogar direkt ein toxischer Effekt durch präfibrilläre $\alpha$-SynKonstrukte gezeigt werden (Karpinar et al. 2009). Dagegen kann vermutet werden, dass die 
Fibrillen und die LK inert, wenn nicht sogar protektiv sind (Goldberg und Lansbury 2000). Dazu passt die Beobachtung, dass die Neurone, die LK enthalten, schließlich die überlebenden Neurone sind - meist sehen diese unter dem Mikroskop auch noch ,gesünder“ aus als die verbleibenden Neurone, die keine LK aufweisen. Auch finden sich LK häufig in Gehirnen alter Menschen, die keinerlei Klinik oder andere Pathologie im Sinne eines PS oder einer anderen LK-assoziierten Erkrankung aufweisen (Goldberg und Lansbury 2000). Andererseits wird hier aber vermutet, dass es sich um präsymptomatische Vorstufen der Erkrankung handeln könnte, schließlich ist das Alter der größte Risikofaktor für die Entwicklung eines IPS (Thal et al. 2004).

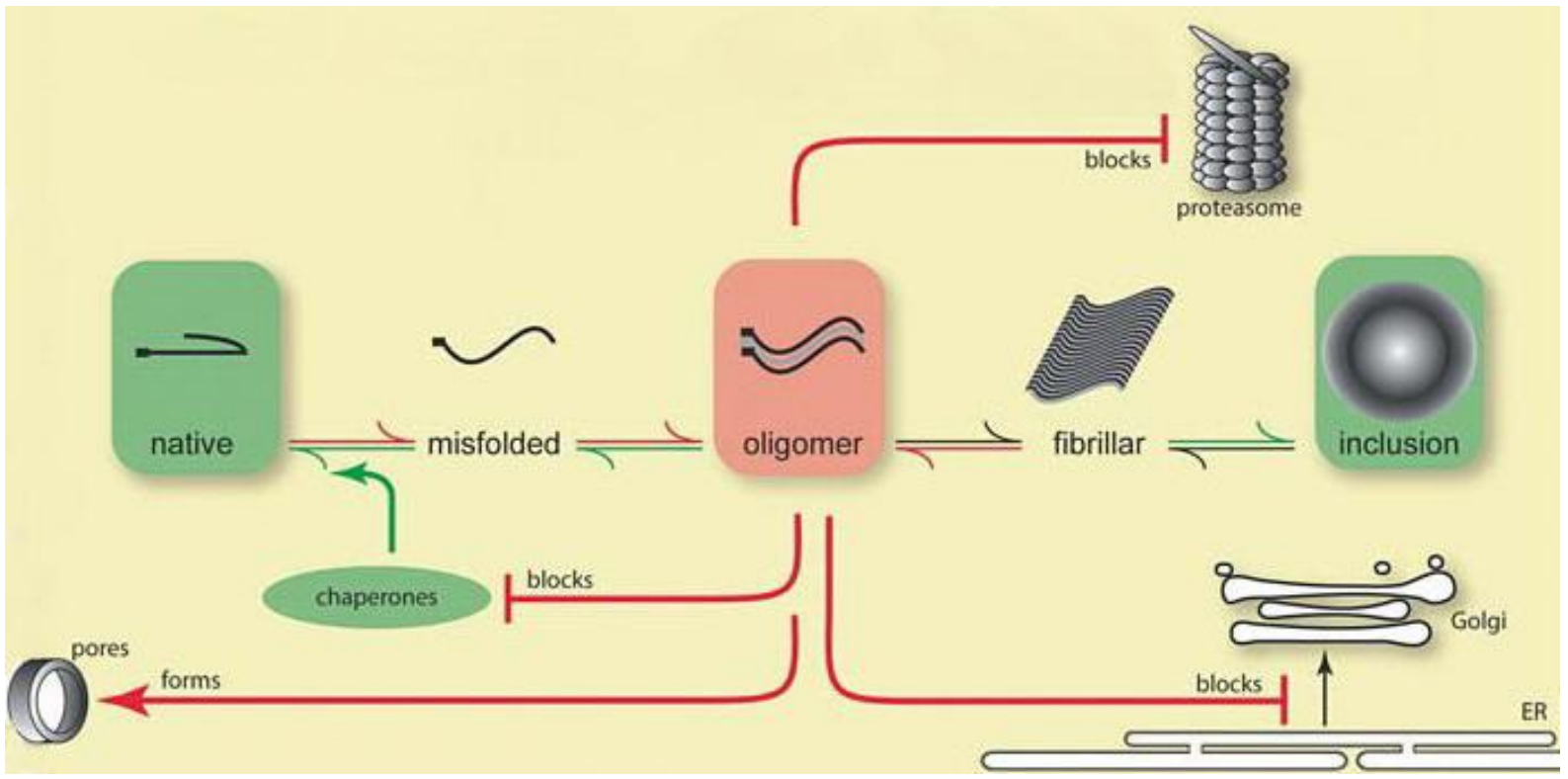

Abb. 1: Aggregation von $\alpha$-Syn und Effekte auf das zelluläre System. Aus nativem, ungefaltetem $\alpha$-Syn entstehen durch Fehlfaltung Oligomere. Aus den Oligomeren können im weiteren Verlauf unlösliche Fibrillen entstehen. Die Oligomere inhibieren das Proteasom und damit ihren eigenen Abbau. Weiterhin inhibieren sie die Chaperon-Funktion, sodass vermehrt fehlgefaltetes $\alpha$-Syn entsteht. Zuletzt können die Oligomere über Formation von toxischen Membranporen Vesikel zerstören und hemmen außerdem die Funktion des Golgi-Apparates (Dohm et al. 2008, S. 323)

Die Protofibrillen scheinen die Fähigkeit zu haben, über die Bildung von toxischen Membranporen durch einen Detergenz-ähnlichen Mechanismus Vesikel zu zerstören (Kim et al. 2009, Volles und Lansbury 2002). Dadurch wird deren Inhalt, z. B. oxidationsanfälliges Dopamin, freigesetzt. Weiterhin stören sowohl die A53T-als auch die A30P-Mutation das lysosomale bzw. das proteasomale System zum intrazellulären Abbau von Proteinen, sodass zum einen Synuclein selbst, aber auch andere Proteine vermindert abgebaut werden können (Stefanis et al. 2001, Tanaka Y et al. 2001, Xilouri et al. 2009). Auch die Aktivität von Chaperonen wird durch die Oligomere gehemmt (Martinez-Vicente et al. 2008), was zur Formation noch größerer Mengen an Oligomeren führt. Ebenso konnte eine Beeinträchtigung 
der Chaperon-vermittelten Autophagie (CVA) und der Funktion des Golgi-Apparates festgestellt werden (Cooper AA et al. 2006, Cuervo et al. 2004, Xilouri et al. 2009).

\subsection{Posttranslationale Modifikation}

Neben den erwähnten Mutationen, welche die Fibrillenbildungstendenz verändern, gibt es posttranslationale Modifikationen des $\alpha$-Syn, die ähnliche Effekte haben. Hier sind vor allem die C-terminale Verkürzung durch alternatives Splicing und die Phosphorylierung an der Position S129 zu nennen. C-terminal verkürztes $\alpha$-Syn ist vermehrt in LK anzutreffen, und außerdem scheint dieses veränderte $\alpha$-Syn die Aggregationsneigung zu erhöhen ( $\mathrm{Li} \mathrm{W}$ et al. 2005). Auch an Position 129 phosphoryliertes $\alpha$-Syn liegt in LK vermehrt vor (Fujiwara et al. 2002), was die Vermutung erlaubt, dass die Phosphorylierung an der Position 129 bei der Formierung von Aggregaten eine Rolle spielt. Zur weiteren Untersuchung dieser Beobachtung wurden die Mutanten S129A und S129D bzw. E konstruiert. Das Alanin (A) blockiert dort eine Phosphorylierung, während die Asparaginsäure (D) bzw. die Glutaminsäure (E) diese imitieren (Chen und Feany 2005). In Parkinson-Familien konnten diese Mutationen aber bisher nicht gefunden werden.

\subsubsection{5 Übertragbarkeit von krankheitspezifischem $\alpha$-Syn}

Neben der genetischen Ausstattung scheint auch die Umgebung der Zellen wichtig zu sein. Es konnte gezeigt werden, dass in transplantierten fetalen dopaminergen Neuronen nach mehr als zehn Jahren LK nachweisbar sind. Dies war überraschend, da die genetische Ausstatttung dieser transplantierten Zellen verschieden von den Umgebenden war (Li JY et al. 2008). $\alpha$ Syn kann damit möglicherweise über Exo- und Endozytose auf benachbarte Neurone und damit auch auf die neuronalen Stammzellen übertragen werden. Auch extrazelluläre Aggregate können von Neuronen aufgenommen werden. Damit kann sich die Pathologie der LK und der verschiedenen potentiell toxischen $\alpha$-Syn-Spezies über verschiedene Nervenzellpopulationen ausbreiten (Desplats et al. 2009, Lee HJ et al. 2008).

\subsection{Neuroprotektion durch $\alpha-S y n$}

Neben all den direkt toxischen Effekten, die $\alpha$-Syn bzw. seine Oligomere auf Zellen haben können, gibt es auch Hinweise auf eine neuroprotektive Funktion von $\alpha$-Syn. So vermag WT$\alpha$-Syn in vivo und in vitro gegen Paraquat-induzierten oxidativen Stress zu schützen, wohingegen die mutierten Formen dies nicht können. Der schützende Effekt (Choi et al. 2006) geht einher mit einer Expressionserhöhung des Chaperons Hitzeschockprotein-70 (Hsp70). Auch in Modellen mit durch 6-Hydroxydopamin (6-OHDA), Dopamin und 1Methyl-4-phenyl-1,2,3,6-tetrahydropyridin (MPTP) induziertem oxidativen Stress konnte eine 
Neuroprotektion durch $\alpha$-Syn, nicht aber durch seine Mutanten, nachgewiesen werden (Colapinto et al. 2006, Jensen et al. 2003, Monti et al. 2007). Neben der Expressionserhöhung von Hsp70 gibt es Hinweise darauf, dass die Inaktivierung von c-Jun N-terminalen Kinasen (cJNKs), sogenannter Stress-Kinasen, durch $\alpha$-Syn die Protektion vermittelt (Hashimoto et al. 2002). Weiterhin ist berichtet worden, dass $\alpha$-Syn bei der Prävention von Neurodegeneration mit dem Cystein-String-Protein- $\alpha-1$ (CSP $\alpha 1)$ kooperiert. Das CSP $\alpha 1$ ist ebenso wie $\alpha$-Syn ein präsynaptisches Protein und spielt eine wichtige Rolle bei der Formation des SNAREKomplexes und fungiert als Co-Chaperon. CSPa1-defiziente Mäuse zeigen schnelle und progressive Neurodegeneration. Diesen Effekt kann $\alpha$-Syn aufheben (Chandra et al. 2005).

\subsubsection{Umwelteinflüsse und Toxine}

Da die Mehrheit der Parkinson-Fälle idiopathisch und nicht monogenetisch bedingt auftritt, muss eine multifaktorielle Genese angenommen werden, die neben genetischen Prädispositionen auch Umwelteinflüsse mit einbezieht (Thomas und Beal 2007). Diese Vermutung wird gestützt von Zwillingsstudien, die zeigten, dass bei einem Erkrankungsalter von über 50 Jahren der genetische Einfluss in den Hintergrund tritt (Tanner et al. 1999). In einzelnen Fällen könnte das Ausbrechen der Erkrankung durch verschiedene Neurotoxine, wie z. B. die Pestizide Rotenon und Paraquat, die den Komplex I der Atmungskette hemmen (Betarbet et al. 2000), oder auch durch Organophosphate (Kamel und Hoppin 2004) verursacht werden. So besteht eine Assoziation zwischen dem IPS-Risiko und dem Wohnen in ländlichen Gegenden, dem Trinken von Brunnenwasser und der Beschäftigung in der Landwirtschaft (Priyadarshi et al. 2001). Neben Pestiziden sind auch Schwermetalle mit einem erhöhten IPS-Risiko assoziiert. Unter anderem ist hier das Element Mangan als Ursache für ein Toxin-bedingtes PS zu nennen, wobei die Neurotoxizität des Mangans durch den Abbau von Dopamin und der folgenden Entstehung von Neurotoxinen wie Dopaminquinonen (DAQ) und Wasserstoffperoxid zustande kommt (Florence und Stauber 1988). Auch die Metalle Eisen und Kupfer scheinen mit einem erhöhten IPS-Risiko in Verbindung zu stehen (Gorell et al. 1999). Außerdem führen diese Metalle im Experiment zu vermehrter $\alpha$-Syn-Fibrillisation (Uversky et al. 2001). Auf der anderen Seite soll z. B. das Rauchen von Zigaretten das IPS-Risiko signifikant vermindern (Baron 1986), wobei es hier wohl um das Nikotin als schützenden Faktor geht (Quik et al. 2008). Einen ähnlichen Effekt soll der Konsum von Kaffee haben (Powers et al. 2008). 


\subsubsection{Das Alter als Risikofaktor für das IPS}

Ein wichtiger Risikofaktor für die Entwicklung eines IPS ist das Alter. Die Erkrankungswahrscheinlichkeit nimmt ab dem 60. Lebensjahr stark zu (Driver et al. 2009). Da die Lebenserwartung weiter steigt, wird vermutet, dass sich von 2005 bis 2030 die Anzahl der IPS-Patienten verdoppelt haben wird (Dorsey et al. 2007). Damit wird das Alter zum stärksten Risikofaktor für die Entstehung eines IPS. Verschiedene Mechanismen für eine altersabhängige Auslösung des IPS werden derzeit diskutiert: Unter anderem die Hochregulation von $\alpha$-Syn in Abhängigkeit vom Alter (Chu und Kordower 2007), die altersabhängige Abnahme der Proteasomen-Aktivität (Zeng et al. 2005), die Zunahme von oxidativem Stress im alternden Gehirn (Andersen 2004) und die verminderte Leistung des Autophagie-Systems (Cuervo et al. 2005) im Alter.

\subsubsection{Mechanismen des Zelltods beim IPS}

\subsubsection{Oxidativer Stress}

Die Oxidation zellulärer Bestandteile durch reaktive Sauerstoffmetabolite (ROS) hat weitreichende schädigende Effekte: Proteinkonformationen werden gestört, wodurch die Proteine funktionsunfähig werden können, Zellmembranen können durch Oxidation in ihrer Integrität gestört werden und die Desoxyribonucleinsäure (DNA) kann geschädigt werden. Besonders gefährdet durch ROS ist das Gehirn, da es einen aktiven Metabolismus, aber nur eine vergleichsweise geringe Regenerationskapazität besitzt. Somit werden ROS für neuronalen Zellschaden und neuronale Degeneration mitverantwortlich gemacht (Andersen 2004). In den Gehirnen von IPS-Patienten finden sich Substanzen, die bei vermehrtem oxidativem Stress entstehen (Dexter et al. 1989). Auch die Nitrierung von Proteinen, als Zeichen von vermehrter Protein-Oxidation, kann in Gehirnen von IPS-Patienten nachgewiesen werden (Good et al. 1998). Nichtsdestotrotz beweisen diese Zeichen nicht, dass der vermehrte oxidative Stress die Ursache der Neurodegeneration ist, denn unklar bleibt, ob der oxidative Stress tatsächlich primärer Effekt oder bloß Konsequenz anderer schädigender Mechanismen ist (Andersen 2004). Es existieren eine ganze Reihe antioxidativer Enzyme wie die Superoxiddismutase, die Glutathion (GSH)-Peroxidase und die GSH-Reduktase, deren Gehalt in der SNpc von IPS-Patienten herabgesetzt ist (Pearce et al. 1997, Perry et al. 1982). Dagegen sind die Konzentrationen von Katalysatoren der oxidativen Reaktionen, wie z. B. Eisen, erhöht (Riederer et al. 1989). Die SNpc weist einen höheren Eisengehalt auf als andere Hirnstrukturen, da das in den Zellen befindliche Neuromelanin als zusätzlicher Eisenspeicher wirkt (Fasano et al. 2006). Es könnten also diese spezifischen Bedingungen in der Zelle sein, 
die mit der Entstehung eines IPS zusammenhängen. So sind zum Bespiel GSH-Peroxidase oder Superoxiddismutase-überexprimierende Mäuse vermindert anfällig gegen die durch MPTP ausgelöste Neurotoxizität (Przedborski et al. 1992), die vor allem durch oxidativen Stress, ausgelöst durch die Hemmung des Komplex I der Atmungskette, zu Stande kommt. Durch den Einsatz von Metallchelatoren, welche die Eisen-Konzentration senken, konnte eine ebensolche Neuroprotektion erreicht werden (Kaur et al. 2003).

ROS können $\alpha$-Syn in seiner Konformation außerdem so verändern, dass sich die potentiell schädlichen Oligomere und höhermolekularen Aggregate bilden. Die Überexpression von Chaperonen, wie Hsp70, kann dies verhindern (Klucken et al. 2004). Andererseits kann $\alpha$-Syn auch selbst oxidativen Stress produzieren: Die Transfektion von Zellen mit der A53TMutante führt zur erhöhten Oxidation von Proteinen und Lipiden (Ostrerova-Golts et al. 2000).

Durch den Dopamin-Metabolismus in der SNpc entstehen dort ständig oxidative Nebenprodukte wie Hyperoxide, Wasserstoffperoxid und DAQ, die, vielleicht im Zusammenspiel mit Eisen, an der Oxidation von $\alpha$-Syn beteiligt sind. Wie beschrieben (1.1.2.1.3) können $\alpha$-Syn-Protofibrillen Vesikel permeabilisieren, wodurch der DopaminGehalt in der Zelle erhöht werden kann. Frei im Zytoplasma kann Dopamin leicht oxidiert werden, was ROS produziert, die wiederum $\alpha$-Syn in seiner Konformation stören und zur Bildung von Protofibrillen anregen. Zusätzlich können Dopaminprodukte, wie das Orthoquinon-Synuclein-Addukt, die Protofibrillen stabilisieren (Conway et al. 2001). $\alpha$-SynProtofibrillen und Oligomere entstehen schneller, wenn Mutationen im $\alpha$-Syn vorliegen oder Degradationswege insuffizient sind. Orthoquinon, das die Oligomere stabilisiert, entsteht durch erhöhten Dopamingehalt und oxidativen Stress in der Zelle (Conway et al. 2001). In diesem Mechanismus kommen also drei potentielle Risikofaktoren zusammen: Dopamin, oxidativer Stress und $\alpha$-Syn. Höchstwahrscheinlich ist die Lösung der Frage, was ein IPS verursacht, auch in dieser Richtung zu suchen: Aller Wahrscheinlichkeit nach wird es nicht eine einzelne Ursache geben, sondern es wird sich um eine Kombination verschiedenster Mechanismen handeln, die zum IPS führen.

\subsubsection{Mitochondriale Dysfunktion}

Die zelluläre Energieversorgung wird durch die im Mitochondrium lokalisierte Atmungskette sichergestellt. Bei mitochondrialer Dysfunktion kommt es zu einem Energiemangel, welcher zu zellulärem Stress führt. Ausgangsprodukt der Atmungskette ist Sauerstoff, der komplett zu Wasser reduziert wird. Das Mitochondrium ist somit auch dem schädlichen Potential des Sauerstoffs in besonderem Maße ausgesetzt. Die mitochondriale Dysfunktion hängt eng mit 
oxidativem Stress zusammen. So führt nicht nur eine mitochondriale Dysfunktion zu oxidativem Stress, sondern auch umgekehrt oxidativer Stress zu mitochondrialer Dysfunktion. Die reduzierte Aktivität des Komplex I der Atmungskette ist eine Form der mitochondrialen Dysfunktion, die in den Gehirnen von IPS-Patienten nachgewiesen werden kann (Cooper JM et al. 1995), wobei der Komplex I dabei oxidativ geschädigt zu sein scheint (Keeney et al. 2006). Die Schädigung führt hier zu einem Mangel an Adenosintriphosphat (ATP) und zur Bildung von ROS. Der Mangel an ATP führt zu verminderter Aktivität des vesikulären Monoamin-Transporters-2 (VMAT2), der für die Einspeicherung von Dopamin in die Vesikel verantwortlich ist. Dies führt zu einem vermehrten Dopamin-Gehalt in der Zelle und damit wiederum zu oxidativem Stress (Andersen 2004). Experimentell lässt sich die Hemmung des Komplex I über das Neurotoxin MPTP hervorrufen. Weiterhin kann die mitochondriale Hemmung auch zur Bildung von LK sowohl in vitro als auch in vivo führen (Fornai et al. 2005, Lee HJ et al. 2002).

Aber auch der Dopamin-Metabolismus selbst kann zur Hemmung des Komplex I führen. Der Abbau von Dopamin erfolgt normalerweise über die Monoaminooxidase (MAO). Wird Dopamin aber im Zytoplasma autooxidiert, bildet sich DAQ. Dieses kann einerseits polymerisieren und Neuromelanin bilden, oder es entstehen durch die Aktivität intrazellulärer Peptidasen 5-S-Cysteinyl-Dopamin-Derivate (Andersen 2004). Diese wiederum können molekulare Spezies bilden, die direkt den Komplex I inhibieren. Dies konnte in histopathologischen Untersuchungen bestätigt werden: Zusammen mit den erniedrigten Konzentrationen an GSH in den SNpc von IPS-Patienten, fanden sich erhöhte Konzentrationen an solchen Derivaten. Die Daten zeigen, dass nicht nur eine Inhibition des Komplex I zu erhöhter Dopamin-Oxidation führt, sondern, dass auch umgekehrt eine vermehrte Dopamin-Oxidation den Komplex I hemmen kann (Berman und Hastings 1999, Spencer et al. 1998). Die Verminderung des GSH in den Zellen scheint hierbei der Hemmung des Komplex I vorauszugehen, denn in Individuen, die zwar LK, aber keine IPS-Symptomatik aufweisen, können verminderte Level an GSH, nicht aber eine verminderte Aktivität des Komplex I nachgewiesen werden (Jha et al. 2000). Mitochondriale Dysfunktion fand man außerdem auch basierend auf Mutationen im $\alpha$-Syn-Gen (Smith WW et al. 2005).

\subsubsection{Proteasomale Dysfunktion}

Der Abbau von zytosolischen Proteinen erfolgt ATP-abhängig über das Ubiquitin-ProteasomSystem (UPS). Dysregulation des UPS ist mit vielen Erkrankungen assoziiert, so auch mit dem IPS. Aggregiertes $\alpha$-Syn, aber auch monomeres $\alpha$-Syn und insbesondere die Protobrillen inhibieren in Zellkultur die proteasomale Funktion, womit $\alpha$-Syn seinen eigenen Abbau, aber 
auch den anderer Proteine hemmt (Snyder et al. 2003, Zhang NY et al. 2008). Umgekehrt führt proteasomale Inhibition in vitro zur Bildung von Ubiquitin- und $\alpha$-Syn-positiven Einschlusskörperchen (Rideout et al. 2001). Aber auch histopathologische Untersuchungen an Gehirnen von IPS-Patienten unterstützen diese Ergebnisse. So kolokalisieren $\alpha$-Syn und Untereinheiten des Proteasoms in LK (Lindersson et al. 2004). Die direkte Hemmung des Proteasoms durch $\alpha$-Syn-Filamente und Oligomere konnte auch in Kulturen humaner Fibroblasten nachgewiesen werden. Hier trat die Hemmung durch die Oligomere sehr viel schneller auf als die durch Filamente. Die durch Filamene ausgelöste proteasomale Toxizität konnte außerdem durch Überexpression von Hsp70 abgemildert werden (Lindersson et al. 2004).

Aber nicht nur die Interaktion mit $\alpha$-Syn stört das UPS. Auch andere Umstände wie die Verringerung der Menge an antioxidativen Substanzen im Gehirn von IPS-Patienten können zur Beinträchtigung des UPS führen. Verminderte Mengen an GSH führen z. B. zur Oxidation von Enzymen, die für Ubiquitinierung von Proteinen verantwortlich sind, sodass diese Proteine nicht abgebaut werden können und sich im Zytoplasma anreichern (Jha et al. 2002). Aber auch Produkte des oxidativen Stresses können schädlich sein und z. B. das Proteasom direkt hemmen (Friguet und Szweda 1997, Okada et al. 1999).

\subsubsection{Verminderte Autophagie}

Neben der proteasomalen Degradation von Proteinen spielt auch der Mechanismus der Autophagie eine entscheidende Rolle. Während Proteine mit kurzen Halbwertszeiten vor allem über das Proteasom degradiert werden, werden die meisten Proteine mit längeren Halbwertszeiten über den Autophagie-Weg in Lysosomen abgebaut (Cuervo et al. 2004, Glickman und Ciechanover 2002). Lysosomale Inhibitoren führen zu erhöhten $\alpha$-SynKonzentrationen im Zytoplasma, was vermuten lässt, dass ein Teil des $\alpha$-Syn-Abbaus über das lysosomale System geschieht (Lee HJ et al. 2004, Paxinou et al. 2001). Bestärkt wird dies dadurch, dass die Überexpression von $\alpha$-Syn zur Aktivierung der Makroautophagie führt (Cuervo et al. 2004). Hierbei werden ein Teil des Zytosols oder auch ganze Organellen von einer Membran umschlossen und bilden dann ein Doppelmembranvesikel, das Autophagosom, welches mit dem Lysosom verschmilzt, wo enthaltene Bestandteile degradiert werden (Cuervo et al. 2004). Die Hemmung der Makroautophagie führt aber nicht zu verminderter Degradation von $\alpha$-Syn (Lee HJ et al. 2004). Dagegen erhöht die Hemmung der CVA die $\alpha$-Syn-Plasmakonzentration (Cuervo et al. 2004). Bei der CVA handelt es sich um einen lysosomalen Degradationsmechanismus, durch den Proteine mit einer durch das Hitzeschockcognatprotein 70 (Hsc70) und das Hsp70 erkennbaren Domäne degradiert werden 
(Cuervo et al. 2004). a-Syn enthält eine solche Domäne (Dice 1990). Somit werden wahrscheinlich sowohl WT- $\alpha$-Syn und seine mutierten Formen als auch $\alpha$-Syn-Oligomere zumindest teilweise über das Autophagie-System abgebaut (Cuervo et al. 2004, Tetzlaff et al. 2008, Vogiatzi et al. 2008). Die mutierten Formen des $\alpha$-Syn, ebenso wie phosphoryliertes und insbesondere durch Interaktionen mit Dopamin modifiziertes $\alpha$-Syn, scheinen im Gegensatz zum WT- $\alpha$-Syn vermindert über die CVA degradiert zu werden und außerdem das Autophagie-System zu hemmen, sodass auch andere Proteine schlechter degradiert werden können (Cuervo et al. 2004, Martinez-Vicente et al. 2008). Die Degradation von $\alpha$-Syn über die CVA scheint an die Interaktion mit dem Carboxyl-Terminus von Hsp70 interagierendem Protein (CHIP) gebunden zu sein, welches außerdem die Entscheidung, ob die Degradation über das proteasomale System oder über die CVA erfolgt, maßgeblich zu beeinflussen scheint (Shin et al. 2005).

Zusammenfassend kann vermutet werden, dass die CVA eine nicht zu unterschätzende Rolle bei der Degradation von $\alpha$-Syn spielt und die Dysfunktion dieses Mechanismus für die Neurodegeneration beim IPS verantwortlich sein könnte

\subsubsection{Modelle des Morbus Parkinson}

Wie schon erläutert ist der Mechanismus, der zum Zelltod der dopaminergen Neurone bei IPS-Patienten führt, weiterhin unverstanden. Die postmortalen Untersuchungen von Gewebe aus den Gehirnen von IPS-Patienten stellt immer nur den fixierten Endzustand einer Erkrankung dar. Deshalb ist die Parkinson-Forschung immer auf der Suche nach Modellen, die das dynamische Bild der neuronalen Degeneration nachahmen. Über die Jahre sind viele verschiedene Toxine benutzt worden, um die selektive Zerstörung dopaminerger Neurone im Modell auszulösen. Obwohl viele Erkenntnisse über das IPS an Hand solcher Modelle gewonnen werden konnten, repräsentiert doch bis heute keines dieser Modelle alle Merkmale des IPS (Jackson-Lewis und Przedborski 2007).

\subsubsection{6-Hydroxydopamin}

6-OHDA ist ein hydroxyliertes Analogon des Neurotransmitters Dopamin und zeigt eine spezifische Neurotoxizität gegenüber monoaminergen Neuronen (Ungerstedt 1968). 6-OHDA als Oxidationsprodukt von Dopamin lässt sich regelrecht in humanen Hirnen nachweisen (Curtius et al. 1974), womit es sich bei 6-OHDA um ein endogenes Neurotoxin handelt. Weiterhin wird es vermehrt im Urin von Patienten mit IPS nachgewiesen, insbesondere, wenn diese unter einer Therapie mit L-DOPA stehen (Andrew et al. 1993). 
Durch aktive Aufnahme über den DAT und den Norepinephrin-Transporter (NET) reichert sich 6-OHDA im Zytosol von Neuronen an und kann durch Autoxidation mit einhergehender Radikalbildung zum Zelltod führen (Bové et al. 2005). Ebenso konnte gezeigt werden, dass 6OHDA direkt die Aktivität des Komplex I der Atmungskette hemmt (Glinka et al. 1996). Dies führt $\mathrm{zu}$ einem ATP-Mangel und oxidativem Stress mit den oben schon erläuterten Konsequenzen (1.1.2.1.3). Weiterhin konnte gezeigt werden, dass 6-OHDA die Spiegel von GSH und der Superoxiddismutase vermindert (Perumal et al. 1992), was zu verminderter Abwehrfähigkeit gegen oxidativen Stress führt.

Da 6-OHDA die Blut-Hirn-Schranke nicht überschreiten kann, wird der dopaminerge Zelltod im Tiermodell, z. B. bei Ratten oder Mäusen, durch Injektion in die SNpc, in das mediale Vorderhirnbündel oder das Striatum erreicht (Javoy et al. 1976, Roberts et al. 1975). 6-OHDA kann hier zum fast selektiven Untergang von dopaminergen Neuronen führen, wie es auch für das IPS typisch ist. Histopathologisch können keine LK nachgewiesen werden (Bové et al. 2005). Die Injektion wird typischerweise als unilaterale Injektion durchgeführt, da beidseitige Läsionen von den Tieren oft nicht überlebt werden (Bové et al. 2005). Interessant ist dieses Modell vor allem deshalb, da bei den einseitig läsionierten Tieren ein typisches Bewegunsmuster, im Sinne einer Drehung um die eigene Achse, zu beobachten ist. Dies lässt sich durch Applikation von Apomorphin noch verstärken. Somit bietet das 6-OHDARattenmodell eine Möglichkeit potentiell neuroprotektive Substanzen durch eine Verbesserung des motorischen Verhaltens der Tiere zu identifizieren (Bové et al. 2005, Ungerstedt und Arbuthnott 1970).

\subsubsection{Rotenon}

Das Insektizid Rotenon ist die wirkstärkste Substanz in der Familie der Rotenoide, einer Stoffgruppe, die aus bestimmten Pflanzen isoliert werden kann. Rotenon wird als Insektizid genutzt. Es ist mit einer Halbwertszeit von maximal drei Tagen sehr instabil und wird intestinal nur langsam und nicht vollständig resorbiert. Außerdem wird es in der Leber schnell inaktiviert. Es ist deshalb sehr unwahrscheinlich, dass seine Nutzung als Insektizid mit einem erhöhten IPS-Risiko in Zusammenhang gebracht werden kann (Bové et al. 2005). In einer kürzlich publizierten Studie konnte allerdings gezeigt werden, dass durch die intragastrale Applikation von Rotenon bei Mäusen, trotz zu keiner Zeit messbaren Blutspiegeln, ein IPSähnlicher Phänotyp induziert werden kann. Erklärt werden kann dies eventuell dadurch, dass Rotenon extrem lipophil ist und somit sehr leicht die Blut-Hirn-Schranke und Zellmembranen penetriert. Es reichert sich in Mitochondrien an und hemmt dort die Funktion des Komplex I (Sherer et al. 2003). Im Tiermodell entstehen bei chronischer subkutaner Rotenon-Infusion 
die typischen Merkmale eines IPS, inklusive nigrostriataler dopaminerger Degeneration und $\alpha$-Syn-positiver, zytoplasmatischer Einschlusskörperchen (Betarbet et al. 2000). Das größte Problem des Rotenon-Tiermodells scheint die starke Variabilität im Zelltod der Neurone in der SNpc zu sein. Kürzlich wurde allerdings über ein zuverlässiges, sehr gut reproduzierbares Protokoll berichtet, bei dem Rotenon täglich intraperitoneal appliziert wird (Cannon et al. 2009). Im Zellkulturmodell vermag Rotenon den Zelltod durch Hemmung des Komplex I innerhalb von 24-48 Stunden auszulösen. Weiterhin konnte gezeigt werden, dass Rotenon die Bildung von Tubulin beeinträchtigt (Marshall und Himes 1978). Dieser Effekt kann relevant für die dopaminerge Neurodegeneration sein, da der Überschuss an Tubulin-Monomeren in der Zelle toxisch sein kann (Burke et al. 1989).

\subsubsection{MPTP}

Ein besonderes Problem von neuen Designerdrogen stellen ihre unvorhersehbaren und teils erschreckenden Nebenwirkungen dar. So wurden 1979 bei Konsumenten des Piperidinderivates 1-Methyl-4-phenyl-4-propion-oxy-piperidin (MPPP), des sogenannten „synthetischen Heroins“, das Auftreten eines PS beobachtet (Davis et al. 1979). Bald darauf wurde aufgeklärt, dass nicht MPPP für den neurotoxischen Effekt verantwortlich war, sondern MPTP, das ein Synthesenebenprodukt des MPPP darstellt (Langston und Ballard 1983). MPTP ist extrem lipophil und penetriert Zellmembranen sowie die Blut-Hirn-Schranke mit Leichtigkeit (Riachi et al. 1989). Hier wird es von Astrozyten und serotoninergen Neuronen endozytiert und in den Lysosomen durch die MAO-B in das eigentlich toxische 1Methyl-4-phenylpyridinium $\left(\mathrm{MPP}^{+}\right.$) umgewandelt (Przedborski und Vila 2003). In dieser Form kann es Zellmembranen nicht mehr penetrieren, wird aber mit hoher Affinität über den DAT aufgenommen. Dementsprechend werden vor allem Zellen mit hoher DAT-Expression geschädigt, also die dopaminergen Neurone (Javitch et al. 1985). In die Zellen aufgenommen führt $\mathrm{MPP}^{+}$zur Hemmung des Komplex I. Dies führt zu oxidativem Stress, zu einem Mangel an ATP und zur Einleitung der Apoptose (Abb. 2). Höchstwahrscheinlich blockiert MPTP dabei den Komplex I an einer anderen Stelle als Rotenon, womit auch der Hemmmechanismus ein anderer zu sein scheint (Heikkila et al. 1985, Przedborski et al. 2004, Vyas et al. 1986).

MPTP ist eine rein synthetische Substanz und kommt so nicht in der Natur vor, deshalb hängt es wohl nicht mit der Entstehung des IPS zusammen. In der Forschung wird MPTP als etablierte Substanz in Parkinson-Modellen benutzt. Da Nagetiere weniger anfällig für MPTP sind, werden in diesen Experimenten relativ hohe Dosen an MPTP eingesetzt, die auch für den Menschen gefährlich werden können (Heikkila et al. 1984), zumal Primaten hochsensibel 
für MPTP sind und das extrem lipophile MPTP leicht die Haut penetriert. Als Antidot für eine Vergiftung mit MPTP stehen MAO-B Hemmstoffe wie Deprenyl zur Verfügung, welche die Giftung des MPTP zu MPP ${ }^{+}$verhindern (Cohen et al. 1984).

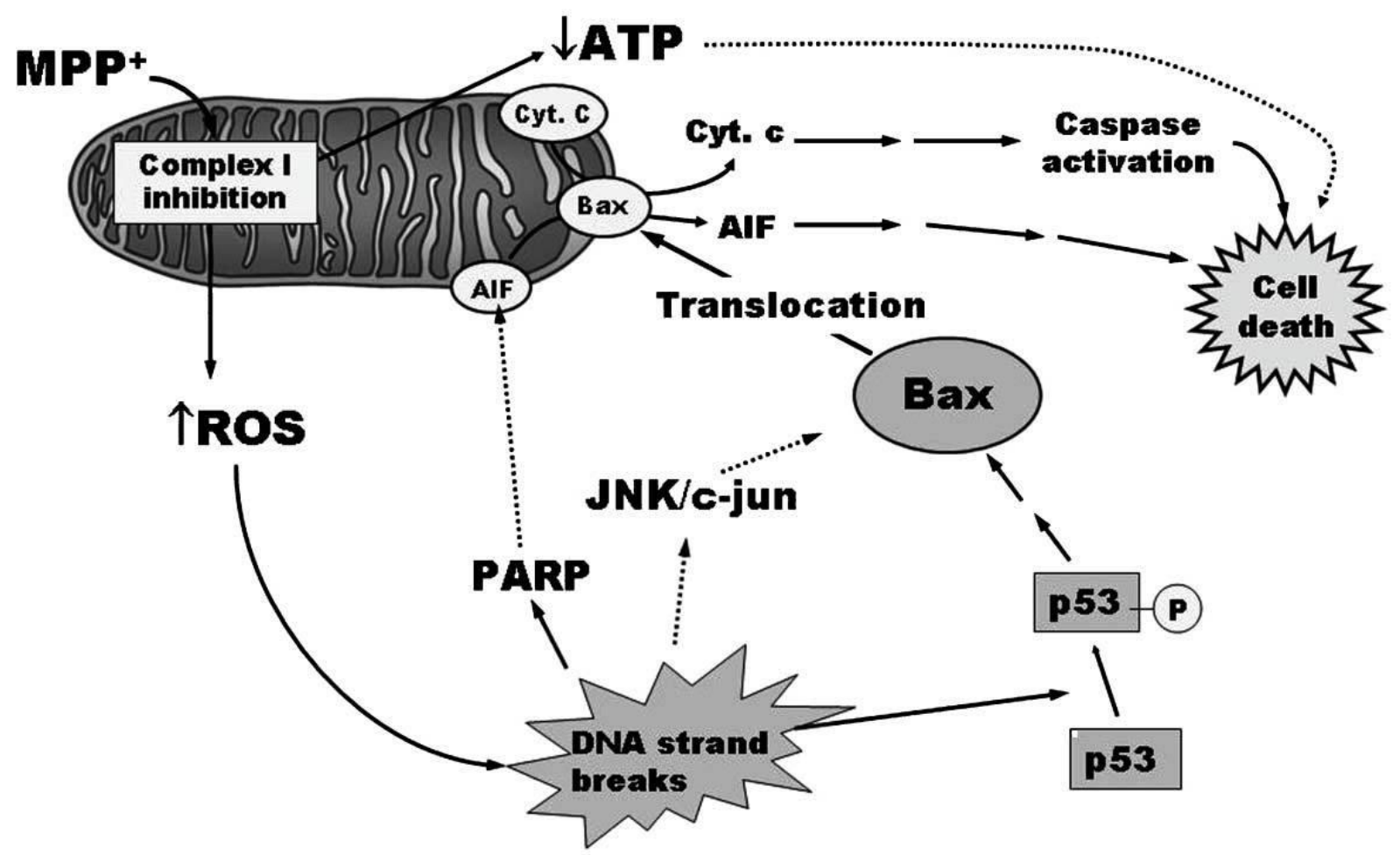

Abb. 2: Illustration Zelltodkaskade ausgelöst durch MPTP. MPP ${ }^{+}$wird ins Mitochondrium aufgenommen und bindet an den Komplex I, womit die ATP-Synthese inhibiert und die Produktion von ROS stimuliert wird. Dies führt zur Schädigung von DNA und Proteinen. Dadurch werden Apoptosekaskaden über das Protein 53 (p53) und cJNK in Gang gesetzt, die zur Aktivierung des Bcl2-assoziierten X-Proteins (Bax) führen. Dadurch kommt es zur Translokation von Cytochrom C (Cyt. c) und des Apoptose-induzierenden Faktors (AIF) vom Mitochondrium ins Zytosol. Cyt.c führt den Zelltod caspaseabhängig herbei, AIF caspaseunabhängig. Daneben führt die DNA-Schädigung zur Aktivierung der Poly-ADP-Ribose-Polymerase (PARP), die ebenfalls zur Beschreitung der durch Bax initiierten Apoptosewege beiträgt. Durchgezogene Pfeile: Bestätigte Mechanismen; Gepunktete Pfeile: Vermutete Mechanismen (Przedborski et al. 2004, S. 378).

Unter den verschiedenen Toxin-Modellen für das IPS ist das MPTP-Modell als das wohl Beste und am häufigsten Benutzte herauszuheben. Dies aus drei Gründen: Zuerst produziert es sowohl in Affen als auch in Menschen ein Syndrom, das nahezu nicht vom IPS zu unterscheiden ist. Zweitens ist für die Arbeit mit MPTP, obwohl es auf Grund der Toxizität natürlich größter Vorsicht bedarf, keine besondere Ausstattung, z. B. im Sinne stereotaktischer Geräte, und auch kein besonderes chirurgisches Können erforderlich. Drittens stellt das MPTP-Modell ein verlässliches, gut reproduzierbares Modell dar, was für andere Toxine nicht unbedingt der Fall ist (Jackson-Lewis und Przedborski 2007). Das erste MPTPTiermodell wurde 1983 im Rhesusaffen entwickelt (Burns et al. 1983). MPTP verursacht sowohl in Menschen, als auch in Affen ein schweres und irreversibles PS, charakterisiert durch die Kardinalsymptome und kognitive Beeinträchtigungen, wie sie auch bei Patienten 
mit IPS beobachtet werden können. Auch das Schädigungsmuster im Gehirn entspricht in etwa dem des IPS (Bové et al. 2005). In älteren MPTP-behandelten Affen konnten auch eosinophile Einschlusskörperchen gefunden werden, die LK ähneln (Forno et al. 1986). Das durch MPTP-induzierte PS lässt sich weiterhin sehr gut mit L-DOPA behandeln (Bové et al. 2005). Das MPTP-Affenmodell ist der Goldstandard zur Erprobung neuer ParkinsonMedikamente (Jackson-Lewis und Przedborski 2007).

Ein weiteres MPTP-Tiermodell wurde in der Maus entwickelt (Heikkila et al. 1984) und hat sich inzwischen als ein Standardmodell in der Parkinson-Forschung etabliert (Przedborski und Vila 2003). Hier wird insbesondere die C57BL/6-Maus verwendet, da diese sich, im Gegensatz zu anderen Mausstämmen oder auch Ratten, als relativ MPTP-sensibel erwiesen hat (Heikkila et al. 1984). Auch das Alter der Mäuse scheint einen Einfluss auf ihre Suszeptibilität gegenüber MPTP zu haben (Irwin et al. 1993). Im Mausmodell gibt es verschiedene Protokolle zur Verabreichung des Toxins. Mit dem Protokoll variiert zunächst die Akuttoxizität des MPTP. Da Mäuse insgesamt recht unempfindlich auf MPTP reagieren (Heikkila et al. 1984), werden recht hohe Dosen eingesetzt, die auch akuttoxisch sind, was die Maximaldosen limitiert. Aber auch das Maß des am Ende hervorgerufenen Zelltodes in der SNpc, ebenso wie die striatale Faserdichte, variieren mit dem Protokoll. LK lassen sich nur in chronischen Modellen nachweisen (Fornai et al. 2005, Gibrat et al. 2009, Jackson-Lewis und Przedborski 2007, Przedborski und Vila 2003).

Den Modellen gemeinsam ist, dass die Mäuse keinen auffälligen parkinsonartigen Phänotyp, wie z. B. Menschen oder Affen, aufweisen, selbst nach starkem Zellverlust in der SNpc. Es konnten aber in komplexen Tests signifikante motorische Defizite aufgedeckt werden (Liebetanz et al. 2007). Interessanterweise sind $\alpha$-Syn-Knockout-Mäuse teilresistent gegen MPTP-Toxizität (Dauer et al. 2002). Daneben führt die Applikation von MPTP zu einer signifikanten Expressionserhöhung von $\alpha$-Syn in der SNpc (Vila et al. 2000), was sich auch mit $\mathrm{MPP}^{+}$in SH-SY5Y-Zellen reproduzieren lässt (Gomez-Santos et al. 2002). Auch die Verminderung von oxidativem Stress durch die Überexpression der Superoxiddismutase vermindert die Neurotoxizität von MPTP (Przedborski et al. 1992). Im Umkehrfall potenziert sich die durch MPTP ausgelöste Toxizität (Zhang J et al. 2000).

\subsubsection{4 $\alpha-S y n u c l e i n$}

Es existieren verschiedenste $\alpha$-Syn-Modelle in der Zellkultur. Der Gentransfer kann hier recht unkompliziert auf verschiedenen Wegen, z. B. per Lipofektion oder viral, erfolgen. In einem Zellkulturmodell mit primären Neuronen und viralem Gentransfer, konnte z. B. nachgewiesen werden, dass die Überexpression der A53T-Mutante zur Deformation und Schwellung von 
Neuriten, sowie granulären Ablagerungen in den Perikaryen führt (Zach et al. 2007). Bei Überexpression von WT- $\alpha$-Syn, der A30P-, A53T- und E46K-Mutante in SH-SY5Y-Zellen per Lipofektion konnten auch Aggregate in den Zellen nachgewiesen werden (Pandey et al. 2006). Daneben konnte auch die Toxizität von $\alpha$-Syn im Zellkulturmodell dokumentiert werden. In einem Modell mit DAT-exprimierenden SH-SY5Y-Zellen in denen der Gentransfer per Lipofection erfolgte, konnte eine erhöhte Zytotoxizität der A30P- und A53TMutante gegenüber dem WT- $\alpha$-Syn nachgewiesen werden (Moussa et al. 2004).

Transgene Tiermodelle für $\alpha$-Syn wurden erstmalig im Jahr 2000 publiziert (Feany und Bender 2000, Kahle et al. 2000, Masliah et al. 2000, van der Putten et al. 2000). Heute existiert eine Vielzahl an verschiedenen Modellen, die entweder humanes WT- $\alpha$-Syn oder seine Mutanten überexprimieren. Da sich die Modelle mit der Tierart, der Wahl des Promotors und im Einbau in das Tiergenom unterscheiden, ist ein Vergleich sehr schwierig. Klassisch ist die Maus als transgenes $\alpha$-Syn-Tier. Hier finden sich in verschiedenen Modellen motorische Defizite der transgenen Mäuse, sowohl durch die A30P-, die A53T-Mutation und die Duplikation des $\alpha$-Syn-Gens ausgelöst. In den meisten Modellen finden sich zwar Einschlusskörperchen, diese sind aber nicht fibrillärer Natur (Maries et al. 2003). Einzig in einer A53T-transgenen Maus konnten auch fibrilläre Einschlusskörperchen nachgewiesen werden, auch diese waren aber nicht LK-ähnlich (Lee MK et al. 2002).

Neben der Maus fungieren vor allem der Fadenwurm (Caenorhabditis elegans) und die Fruchtfliege (Drosophila melanogaster), die beide kein Ortholog zum humanen $\alpha$-Syn besitzen, als Modellsysteme. Im $\alpha$-Syn-überexprimierenden Fadenwurm konnte sowohl mit der A30P- und der A53T-Mutante, als auch mit WT- $\alpha$-Syn ein neuronaler und dendritischer Verlust erzeugt werden. Es konnten jedoch keine LK-ähnlichen Einschlüsse beobachtet werden. Weiterhin entwickelten die Würmer motorische Defizite (Kuwahara et al. 2006, Lakso et al. 2003). Die Überexpression von WT- $\alpha$-Syn, sowie der A30P- und der A53TMutante in der Fruchtfliege führten zum altersabhängigen Verlust dopaminerger Neurone mit LK-ähnlichen Einschlusskörperchen, sowie zu retinaler Degeneration und motorischen Defiziten (Feany und Bender 2000).

Neben der Entwicklung transgener Tiere gibt es auch die Möglichkeit im Rahmen eines viralen Transfers Transgene lokal überzuexprimieren. Die lokale Überexpression von $\alpha$-Syn in der SNpc durch Adeno- oder Lentiviren führte hier ebenfalls $\mathrm{zu} \alpha$-Syn-positiven Aggregaten und neuronaler Degeneration (Kirik et al. 2002, Lo Bianco et al. 2002). Die Überexpression von humanem $\alpha$-Syn im Tiermodell führt auch in Motoneuronen (Lakso et al. 
2003), sowie in Neuronen der Amygdala (Lauwers et al. 2003) zu Pathologien. Dies legt nahe, dass die von $\alpha$-Syn ausgehende Toxizität nicht auf dopaminerge Neurone beschränkt ist.

\subsubsection{Therapie}

\subsubsection{Aktuelle therapeutische Strategien}

Die aktuelle Therapie des IPS ist rein symptomatisch und das Wirkprinzip beruht auf der Erhöhung der Dopaminkonzentration im Striatum. Die Therapie erfolgt mit L-DOPA oder Dopaminagonisten. Im Verlauf der Therapie kommt es häufig zum Nachlassen der Wirkung, bzw. zu schwerwiegenden Nebenwirkungen, wie plötzlichem Wirkungsverlust mit Akinesien, starken Fluktuationen der Beweglichkeit und Dyskinesien. Dies kann ein Ausmaß annehmen, welches medikamentös nicht mehr $\mathrm{zu}$ beherrschen ist. In solchen Fällen ist die Tiefenhirnstimulation in Betracht $\mathrm{zu}$ ziehen. Hier wird der Nucleus subthalamicus über implantierte Elektroden stimuliert, wodurch wieder ein Gleichgewicht in den Basalganglien erzeugt wird. Die Tiefenhirnstimulation gilt als eine potente Behandlungsmethode des IPS im fortgeschrittenen Stadium. Trotzdem stellt die Tiefenhirnstimulation, schon allein ihrer Invasivität und Infektionsgefährdung wegen, kein optimales Therapieverfahren dar. Nebenbei sind andere, wie z. B. auch die vegetativen Parkinson-Symptome mit diesem Verfahren nicht adäquat behandelbar (Eggert et al. 2008).

\subsubsection{Experimentelle Therapien}

Auf Grund der oben geschilderten Probleme mit den Standardprinzipien zur Behandlung des IPS wird weiter nach innovativen Therapieoptionen gesucht. Insbesondere wird natürlich versucht, Therapien zu entwickeln, die nicht, wie die oben genannten, rein symptomatisch sind, sondern die den Erkrankungsverlauf positiv beeinflussen, im günstigsten Fall sogar heilen können. Hier sind insbesondere zwei Ansätze zu nennen: Die neuroprotektive GenTherapie (1.1.5.2.1) und die Transplantation von fetalen Stammzellen, die im Gehirn die Aufgabe der dopaminergen Neurone übernehmen sollen. Für Letzteres konnte, trotz vieler ermutigender Studien im Vorfeld, in drei kürzlich durchgeführten, randomisierten, doppelblinden, placebokontrollierten Studien kein Benefit durch die Transplantate nachgewiesen werden. In zwei der Studien entwickelten Patienten sogar persistierende Dyskinesien (Greene 2009).

\subsection{Neuroprotektive Gentherapie}

Die Gentherapie weckt große Hoffnungen für IPS-Patienten. In einer chirurgischen Sitzung kann ein Transgen appliziert werden, das idealerweise lebenslang exprimiert wird (Fiske et al. 
2008). Als Vehikel für die Expression von Genen werden hierfür insbesondere Adenoviren, Adeno-assoziierte-Viren (AAV) und Lentiviren genutzt (Björklund et al. 2000). Auf diese Weise können auch Bereiche gezielt therapiert werden, die sonst schwer erreichbar sind, da sie z. B. hinter der Blut-Hirn-Schranke liegen. Dabei ist es ausreichend, das Gen im betroffenen Areal, z. B. der SNpc überzuexprimieren, sodass die potentiellen Nebenwirkungen gering gehalten werden können. Trotzdem ist es natürlich übertrieben, zu behaupten, dass Gentherapie sicher sei (Fiske et al. 2008). Die Erfolgsgeschichte der Gentherapie wurde bereits durch einige unerwartete Ereignisse, wie z. B. den Tod von Studienteilnehmern, getrübt (Frank et al. 2009).

Speziell für neurodegenerative Erkrankungen sind in den letzten Jahren viele verschiedene gentherapeutische Strategien entwickelt worden. So kann die Apoptose von Neuronen durch die Überexpression antiapoptotischer Proteine, wie die der B-cell-lymphoma 2-Protein (Bcl2)-Familie gehemmt werden (Azzouz et al. 2000, Malik et al. 2005, Wong et al. 2005). Des Weiteren ist die Applikation von neurotrophen Faktoren aus Gliazellen, wie z. B. Glial cell line derived neurotrophic factor (GDNF) vielversprechend (Hong et al. 2008, Shevtsova et al. 2006). Hier existiert sogar eine ex-vivo-Studie, in der gentherapierte Zellen transplantiert wurden, wodurch die Methoden der Zelltransplantation und der Gentherapie kombiniert werden konnten (Lindvall und Wahlberg 2008). Weiterhin besteht die Möglichkeit der Überexpression von Chaperonen, wie Hsp70 (Dong $Z$ et al. 2005), was ebenfalls neuroprotektiv wirkt. Eine vierte Methode ist die gentherapeutische Enzymersatztherapie, in der versucht wird die Neurotransmitterlevel in den Basalganglien positiv zu beeinflussen.

Zur Zeit laufen drei klinische Phase-1-Studien für IPS-Patienten, von denen sich zwei auf den palliativen Effekt der Enzymersatztherapie konzentrieren und eine auf den Einsatz eines neurotrophen Faktors. Vehikel ist in allen Studien das AAV-2. Bis jetzt konnten in keiner dieser Studien negative Effekte des Virus nachgewiesen werden. Der tatsächliche therapeutische Effekt ist bis jetzt kaum zu beurteilen, da Kontrollgruppen fehlen. Es scheint aber Grund für vorsichtigen Optimismus zu geben (Eberling et al. 2008, Fiandaca et al. 2008, Kaplitt et al. 2007).

\subsection{AAV-Vektoren als Werkzeuge der Gentherapie}

Um transgene Proteine im zentralen Nervensystem (ZNS) zu exprimieren, benötigt man effektive Werkzeuge für den Gentransfer. Das AAV ist ein solches Werkzeug. Beim AAV handelt es sich um ein kleines Dependovirus der Parvoviridae-Familie, das in der Abwesenheit von Adenoviren, Herpesviren oder Vacciniaviren nicht in der Lage ist, sich zu replizieren (Buller et al. 1981). WT-AAV ist nicht mit Erkrankungen in Menschen oder 
Säugetieren assoziiert, was es zu einem attraktiven Werkzeug für die Gentherapie macht. Das AAV beherbergt ein lineares Einzelstrang-Genom von 4675 Nucleotiden, welches invertierte terminale Repeats (ITRs) von 145 Nucleotiden enthält (Srivastava et al. 1983). Es besitzt zwei große open reading frames (ORF) die sich nicht überschneiden. Einer (Cap) codiert für das Hüllprotein, der andere (Rep) für die Proteine, die für die Virus-Replikation nötig sind. Bis heute konnten zehn verschiedene AAV-Serotypen (AAV-1 bis AAV-9 und AAV-Rh10) identifiziert werden (Cearley und Wolfe 2006). Den für die Gentherapie eingesetzten rekombinanten AAV-Vektoren fehlt fast ihr gesamtes Genom mit Ausnahme der ITRs, welche für die Verpackung des Virus notwendig sind (Samulski et al. 1989). Aus diesem Grund werden die rekombinanten AAV-Vektoren als besonders sicher eingestuft. Da den rekombinanten AAV-Vektoren das WT-Rep-Gen, welches für die spezifische Integration in die chromosomale DNA verantwortlich ist, fehlt, liegen sie vor allem in episomaler Form vor (Duan et al. 1998). Nichtsdestotrotz können sie die stabile Genexpression für mehr als ein Jahr sicherstellen (Stieger et al. 2006, Woo et al. 2005). Weiterhin haben AAV-Vektoren die besonders günstige Eigenschaft, sowohl Zellen zu transduzieren, die sich teilen, als auch solche, die sich nicht teilen (Flotte et al. 1994, Flotte et al. 1992). Rekombinante AAVVektoren scheinen nicht toxisch zu sein, wirken nicht entzündlich, und induzieren nur eine sehr geringe Immunantwort, welche nicht zur Minderung der Expression des Transgens führt (Mastakov et al. 2002). In einigen Individuen konnten allerdings AAV-neutralisierende Antikörper nachgewiesen werden (Moskalenko et al. 2000). Ein weiteres Problem des AAVVektors stellt noch die Tatsache dar, dass sich nur verhältnismäßig kleine Transgene integrieren lassen (Dong JY et al. 1996).

Der AAV-2 Serotyp ist besonders gut geeignet, Neurone im ZNS zu transduzieren und hat eine besonders hohe Affinität zu den dopaminergen Neuronen der SNpc (Paterna et al. 2004). Diese Eigenschaft der AAV-2 Vektoren kann durch die hohe Dichte an Heparansulfatproteoglykan-Rezeptoren auf nigralen Neuronen erklärt werden, die für den Eintritt des Virus nötig sind (Fuxe et al. 1994).

\subsection{BAG1}

\subsubsection{Struktur}

Wie die anderen Mitglieder der BAG-Familie besitzt das Bcl-2-assoziierte Athanogen-1 (BAG1) eine eine hochkonservierte BAG-Domäne, die aus etwa 70 Aminosäuren besteht und am C-Terminus lokalisiert ist. Die BAG-Domäne beinhaltet mehrere Bindungsstellen und vermittelt so Interaktionen mit Proteinen wie dem V-Raf-1 murine leucemia viral oncogene 
homolog 1 (Raf-1), Bcl-2 und Hsp70 (Takayama et al. 1995, Takayama et al. 1997). Außerdem besitzt BAG1 eine Ubiquitin-ähnliche Domäne (ULD), die sich am N-Terminus befindet (Abb. 3). Diese Domäne besteht aus 36 Aminosäuren (Takayama et al. 1995). Die ULD ist notwendig für die Bindung an das Proteasom (Lüders et al. 2000). Es existieren 4 Isoformen des BAG1: BAG1L (52 kDa), BAG1M (46 kDa), BAG1 (34 kDa) und BAG1S (29 $\mathrm{kDa}$ ). Diese Isoformen unterscheiden sich durch die Länge des Amino-Terminus (Alberti et al. 2003, Zeiner et al. 1997). Das Gen für BAG1 ist auf der Region p12 des humanen Chromosom 9 lokalisiert (Takayama et al. 1996).

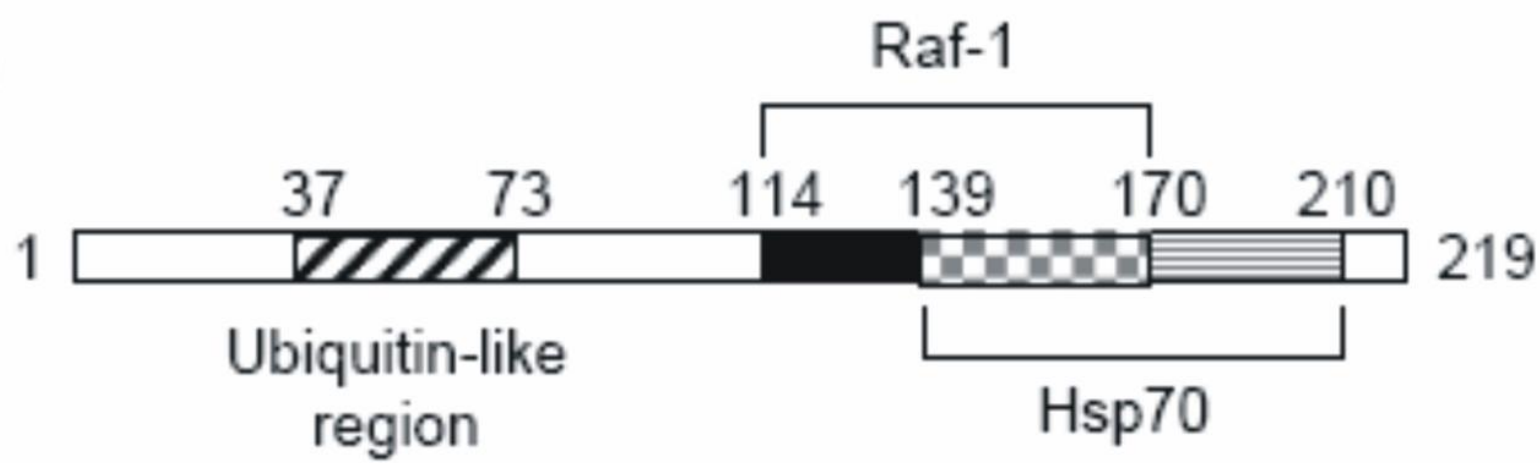

Abb. 3: Struktur der kurzen Maus-BAG1-Isoform. Schwarz gestreifte Region: ULD, schwarze und grau karierte Region: Raf-1-Bindungsstelle, graue Region: Hsp70-Bindungsstelle. Die Zahlen stehen für die Aminosäureanzahlen (Song et al. 2001, S. 277).

\subsubsection{Funktion}

BAG1 wurde zuerst als ein mit Bcl-2-interagierendes Protein beschrieben, wobei es hier den antiapoptotischen Effekt von Bcl-2 noch zu verstärken vermag (Takayama et al. 1995). Auch in der Interaktion mit aus Hepatozyten und Thrombozyten stammenden Wachstumsfaktoren zeigt sich die antiapoptotische Funktion von BAG1 (Bardelli et al. 1996).

Daneben hat BAG1 noch viele andere Funktionen, wobei insbesondere die als Co-Chaperon der Hsc/Hsp70-Familie herauszustellen ist. Die molekulare Basis der Chaperon-Funktion besteht in der transienten Interaktion mit Substraten in ATP-kontrollierten Zyklen. Im ATPgebundenen Status haben die Chaperone eine niedrige, im Adenosindiphosphat (ADP)gebundenen Status dagegen eine hohe Substrataffinität. Die Hydrolyse von ATP kann durch Co-Chaperone stimuliert werden. BAG1 soll hier die Freisetzung von ADP durch Hsc/Hsp70 beschleunigen können (Gässler et al. 2001, Höhfeld und Jentsch 1997), nicht aber die Dissoziation von Hsp70-ADP- oder Hsp70-ATP-Komplexen (Bimston et al. 1998). Ob BAG1 damit das Falten denaturierter Substrate durch Hsp70 stimuliert oder hemmt war kontrovers diskutiert worden (Gässler et al. 2001), denn BAG1 scheint sowohl als negativer (Bimston et al. 1998, Nollen et al. 2001, Takayama et al. 1997) als auch als positiver (Gässler et al. 2001, Terada und Mori 2000) Regulator der Hsc/Hsp70-Funktion fungieren. Übereinstimmung 
besteht allerdings in der Auffassung, dass BAG1 das Fließgleichgewicht der ATPaseAktivität von Hsp70 und Hsc70 stimuliert, wenn auch das Außmaß der beobachteten Stimulation stark variiert (Bimston et al. 1998, Gässler et al. 2001, Höhfeld und Jentsch 1997, Sondermann et al. 2001). Diese gegensätzlichen Funktionen scheinen konzentrationsabhängig zu sein: BAG1 verbessert die Chaperon-Aktivität von Hsc/Hsp70 nur unter physiologischen Bedingungen mit sehr niedrigen Konzentrationen (Gässler et al. 2001).

Daneben interagiert BAG1 mit einer großen Anzahl anderer zellulärer Targets, unter anderem mit dem UPS, wobei die ULD, die für diese Interaktion verantwortlich ist, wohl vor allem regulatorische Funktionen ausübt und damit den Abbau anderer Proteine beeinflusst (Alberti et al. 2002, Lüders et al. 2000). Ein weiterer wichtiger Interaktionspartner ist CHIP (Demand et al. 2001). Durch die Bildung eines ternären Komplexes aus BAG1, Hsp70 und CHIP erfolgt die verstärkte Ubiquitinylierung von BAG1. Demnach ist BAG1 Substrat der Ubiquitin-Ligase CHIP (Alberti et al. 2002). Die Polyubiquitin-Kette induziert in diesem Fall allerdings nicht den Abbau von BAG1, sondern fördert die, von der Degradation unabhängige, Assoziation von BAG1 an das Proteasom, wo es wahrscheinlich regulatorisch tätig ist (Alberti et al. 2002). So stimuliert beispielsweise die Überexpression von BAG1 die CHIP-abhängige Degradation des Glucocorticoid-Rezeptors (Demand et al. 2001). Es scheint, dass die beiden Co-Chaperone BAG1 und CHIP gemeinschaftlich die Chaperon-Aktivität vom Proteinfalten auf die Proteindegradation umschalten können (Alberti et al. 2003).

Weitere beschriebene Interaktionspartner von BAG1 sind zahlreiche Steroid-HormonRezeptoren und andere Kernrezeptoren (Kullmann et al. 1998, Zeiner und Gehring 1995). Außerdem wird in der Literatur von Interaktionen des BAG1 mit Tyrosin-KinaseWachstumsfaktoren, wie dem Retinsäure-Wachstumsfaktor (Liu et al. 1998) und der Serin/Threonin-spezifischen Kinase Raf-1 berichtet (Wang et al. 1996). Die Bindungsstelle für Raf-1 überlappt mit der für Hsp70 und stellt einen wichtigen Faktor für Proliferation und Differenzierung von Zellen dar (Wang et al. 1996), letzteres insbesondere auch in Abhängigkeit von verschiedenen Stress-Faktoren (Song et al. 2001). So scheint BAG1 auch Aufgaben bei der Entwicklung des Nervensystems zu erfüllen, denn es wird schon ab der frühen Embryogenese in neuronalen Vorläuferzellen exprimiert (Kermer et al. 2002). Wahrscheinlich kommt die Interaktion und Regulation der verschiedenen molekularen Targets durch Änderungen in der Konformation des Proteins zustande (Takayama und Reed 2001). Außerdem sind für die verschiedenen Effekte von BAG1 unter anderem der Zelltyp und auch die intrazelluläre Lokalisation entscheidend (Kermer et al. 2002, Liman et al. 2008). Wahrscheinlich wirkt BAG1 somit als eine Art molekularer Schalter, der bei physiologischen 
Bedingungen über die Aktivierung von Raf-1, anderen Kinasen oder auch Transkriptionsfaktoren Zellwachstum fördern und unter Stress-Bedingungen als Co-Chaperon fungieren kann (Gehring 2004, Song et al. 2001).

\subsection{3 Überexpression und Knockout}

Durch die vielen Interaktionspartner von BAG1 wundert es nicht, dass seine Überexpression in verschiedenen Zelllinien $\mathrm{zu}$ veränderten Zelleigenschaften führt. Tumorzellen beispielsweise zeigen eine erhöhte Proliferationsrate und Zellbeweglichkeit, was zu einer höheren Metastasierungsrate führen kann, sowie eine geringere Apoptoseneigung zur Folge hat (Clevenger et al. 1997, Naishiro et al. 1999, Townsend et al. 2003). Eventuell kann BAG1 sogar als prognostischer Marker Verwendung finden. Die Überexpression von BAG1 in verschiedenen Tumoren scheint je nach subzellulärer Verteilung mit einer schlechteren Prognose assoziiert zu sein (Tang 2002). In neuronalen CSM14.1-Zellen dagegen verringert BAG1 die Proliferationsrate (Kermer et al. 2002) und verändert die Differenzierung. So konnte ein vermehrtes Wachstum an Axon-ähnlichen Fortsätzen in stabil BAG1überexprimierenden CSM14.1-Zellen detektiert werden (Kermer et al. 2002). In vitro (Liman et al. 2005) und in vivo (Kermer et al. 2003) finden sich erhöhte Konzentrationen von Hsc/Hsp70-Chaperonen durch Überexpression von BAG1. Außerdem ist die Überexpression von BAG1 mit neuroprotektiven Effekten assoziiert (siehe 1.2.4) und BAG1-KnockoutMäuse sterben in der Embryogenese durch eine fehlerhafte Entwicklung des Nervensystems, was Hinweise auf wichtige Aufgaben von BAG1 in den Prozessen von neuronaler Entwicklung und Differenzierung gibt (Götz et al. 2005).

\subsubsection{Neuroprotektion}

Die neuroprotektiven Effekte von BAG1 sind in verschiedenen Modellen nachgewiesen: Im Schlaganfall-Modell zeigten BAG1-überexprimierende Mäuse, denen durch Verschluss der Arteria cerebri media eine ischämische Läsion gesetzt wurde, einen geringeren Zellverlust als eine Kontrollgruppe (Kermer et al. 2003). Daneben ist es in der Lage axonale Regeneration in vivo zu fördern. Eine Neuroprotektion im Huntigtonmodell konnte sowohl in vitro (Sroka et al. 2009), als auch in vivo, hier im Drosophila- (Sroka et al. 2009) und auch im Maus-Modell (Orr et al. 2008), nachgewiesen werden. BAG1 scheint die Aggregation von Huntingtin zu reduzieren (Jana und Nukina 2005). Daneben konnte eine Kolokalisation von BAG1 mit Aggregaten des mutierten Huntingtin nachgewiesen werden (Jana und Nukina 2005). In einem anderen Experiment konnten retinale Zellen vor der Degeneration gerettet werden. Hier allerdings war die Coexpression von Bcl-2 und BAG1 erforderlich (Eversole-Cire et al. 
2000). In Modellen der Amyotrophen Lateralsklerose (ALS) findet sich eine Herunterregulation von BAG1 durch bestimmte toxische Mutanten der Superoxiddismutase (Kirby et al. 2002), es konnte allerdings kein neuroprotektiver Effekt in vivo gezeigt werden (Rohde et al. 2008).

In Modellen des Morbus Alzheimer führt die Überexpression von BAG1 dagegen zu einem Anstieg der Tau-Level in den Zellen, was wohl durch die Hemmung des proteasomalen Abbaus von Tau zu erklären ist (Elliott et al. 2007). Weiterhin kann eine Hochregulierung von BAG1 in Tau-Tangles-enthaltenden Neuronen im Alzheimer-Maus-Modell nachgewiesen werden (Elliott et al. 2007). Aber auch in den Hippokampi von Alzheimer-Patienten wird BAG1 vermehrt nachgewiesen - auch hier insbesondere in solchen Neuronen, die vermehrt Tau oder Amyloid enthalten (Elliott et al. 2009). Daneben ist auch die direkte Bindung von BAG1 an Tau und an das Amyloid-Vorläuferprotein beschrieben worden (Elliott et al. 2009).

\subsection{FRAGESTELLUNG DIESER ARBEIT}

Nachdem die neuroprotektive Wirkung von BAG1 schon im Schlaganfall- (Kermer et al. 2003) und im Huntington-Modell (Orr et al. 2008, Sroka et al. 2009) nachgewiesen ist, erschien es vielversprechend, BAG1 auch in weiteren neurodegenerativen Erkrankungen zu testen. BAG1 erscheint hier insbesondere deshalb als vielversprechendes Molekül, da es zum einen die Expression von Hsp70 erhöht (Kermer et al. 2003, Liman et al. 2005) und zum anderen auch als positiver Regulator der Chaperon-Aktivität wirken kann (Gässler et al. 2001, Terada und Mori 2000). Die Überexpression von Hsp70 selbst hat sich bereits als protektiv im Parkinson-Modell erwiesen (Dong $\mathrm{Z}$ et al. 2005). Weiterhin übt BAG1 gemeinsam mit CHIP regulatorische Wirkung auf das Proteasom aus und kann bestimmte Proteine in Kooperation mit CHIP und Hsp70 der Degradation zuführen (Demand et al. 2001). Auch die Degradation von $\alpha$-Syn läuft zum Teil CHIP-assoziiert ab (Shin et al. 2005). Auch dies lässt auf einen protektiven Effekt im Parkinson-Modell hoffen. Zu guter Letzt ist BAG1 primär als ein mit Bcl-2 interagierendes Protein beschrieben worden, welches die durch Bcl-2 vermittelten antiapoptotischen Wirkungen $\mathrm{zu}$ verstärken vermag. Bcl-2 selbst hat sich ebenfalls als protektiv im Parkinson-Modell erwiesen (Zhong et al. 1993). Für das IPS existieren zahlreiche Modelle (1.1.4), die alle Vor- und Nachteile haben, insbesondere da Keines das volle Bild des IPS abbildet, sondern nur bestimmte Aspekte der Erkrankung wiederspiegeln (Jackson-Lewis und Przedborski 2007). In der vorliegenden Arbeit soll es deshalb darum gehen, die neuroprotektive Potenz von BAG1 in verschiedenen in-vitro-Modellen und einem in-vivo-Modell des IPS zu testen. 


\section{MATERIAL UND METHODEN}

\subsection{MATERIAL}

\subsubsection{Chemikalien, Reagenzien und Kits}

Tabelle 2: Chemikalien, Reagenzien und Kits

\begin{tabular}{|c|c|}
\hline Substanz & Herkunft \\
\hline Agarose & Merck, Darmstadt, Deutschland \\
\hline Alkalische Phosphatase & New England Biolabs, Frankfurt am Main, Deutschland \\
\hline Ammoniumperoxidsulfat & Merck, Darmstadt, Deutschland \\
\hline Ampicillin & Roth, Karlsruhe, Deutschland \\
\hline Aqua ad iniectabilia $10 \mathrm{ml}$ & Braun, Melsungen, Deutschland \\
\hline Augensalbe Corneregel & Bausch \& Lomb, Berlin, Deutschland \\
\hline BCA (Bicinchoninsäure) -Assay & Pierce, Bonn, Deutschland \\
\hline Borsäure & Roth, Karlsruhe, Deutschland \\
\hline Bromphenolblau & Roth, Karlsruhe, Deutschland \\
\hline BSA (Bovines Serumalbumin) -Standardprotein & Roth, Karlsruhe, Deutschland \\
\hline Calciumchlorid $\left(\mathrm{CaCl}_{2}\right)$ & Roth, Karlsruhe, Deutschland \\
\hline Chloralhydrat & Fluka, Taufkirchen, Deutschland \\
\hline DAB (3,3'Diaminobenzidin) Peroxidase Substrate Kit & Vector Laboratories, Loerrach, Deutschland \\
\hline DAPI (4',6-Diamidin-2'Phenylindoldihydrochlorid) & Sigma, Taufkirchen, Deutschland \\
\hline Dinatrium-EDTA (Ethylendiamintetraacetat) & Roth, Karlsruhe, Deutschland \\
\hline DMEM (Dulbecco’s modified eagle medium) & Gibco, Karlsruhe, Deutschland \\
\hline DMSO (Dimethylsulfoxid) & Sigma, Taufkirchen, Deutschland \\
\hline DNA Marker GIBCO® $1 \mathrm{~kb}$ plus & Invitrogen, Karlsruhe, Deutshland \\
\hline dNTP-Set (Desoxyribonucleinsäuretriphosphat) & Amersham Biosciences, Freiburg, Deutschland \\
\hline DSS (Disuccinidylsuberat) & Pierce, Bonn, Deutschland \\
\hline DTT (Dithiothreitol) & Roth, Karlsruhe, Deutschland \\
\hline Dual® Color Marker & BioRad, München, Deutschland \\
\hline EDTA (Ethylendiamintetraessigsäure) & Roth, Karlsruhe, Deutschland \\
\hline Eisessig & Roth, Karlsruhe, Deutschland \\
\hline Entellan® & Roth, Karlsruhe, Deutschland \\
\hline Enzym HindIII & New England Biolabs, Frankfurt am Main, Deutschland \\
\hline Enzym XhoI & New England Biolabs, Frankfurt am Main, Deutschland \\
\hline Ethanol absolut & Riedel de Haën, Seelze, Deutschland \\
\hline Ethidiumbromid & Sigma, Taufkirchen, Deutschland \\
\hline FCS (Fötales Rinderserum) & PAA, Coelbe, Deutschland \\
\hline Gene Porter II® & Genlantis, San Diego, CA, USA \\
\hline
\end{tabular}




\section{Glycerol}

\section{G418 (Geneticin)}

Hefe-Extrakt

HEPES (2-(4-(2-Hydroxyethyl)-1-Piperazinyl)Ethansulfonsäure

Isopropanol

Kaliumchlorid

LB (Luria Bertani) Agar

LB Pulver

Lipofectamine $2000 ®$

Luminol

Magnesiumchlorid

Magnetic Assistant Transfection (MATra®)

Methanol

Milchpulver

MPTP

Natriumacetat

Natriumazid

Natriumchlorid

Natriumchlorid 0,9\%,10 ml, zur Infusion

Natriumdeoxycholat

Natriumhypochlorit

NGS (Natürliches Ziegenserum)

Nonidet P-40

Nucleospin Plasmid Mini Kit (Mini-Präp Kit)

PBS (phosphatgepufferte physiologische

Kochsalzlösung) -Pulver

p-Coumarsäure

PFA (Paraformaldehyd)

Polymerase Pfu

Polymerase-Pfu-Puffer (10 x)

Proteinase-Inhibitor

Puromycin

Qiagen Plasmid Maxi Kit (Maxi-Präp Kit)

Quiaquick PCR Purification Kit

Quiaquick Gel Extraction Kit

Rimadyl®

Rotiphorese (30\%)

SDS (Natriumdodecylsulfat)

Streptomycin

Sucrose (D(+)Saccharose)
Roth, Karlsruhe, Deutschland

PAA, Coelbe, Deutschland

Sigma, Taufkirchen, Deutschland

AppliChem, Darmstadt, Deutschland

AppliChem, Darmstadt, Deutschland

AppliChem, Darmstadt, Deutschland

Roth, Karlsruhe, Deutschland

Roth, Karlsruhe, Deutschland

Invitrogen, Karlsruhe, Deutschland

Sigma, Taufkirchen, Deutschland

Sigma, Taufkirchen, Deutschland

IBA BioTAGnology, Göttingen, Deutschland

Roth, Karlsruhe, Deutschland

AppliChem, Darmstadt, Deutschland

Sigma, Taufkirchen, Deutschland

Roth, Karlsruhe, Deutschland

Sigma, Taufkirchen, Deutschland

Roth, Karlsruhe, Deutschland

Braun, Melsungen, Deutschland

Sigma, Taufkirchen, Deutschland

Roth, Karlsruhe, Deutschland

PAA, Coelbe, Deutschland

Roche, Mannheim, Deutschland

Machery-Nagel, Düren, Deutschland

AppliChem, Darmstadt, Deutschland

Fluka, Taufkirchen, Deutschland

Roth, Karlsruhe, Deutschland

Stratagene, La Jolla, CA, USA

Stratagene, La Jolla, CA, USA

Sigma, Taufkirchen, Deutschland

Sigma, Taufkirchen, Deutschland

Quiagen, Hilden, Deutschland

Quiagen, Hilden, Deutschland

Quiagen, Hilden, Deutschland

Pfitzer, Karlsruhe, Deutschland

Roth, Karlsruhe, Deutschland

Roth, Karlsruhe, Deutschland

PAA, Coelbe, Deutschland

Roth, Karlsruhe, Deutschland 
$\mathrm{T}_{4}$-Ligase

$\mathrm{T}_{4}$-Ligase Puffer (10 x)

TEMED (Tetramethylethylendiamin)

Thioninacetat

Tissue-Tek®.

ToxiLight ${ }^{\mathrm{TM}}$ BioAssay Kit

ToxiLight ${ }^{\mathrm{TM}}$ 100\% Lysis Reagent Set

Tris

Triton-X100

Trypanblau

Trypsin

Trypton

Tween

Vectastain ${ }^{\circledR}$ ABC Kit Standard

Vitamin C

Wasserstoffperoxid $30 \%$

Xylenxyanol

Xylol

6-Hydroxydopamin
New England Biolabs, Frankfurt am Main, Deutschland

New England Biolabs, Frankfurt am Main, Deutschland

Roth, Karlsruhe, Deutschland

Sigma, Taufkirchen, Deutschland

Sakura, Zoeterwoude, Niederlande

Lonza, Rockland, ME, USA

Lonza, Rockland, ME, USA

AppliChem, Darmstadt, Deutschland

Roth, Karlsruhe, Deutschland

Sigma, Taufkirchen, Deutschland

Sigma, Taufkirchen, Deutschland

Sigma, Taufkirchen, Deutschland

Sigma, Taufkirchen, Deutschland

Vector Laboratories, Loerrach, Deutschland

Sigma, Taufkirchen, Deutschland

Merck, Darmstadt, Deutschland

Merck, Darmstadt, Deutschland

Roth, Karlsruhe, Deutschland

Sigma, Taufkirchen, Deutschland

\subsubsection{Geräte}

Tabelle 3: Geräte und Software

\begin{tabular}{ll}
\hline Geräte und Software & Herkunft \\
\hline Autoklav & Greiz, Deutschland \\
\hline Axio Vision 4.6 Software Paket & Zeiss, Göttingen, Deutschland \\
easy WIN basic 6.1 & Tecan, Crailsheim, Deutschland \\
Eismaschine, Scotman® & Frimont, Mailand, Italien \\
Elektrophoresekammer für DNA (Mini-Sub® Cell & BioRad, München, Deutschland \\
GT-System, 15 x 7 cm und 15 x 25 cm) & \\
Elektrophoresekammer für Western Blots (Mini- & BioRad, München, Deutschland \\
PROTEAN® 3 Cell-System) & \\
Entwicklungsmaschine für Röntgenfilme Curix 60 & AGFA, Düsseldorf, Deutschland \\
Fluoreszenz Mikroskop, Axioplan & Zeiss, Göttingen, Deutschland \\
Fluoreszenz Mikroskop, Axiovert & Zeiss, Göttingen, Deutschland \\
Fluoreszenz Mikroskop, Axiovision & Zeiss, Göttingen, Deutschland \\
Fluor-STM-MultiImager & Bio-Rad, München, Deutschland \\
Gefrierschrank & Heraeus, Hanau, Deutschland \\
Heizblock, ThermoStat Plus & Eppendorf, Hamburg, Deutschland \\
Injektionspumpe & World Precision Instruments, Berlin, Deutschland \\
\hline
\end{tabular}


Inkubator für Bakterienkultur

Inkubator für Zellkultur

Kryostat

Kühlschränke

Luminometer Wallac 1450 Microbeta Trilux

Magnetplatte (24 Well)

Micro Syringe Pump Controler Micro4

Mikroskop, invertiertes ID 02

Neubauer-Zählkammer ,improved““

Operationsbohrer

Operationsmikroskop

PCR-Maschine Cyclon 25

pH-Meter

Photometer, Bio-Photometer

Photometer, ELISA-Photometer Tecan RainBow

Pipetten

Präparationsbesteck (Skalpell, Pinzetten, Scheren)

Quantity One 4.2.1

Schüttler

Sonicator

Stereo Investigator Software 6.0

Stereotaxierahmen

Stereotaxiezubehör: Maul- und Ohrenhalter

Transfer-Kammer (Mini-PROTEAN@

Elektrophorese-System)

Vortex-Mixer

Waage

Wallac 1450 MicroBeta Workstation 2.7

Wasserbad

Wasserreiniger, PureLab Plus

Zellkulturbank, Hera safe

Zentrifugen
Heraeus, Hanau, Deutschland

Sanyo, Bad Nenndorf, Deutschland

Leica, Wetzlar, Deutschland

Liebherr, Biberach, Deutschland

PerkinElmer, CT, USA

IBA BioTAGnology, Göttingen, Deutschland

World Precision Instruments, Berlin, Deutschland

Zeiss, Göttingen, Deutschland

Hecht-Assistent, Sondheim, Deutschland

Proxxon, Niersbach, Deutschland

Zeiss, Göttingen, Deutschland

PEQLAB Biotechnologie GmbH, Erlangen, Deutschland

Sartorius, Göttingen, Deutschland

Eppendorf, Hamburg, Deutschland

Tecan, Crailsheim, Deutschla nd

Gilson, Villiers le Bel, Frankreich

Fine Science Tools, Heidelberg, Deutschland

BioRad, München, Deutschland

Heidolph Instruments, Schwabach, Deutschland

Bandelin, Berlin, Deutschland

MicroBrightField Inc., Magdeburg, Deutschland

Kopf Instruments, CA, USA

Kopf Instruments, CA, USA

BioRad, München, Deutschland

NeoLab, Heidelberg, Deutschland

Sartorius, Göttingen, Deutschland

PerkinElmer, CT, USA

GFL, Burgwedel, Deutschland

Elga Labwaters, Ransbach-Baumbach, Deutschland

Heraeus, Hanau, Deutschland

Eppendorf, Hamburg, Deutschland

\subsubsection{Puffer und Lösungen}

Tabelle 4: Puffer und Lösungen

\begin{tabular}{ll}
\hline Puffer / Lösung & Herstellung \\
\hline Agarosegel & $1 \%$ Agarose, $0,006 \%$ Ethidiumbromid in TBE-Puffer \\
BCA-Farblösung & $2 \%$ Reagenz B in Reagenz A. \\
\hline
\end{tabular}


BSA-Standardprotein (Stocklösung) $10 \mu \mathrm{g} / \mu \mathrm{l}$ BSA in Lysepuffer.

Chloralhydrat $7 \%$

DAPI-Lösung

DNA-Puffer 6x

ECL (Enhanced Chemiluminiscence)

Elektrophoresepuffer

Glycin/SDS

$\mathrm{H}_{2} \mathrm{O}_{2}$-Lösung

Lysepuffer

Milchlösung

MPTP-Lösung 4mg/ml (free base)

Natriumazid-Lösung

Natriumhypochlorit-Lösung

NEBuffer 2

Nissl-Arbeits Lösung

Nissl-Puffer Lösung

Nissl-Stock Lösung

Paraformaldehyd-Lösung (4\%)

PBS

Proteinase-Inhibitor Stocks

Purifiziertes $\mathrm{H}_{2} \mathrm{O}$

Rimadyl-Lösung zur Injektion

RIPA-Puffer

Sammelgel für Western Blots (5\%)

Sucrose-Lösung

TBE (Tris-Borsäure-EDTA-Puffer)

TBS (Tris-gepufferte-Salzlösung)

TBS-T (TBS mit Tween)

Transfer-Puffer

Trenngel für Western Blots (12\%)

TrisCl/SDS 4x pH 6.8

TrisCl/SDS 4x pH 8.8
$7 \mathrm{~g}$ Chloralhydrat in $100 \mathrm{ml} \mathrm{H} \mathrm{O}_{\text {dest. }}$; steril filtriert.

$2 \mu \mathrm{g} / \mathrm{ml}$ DAPI in PBS.

$0,15 \%$ Bromphenolblau, 0,15\% Xylenxyanol, $40 \%$ Saccharose in $\mathrm{H}_{2} \mathrm{O}_{\text {dest }}$.

Lösung 1 : 2,5 mM Luminol, 0,4 mM p-Coumarsäure, 0,1 M Tris-Chlorid in $\mathrm{H}_{2} \mathrm{O}_{\text {dest }} ; \mathrm{pH} 8.5$.

Lösung 2 : $18 \% \mathrm{H}_{2} \mathrm{O}_{2}, 0,1 \mathrm{M}$ Tris-Chlorid in $\mathrm{H}_{2} \mathrm{O}_{\text {dest }} ; \mathrm{pH} 8$.

Kurz vor der Verwendung wurden die Lösungen im Verhältnis 1:1 gemischt.

$25 \mathrm{mM}$ Tris-Chlorid, $192 \mathrm{mM}$ Glycin und 0.1\% $\mathrm{H}_{2} \mathrm{O}_{\text {dest. }}$; $\mathrm{pH}$ 8.3.

0,2 M Glycin, 0,5\% SDS in PBS

$10 \%$ Methanol, $3 \% \mathrm{H}_{2} \mathrm{O}_{2}$ in TBS.

$100 \mu 1$ Proteinase-Inhibitor-Lösung in 2,5 ml RIPA-Puffer.

$5 \%$ Milchpulver in TBS-T

$100 \mathrm{mg}$ MPTP in 20,67 ml in Aqua ad iniectabilia

$0,02 \%$ Natriumazid in $\mathrm{H}_{2} \mathrm{O}_{\text {dest. }}$

$1 \%$ Natriumhypochlorit in $\mathrm{H}_{2} \mathrm{O}_{\text {dest }}$

$10 \mathrm{mM}$ Tris-Clorid, 10 mM MgCl, 50 mM NaCl, 1 mM DTT; pH 7,9

$10 \%$ Nissl-Stock Lösung und 80 \% Nissl-Puffer Lösung

$0.7 \%$ Natriumacetat, $0.2 \%$ Eisessig in $\mathrm{H}_{2} \mathrm{O}_{\text {dest }}$

$1 \%$ Thioninacetat in $\mathrm{H}_{2} \mathrm{O}_{\text {dest. }}$.

40 g Paraformaldehyd in $1000 \mathrm{ml}$ PBS; filtriert.

9,55 g PBS-Pulver in $1000 \mathrm{ml} \mathrm{H}_{2} \mathrm{O}_{\text {dest. }}$; steril filtriert für alle Zellkulturund in-vivo-Experimente

2 Tabletten in $840 \mu \mathrm{l} \mathrm{H}_{2} \mathrm{O}_{\text {dest. }}(8,8 \mathrm{mg} / \mathrm{ml})$.

Mit dem Wasserreiniger PureLab Plus gereinigtes $\mathrm{H}_{2} \mathrm{O}$.

$0,25 \mathrm{mg} / \mathrm{ml}$ Rimadyl in $\mathrm{NaCl}(0,9 \%)$

$20 \mathrm{mM}$ Tris-Chlorid ( $\mathrm{pH} 7,5$ ), $150 \mathrm{mM} \mathrm{NaCl}, 1 \%$ Nonidet P-40, 0,5\% Natriumdeoxycholat, $1 \mathrm{mM}$ EDTA, $0,1 \%$ SDS in $\mathrm{H}_{2} \mathrm{O}_{\text {dest }}$.

$0,68 \mathrm{ml}$ purifiziertes $\mathrm{H}_{2} \mathrm{O}, 0,17 \mathrm{ml} 30 \%$ Rotiphorese Gel, 0,13 $\mathrm{ml} 1 \mathrm{M}$ TrisCl/SDS (4x, $\mathrm{pH} \quad 6,8), \quad 0,01 \mathrm{ml} 10 \quad \% \quad$ SDS, 0,01 $\mathrm{ml} 10 \%$ Ammoniumperoxidsulfat und 0,001 ml TEMED (Angaben für $1 \mathrm{Gel}$ ).

$30 \%$ Sucrose in PBS.

$84 \mathrm{mM}$ Tris-Chlorid, $89 \mathrm{mM}$ Borsäure, $2 \mathrm{mM} \mathrm{Na}$-EDTA in $\mathrm{H}_{2} \mathrm{O}_{\text {dest. }}$.

$150 \mathrm{mM} \mathrm{NaCl}, 10 \mathrm{mM}$ Tris-Chlorid in $\mathrm{H}_{2} \mathrm{O}_{\text {dest. }}$; $\mathrm{pH}$ 9.0.

0,1\% Tween in TBS; pH 7.6.

$25 \mathrm{mM}$ Tris-Chlorid, $192 \mathrm{mM}$ Glycin und $20 \% \mathrm{ml}$ Methanol in $\mathrm{H}_{2} \mathrm{O}_{\text {dest. }}$; $\mathrm{pH} 8.3$.

1,6 ml purifiziertes $\mathrm{H}_{2} \mathrm{O}, 2,00 \mathrm{ml} 30 \%$ Rotiphorese-Gel, 1,3 ml 1,5 M TrisCl/SDS (4x, pH 8,8), $0,05 \mathrm{ml} 10 \%$ SDS, $0,05 \quad \mathrm{ml} 10 \%$ Ammoniumperoxidsulfat und 0,002 $\mathrm{ml}$ TEMED (Angaben für $1 \mathrm{Gel}$ ).

0,5 M Tris-Chlorid und 0,4\% SDS in $\mathrm{H}_{2} \mathrm{O}_{\text {dest }}$; $\mathrm{pH} 6,8$.

1,5 M Tris-Chlorid und 0,4\% SDS in $\mathrm{H}_{2} \mathrm{O}_{\text {dest. }} ; \mathrm{pH} 8,8$. 
Vectastain® ABC Arbeitslösung

Western-Blot-Ladepuffer (6x)

Zähllösung
Je 2 Tropfen Reagenz A und B auf 10 ml TBS

$7 \mathrm{ml} 4$ x TrisCl/SDS (4x, pH 6,8); 3 ml Glycerol; 1 g SDS; 0,93 g DTT und 1,2 mg Bromphenol-Blau (Angaben für $10 \mathrm{ml}$ ).

$50 \%$ Trypanblau in PBS.

\subsubsection{Kulturmedien}

Tabelle 5: Kulturmedien

\begin{tabular}{|c|c|}
\hline Bezeichnung & Herstellung \\
\hline Calciumchlorid-Lösung & $50 \mathrm{mM} \mathrm{CaCl}_{2}, 15 \%$ Glycerol in $\mathrm{H}_{2} \mathrm{O}_{\text {dest. }}$ \\
\hline CSM14.1-Zellen & $\begin{array}{l}\text { WT-Zellen: } 10 \% \mathrm{FCS}, 100 \mathrm{U} / \mathrm{ml} \text { Penicillin, } 100 \mu \mathrm{g} / \mathrm{ml} \text { Streptomycin in DMEM . } \\
\text { Selektionsmedium für stabile BAG1-Zellen: } 10 \% \mathrm{FCS}, 100 \mathrm{U} / \mathrm{ml} \text { Penicillin, } 100 \\
\mu \mathrm{g} / \mathrm{ml} \text { Streptomycin, } 8 \mu \mathrm{g} / \mathrm{ml} \text { Puromycin in DMEM. }\end{array}$ \\
\hline DMEM-Full & $10 \%$ FCS, $100 \mathrm{U} / \mathrm{ml}$ Penicillin/ $100 \mu \mathrm{g} / \mathrm{ml}$ Streptomycin in DMEM \\
\hline Einfriermedium & $10 \%$ DMSO in FCS. \\
\hline LB-Agar & $\begin{array}{l}11,2 \mathrm{~g} \mathrm{LB}-\text { Agar in } 350 \mathrm{ml} \mathrm{H} \mathrm{O}_{\text {dest. }} \text {; autoklaviert. Auf } 60^{\circ} \mathrm{C} \text { abgekühlt. Versetzt mit } \\
\text { Antibiotikum; z. B. } 100 \mu \mathrm{g} / \mathrm{ml} \text { Ampicillin. } 18 \mathrm{ml} \text { Agar pro, über Nacht getrocknet. } \\
\text { Bei } 4^{\circ} \mathrm{C} \text { gelagert. }\end{array}$ \\
\hline LB-Medium & $\begin{array}{l}25 \mathrm{~g} \text { LB-Pulver in } 1000 \mathrm{ml} \mathrm{H}_{2} \mathrm{O}_{\text {dest. }} \text { pH } 7.0 \text {; autoklaviert. Versetzt mit } \\
\text { Antibiotikum; z. B. } 100 \mu \mathrm{g} / \mathrm{ml} \text { Ampicillin }\end{array}$ \\
\hline \multirow[t]{3}{*}{ SH-SY5Y-Zellen } & WT-Zellen: 15 \% FCS, 100 U/ml Penicillin/ 100 g/ml Streptomycin in DMEM . \\
\hline & $\begin{array}{l}\text { Selektionsmedium für stabile BAG1-Zellen: } 15 \% \mathrm{FCS}, 100 \mathrm{U} / \mathrm{ml} \text { Penicillin, } 100 \\
\mu \mathrm{g} / \mathrm{ml} \text { Streptomycin, } 500 \mu \mathrm{g} / \mathrm{ml} \mathrm{G} 418 \text { in DMEM. }\end{array}$ \\
\hline & $\begin{array}{l}\text { Selektionsmedium für stabile pcDNA3.1-Zellen: } 15 \% \mathrm{FCS}, 100 \mathrm{U} / \mathrm{ml} \text { Penicillin, } \\
100 \mu \mathrm{g} / \mathrm{ml} \text { Streptomycin, } 500 \mu \mathrm{g} / \mathrm{ml} \mathrm{G} 418 \text { in DMEM. }\end{array}$ \\
\hline $\begin{array}{l}\text { SOB (Super optimal } \\
\text { broth)-Medium }\end{array}$ & $\begin{array}{l}20 \mathrm{~g} / 1 \text { Trypton, } 5 \mathrm{~g} / \mathrm{l} \text { Hefe-Extrakt, } 10 \mathrm{mM} \mathrm{NaCl}, 2.5 \mathrm{mM} \mathrm{KCl}, 10 \mathrm{mM} \mathrm{MgCl} \\
2\end{array}$ \\
\hline $\begin{array}{l}\text { SOC (SOB mit Glucose)- } \\
\text { Medium }\end{array}$ & $20 \mathrm{mM}$ Glucose in SOB-Medium. \\
\hline
\end{tabular}

\subsubsection{Verbrauchsmaterialien}

Tabelle 6: Verbrauchsmaterialien

\begin{tabular}{ll}
\hline Material & Herkunft \\
\hline Blotting-Papiere & Roth, Karlsruhe, Deutschland \\
Chemiluminiszenzfilme, Hyperfilm ${ }^{\mathrm{TM}}$ ECL & GE Healthcare, Buckinghamshire, UK \\
Kanülen Sterican 26G x 1“ & Braun, Melsungen, Deutschland \\
Multifly®-Set 21Gx3/4“TD 0,8x19mm & Sarstedt, Nümbrecht, Deutschland \\
Nahtmaterial 4-0 Perma-hand*seide & Ethicon, Norderstedt, Deutschland \\
Nitrocellulose PROTAN® & Schleicher \& Schuell Bioscience GmbH \\
Reaktionsgefäße $(0,5 \mathrm{ml}, 1,5 \mathrm{ml})$ & Eppendorf, Hamburg, Deutschland
\end{tabular}


Reaktionsgefäße (15 ml, $50 \mathrm{ml})$

Spritzen $1 \mathrm{ml}$, Inject ${ }^{\circledR}-\mathrm{F}$

Spritzen $50 \mathrm{ml}$, Original Perfusor®-Spritze OPS

Superfrost plus Objektträger

Zellkulturplatten (96 Well, undurchsichtig)
Greiner Bio One, Solingen

Braun, Melsungen, Deutschland

Braun, Melsungen, Deutschland

Thermo Fisher Scientific, Bonn, Deutschland

Nunc A/S, Roskilde Dänemark

Zellkulturplatten $(10$ cm, 6 Well, 24 Well, 96 Greiner Bio One, Solingen

Well)

\subsubsection{Antikörper}

Tabelle 7: Antikörper

\begin{tabular}{ll}
\hline Antikörper & Herkunft \\
\hline Anti-Maus- IgG-HRP-Ziegen-Antikörper & Santa Cruz Biotechnology, CA,USA \\
Anti-Kaninchen-IgG-HRP-Ziegen-Antikörper & Santa Cruz Biotechnology, CA, USA \\
Anti-BAG1-Kaninchen-Antikörper & Prof. J.C. Reed, Burnham Institute, CA, USA \\
Anti-ß-Tubulin-Maus-Antikörper & Sigma, Taufkirchen, Deutschland \\
Anti $\alpha$-Synuclein Maus-Antikörper & Zymed Labaratories, CA, USA \\
Anti-TH Kaninchen-Antikörper & Advanced Immunochemical Inc., Long Beach, CA, USA \\
Anti-Kaninchen-IgG-Cy3-Ziegen-Antikörper & Jackson ImmunoResearch Laboratories Inc., PA USA \\
Anti-Kaninchen-IgG-Biotin-Ziegen-Antikörper & Jackson ImmunoResearch Laboratories Inc., PA USA \\
\hline
\end{tabular}

\subsubsection{Plasmide}

\subsubsection{1 pEGFP-N1}

Das Plasmid pEGFP-N1 (Clontech, Mountain View, CA, USA) exprimiert das Green fluorescent protein (GFP) unter der Kontrolle eines Zytomegalievirus (CMV) -Promotors. Außerdem weist es eine Neomycin-Resistenz auf.

\subsubsection{2 pcDNA3.1}

Das pcDNA3.1-Plasmid (Invitrogen, Karlsruhe, Deutschland) weist eine Ampicillin- und eine Neomycin-Resistenz auf. Daneben beinhaltet das Plasmid sowohl einen CMV-als auch einen Affen-Virus-40 (SV40) -Promotor. Die Gesamtgröße des Plasmids beträgt 5445 Basenpaare (Abb. 4). 


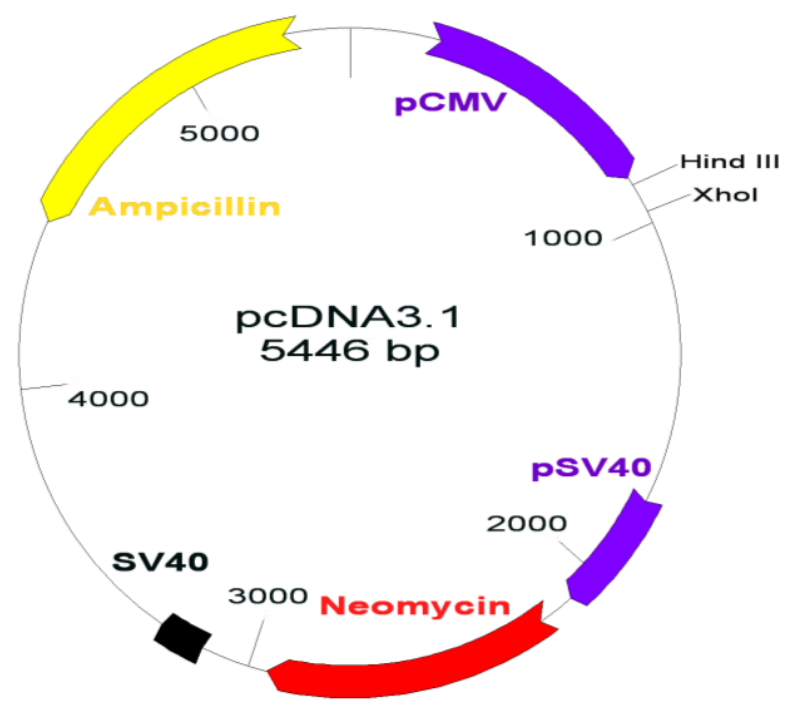

Abb. 4: Schematische Darstellung pcDNA3.1-Plasmids. Zahlen: Basenpaare, pCMV: CMV-Promotor, pSV40: Affen-Virus-40-Promotor, SV40: Affen-Virus-40 Polyadenylierungssequenz, Hind III und XhoI: Restriktionsenzymstellen

\subsubsection{3 pFlag-BAG1}

Das Plasmid pFlag-BAG1 (Kermer et al. 2002) enthält die kleine Isoform (29 kDa) der MausBAG1 cDNA und beinhaltet außerdem ein N-terminales Flag-Tag. Die Expression wird über den Neuronen-spezifische-Enolase (NSE)-Promotor gesteuert. Die schematische Darstellung des Plasmids ist in Abb. 5 gezeigt. Die kleine BAG1-Isoform (Abb. 3) wurde wegen ihrer hohen Expressionsrate im Gehirn gewählt.

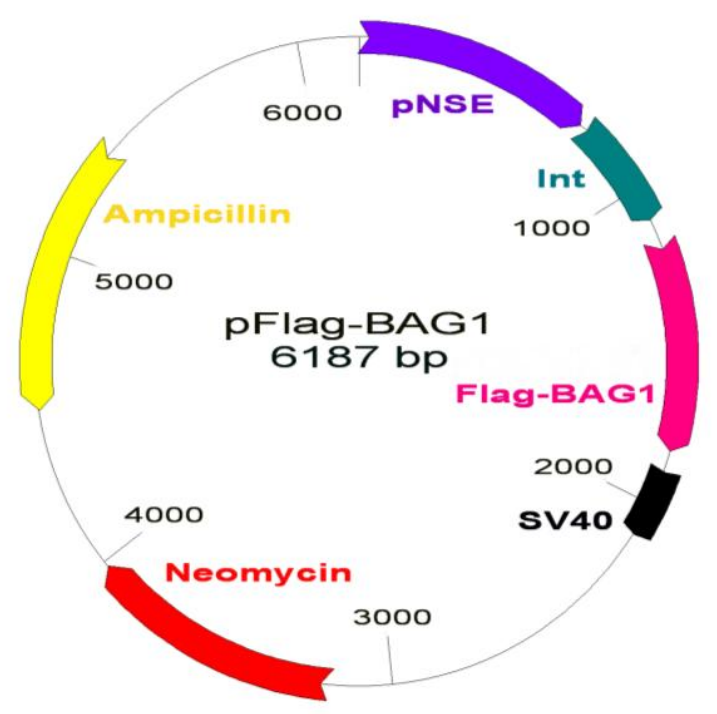

Abb. 5: Schematische Darstellung des pFlag-BAG1 Plasmids. Zahlen: Basenpaare, pNSE: NSE-Promotor, Int: Intron, SV40: Affen-Virus-40 Polyadenylierungssequenz 


\subsubsection{4 pBABEpuro}

Das Plasmid pBABEpuro wurde freundlicherweise von Prof. J. C. Reed vom Burnham Institute (La Jolla, CA, USA) bereitgestellt. Es beinhaltet insgesamt 5169 Basenpaare und verfügt über eine Puromycin Resistenz.

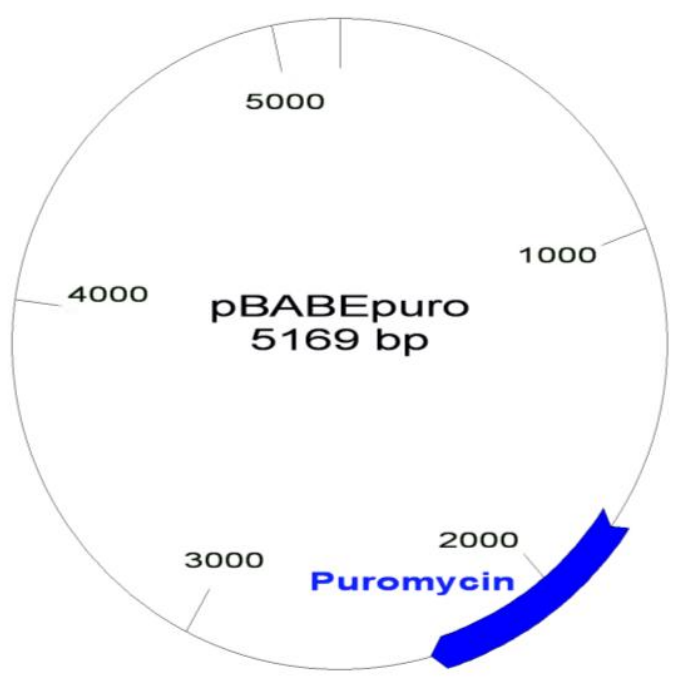

Abb. 6: Schematische Darstellung des pBABEpuro-Plasmids. Zahlen: Basenpaare

\subsubsection{WT-, A30P- und A53T- $\alpha-S y n u c l e i n$}

Die WT- $\alpha-S y n, \quad$ A30P- $\alpha-S y n$ und A53T- $\alpha-S y n$ enthaltenden Vektoren wurden freundlicherweise von Dr. O. Schlüter (Max-Planck-Institut für experimentelle Medizin, Göttingen, Deutschland) zur Verfügung gestellt. Mit Hilfe dieser Vektoren wurden die Plasmide pcDNA3.1-WT- $\alpha$-Syn, pcDNA3.1-A30P- $\alpha$-Syn und pcDNA3.1-A53T- $\alpha-S y n$ kloniert (2.2.1, Abb. 9).

\subsubsection{Viren}

Die genutzten AAV-2-Vektoren AAV-BAG1-EGFP (Enhanced green fluorescent protein) und AAV-EGFP wurden freundlicherweise von Dr. S. Kügler (AG Bähr, Göttingen, Deutschland) zur Verfügung gestellt (Abb. 7). Der AAV-BAG1-EGFP-Vektor exprimiert die Maus-Isoform des BAG1 unter der Kontrolle eines humanen Synapsin-1-Promotors (hSyn1). In einer zweiten, unabhängigen Kassette exprimiert der Vektor außerdem ein EGFP, ebenfalls unter der Kontrolle eines hSyn1-Promotors. Der AAV-EGFP-Vektor exprimiert EGFP ebenfalls unter der Kontrolle eines hSyn1-Promotors und enthält außerdem eine deaktivierte B-cell-lymphoma protein bei Xenopus laevis $\left(\mathrm{Bcl}-\mathrm{X}_{\mathrm{L}}\right)$-Expressions-Kassette (Malik et al. 2005). 


\section{AAV-BAG1-EGFP}

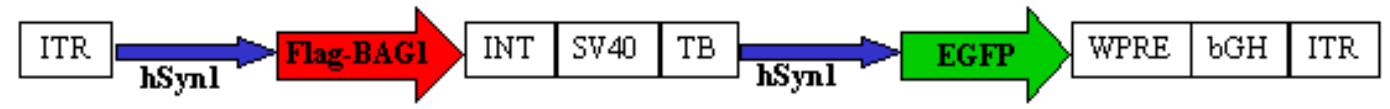

\section{AAV-EGFP}

\begin{tabular}{|c|c|c|c|c|c|c|c|c|c|c|c|c|c|}
\hline ITR & SV 40 & TB & Bil $x_{2}$ & INT & SV 40 & TB & 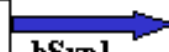 & EGF & & WPF & & $\mathrm{bGH}$ & ITR \\
\hline
\end{tabular}

Abb. 7 Schematische Darstellung der AAV-2-Vektor-Genome. ITR: AAV-2 invertierte terminale Repeats; hSyn: humaner-Synapsin-1-Promotor; Flag-BAG1: Maus-BAG1-cDNA mit einem N-terminalen Flag-Tag; Bcl- $\mathrm{X}_{\mathrm{L}}$ : Ratten-Bcl- $\mathrm{X}_{\mathrm{L}}-\mathrm{cDNA}$ mit einem N-terminalen Flag-Tag (wird nicht transkribiert); Int: Intron; SV40: Affen-Virus-40-Polyadenylierungs-Sequenz; TB: synthetischer TranskriptionsBlocker; WPRE: Murmeltier-Hepatitis-Virus posttranskriptionales regulatorisches Element, bGH: Bovines Wachstumshormon Polyadenylierungs-Sequenz

\subsubsection{Elektrokompetente Bakterien}

Als kompetente Bakterien wurden bei $-80^{\circ} \mathrm{C}$ in steriler Calciumchlorid-Lösung gelagerte $\mathrm{E}$. coli DH5 $\alpha$-Bakterien (Stratagene, La Jolla, CA, USA) verwendet.

\subsubsection{Versuchstiere}

Es wurden 4-6 Wochen alte männliche C57BL/6-Mäuse (Harlan Winkelmann GmbH, Borchen, Deutschland) verwendet.

\subsection{HERSTELLUNG UND AMPLIFIKATION DER PLASMIDE}

\subsubsection{Klonierungen}

Die Plasmide pcDNA3.1-WT- $\alpha$-Syn, pcDNA3.1-A30P- $\alpha-S y n$ sowie pcDNA3.1-A53T- $\alpha-S y n$ wurden wie folgt kloniert: Die Synuclein-cDNAs wurden mittels Polymerasekettenreaktion (PCR, 2.2.2) aus den Ursprungsvektoren (2.1.7.5) amplifiziert. Mit Hilfe der Primer wurden gleichzeitig Schnittstellen für die Enzyme HindIII und XhoI, sowie eine Kozac-Sequenz vor dem Startcodon inseriert. Anschließend erfolgte die Aufreinigung der PCR-Produkte mit dem Qiagen PCR Purification Kit bevor die isolierten PCR-Produkte und der pcDNA3.1-Vektor in einem Restriktionsenzymverdau (2.2.6) mit den Enzymen HindIII und XhoI behandelt wurde. Nach dem Auftragen auf ein Agarosegel wurden die den Synuclein-PCR-Produkten und die dem pcDNA3.1-Vektor entsprechenden Banden herausgetrennt und mit Hilfe des Quiaquick Gel Extraction Kits isoliert (2.2.4). Anschließend wurde der pcDNA3.1-Vektor mit alkalischer Phosphatase behandelt, die das 5'-Phosphat entfernt und so eine 
Vektorselbstligation verhindert. Nach erneuter Aufreinigung von Vektor und Insert erfolgte die Ligation mit T4-Ligase bei einem molaren Vektor-Insert-Verhältnis von 1:5 über Nacht bei $16^{\circ} \mathrm{C}$ (2.2.7). Im Anschluss wurde das Ligationsprodukt in kompetente E.coli transformiert (2.2.8). Nach Anzucht auf Ampicillin-Agaroseplatten wurden jeweils vier Bakterienkolonien in Ampicillin-haltigem LB-Medium vermehrt, mittels Mini-Präp (2.2.9) die Plasmid-DNA isoliert und durch Restriktionsverdau und Sequenzierung (2.2.11) das korrekte Klonierungsergebnis verifiziert. Die so erstellten Plasmide sind analog zu dem in Abb. 9 schematisch dargestellten Plasmid.

\subsubsection{PCR}

Mit Hilfe der PCR können DNA-Fragmente amplifiziert werden. Das Grundprinzip besteht darin, dass spezifische Primer, die komplementär zum 5'- und zum 3'-Ende des zu amplifizierenden Fragments gewählt werden, als Basis für eine hitzestabile Polymerase dienen, die den Genabschnitt amplifiziert. Im ersten Schritt wird die DNA denaturiert, sodass Einzelstränge vorliegen. Anschließend können die Primer sich an die komplementären Abschnitte der Ursprungs-DNA anlagern, bevor die DNA-Polymerase beginnt die fehlenden Nucleotide aufzufüllen. Im nächsten Schritt wird wieder denaturiert, die anschließende Anlagerung der Primer erfolgt dabei auch an die im vorherigen Zyklus neu synthetisierten Stränge. Am Ende der PCR liegt das gewünschte Genprodukt in großer Zahl vor.

Die verschiedenen Formen des $\alpha$-Syn wurden mit Hilfe der PCR aus den Ursprungsvektoren herausamplifiziert. Gleichzeitig wurden Schnittstellen für HindIII und XhoI inseriert. Hierzu wurden die folgenden Primer genutzt: Vorwärts: 5'-CGCGAAGCTTGCCACCATG GATGTATTCATGAAAGGACTTTCAAAGGCCAAGG-3' Rückwärts: 5'-CGCCTCGAGT TAGGCTTCAGGTTCGTAGTCTTGATACCCT-3'. Primer wurden mit purifiziertem $\mathrm{H}_{2} \mathrm{O}$ auf $10 \mu \mathrm{M}$ verdünnt Für den PCR-Ansatz wurden $1 \mu \mathrm{l}$ DNA $(100 \mathrm{ng} / \mu \mathrm{l}) \mathrm{mit} 5 \mathrm{ml} 10 \mathrm{x}$ Polymerase-Pfu-Puffer sowie $2 \mu l$ dNTPs, jeweils $2 \mu l$ des Vorwärts- und des Rückwärtsprimers und 0,5 $\mu$ l Polymerase Pfu pipettiert und der Ansatz anschließend mit purifiziertem $\mathrm{H}_{2} \mathrm{O}$ auf $50 \mu \mathrm{l}$ aufgefüllt. Die PCR wurde mit einer PCR-Maschine durchgeführt, die wie folgt programmiert wurde: Fünf Minuten Denaturierung bei $95^{\circ} \mathrm{C}$ gefolgt von 30 Amplifizierungszyklen bestehend aus 30 Sekunden bei $95^{\circ} \mathrm{C}$ (Denaturierung), 20 Sekunden bei $50^{\circ} \mathrm{C}$ (Hybridisierung) und 90 Sekunden bei $72^{\circ} \mathrm{C}$ (Elongation). Anschließend wurde das PCR-Produkt bis zur weiteren Verwendung bei $4^{\circ} \mathrm{C}$ gekühlt. 


\subsubsection{Aufreinigung der PCR}

Die Aufreinigung von PCR-Produkten erfolgte mit Hilfe des Quiaquick PCR Purification® Kits und den zugehörigen Puffern (PB, PE und EB) und Säulen. Sie wurde entsprechend dem beiliegenden Protokoll durchgeführt. Hierzu wurde zunächst der Puffer PB im Verhältnis 5:1 zum PCR-Produkt gegeben und gemischt. Zwischenzeitlich wurde eine Quiaquick-Säule in einem 1,5-ml-Reaktionsgefäß platziert, in die anschließend die DNA-haltige Lösung pipettiert wurde. Die Säule wurde dann für eine Minute bei 10.000 x g zentrifugiert und die abzentrifugierte Lösung verworfen. Das Waschen der Säule erfolgte mit $750 \mu$ l Puffer PE (1 min bei $10.000 \mathrm{x}$ g), die abzentrifugierte Waschlösung wurde ebenfalls verworfen. Anschließend wurde die Säule noch einmal eine Minute bei 10.000 x g trocken zentrifugiert. Um die DNA wieder zu eluieren wurden $50 \mu$ l Puffer EB auf die Säule gegeben, die inzwischen auf ein frisches 1,5-ml-Reaktionsgefäß gesetzt worden war, und wiederum für eine Minute bei 10.000 x g zentrifugiert.

\subsubsection{Agarosegelelektrophorese}

Mit Hilfe der Agarosegelelektrophorese werden DNA-Fragmente der Größe nach aufgetrennt. In einem elektrischen Feld wandern die Fragmente zum positiven Pol, da sie selbst negativ geladen sind. Die Wanderungsgeschwindigkeit der Fragmente bestimmt sich dabei durch ihre Größe. Mit der Agarosegelelektrophorese kann kontrolliert werden, ob eine PCR oder ein Restriktionsenzymverdau das erwünschte Ergebis erbracht hat (analytisches Gel). Alternativ können aus einem präparativen Agarosegel bestimmte Banden ausgeschnitten und damit isoliert werden, um die DNA weiter zu verarbeiten.

Für ein analytisches Agarosegel wurde eine kleine Elektrophoresekammer (für DNA) mit einem 1\%igen Agarosegel verwendet. Für jede Probe wurden $5 \mu$ l PCR-Produkt oder Restriktionsenzymverdauprodukt mit $1 \mu 1$ 6x DNA-Puffer gemischt und in die Taschen des Gels geladen. Zusätzlich wurden für jedes Gel $2 \mu$ l DNA-Marker geladen. Anschließend wurden die DNA-Fragmente für etwa eine Stunde bei $100 \mathrm{~V}$ aufgetrennt. Durch das interkalierende, fluoreszierende Ethidiumbromid konnte die DNA nach Anregung durch ultraviolettes Licht (UV-Licht) mit Hilfe des Fluor- $S^{\mathrm{TM}}$-MultiImagers, sowie der Software Quantity One 4.2.1, sichtbar gemacht werden. Anhand des mitgeladenen Markers konnte anschließend die Größe der Fragmente bestimmt werden.

Für ein präparatives Agarosegel wurde eine große Elektrophoresekammer (für DNA) mit einem 1\%igen Agarosegel verwendet. Um mehr DNA laden zu können wurden die Taschen vergrößert. $50 \mu \mathrm{l}$ PCR-Produkt oder Restriktionsenzymverdauprodukt wurden mit $10 \mu \mathrm{l}$ 6x DNA-Puffer gemischt und geladen. Auch hier wurden für jedes Gel $2 \mu$ l DNA-Marker 
geladen. Anschließend wurden die DNA-Fragmente für etwa eineinhalb Stunden bei $100 \mathrm{~V}$ aufgetrennt. Mit Hilfe von UV-Licht wurden die Banden sichtbar gemacht und die entsprechenden Vektor- und Insert-Banden ausgeschnitten und in ein Reaktionsgefäß gegeben. Anschließend wurden die so isolierten Inserts und Vektoren der Aufreinigung zugeführt.

\subsubsection{Aufreinigung der Agarosegelelektrophoreseprodukte}

Die Aufreinigung von Vektoren und Inserts aus Agarosegelfragmenten erfolgte mit Hilfe des Quiaquick Gel Extraction® Kits und den zugehörigen Puffern (QG, PE und EB) sowie Säulen, entsprechend dem beiliegenden Protokoll. Hierzu wurde zunächst das Gewicht der ausgeschnittenen Fragmente bestimmt. Anschließend wurde Puffer QG im Verhältnis 3:1 zum Gelfragment gegeben $(100 \mathrm{mg} \sim 100 \mu \mathrm{l})$. Dieses Gemisch wurde dann für zehn Minuten bei $50^{\circ} \mathrm{C}$ inkubiert. Nachdem sich das Gelfragment komplett gelöst hatte, wurde die Lösung mit einem Gelfragmentvolumen Isopropanol versetzt. Zwischenzeitlich wurde eine Quiaquick Spin®-Säule in einem 1,5-ml-Reaktionsgefäß platziert, in die anschließend die DNA-haltige Lösung pipettiert wurde. Die Säule wurde dann für eine Minute bei 10.000 x g zentrifugiert und die abzentrifugierte Lösung verworfen. Das Waschen der Säule erfolgte mit $750 \mu 1$ Puffer PE (eine Minute bei 10.000 x g), die abzentrifugierte Waschlösung wurde ebenfalls verworfen. Anschließend wurde die Säule noch einmal eine Minute bei 10.000 x g trocken zentrifugiert. Um die DNA wieder zu eluieren wurden $50 \mu$ l Puffer EB auf die Säule gegeben, die inzwischen auf ein frisches 1,5-ml-Reaktionsgefäß gesetzt worden war, und wiederum für eine Minute bei $10.000 \mathrm{x} g$ zentrifugiert.

\subsubsection{Restriktionsenzymverdau}

Bei einem Restriktionsenzymverdau wird ein Vektor durch bestimmt Enzyme an spezifischen Stellen geschnitten. Dies kann zum einen dem Öffnen eines Vektors dienen, wenn in einer anschließenden Ligation ein Insert eingefügt werden soll, oder zum anderen dem Ausschneiden eines Inserts vor der Agarosegelelektrophorese, in der dann kontrolliert werden kann ob der Vektor das korrekte Insert enthält.

Im Falle der $\alpha$-Syn-Plasmide, bzw. Inserts und des pcDNA3.1-Vektors erfolgte der Restriktionsenzymverdau mit den Enzymen HindIII und XhoI. Die verschiedenen Ansätze wurden dazu für 2 Stunden bei $37^{\circ} \mathrm{C}$ inkubiert. Nach Empfehlungen des Herstellers wurden für einen $20 \mu \mathrm{l}$ Ansatz $1 \mu \mathrm{g}$ DNA, $5 \mathrm{U}$ HindIII und $5 \mathrm{U}$ XhoI, $2 \mu$ l NEBuffer 2, sowie 100 $\mu \mathrm{g} / \mathrm{ml} \mathrm{BSA}$ in purifiziertem $\mathrm{H}_{2} \mathrm{O}$ verwendet. Anschließend wurden die Enzyme inaktiviert 
und das Restriktionsenzymverdauprodukt bis zur Durchführung der Agarosegelelektrophorese bei $4^{\circ} \mathrm{C}$ gelagert.

\subsubsection{Ligation}

Im Rahmen der oben beschriebenen Klonierung (2.2.1) wurden die Inserts WT- $\alpha$-Syn, A30P$\alpha$-Syn sowie A53T- $\alpha$-Syn in den pcDNA3.1-Vektor ligiert. Der pcDNA3.1-Vektor und die $\alpha$ Syn-Inserts waren zuvor per Restriktionsenzymverdau (2.2.6) geschnitten worden. Der Ligationsansatz (insgesamt $15 \mu \mathrm{l}$ ) bestand aus $1 \mu \mathrm{l}$ T4-Ligase, 1,5 $\mu 1$ 10x-T 4 -Ligase-Puffer, Vektor und Insert im molaren Verhältnis 1:5, sowie purifiziertem $\mathrm{H}_{2} \mathrm{O}$. Die Inkubation erfolgte bei $16^{\circ} \mathrm{C}$ über Nacht.

\subsubsection{Transformation kompetenter Bakterien}

Viele Bakterien haben die Eigenschaft, dass sie ringförmige DNA unabhängig von ihrem eigenen Genom vervielfältigen können. Über eine sogenannte Transformation können Plasmide in solche kompetenten Bakterien hineingebracht werden, sodass das betreffende Plasmid amplifiziert werden kann.

Als kompetente Bakterien wurden E. coli DH5a-Bakterien genutzt. Diese wurden zunächst auf Eis aufgetaut. Anschließend wurden je $100 \mu$ l kompetente Bakterien mit je $5 \mu 1$ Ligationsansatz versetzt. Nach Inkubation für 30 Minuten auf Eis wurden die Transformationsansätze im Wasserbad für 45 Sekunden auf $42^{\circ} \mathrm{C}$ erhitzt und anschließend auf Eis abgekühlt. Diese Temperaturänderung ermöglicht den Eintritt der Plasmide in das Bakterium. Zur Vermehrung der Bakterien und damit auch des jewiligen Plasmids wurden die Ansätze mit je $400 \mu \mathrm{l}$ warmem SOC-Medium versetzt und dann im Schüttler $\left(37^{\circ} \mathrm{C}\right)$ für eine Stunde inkubiert. Für selektives Wachstum der korrekt transformierten Bakterien wurden die Bakterien auf antibiotikahaltigem LB-Agar ausgesät. Das Antibiotikum wurde entsprechend der über das transformierte Plasmid vermittelten Resistenz ausgewählt. Für alle SynucleinPlasmide und den pcDNA3.1 Leervektor wurde Ampicillin verwendet. Nach Inkubation bei $37^{\circ} \mathrm{C}$ über Nacht war davon auszugehen, dass nur solche Bakterien gewachsen waren, die erfolgreich transformiert worden waren.

\subsubsection{Mini-Präparation}

Plasmid-Präparationen dienen dazu, die amplifizierten Plasmide aus den kompetenten Bakterien zu isolieren. Über eine Mini-Präparation können etwa $20 \mu \mathrm{g}$ Plasmid-DNA gewonnen werden, in einer Maxi-Präparation dagegen bis zu $1000 \mu \mathrm{g}$. 
Nach der Transformation wurden jeweils mehrere Bakterienkolonien von der Agar-Platte in je $2 \mathrm{ml}$ Antibiotika-haltiges LB-Medium überführt. Auch hier wurde das Antibiotikum entsprechend der über das transformierte Plasmid vermittelten Resistenz ausgewählt (Ampicillin für alle Synuclein-Plasmide, bzw. den pcDNA3.1 Leervektor). Die Hälfte dieses Ansatzes wurde für die Mini-Präparation verwendet, die andere Hälfte wurde für eine spätere Maxi-Präparation bei $4^{\circ} \mathrm{C}$ aufbewahrt. Die Mini-Präparation wurde mit Hilfe des Nucleospin Plasmid Mini Kits und mitgelieferter Puffer (A1, A2, A3, A4 und AE), entsprechend dem beiliegenden Protokoll, durchgeführt. Nach einer Zentrifugation bei $11000 \mathrm{x}$ g für 30 Sekunden wurde das die Bakterien enhaltende Pellet mit $250 \mu 1$ Puffer A1, 250 $\mu 1$ Puffer A2 für fünf Minuten bei Raumtemperatur inkubiert. Dies diente zur Lysierung der Bakterien. Anschließend wurden $300 \mu \mathrm{l}$ Puffer A3 zugefügt und zehn Minuten bei 11000 x g zentrifugiert. Im Pellet war nun der Bakteriendetritus gesammelt, im Überstand lagen die Plasmide in gelöster Form vor. Der Überstand wurde auf die NucleoSpin® Säulen überführt und anschließend die Säule bei 11000 x g für eine Minute zentrifugiert. Dabei verblieb die DNA in der Säule. Mit Hilfe von $600 \mu$ l Puffer A4, der auf die Säule pipettiert wurde, und anschließender Zentrifugation bei 11000 x g für eine Minute wurde die DNA gewaschen und außerdem Nukleasen inaktiviert. Anschließend wurde die Säule durch zweiminütige Zentrifugation bei $11000 \mathrm{x}$ g getrocknet, bevor zuletzt durch $50 \mu \mathrm{l}$ Puffer AE und anschließende Zentrifugation bei 11000 x g für eine Minute die DNA wieder gelöst wurde.

Nach der Mini-Präparation wurden die Plasmid-Ansätze mittels Restriktionsenzymverdau und anschließender Agarosegelelektrophorese auf Anwesenheit des jeweiligen Plasmids geprüft. Anhand dessen konnte anschließend ein Ansatz mit korrektem Insert für eine MaxiPräparation ausgewählt werden. Sowohl die Reinheit als auch die Konzentration der gewonnenen Plasmid-DNA wurde mit einem Bio-Photometer bestimmt.

\subsubsection{Maxi-Präparation}

Über eine Maxi-Präparation können etwa 500-1000 $\mu \mathrm{g}$ Plasmid gewonnen werden. Ausgangspunkt für eine Maxi-Präparation war ein über die Agarosegelelektrophorese (2.2.9), sowie über die Sequenzierung (2.2.11) ausgewählter Mini-Präparationsansatz. Die Bakterien wurden hierzu in jeweils $200 \mathrm{ml}$ antibiotikahaltiges LB-Medium überführt und über Nacht bei $37^{\circ} \mathrm{C}$ geschüttelt. Die Maxi-Präparation wurde mit Hilfe des Quiagen Plasmid Maxi Kits, entsprechend den Herstellerangaben, durchgeführt. Die Durchführung der Maxi-Präparation ist der Durchführung der Mini-Präparation bis auf einige zusätzliche Reinigungsschritte nahezu identisch, sodass auf eine ausführliche Darstellung verzichtet wird. Auch nach der Maxi-Präparation erfolgte die Kontrolle des korrekten Inserts über einen 
Restriktionsenzymverdau und anschließende Agarosegelelektrophorese. Die DNAKonzentration und Reinheit wurden wie nach der Mini-Präparation mit dem Bio-Photometer bestimmt. Ein Teil der DNA-Lösung wurde anschließend entnommen und mit purifiziertem $\mathrm{H}_{2} \mathrm{O}$ auf eine Konzentration von $500 \mathrm{ng} / \mu \mathrm{l}$ eingestellt. Die so entstandenen Plasmid-Ansätze wurden für alle nachfolgenden Experimente verwendet.

\subsubsection{Sequenzierung}

Über einen Restriktionsenzymverdau mit anschließender Gelelektrophorese kann das Vorhandensein, beispielsweise eines Inserts, anhand seiner Größe überprüft werden. Die genaue Basensequenz kann allerdings nur mit Hilfe einer Sequenzierung überprüft werden. Die Sequenzierung beruht auf einem PCR-ähnlichen Prinzip. Neben den normalen dNTPs werden dem Sequenzierungs-Ansatz noch sogenannte Didesoxyribonukleosidtriphosphate (ddNTPs) hinzugefügt. Dies sind fluoreszenzmarkierte Desoxynukleotide mit spezifischen Fluoreszenzen für jede Base. Diesen Nucleotiden fehlt am 3'Ende die Hydroxylgruppe, die für die Verlängerung des DNA-Stranges unerlässlich ist. Wird also ein ddNTP eingebaut stoppt die DNA-Synthese, wodurch in der Summe viele unterschiedlich lange DNAFragmente entstehen. Anschließend werden die Fragmente in einem Gel der Größe nach aufgetrennt. Anhand der unterschiedlichen Fluoreszenzmarkierung der verschiedenen Basen kann die Sequenz abgelesen werden. Die Durchführung der Sequenzierung erfolgte durch die Firma Seqlab, Göttingen, Deutschland. Die ermittelten Sequenzen der verschiedenen $\alpha$-SynInserts wurden manuell mit den in der Literatur beschriebenen Sequenzen verglichen.

\subsection{ZELLKULTUR}

\subsubsection{Zelllinien}

\subsubsection{CSM14.1-Zellen}

CSM14.1-Zellen sind nigro-striatale Rattenzellen. Sie sind durch das temperatursensitive SV40-large-T-Antigen immortalisiert worden. Weiterhin weisen die Zellen eine NeomycinResistenz auf (Zhong et al. 1993). Über das temperatursensitive Antigen können die Zellen bei $39^{\circ}$ differenziert werden (Haas und Wree 2002).

\subsubsection{SH-SY5Y-Zellen}

SH-SY5Y-Zellen sind die dritte Generation einer humanen Neuroblastomzelllinie, hervorgegangen aus der Neuroepitheliom-Zelllinie SK-N-SH. Die ursprüngliche Zelllinie wurde im Jahr 1970 aus der Knochenmarkbiopsie eines 4-jährigen Mädchens mit 
metastasiertem Neuroblastom isoliert (Biedler et al. 1973). SH-SY5Y-Zellen sind sympathische adrenerge Ganglienzellen (Scott et al. 1986), die als epithelartige Monolayer bzw. bei höherer Konfluenz in Clustern wachsen. Mit Stoffen wie Retinolsäure oder Brain derived neurotrophic factor (BDNF) kann man die Zellen zur Ausbildung von Dendriten und damit zur Differenzierung bringen (Encinas et al. 2000). Außerdem sind die Zellen charakterisiert durch die Expression von Neurofilamenten und Vimentin.

\subsubsection{Stabil transfizierte Zellen}

Ziel einer stabilen Transfektion ist es, dass die eingebrachte DNA fest in das Genom einer Zelle eingebaut wird. Dies kann über die Ausnutzung eines Antibiotikaresistenzgens im Vektor, oder über eine Doppeltransfektion mit zwei separaten DNA- bzw. Antibiotikaresistenzplasmiden erreicht werden. Nicht transfizierte Zellen haben in Selektionsmedium einen Nachteil gegenüber transfizierten Zellen und können dadurch selektiert werden. Über die Herstellung von Zellkolonien, deren Zellen von einer einzelnen stabil transfizierten Zelle abstammen, wird zusätzlich sichergestellt, dass alle Zellen dieser Einzelzellklonkolonie das gewünschte Protein exprimieren und an ihre Tochterzellen weiter geben.

\subsection{CSM14.1}

Es wurden stabil BAG1-überexprimierende CSM14.1-Einzelzellklonkolonien hergestellt. Hier musste eine Doppeltransfektion durchgeführt werden, da die auf dem Flag-BAG1Plasmid vorhandene Neomycin-Antibiotikaresistenz aufgrund der genuinen NeomycinResistenz der CSM14.1-Zellen nicht genutzt werden konnte. Bei einer Doppeltransfektion wird davon ausgegangen, dass statistisch beide Plasmide gleichermaßen in eine Zelle eingeschleust werden. Es ist daher zusätzlich das Puromycin-Antibiotikaresistenzplasmid pBABEpuro, im Verhältnis 1:5 gegenüber dem Flag-BAG1-Plasmid transfiziert worden. Die Transfektion wurde durchgeführt mit Gene Porter II®, entsprechend den Herstellerangaben. 48 Stunden nach der Transfektion wurde das Medium in Antibiotika-haltiges CSM14.1Selektionsmedium gewechselt. Nach erneuter Konfluenz der 6-Well-Platte unter Selektion wurde ein Teil der Zellen bei $-80^{\circ} \mathrm{C}$ eingefroren. Ein Teil der transfizierten Zellen wurde außerdem für einen proteinbiochemischen Expressionsnachweis (2.5) aufbereitet. Zur Herstellung von Einzellzellklonkolonien wurde rechnerisch eine halbe Zelle pro Well in einer 96-Well-Platte in Selektionsmedium ausplattiert. Nach drei bis vier Wochen wurden die Platten lichtmikroskopisch auf Einzelzellklonkolonien durchsucht, welche anschließend auf größere Platten transferiert wurden. Nach einem weiteren Expressionscheck wurden mehrere 
BAG1-positive Klone für alle nachfolgenden Experimente expandiert. Die stabilen CSM14.1BAG1-Zellen wurden im Vorfeld von Prof. Dr. P. Kermer (Universitätsmedizin Göttingen, Deutschland) generiert (Kermer et al. 2002).

\subsection{SH-SY5Y}

Es wurden stabil BAG1- und pcDNA3.1-überexprimierende SH-SY5YEinzelzellklonkolonien hergestellt. Die stabile Transfektion wurde mit Lipofectamine2000® nach demselben Protokoll wie die transiente Transfektion durchgeführt (2.3.3.1). Die transfizierte Gesamtplasmidmenge betrug $4 \mu \mathrm{g}$ pro Well einer 6-Well-Platte. 48 Stunden nach Transfektion wurde das Medium in Antibiotika-haltiges SH-SY5Y-Selektionsmedium gewechselt. Nach erneuter Konfluenz der 6-Well-Platte unter Selektion wurde ein Teil der Zellen bei $-80^{\circ} \mathrm{C}$ eingefroren. Ein Teil der transfizierten Zellen wurde außerdem für einen proteinbiochemischen Expressionsnachweis (2.5) aufbereitet. Zur Herstellung von Einzellzellklonkolonien wurde rechnerisch eine halbe Zelle pro Well in einer 96-Well-Platte in Selektionsmedium ausplattiert. Nach drei bis vier Wochen wurden die Platten lichtmikroskopisch auf Einzelzellklonkolonien durchsucht, welche anschließend auf größere Platten transferiert wurden. Nach einer weiteren Expressionsprüfung wurden mehrere BAG1bzw. pcDNA3.1-positive Klone für alle nachfolgenden Experimente expandiert.

\subsubsection{Kontinuierliche Zellkultur}

\subsubsection{Kultivierung}

SH-SY5Y-Zellen wurden in 10-cm-Rundschalen bei $37^{\circ} \mathrm{C}, 5 \% \mathrm{CO}_{2}$ und in mit Wasserdampf gesättigter Atmosphäre im Inkubator in SH-SY5Y-Kulturmedium kultiviert.

CSM14.1-Zellen wurden ebenfalls in Kulturmedium in 10-cm-Rundschalen, bei $5 \% \mathrm{CO}_{2}$ und in mit Wasserdampf gesättigter Atmosphäre, allerdings bei $32^{\circ} \mathrm{C}$, im Inkubator in CSM14.1Kulturmedium kultiviert.

\subsubsection{Passagierung}

Zum Passagieren unter sterilen Bedingungen wurden konfluente Zellen einmal mit $5 \mathrm{ml}$ PBS gewaschen. CSM14.1-Zellen wurden, zum Lösen des Zellrasens für zehn Minuten bei $32^{\circ} \mathrm{C}$ in 2,5 $\mathrm{ml}$ Trypsin (1\%) inkubiert, und anschließend mit weiteren 2,5 $\mathrm{ml}$ Kulturmedium in ein Reaktionsgefäß aufgenommen. SH-SY5Y-Zellen wurden nach vorsichtigem Waschen in $5 \mathrm{ml}$ PBS, ebenfalls mit einer Gesamtmenge von $5 \mathrm{ml}$ Kulturmedium, aufgenommen. Die Zellen wurden anschließend bei 390 x g für fünf Minuten bei Raumtemperatur abzentrifugiert. Nach Verwerfen des Überstandes wurden sie in $1 \mathrm{ml}$ des jeweiligen Kulturmediums wieder 
aufgenommen und je $300 \mu \mathrm{l} \mathrm{SH-SY5Y-Zellsuspension} \mathrm{bzw.} 200 \mu 1$ CSM14.1-Zellsuspension auf einer neuen 10-cm-Rundschale in $5 \mathrm{ml}$ des jeweiligen Kulturmediums ausplattiert.

\subsubsection{Quantifizierung}

Um die Zellzahl zu ermitteln, wurden alle drei Zelllinien wie beim Passagieren von den Kulturschalen gelöst. Nach dem Zentrifugieren wurde eine geringe Menge ( $25 \mu 1)$, der in $1 \mathrm{ml}$ Medium wieder aufgenommenen Zellen, 1:10 in Zählmedium verdünnt. Die Zellzahl wurde für $0,4 \mu \mathrm{l}$ dieses Gemisches unter dem invertierten Mikroskop ID 02 in einer NeubauerZählkammer ermittelt und anschließend auf $1 \mathrm{ml}$ hochgerechnet. Das Volumen mit der gewünschten Anzahl von Zellen wurde auf entsprechende Zellkulturplatten ausgesät.

\subsubsection{Einfrieren der Zellen}

Zum Einfrieren wurden die Zellen, wie beim Passagieren beschrieben, von den Platten gelöst und abzentrifugiert. Nach dem Zentrifugieren wurden die Zellen in $1 \mathrm{ml}$ kaltem Einfriermedium resuspendiert und dann nach langsamer Abkühlung bei $-80^{\circ} \mathrm{C}$ eingefroren.

\subsubsection{Auftauen der Zellen}

Alle Zelllinien wurden im Wasserbad bei $37^{\circ}$ aufgetaut. Anschließend wurden die Zellen mit ihrem Einfriermedium in $2 \mathrm{ml}$ Kulturmedium aufgenommen. Nach Abzentrifugation (174 x g für fünf Minuten bei Raumtemperatur) wurde der Überstand verworfen, die Zellen in $1 \mathrm{ml}$ Kulturmedium resuspendiert und dann im jeweiligen Kulturmedium auf 10-cm-Rundschalen ausplattiert.

\subsubsection{Transfektionen}

\subsubsection{Lipofectamine $2000 ®$}

Über eine Transfektion wird fremde DNA in eine eukaryote Zelle eingeschleust. Bei einer transienten Transfektion wird die DNA nicht fest in das Genom eingebaut, sondern, unter Kontrolle eines entsprechenden Promotors, vom frei liegenden Plasmid abgelesen, sodass die Zelle das Plasmid nach einiger Zeit häufig wieder spontan entfernt. Lipofectamine 2000® wurde genutzt um Plasmide in CSM14.1-Zellen überzuexprimieren. Hierzu wurden die CSM14.1-Zellen 48 Stunden vor der Transfektion im jeweiligen Nährmedium auf 6-WellPlatten ausplattiert. Die Transfektion wurde mit dem Transfektans Lipofectamine 2000® nach dem zugehörigen Protokoll durchgeführt. Dazu wurden pro Well $4 \mu \mathrm{g}$ des jeweiligen Plasmids und $10 \mu \mathrm{l}$ Lipofectamine $2000 ®$ getrennt voneinander in je $250 \mu \mathrm{l}$ Antibiotika- und Serum-freiem Kulturmedium (DMEM) für fünf Minuten bei Raumtemperatur inkubiert. 
Anschließend wurden DNA und Transfektans vermischt und, nach weiteren 30 Minuten Inkubationszeit bei Raumtemperatur, in einem Gesamtvolumen von $2 \mathrm{ml}$ Antibiotika- und Serum-freiem Kulturmedium pro Well auf die vorher mit PBS gewaschenen Zellen gebracht. Nach sechs Stunden Inkubation bei $32^{\circ} \mathrm{C}$ wurde das Medium wieder in zellspezifisches Kulturmedium getauscht.

\subsubsection{MATra ${ }^{\circledR}$}

Die MATra®-Transfektion wurde für die Transfektion der SH-SY5Y-Zellen genutzt, da diese Zellen sehr vulnerabel sind und eine Transfektion mit Lipofectamine 2000® eine große Transfektionstoxizität aufwies. Das Verfahren bedient sich superparamagnetischer Nanopartikel. Diese werden zunächst mit der einzubringenden DNA komplexiert und dann auf die Zellkultur gegeben. Durch einen unter den Zellen platzierten Magneten wird der Komplex anschließend auf die Zellmembran gezogen und endozytotisch aufgenommen.

Die stabil pcDNA3.1- und stabil BAG1-überexprimierenden SH-SY5Y-Zellen wurden auf 24-Well-Platten in Selektionsmedium ausplattiert. 72 Stunden später erfolgte dann die Transfektion mit MATra®. Hierzu wurden pro Well je 0,6 $\mu \mathrm{g}$ DNA in $50 \mu$ l DMEM für fünf Minuten inkubiert. Dazu wurden dann 0,6 $\mu$ l MATra®-Suspension pipettiert und das DNA/Beads-Gemisch anschließend, nach kurzem Vortexen, 20 Minuten inkubiert. In der Zwischenzeit wurde bei den zu transfizierenden Zellen ein Mediumwechsel durchgeführt. Dazu wurde einmal vorsichtig mit PBS gewaschen und dann pro Well $250 \mu$ l DMEM-Full hinzugefügt. Nach Ende der Inkubationszeit wurde das DNA/Beads-Gemisch mit DMEMFull soweit verdünnt, dass ein Gesamtvolumen von $100 \mu \mathrm{l}$ in jedes Well gegeben werden konnte. Durch vorsichtiges Rütteln der Platte wurde gut gemischt. Anschließend wurde die 24-Well-Platte für 30 Minuten im Inkubator bei $37^{\circ} \mathrm{C}$ auf einer 24-Well-Magnetplatte inkubiert. Ein anschließender Mediumwechsel war nicht nötig.

\section{$2.4 \quad$ ZELLTODASSAYS}

Alle Zelltodassays wurden mindestens als Vierfach-Bestimmung durchgeführt und mindestens drei Mal wiederholt.

\subsubsection{6-Hydroxydopamin}

Für die 6-OHDA-Assays wurden SH-SY5Y-pcDNA3.1- und SH-SY5Y-BAG1-Zellen auf 96Well-Platten (20.000 Zellen pro Well) ausplattiert. 48 Stunden später erfolgte die Toxinzugabe. Hierzu wurde das 6-OHDA in 0,2 \% Vitamin C in PBS gelöst, sodass eine 5 mM-Lösung entstand. Diese Lösung wurde dann mit DMEM-Full-Medium verdünnt, sodass 
die Zellen den Konzentrationen $0 \mu \mathrm{M}, 25 \mu \mathrm{M}, 50 \mu \mathrm{M}$ und $75 \mu \mathrm{M}$ 6-OHDA ausgesetzt wurden. Dazu wurde als Kontrolle für die Gesamtzellzahl das ToxiLight ${ }^{\mathrm{TM}}$ 100\% Lysis Reagent Set verwendet. Die Zugabe des Reagenzes erfolgte, nach Herstellerangaben verdünnt mit DMEM-Full, zum Zeitpunkt der Toxinzugabe. 48 Stunden nach der Toxinzugabe erfolgte die Auswertung mit Hilfe des ToxiLight ${ }^{\mathrm{TM}}$-Assays (2.4.4).

\subsubsection{Rotenon}

Für die Rotenonassays wurden SH-SY5Y-pcDNA3.1- und SH-SY5Y-BAG1-Zellen auf 96Well-Platten (20.000 Zellen pro Well) ausplattiert. 48 Stunden später erfolgte die Toxinzugabe. Hierzu wurde das Rotenone in DMSO gelöst, sodass eine $5 \mathrm{mM}$-Lösung entstand. Diese Lösung wurde dann mit DMEM-Full-Medium verdünnt, sodass die Zellen den Konzentrationen $0 \mu \mathrm{M}, 0,25 \mu \mathrm{M}, 0,5 \mu \mathrm{M}$ und $1 \mu \mathrm{M}$ Rotenone ausgesetzt wurden. Dazu wurde als Kontrolle für die Gesamtzellzahl das ToxiLight ${ }^{\mathrm{TM}}$ 100\% Lysis Reagent Set verwendet. Die Zugabe des Reagenzes erfolgte, nach Herstellerangaben verdünnt mit DMEM-Full, zum Zeitpunkt der Toxinzugabe. 48 Stunden nach der Toxinzugabe erfolgte die Auswertung mit Hilfe des ToxiLight ${ }^{\mathrm{TM}}$-Assays (2.4.4).

\subsection{3 $\quad \alpha$-Synuclein}

Um die Toxizität der verschiedenen $\alpha$-Synuclein-Mutanten auf SH-SY5Y-Zellen zu evaluieren, wurden je 70.000 der stabil pcDNA3.1- und der stabil BAG1-überexprimierenden Zellen auf 24-Well-Platten in Selektionsmedium ausplattiert. 72 Stunden später erfolgte die Transfektion mit MATra ${ }^{\circledR}$ (2.3.3.2). Um die Transfektionseffizienz zu kontrollieren, wurden je zwei Wells pro Zellart mit einem GFP-Plasmid transfiziert und die Transfektionseffizienz unter dem Axiovert Fluoreszenzmikroskop beurteilt. 72 Stunden nach der Transfektion erfolgte die Auswertung mit Hilfe des ToxiLight ${ }^{\mathrm{TM}}$-Assays (2.4.4).

\subsubsection{Auswertung}

Zur Auswertung der Zelltodassays wurde der ToxiLight ${ }^{\mathrm{TM}}$-Assay genutzt. Der Assay beruht auf der Freisetzung der Adenylatkinase aus Zellen in den terminalen Phasen des Zelltodes. In einem ersten Schritt wird mit Hilfe der Adenylatkinase ADP zu ATP umgewandelt, was dann in einem zweiten Schritt Luciferase-abhängig zur Emission von Licht führt, welches von einem Luminometer detektiert werden kann.

Der Toxilight ${ }^{\mathrm{TM}}$-Assay wurde für die verschiedenen Modelle (6-OHDA, Rotenon und $\alpha$ Synuclein) analog durchgeführt. Das ToxiLight ${ }^{\mathrm{TM}}-$ Reagenz $_{\text {w }}$ wrde, entsprechend der Herstellerangaben, angesetzt und vor Licht geschützt. Aus jedem Well der auszuwertenden 
Platten wurden je $50 \mu 1$ in eine undurchsichtige 96-Well-Platte pipettiert. Dazu wurden je 50 $\mu l$ des ToxiLight ${ }^{\text {TM}}$-Reagenzes gegeben. Jedes Well wurde dann vor der Messung im Luminometer exakt fünf Minuten inkubiert. Die Auswertung erfolgte mit Hilfe der Software Wallac 1450 MicroBeta Workstation 2.7.

\subsection{PROTEINANALYSEN}

\subsubsection{Lysate}

Die Lysierung von Zellen setzt die enthaltenden Proteine frei, sodass diese nachfolgenden Untersuchungen zugänglich sind.

\subsubsection{Einfache Lysate}

Zur einfachen Lysierung der Zellen, wie es z. B. für die Expressionschecks erfolgte, wurden CSM14.1- und SH-SY5Y-Zellen einer 6-Well-Platte zuerst mit PBS gewaschen und anschließend mit je $80 \mu$ l Lysepuffer versetzt. Danach wurden die Zellen mit einem Zellkratzer von der Platte geschabt und in ein 1,5-ml-Reaktionsgefäß pipettiert. Nach der anschließenden Inkubation auf Eis für 15 Minuten erfolgte die Ultraschallbehandlung des Lysats mit dem Sonicator. Zuletzt wurde das Lysat 15 Minuten bei 16060 x g zentrifugiert. Der Protein-haltige Überstand wurde dann in ein neues Reaktionsgefäß pipettiert und das Reaktionsgefäß bis zur weiteren Verarbeitung bei $-20^{\circ} \mathrm{C}$ gelagert.

\subsubsection{Lysate mit Protein-Crosslinker}

Die Behandlung von Lysaten mit dem Protein-Crosslinker DSS erfolgte zur Stabilisierung von $\alpha$-Syn-Aggregaten im Lysat. Für diese Art von Lysaten wurden nur CSM14.1-Zellen verwendet. Pro Kondition wurden je zwei Wells einer 6-Well-Platte gleich behandelt und zusammen verwendet. $\mathrm{Zu}$ den 80-90 \% konfluenten Zellen wurden zunächst je $500 \mu \mathrm{l}$ Trypsin-Lösung pro Well pipettiert. Nach einer Inkubationszeit von 5 Minuten wurden die Zellen dann mit $1 \mathrm{ml}$ PBS von der Platte gewaschen und in ein 15-ml-Reaktionsgefäß pipettiert, dabei wurden die jeweils gleich behandelten Zellen aus zwei Wells in ein Reaktionsgefäß gegeben. Anschließend erfolgte die Zentrifugation für fünf Minuten bei 390 x g. Der Überstand wurde verworfen und das Pellet in $1 \mathrm{ml}$ PBS resuspendiert. Anschließend wurde die Zahl der Zellen pro Reaktionsgefäß bestimmt (2.3.2.3) und je 1.000.000 Zellen in ein 1,5-ml-Reaktionsgefäß pipettiert, bevor ein Zentrifugationsschritt (5 Minuten bei 390 x g) erfolgte. Der Überstand wurde verworfen und das Pellet in $100 \mu$ I PBS resuspendiert. In der Zwischenzeit wurden $2 \mathrm{mg}$ DSS in $1080 \mu \mathrm{l}$ DMSO gelöst. Von dieser Lösung wurden zum Start der Crosslinking-Reaktion 3,5 $\mu$ l in jedes Reaktionsgefäß pipettiert. Anschließend 
erfolgte eine Inkubation über exakt 30 Minuten. Durch die vorher bestimmte Zellzahl wurde sichergestellt, dass jeweils gleiche Konzentrationen an DSS pro Zelle appliziert wurden. Zum Stoppen der Reaktion wurden je 3,6 $\mu 11$ M Tris-Chlorid, pH 7,4 in jedes Reaktionsgefäß pipettiert und über 15 Minuten inkubiert. Darauf folgte ein erneuter Zentrifugationsschritt über 5 Minuten bei 390 x g. Im Anschluss wurde der Überstand verworfen und das Pellet in $50 \mu 1$ Lysepuffer resuspendiert. Die Lyse erfolgte auch hier über 15 Minuten auf Eis. Nach Ultraschallbehandlung des Lysats mit dem Sonicator wurde das Lysat erneut 15 Minuten bei 16060 x g zentrifugiert. Der Protein-haltige Überstand wurde dann in ein neues Reaktionsgefäß pipettiert und das Reaktionsgefäß bis zur weiteren Verarbeitung bei $-20^{\circ} \mathrm{C}$ gelagert.

\subsubsection{BCA-Assay}

Der BCA-Assay ist eine empfindliche Methode zur quantitativen Proteinbestimmung. Prinzip dieses Assays ist, dass zweiwertige Kupferionen quantitativ mit Proteinen reagieren, sodass einwertige Kupferionen entstehen. Zusammen mit der BCA entsteht dann ein violetter Farbstoff der bei $562 \mathrm{~nm}$ photometrisch detektiert werden kann (Smith PK et al. 1985). Mit Hilfe eines BCA-Assays kann durch den Vergleich mit Standardkonzentrationen an Protein die Proteinkonzentration in einem Lysat bestimmt werden. Dazu wurden in eine 96-WellPlatte veschiedene Konzentrationen an BSA als Konzentrationsstandard (40 $\mu \mathrm{g}, 20 \mu \mathrm{g}, 10 \mu \mathrm{g}$, $5 \mu \mathrm{g}, 2,5 \mu \mathrm{g}, 1,25 \mu \mathrm{g}, 0,625 \mu \mathrm{g}$ ), sowie je $1 \mu \mathrm{l}$ aus jedem Lysat (Doppelansatz) mit je $200 \mu \mathrm{l}$ BCA-Färbelösung versetzt und für 30 Minuten bei Raumtempereatur inkubiert. Anschließend wurde mit einem Photometer unter Verwendung der easy WIN basic 6.1 Software die Extinktion bei $562 \mathrm{~nm}$ bestimmt. Die Proteinkonzentrationen wurden anschließend anhand einer Eichreihe ermittelt, die sich aus der BSA-Konzentrationsstandardreihe ergab.

\subsubsection{SDS-Polyacrylamid-Gel-Elektrophorese}

Eine Natriumdodecylsulfat-Polyacrylamid-Gel-Elektrophorese (SDS-PAGE) dient der Auftrennung von Proteinen. Die Auftrennung erfolgt in einem elektrischen Feld anhand des Molekulargewichtes. In einer Elektrophoresekammer wurde ein SDS-Polyacrylamidgel bestehend aus einem $12 \%$ igen Trenngel und einem 5\%igen Sammelgel gegossen. Des weiteren wurden die Proteinproben mit Lysepuffer soweit verdünnt und im Verhältnis 5:1 mit Western-Blot-Ladepuffer (6x) versetzt, dass die Proteinkonzentration in jedem Reaktionsgefäß $40 \mu \mathrm{g}$ Protein pro $12 \mu \mathrm{l}$ entsprach. Anschließend wurden die ProteinReaktionsgefäße im Heizblock für fünf Minuten auf $95^{\circ} \mathrm{C}$ erhitzt. 
Pro Probe wurden je $12 \mu \mathrm{l}$ in die Geltaschen des Sammelgels geladen. Außerdem wurde in jedem Gel ein Marker mitgeladen (4 $\mu 1$ Dual®-Color-Marker). Die SDS-PAGE wurde mit $4^{\circ} \mathrm{C}$ kaltem Elektrophoresepuffer für Western Blots befüllt und dann bei einer Umgebungstemperatur von $4^{\circ} \mathrm{C}$ durchgeführt. Bis die Markerfront das Ende des Sammelgels erreicht hatte, wurde die Spannung auf $80 \mathrm{~V}$ eingestellt, anschließend wurde die Spannung auf $100 \mathrm{~V}$ gesteigert.

\subsubsection{Western Blotting}

Im Western Blot werden Proteine nach erfolgter SDS-PAGE aus dem Polyacrylamidgel auf eine Membran transferiert, auf der sie durch entprechende Antikörper sichtbar gemacht werden können. Der Western Blot erfolgte in einer Transfer-Kammer zwischen zwei 6 x $9 \mathrm{~cm}$ großen Blotting-Papieren. Der Transfer der Proteine erfolgte über eine Stunde bei $100 \mathrm{~V}$ in $4^{\circ} \mathrm{C}$ kaltem Transfer-Puffer auf eine $6 \times 9 \mathrm{~cm}$ große Nitrocellulose-Membran. Auch der Transfer erfolgte in $4^{\circ} \mathrm{C}$ kalter Umgebungstemperatur, zusätzlich wurde hier die Kammer mit mit Eis gekühlt.

\subsubsection{Immundetektion der Proteine}

Nach dem Blotten wurden die Nitrocellulosemembranen zuerst 5 Minuten in TBS-T gewaschen, anschließend erfolgte das Blocken unspezifischer Bindungssstellen für eine Stunde in 5\%iger Milchlösung. Die Inkubation mit dem ersten Antikörper erfolgte über Nacht bei $4^{\circ} \mathrm{C}$. Für den Nachweis von $\alpha$-Syn wurde der Anti- $\alpha$-Synuclein-Maus-Antikörper in einer Konzentration von 1:800, für den Nachweis von B-Tubulin der Anti- $\beta$-Tubulin-MausAntikörper in einer Konzentration von 1:1000 und für den Nachweis von BAG1 der AntiBAG1-Kaninchen-Antikörper in einer Konzentration von 1:500 verwendet. In allen Fällen erfolgte die Verdünnung der Antikörper mit 5\%iger Milchlösung. Am nächsten Morgen wurden die Membranen, nach dreimaligem Waschen für fünf Minuten in TBS-T, mit dem zweiten Antikörper versetzt. Zweitantikörper wurden immer in der Konzentration 1:1000 in $5 \%$ iger Milchlösung verwendet. Sowohl für den Nachweis von $\alpha$-Syn, als auch für den $\beta$ Tubulinnachweis wurde der Anti-Maus-IgG-HRP-Ziegen-Antikörper verwendet. Der Nachweis von BAG1 erfolgte mit dem Anti-Kaninchen-IgG-HRP-Ziegen-Antikörper als Zweitantikörper. Die Inkubationszeit für den Zweitantikörper betrug zwei Stunden. Nach erneutem dreimaligem Waschen für fünf Minuten in TBS-T erfolgte die Detektion der Proteine mittels ECL-Reagenz. ECL reagiert unter Bildung von Chemolumineszenz mit der Meerrettich-Peroxidase (HRP), die an die Zweitantikörper gekoppelt ist. Hierzu wurden die ECL-Lösungen 1 und 2 miteinander versetzt und für zwei Minuten inkubiert. Anschließend 
wurde die Lösung auf die Membranen gegeben und die Chemolumineszenz mittels einer Entwicklungsmaschine auf Chemoluminiszenzfilmen nachgewiesen. Erfolgten mehrere Färbungen auf einer Membran wurde die Membran zwischen den verschiedenen Färbungen für eine Stunde mit Glycin/SDS gestrippt.

\subsection{IN-VIVO-EXPERIMENTE}

Es wurden vier bis sechs Wochen alte männliche C57BL/6-Mäuse (Harlan Winkelmann $\mathrm{GmbH}$ ) verwendet. Die Tiere wurden unter optimierten hygienischen Bedingungen mit Trinkwasser- und Futterzugang ad libitum in einem 12h/12h-Tag/Nacht-Zyklus gehalten. Alle Maßnahmen im Zusammenhang mit Bestellung, Haltung, Versorgung und Einsatz der Tiere wurden nach geltenden Tierschutz-Richtlinien und Verordnungen durchgeführt und kontrolliert. Die Durchführung der Tierversuche erfolgte gemäß der europäischen Richtlinie 86/609/EEC. Die Nummer des genehmigten Tierversuchsantrages ist G18.02.

\subsubsection{Stereotaktische Virusinjektion in das Mausgehirn}

Zur stereotaktischen Virusinjektion wurden die Mäuse mit Chloralhydrat-Lösung $10 \mu 1 / \mathrm{g}$ Körpergewicht (KG) intraperitoneal (i.p) narkotisiert und mit Rimadyl-Lösung $(0,005$ mg/g $\mathrm{KG}$ ) analgesiert, wobei dieses zur besseren Depotwirkung subkutan verabreicht wurde.

Der Kopf der tief narkotisierten Maus wurde mit Ohrenhaltern und einem Maulhalter im stereotaktischen Rahmen fixiert. Mit einem Skalpell wurde ein longitudinaler Hautschnitt vom Mittelpunkt der imaginären Verbindungslinie der Augen zum Mittelpunkt der imaginären Verbindungslinie der Gehörgänge gesetzt. Mit Hilfe von Skalpell und Pinzette wurde nun der Schnitt auseinandergezogen und verbleibendes Bindegewebe vorsichtig abpräpariert, sodass die Schädelnähte optimal sichtbar wurden. Zur optimal horizontalen Ausrichtung des Kopfes wurden nun Bregma (Schnittpunkt der Koronar- und Sagittalnaht) und Lambda (Schnittpunkt der Lambda- und Sagittalnaht) durch Verstellung des Maulhalters auf eine Ebene gebracht. Die Koordinaten des Bregmas wurden als Nullpunkt definiert, von ihnen ausgehend ergaben sich die Koordinaten für die Injektion in die rechte SNpc. Diese Koordinaten wurden nach Daten der Gruppe um Patrick Aebischer (Bensadoun et al. 2000) modifiziert: Anterior-posterior: $-2,9 \mathrm{~mm}$, medio-lateral: $-1,3 \mathrm{~mm}$, dorso-ventral: $-4,5 \mathrm{~mm}$. Eine mit Mineralöl und der Injektionslösung gefüllte Glaskapillare wurde nun an die Injektionspumpe angeschlossen, die wiederum mit dem Micro Syringe Pump Controler Micro 4 verbunden war, der die Einstellungen der Injektionsparameter (Volumen und Geschwindigkeit) ermöglicht. Die AAV-Vektoren wurden in einer Geschwindigkeit von 250 $\mathrm{nl} / \mathrm{min}$ in die SNpc injiziert. Das injizierte Volumen war vom Virustiter abhängig: AAV- 
BAG1: $1000 \mathrm{nl}$; AAV-EGFP: $1013 \mathrm{nl}$ und entsprach je 1,52 x $10^{8}$ i.u. (infective units). Nach der Injektion wurde der Hautschnitt mit wenigen Stichen genäht.

\subsubsection{MPTP-Applikation}

Drei Wochen nach der Virusinjektion wurden an fünf aufeinanderfolgenden Tagen (Tag 22, 23, 24, 25 und 26 des Experimentes) MPTP- und PBS-Injektionen vorgenommen. Hierzu wurden je $30 \mathrm{mg} / \mathrm{kg}$ KG MPTP und äquivalente Volumina an PBS i.p. injiziert. Dies entspricht dem subakuten MPTP-Modell (Anderson et al. 2006). Die am Ende ausgewerteten Tieranzahlen waren: AAV-BAG1 + PBS: $\mathrm{n}=5$, AAV-BAG1 + MPTP: $\mathrm{n}=$ 9, AAV-EGFP + PBS: $\mathrm{n}=2$, AAV-EGFP + MPTP: $\mathrm{n}=2$. Zur Inaktivierung des MPTPs wurde Natriumhypochlorit-Lösung verwendet.

\subsubsection{Transkardiale Perfusion und Weiterverarbeitung der Hirne}

Die transkardiale Perfusion unter terminaler Anästhesie ist ein etabliertes Verfahren für Gewebefixation in immunhistochemischen Protokollen. Dieses Verfahren bedient sich des Kreislaufsystemes, welches die Fixationslösung an jede Körperstelle bringt, und insbesondere auch eine optimale Fixation des Gehirns möglich macht. Die Fixation konserviert die Ultrastruktur und stabilisiert Protein- und Peptid-Konformationen, sodass die Bindung von Antikörpern an entsprechende antigene Strukturen ermöglicht wird. Zur Fixation wurde 4\%iges PFA in PBS genutzt.

Die Mäuse wurden durch $\mathrm{CO}_{2}$-Inhalation tief betäubt und dann auf einem Gestell fixiert. Mit einer scharfen Schere wurde zuerst die Peritonealhöhle eröffnet und dann das Zwerchfell eingeschnitten, um den Zugang zum Thorax zu ermöglichen. Mit großen Scheren wurden nun beidseits lateral die Rippen zerschnitten und der Brustkorb weiter eröffnet, um den optimalen Zugang zum Herz zu ermöglichen. Hier wurde mit einer Perfusionsnadel (Multifly®-Set) der linke Ventrikel penetriert und die Nadel bis in die Aorta vorgeschoben. Zuletzt wurde die Leber eingeschnitten, um dort den Austritt des Blutes zu ermöglichen und die Aorta abdominalis abgeklemmt, um die Perfusion auf den oberen Teil des Körpers zu begrenzen. Eine $50 \mathrm{ml}$ Spritze mit eiskaltem PBS wurde nun über einen Katheter an die Nadel angeschlossen und mit einer Geschwindigkeit von 15-20 ml/min in den Kreislauf appliziert. Nachdem das Blut nahezu vollständig ausgewaschen war (ca. $100 \mathrm{ml}$ PBS) wurde die PBSenthaltende Spritze durch eine Spritze mit eiskalter 4\%iger PFA-Lösung ersetzt (ca. $100 \mathrm{ml}$ ). Anschließend wurde der Kopf vom Rumpf abgetrennt und das Gehirn vorsichtig aus dem Schädel gelöst. Die Gehirne wurden über Nacht bei $4^{\circ} \mathrm{C}$ in $4 \%$ iger PFA-Lösung nachfixiert. Zur Vorbereitung der weiteren Schritte wurden die Gehirne in 30\%iger Sucrose-Lösung 
dehydriert und anschließend bei $-80^{\circ} \mathrm{C}$ eingefroren. Der hintere Teil der Gehirne, welcher die SNpc beinhaltet, wurde dann mit dem Kryostaten, nach Einbettung in Tissue-Tek $®$, in $50 \mu \mathrm{m}$ dicke, koronare Schnitte geschnitten und die Schnitte in einer 24-Well-Platte mit Natriumazid-Lösung gesammelt.

\subsubsection{Färbungen}

\subsubsection{TH-Färbung (Immunfluoreszenz)}

Zur Beurteilung der Genauigkeit der Virsinjektion wurden auf jedem dritten Schnitt eines jeden Gehirnes mit einer Immunfluoreszenzfärbung die Tyrosinhydroxylase (TH)-positiven Neurone gefärbt. Zu diesem Zweck wurden die Schnitte zunächst drei mal fünf Minuten in PBS-Triton-X100 $(0,1 \%)$ gewaschen und dann 30 Minuten in $10 \%$ NGS in PBS-TritonX100 (0,1\%) geblockt. Anschließend wurden die Schnitte über Nacht bei $4^{\circ} \mathrm{C}$ mit einem Anti-TH-Antikörper (1:1000 in 1\% NGS in PBS) inkubiert. Am nächsten Tag wurden die Schnitte wieder drei mal fünf Minuten in PBS-Triton-X100 (0,1 \%) gewaschen und anschließend mit einem Cyanin 3 (Cy3) gekoppelten Anti-Kaninchen-Antikörper (1:200 in PBS-Triton-X100 0,1\%) für eine Stunde bei Raumtemperatur inkubiert. Anschließend wurde wieder, wie schon beschrieben, gewaschen und zuletzt noch eine DAPI-Färbung durchgeführt. Hierzu wurden die Schnitte für zwei Minuten in DAPI-Lösung inkubiert und anschließend wieder gewaschen. Dann wurden die Schnitte auf Objektträger aufgezogen und nach dem lichtgeschützten Trocknen über Nacht am nächsten Tag mit Entellan® eingedeckelt.

\subsubsection{TH-Färbung (DAB)}

Die DAB-Färbung der TH-positiven Neurone wurde auf jedem dritten Schnitt eines jeden Gehirnes ausgeführt. Nach der DAB-Färbung wurden dieselben Schnitte auch noch Nisslgefärbt, anschließend erfolgte die stereologische Auszählung.

Die Schnitte wurden zunächst drei mal fünf Minuten mit TBS gewaschen und anschließend für fünf Minuten in Wasserstoffperoxid-Lösung inkubiert, um die endogenen Peroxidasen zu blocken. Nach dreimaligem Waschen mit TBS wurden die Schnitte eine Stunde in $5 \%$ NGS (in 0,1 M TBS) inkubiert, um im Verlauf die unspezifische Bindung von Antikörpern zu verhindern. Anschließend folgte die Inkubation mit dem ersten Antikörper, einem Anti-THAntikörper (1:1000 in $2 \%$ NGS / 0,1 M TBS) bei $4^{\circ} \mathrm{C}$ über 48 Stunden. Anschließend wurde wieder drei mal fünf Minuten in 0,1 M TBS gewaschen, bevor die Schnitte dann für eine Stunde bei Raumtemperatur mit einem Biotin-gekoppelten-Anti-Kaninchen-Antikörper 
(1:200 in $2 \%$ NGS / 0,1 M TBS) inkubiert wurden. Die Vectastain® ABC-Arbeitslösung wurde, 45 Minuten bevor sie auf die Schnitte gegeben wurde, hergestellt. Die Inkubation der Schnitte in der Arbeitslösung erfolgte für eine Stunde. Anschließend folgte wieder ein Waschschritt (drei mal fünf Minuten in 0,1 M TBS), bevor die Schnitte mit Hilfe des DAB Peroxidase Substrate Kits über vier Minuten entwickelt wurde. Die DAB-Lösung wurde mit Natriumhypochlorit inaktiviert. Die Schnitte wurden dann auf Superfrost plus Objektträger aufgezogen und über Nacht getrocknet.

\subsubsection{Nissl-Färbung}

Die vorher DAB-gefärbten und über Nacht getrockneten Schnitte wurden am nächsten Tag Nissl-gefärbt. Hierzu wurden die Objekträger in den jeweiligen Lösungen inkubiert. Das Färbeschema stellte sich wie folgt dar: Fünf Minuten $\mathrm{H}_{2} \mathrm{O}_{\text {dest. }}$, sieben Minuten Nissl-ArbeitsLösung, in $\mathrm{H}_{2} \mathrm{O}_{\text {dest. }}$ spülen, zwei Minuten $70 \%$ Ethanol, zwei Minuten $90 \%$ Ethanol, fünf Minuten 96 \% Ethanol, fünf Minuten Isopropanol, fünf Minuten Xylol und fünf Minuten Xylol. Anschließend wurden die Schnitte sofort mit Entellan® eingedeckelt.

\subsubsection{BAG1-Färbung}

Die BAG1-Färbung der Gehirne erfolgte analog zur oben beschriebenen THImmunfluoreszenzfärbung. Anstelle des TH-Antikörpers wurde ein BAG1-Antikörper (1:500 in $1 \%$ NGS in PBS) verwendet.

\subsubsection{Auswertung}

\subsubsection{Stereotaxie}

Die Effizienz der stereotaktischen Injektion und die ausreichende Transfektion der SNpc wurde unter dem Fluoreszenzmikroskop Axioplan mit Hilfe des AxioVision 4.6 SoftwarePaketes bewertet.

\subsubsection{Stereologie}

Zur stereologischen Auswertung der Zellzahlen wurden die TH-positiven und die Nisslpositiven Zellen in der SNpc getrennt voneinander auf je zehn Schnitten gezählt. Hierzu wurde ein Computer-assistiertes System aus einem Axiovision Fluoreszenz Mikroskop und der Stereo Investigator Software genutzt (Dehmer et al. 2004). Die Auszählung wurde manuell und verblindet durchgeführt. In Abb. 8 sind exemplarisch sowohl typische THpositive als auch typische Nissl-positive Zellen gezeigt. Für die Auswertungen wurden die Zellzahlen der TH-positiven und der Nissl-positiven Zellen einer SNpc zusammengezählt, da 
davon auszugehen ist, dass es sich bei den Nissl-positiven Zellen im Bereich der SNpc ebenfalls um dopaminerge Neurone handelt, die durch die erfolgte Behandlung eine Herunterregulation der TH aufweisen.
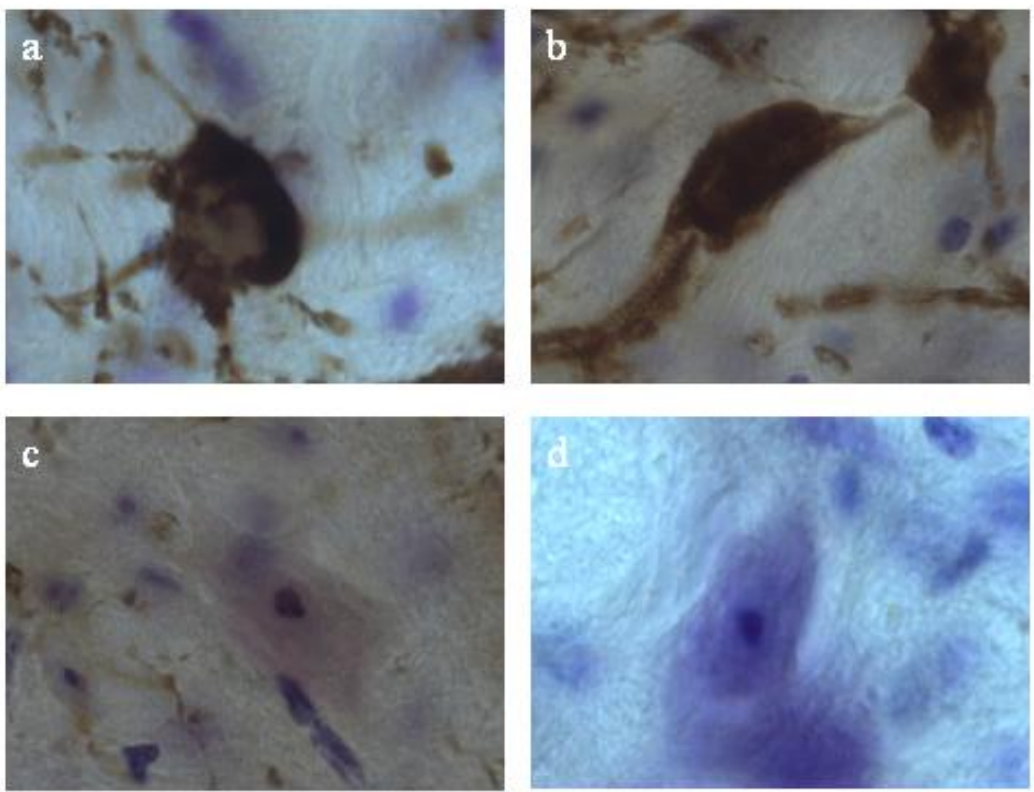

Abb. 8 TH- und Nissl-positive Zellen. a-b: TH-positive Zellen. c-d: Nissl-positive Zellen. 


\section{ERGEBNISSE}

\subsection{BAG1 IN VITRO}

\subsection{1 a-Syn-Konstrukte}

Die $\alpha$-Syn-Konstrukte WT- $\alpha$-Syn, A30P- $\alpha-S y n$ und A53T- $\alpha-S y n$ wurden über die Resriktionsenzymstellen HindIII und XhoI in einen pcDNA3.1-Vektor kloniert. Die $\alpha$-SynDNA wird hier unter der Kontrolle eines CMV-Promotors exprimiert (Abb. 9).

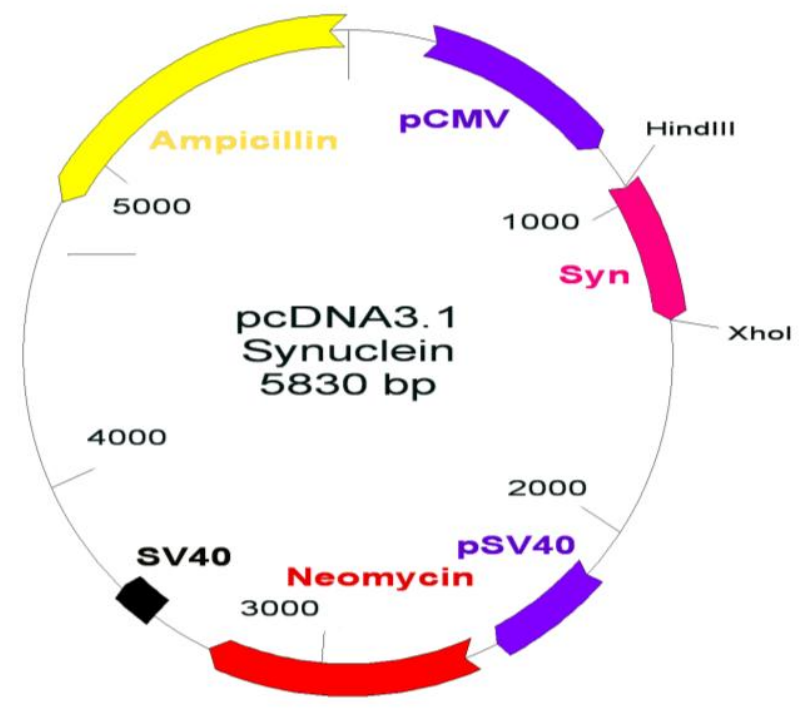

Abb. 9 Schematische Darstellung des pcDNA3.1-Synuclein-Plasmids. Zahlen: Basenpaare, pCMV: CMVPromotor, pSV40: Affen-Virus-40-Promotor, SV40: Affen-Virus-40-Polyadenylierungssequenz, Syn: WT- $\alpha$-Syn, A30P- $\alpha-$ Syn oder A53T- $\alpha-$ Syn.

\subsubsection{Restriktionsverdau der $\alpha$-Syn-Konstrukte}

Zur Kontrolle der korrekten Klonierung wurden die $\alpha$-Syn-Konstrukte nach der Amplifikation über Mini- bzw. Maxipräp erneut mit den Restriktionsenzymen HindIII und XhoI verdaut. Im Anschluss wurde eine Agarosegelelekrtophorese durchgeführt. Die folgende Abbildung (Abb. 10) zeigt die Produkte des Restriktionsenzymverdaus. Alle DNA-Banden weisen die korrekten, vorher berechneten Größen auf. So finden sich die herausgeschnittenen $\alpha$-SynInserts etwas unterhalb von $500 \mathrm{~kb}$, der eröffnete pcDNA3.1-Vektor bei ungefähr $5000 \mathrm{~kb}$. Die berechneten Größen sind 422 bp für die Inserts und 5408 für die eröffneten Leervektoren. Die korrekte Klonierung konnte somit bestätigt werden. 


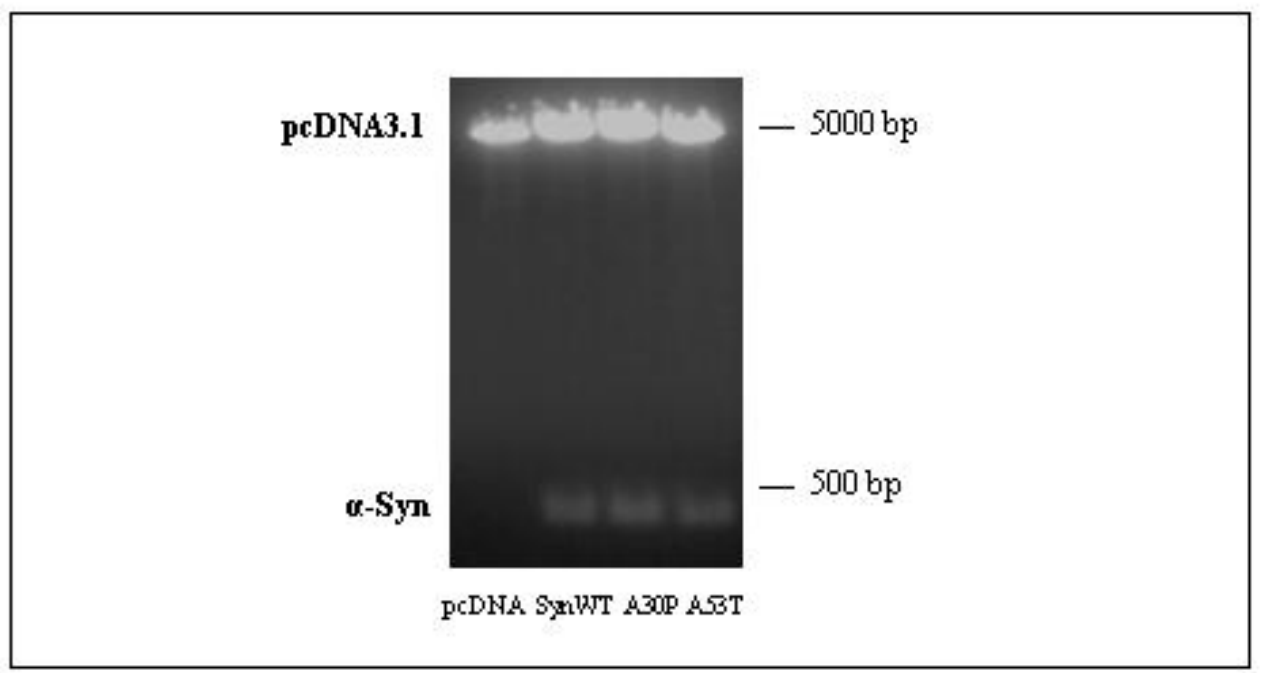

Abb. 10 Restriktionsverdau der $\boldsymbol{\alpha}$-Syn-Konstrukte. $\alpha$-Syn-Inserts und der eröffnete pcDNA3.1-Leervektor weisen die vorher errechneten Größen auf.

\subsubsection{Sequenzierung der $\alpha$-Syn-Konstrukte}

Die nach der Sequenzierung durch Seqlab (Göttingen, Deutschland) erhaltenen Basenfolgen der $\alpha$-Syn-Inserts wurden manuell mit den bekannten Sequenzen verglichen. Die Sequenzen stimmten vollständig überein, sodass Mutationen ausgeschlossen werden konnten. Auch der pcDNA3.1-Vektor wurde teilweise sequenziert. Die hier erhaltenen Sequenzen stimmten ebenfalls vollständig mit der vom Hersteller (Invitrogen, Karlsruhe, Deutschland) angegebenen Sequenz überein.

\subsubsection{Stabile Überexpression von BAG1 in vitro}

Alle Assays und Proteinanalysen wurden im Vergleich an WT-Zellen, bzw. einen Leervektorund stabil BAG1-überexprimierenden CSM14.1- und SH-SY5Y-Zellen durchgeführt. Der in Abb. 11 gezeigte Immunoblot dokumentiert die stabile Überexpression von BAG1 in CSM14.1- und SH-SY5Y-Zellen. Das exogene BAG1, welches über das pFlagBAG1-Plasmid in die Zellen eingeschleust wurde, besitzt ein Flag-Tag, weshalb seine Bande knapp über der des endogenenen BAG1 erscheint (CSM14.1-Zellen). Die CSM14.1-WT-Zellen weisen deshalb nur eine BAG1-Bande auf, die dem zelleigenen BAG1 entspricht. Die CSM14.1BAG1-Zellen weisen zwei Banden auf, wobei die untere dem endogenen und die oberere dem exogenen BAG1 entspricht. SH-SY5Y-Zellen besitzen kein BAG1 in detektierbarer Menge, sodass sich in den stabil mit dem pcDNA3.1-Leervektor transfizierten Zellen keine BAG1Bande findet. In den stabil BAG1-überexprimierenden SH-SY5Y-Zellen findet sich eine starke BAG1-positive Bande. Zur quantitativen Abschätzung der Proteinmengen wurde für jedes Lysat die B-Tubulin-Bande dargestellt. Diese Bande diente als Ladekontrolle. 


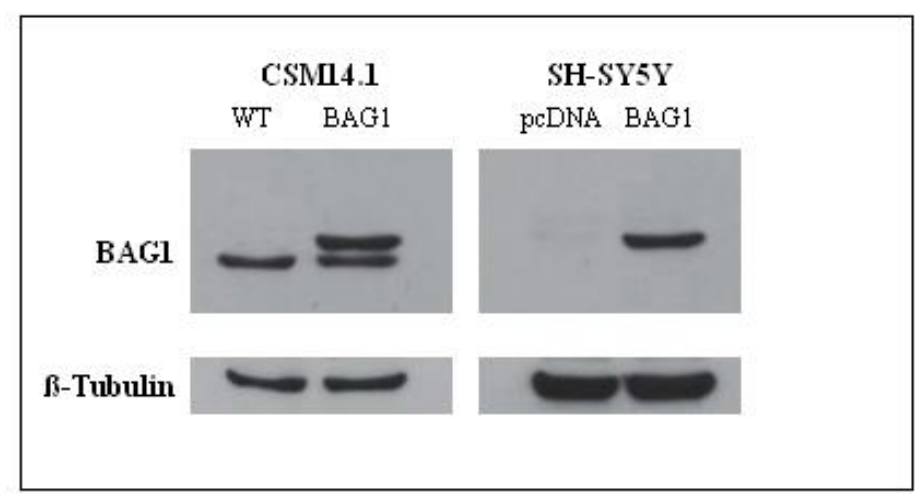

Abb. 11 Expressionskontrolle BAG1. Immunoblot stabil BAG1-überexprimierender CSM14.1- und SHSY5Y-Zellen. WT/pcDNA: Wiltyp-Zellen, bzw. einen Leervektor-exprimierende Zellen. BAG1: stabil BAG1-überexprimierende Zellen.

\subsubsection{Proteinanalysen}

\subsubsection{Keine Aggregation von $\alpha$-Syn detektierbar bei einfachen Lysaten}

Zur Beurteilung der Aggregationsneigung von $\alpha$-Syn in CSM14.1-Zellen wurden WT- $\alpha$-Syn, sowie die Mutanten A30P- $\alpha$-Syn und A53T- $\alpha$-Syn transient in CSM14.1-WT- und CSM14.1BAG1-Zellen überexprimiert. Als Negativkontrolle diente das pcDNA3.1-Plasmid. Nach Erstellung von einfachen Lysaten (2.5.1.1, S. 47), nachfolgender SDS-PAGE und Western Blot konnte in den auf $\alpha$-Syn gefärben Immunoblots keine Aggregation von $\alpha$-Syn dargestellt werden. Auf dem in Abb. 12 gezeigten Immunoblot finden sich nur die $\alpha$-Syn-Monomere. Zur quantitativen Abschätzung der Proteinmengen wurde für jedes Lysat die ß-Tubulin-Bande dargestellt. Diese Bande diente als Ladekontrolle.

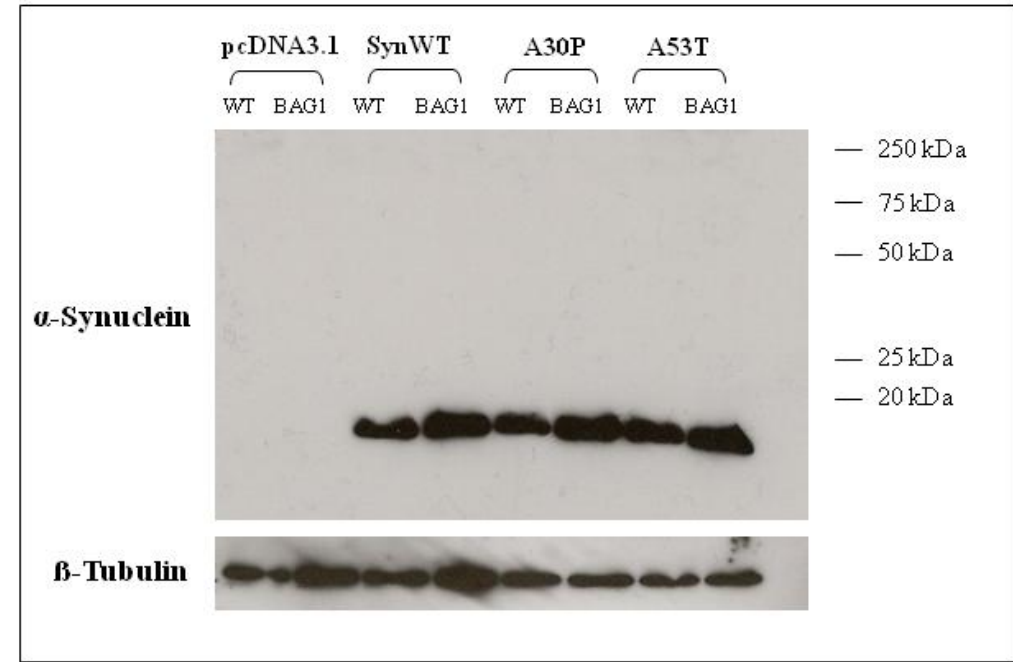

Abb. 12 a-Syn im Immunoblot. Einfache Lysate. CSM14.1-Zellen. WT: Wildtyp-Zellen, , BAG1: Stabil BAG1-überexprimierende Zellen. 


\subsubsection{Auswirkungen von BAG1 auf die Aggregationsneigung von $\alpha-S y n$}

Zur Beurteilung des Einflusses von BAG1 auf die Aggregation von $\alpha$-Syn wurden Zelllysate mit Crosslinker erstellt (2.5.1.2, S. 47), da in einfachen Lysaten keine Aggregation von $\alpha$-Syn darstellbar war (3.1.3.1). WT- $\alpha-$ Syn, sowie die Mutanten A30P- $\alpha-S y n$ und A53T- $\alpha-$ Syn wurden transient in CSM14.1-Zellen überexprimiert. Als Negativkontrolle diente das pcDNA3.1-Plasmid. Die Transfektionen wurden sowohl mit WT-Zellen als auch mit stabil BAG1-überexprimierenden Zellen durchgeführt. Nach Erstellung von Lysaten mit Crosslinker, anschließender SDS-PAGE und Western Blot konnten in den auf $\alpha$-Syn gefärben Immunoblots (Abb. 13) höhermolekulare $\alpha$-Syn-positive Aggregate dargestellt werden (bei ca. $250 \mathrm{kDa}$ ). Außerdem finden sich die $\alpha$-Syn-Monomere bei ca. $14 \mathrm{kDa}$, sowie bei ca. 30 kDa eine Bande, die $\alpha$-Syn-Dimeren entsprechen könnte. Bei den Mutanten A30P- $\alpha$-Syn und A53T- $\alpha-S y n$ zeigt sich eine stärkere Aggregationsneigung des $\alpha$-Syn in den stabil BAG1überexprimierenden Zellen als in den WT-Zellen. Für WT- $\alpha$-Syn scheint dies nicht zu gelten. Zur quantitativen Abschätzung der Proteinmengen wurde für jedes Lysat die B-Tubulin-Bande als Ladekontrolle dargestellt.

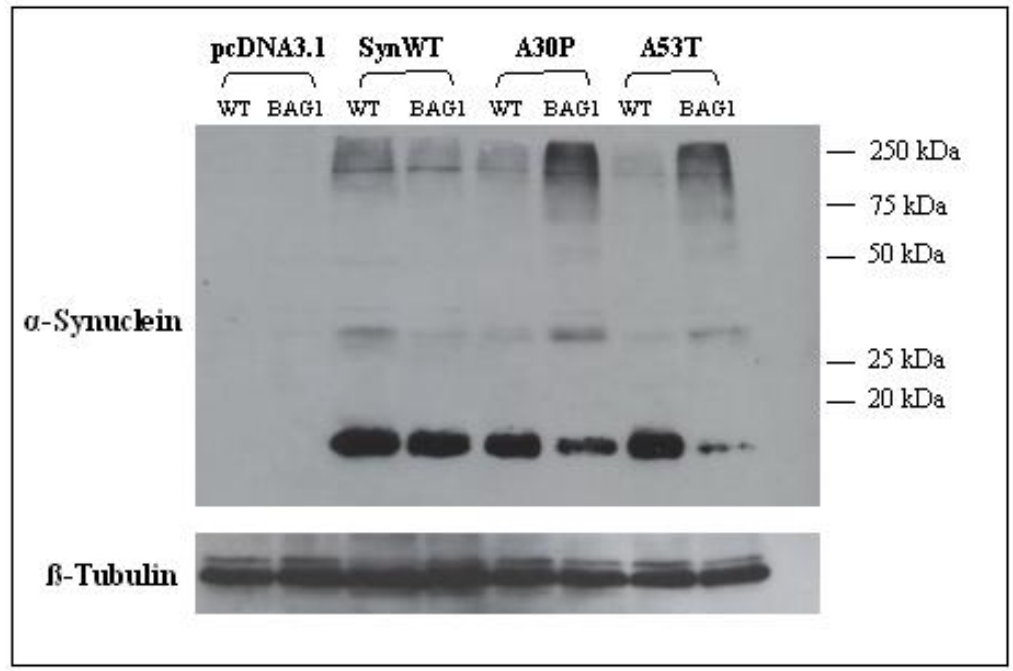

Abb. 13 a-Syn-Aggregate im Immunoblot. Lysate mit DSS-Crosslinker. CSM14.1-Zellen. WT: WildtypZellen, BAG1: Stabil BAG1-überexprimierende Zellen.

\subsubsection{Toxizitätsmodelle}

Die Wirkung von BAG1 sollte in verschiedenen Toxizitätsmodellen untersucht werden, da sich BAG1 schon in anderen Modellen neurodegenerativer Erkrankungen als protektiv erwiesen hat (1.2.4).

\subsubsection{BAG1 ist nicht protektiv im 6-OHDA-Zellkultur-Modell}

6-OHDA kann durch Autoaxidation mit Radikalbildung zu vermehrtem oxidativen Stress führen, was den Zelltod zur Folge haben kann. Weiterhin inhibiert 6-OHDA Enzyme die 
gegen oxidativen Stress schützen und hemmt außerdem die Aktivtät des Komplex I der Atmungkette (1.1.4.1, S. 14). Die folgende Abbildung (Abb. 14) zeigt den prozentualen Zelltodanteil von SH-SY5Y-Zellen, die über 48 Stunden verschiedenen Konzentrationen von 6-OHDA ausgesetzt waren. Als Bezugspunkt für den Wert $100 \%$ Zelltod dienten die Werte der Zellen, die mit dem ToxiLight ${ }^{\mathrm{TM}} 100 \%$ Lysis Reagenz versetzt worden waren. Als Leerwert wurden Zellen ohne Toxin für dieselbe Zeit inkubiert. Die Daten aus allen durchgeführten Assays wurden hier zusammengefasst. Bei keiner der drei gewählten 6OHDA-Konzentrationen konnte ein signifikanter Schutz der stabil BAG1überexprimierenden gegenüber den pcDNA3.1-Leervektor-überexprimierenden Zellen nachgewiesen werden.

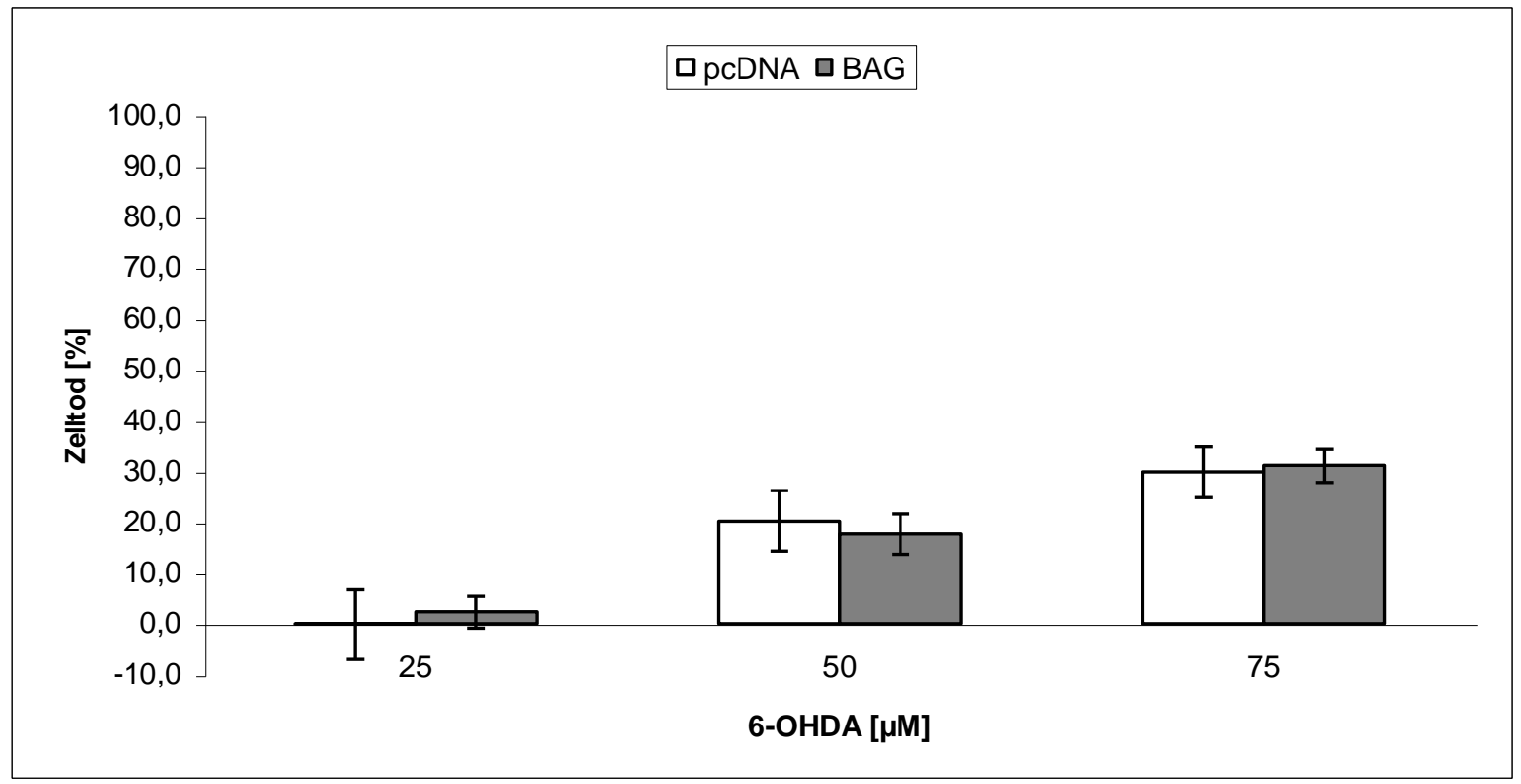

Abb. 14 Zelltod im 6-OHDA-Modell. SH-SY5Y-Zellen. Fehlerbalken: Standardabweichung. Es konnte kein signifikanter Schutz der stabil BAG1-überexprimierenden Zellen gegenüber den pcDNA3.1Leervektor-exprimierenden Zellen nachgewiesen werden.

\subsubsection{BAG1 ist protektiv gegen geringe Konzentrationen von Rotenon}

Rotenon, das als Insektizid Verwendung findet, hemmt die Funktion des Komplex I der Atmungskette. Außerdem beeinträchtigt Rotenon die Bildung von Tubulin, was zusätzliche Neurotoxizität bedingen kann (1.1.4.2, S. 15).

Die folgende Abbildung (Abb. 15) zeigt den prozentualen Zelltodanteil von SH-SY5YZellen, die über 48 Stunden verschiedenen Konzentrationen von Rotenon ausgesezt waren. Als Bezugspunkt für den Wert $100 \%$ Zelltod dienten die Werte der Zellen, die mit dem ToxiLight ${ }^{\mathrm{TM}} 100 \%$ Lysis Reagenz versetzt worden waren. Als Leerwert wurden Zellen ohne Toxin für dieselbe Zeit in einfachem Medium inkubiert. Die Daten aus allen durchgeführten Assays wurden hier zusammengefasst. Bei einer Konzentration von $25 \mu \mathrm{M}$ Rotenon konnte 
mit Hilfe eines Student-T-Testes $(\mathrm{p}<0,05)$ ein signifikanter Schutz der stabil BAG1überexprimierenden Zellen gegenüber den pcDNA3.1-Leervektor-exprimierenden Zellen nachgewiesen werden. Für die anderen Konzentrationen ergab sich kein signifikanter Schutz.

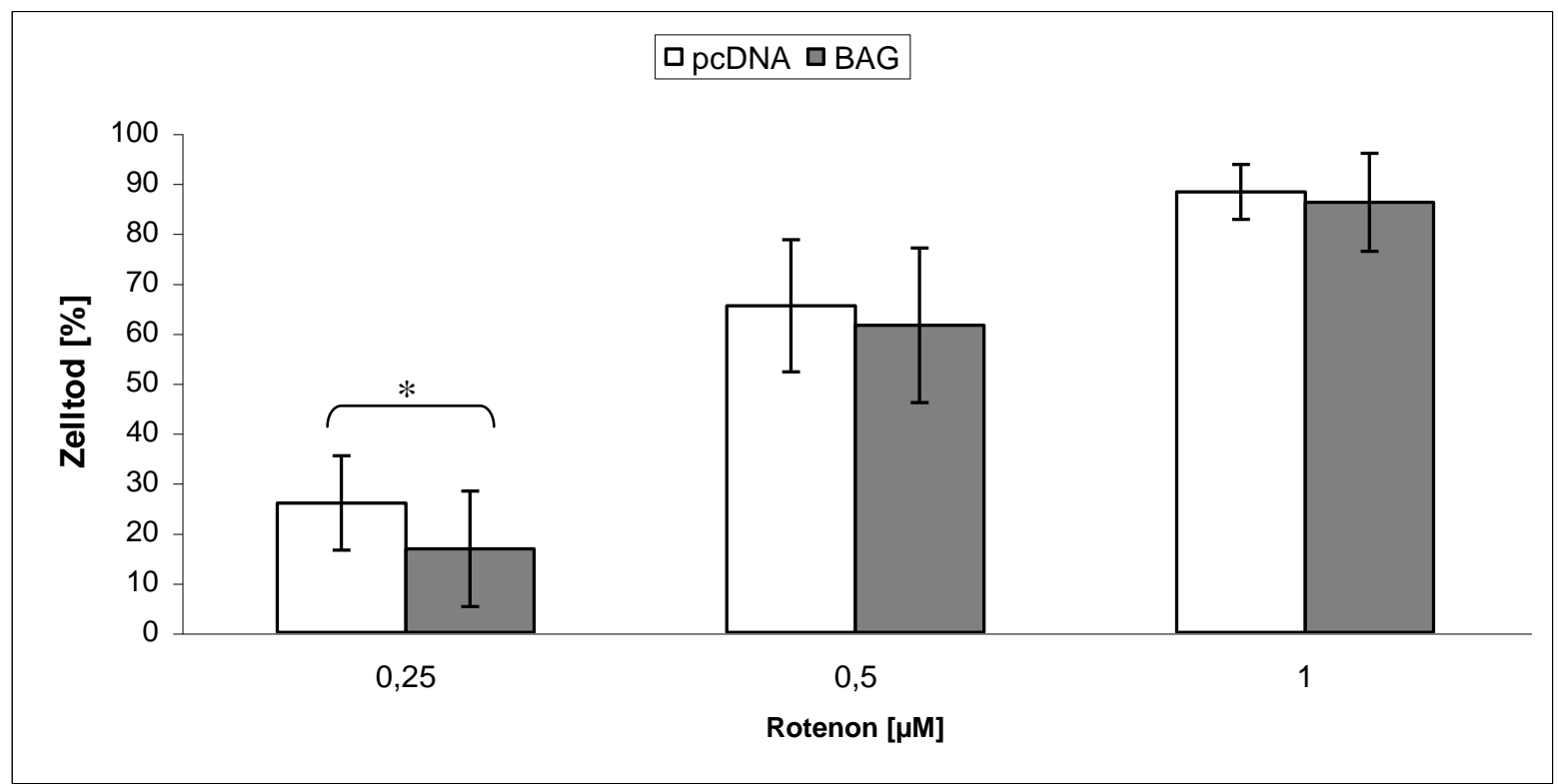

Abb. 15 Zelltod im Rotenon-Modell. SH-SY5Y-Zellen. Fehlerbalken: Standardabweichung. *: p<0,05. Für die Konzentration von 0,25 $\mu \mathrm{M}$ konnte ein signifikanter Schutz der stabil BAG1-überexprimierenden Zellen gegenüber den pcDNA3.1-Leervektor-exprimierenden Zellen nachgewiesen werden. Für die anderen Konzentrationen konnte kein signifikanter Schutz nachgewiesen werden.

\subsubsection{BAG1 ist protektiv im $\alpha$-Syn-Zellkultur-Modell}

In diesem Toxizitätsassay sollte untersucht werden, ob BAG1 gegen die durch $\alpha$-Syn und seine Mutanten vermittelte Toxizität zu schützen vermag. Hierzu wurden $\alpha$-Syn-WT, sowie seine Mutanten A30P und A53T transient in SH-SY5Y-pcDNA3.1- und SH-SY5Y-BAG1Zellen überexprimiert. Die Transfektionseffizienz in beiden Zellreihen wurde über die parallele Transfektion von pEGFP-N1, eines EGFP-exprimierenden Plasmids visualisiert (Abb. 16), um auszuschließen, dass allein eine höhere Transfektionstoxizität bei einem der Zelltypen zu erhöhtem Überleben der Zellen des anderen Typs führt. Hier fanden sich ungefähr gleiche Zelldichten und äquivalente Anzahlen transfizierter Zellen. In den SHSY5Y-BAG1-Zellen (b) zeigte sich eine etwas kräftigere Expression des Transgens.
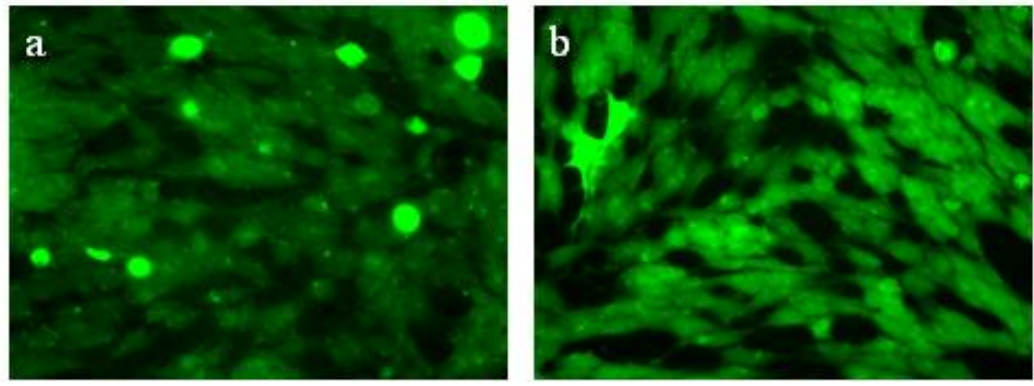

Abb. 16 Transfektionskontrolle (20x Objektiv). pEGFP-N1 in SH-SY5Y-pcDNA3.1- (a) und SH-SY5YBAG1-Zellen (b). 
Im Toxizitätsassay findet sich in den SH-SY5Y-pcDNA3.1-Zellen eine signifikant erhöhte Toxizität von A30P ( $p<0,001$ im Student-T-Test) und A53T ( $p<0,01$ im Student-T-Test) gegenüber $\alpha$-Syn-WT. Weiterhin findet sich ein protektiver Effekt $(\mathrm{p}<0,05$ im Student-TTest) von BAG1 gegenüber der durch die Mutanten A30P und A53T induzierten Toxizität. Als Leerwert wurden in diesem Assay mit dem pcDNA3.1-Leervektor-transfizierte Zellen verwendet. Für Syn-WT fand sich kein signifikanter Unterschied zwischen den stabil pcDNA3.1- und den stabil BAG1-überexprimierenden Zellen. In der Abb. 17 ist ein exemplarischer Assay gezeigt.

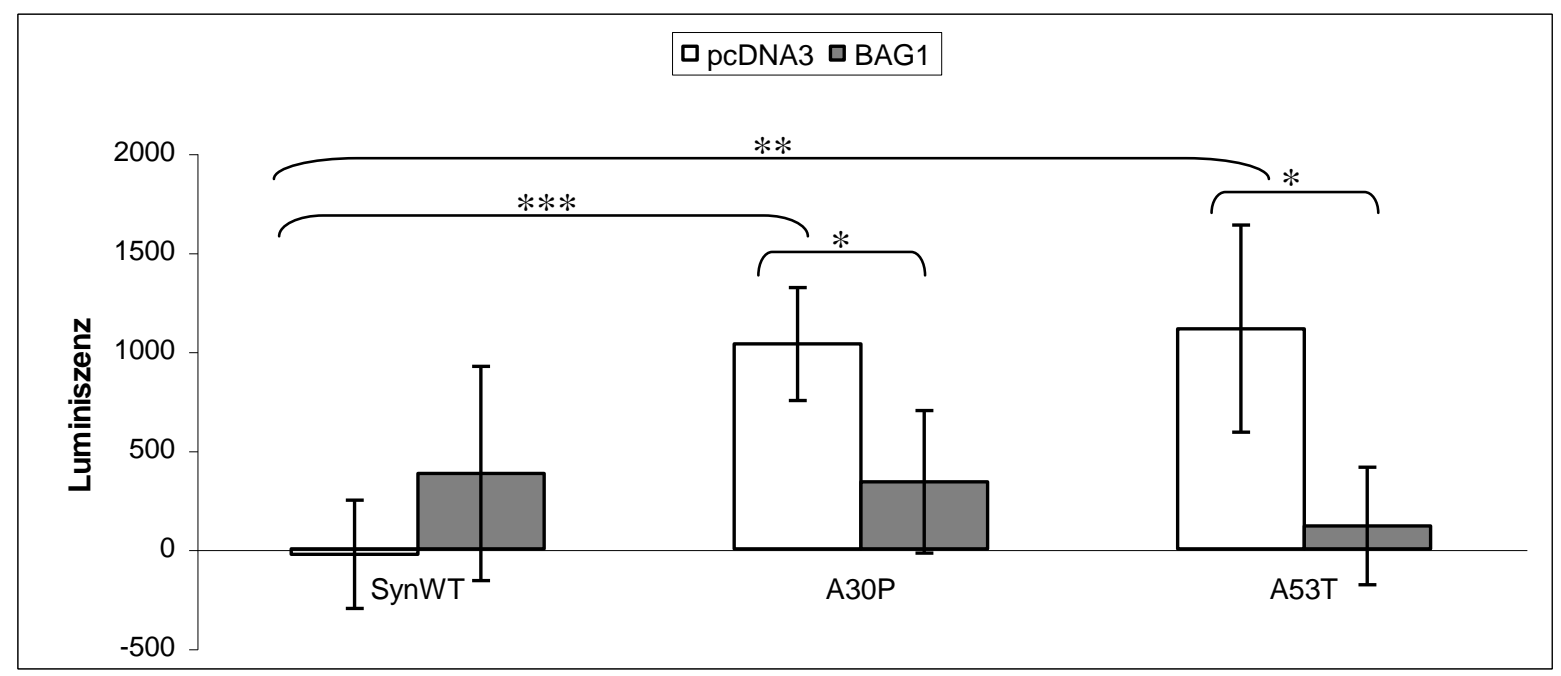

Abb. 17 Zelltod im a-Syn-Modell. SH-SY5Y-Zellen. Fehlerbalken: Standardabweichung. *: p<0,05, **: p<0,01, ***: p<0,001. Für die Mutanten A30P und A53T findet sich ein signifikanter, protektiver Effekt durch BAG1.

\subsection{BAG1 IN VIVO}

\subsubsection{AAV-BAG1-EGFP und AAV-EGFP transduzieren dopaminerge Neurone}

BAG1 wurde in der SNpc von C57BL/6-Mäusen überexprimiert, um eine Neuroprotektion von BAG1 im MPTP-Modell nachzuweisen. Zu diesem Zweck wurde ein BAG1exprimierender AAV-2-Vektor genutzt, der zusätzlich ein fluoreszierendes Reporter-Protein (EGFP) exprimierte. Dies sollte das Auffinden der transduzierten Neurone vereinfachen. Als Kontrollvektor wurde ein AAV-2-Vektor, der zwar das Reporter-Protein, aber kein funktionelles Transgen exprimierte, injiziert. Der AAV-2-Serotyp wurde wegen seiner besonders guten Fähigkeit zum Transfizieren von dopaminergen Neuronen der SNpc ausgewählt (Paterna et al. 2004). Auch der hSyn1-Promotor fördert die selektive neuronale Expression (Schoch et al. 1996). Nach stereotaktischer Injektion von je 1,52 x $10^{8}$ i.u. des AAV-BAG1-EGFP-Vektors, sowie des AAV-EGFP-Kontrollvektors, konnten eine effiziente EGFP-Expression detektiert werden. Durch eine zusätzliche TH-Färbung der Schnitte konnte 
die Kolokalisation des EGFP-Reporters mit der SNpc visualisiert werden ( Abb. 18 a-c). Die effiziente Transduktion, nicht nur der Region der SNpc, sondern auch der dopaminergen Neurone, wurde über eine Kolokalisation des EGFP-Reporter-Proteins mit TH-positiven Neuronen detektiert. Es findet sich eine Kolokalisation von EGFP und TH sowohl auf den mit AAV-BAG1-EGFP ( Abb. 18 d-f) als auf den AAV-EGFP ( Abb. 18 g-i) transduzierten Schnitten.
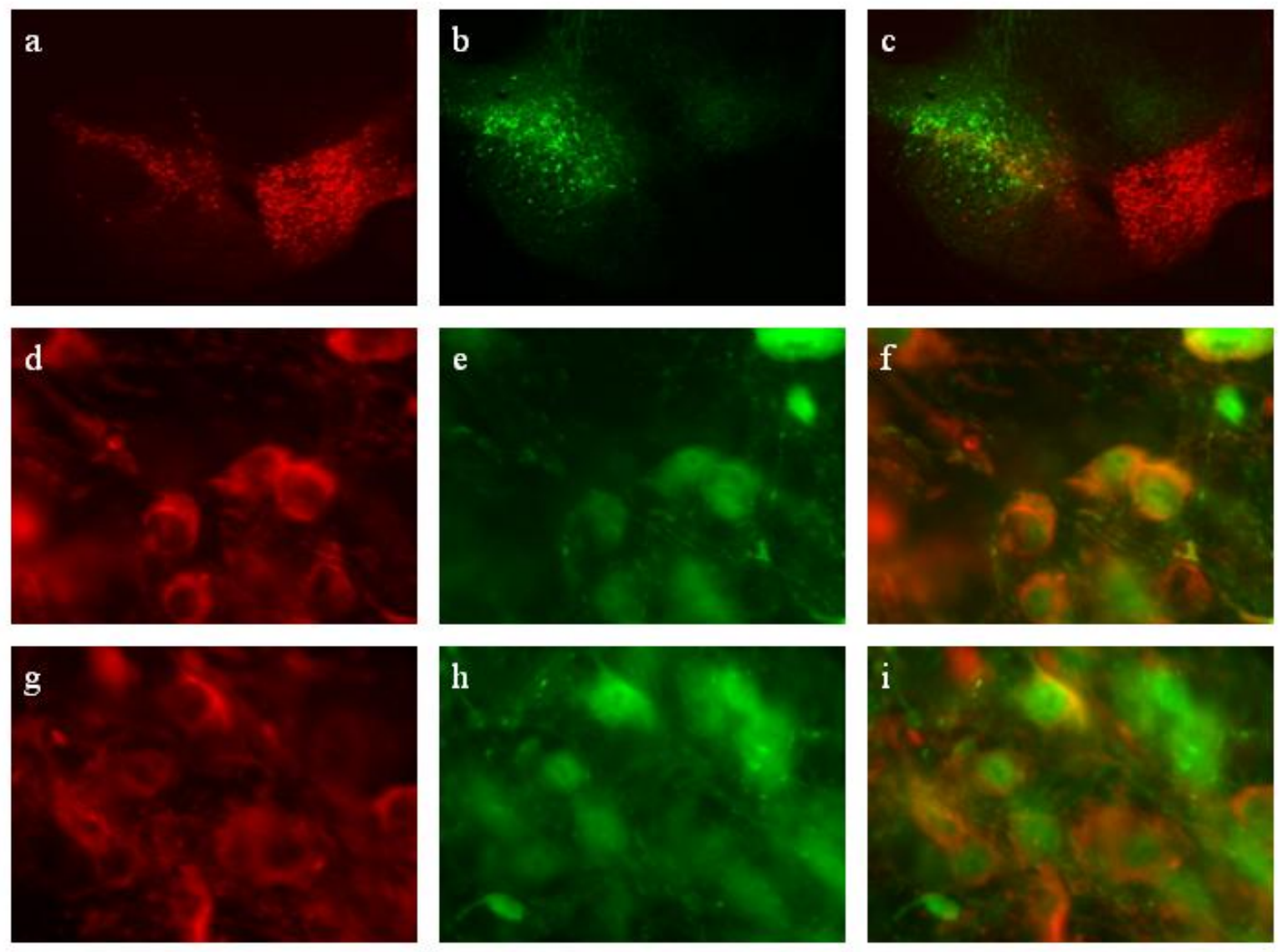

Abb. 18 TH-Färbung. a-c: AAV-BAG1-EGFP (5x Objektiv). a: TH-Färbung, b: EGFP-Reporter; c: Überlagerung. Das durch das Virus transduzierte EGFP kolokalisiert mit der SNpc. d-e: AAV-BAG1EGFP (40x Objektiv). d: TH-Färbung, e: EGFP-Reporter; f: Überlagerung. TH-positive Neurone kolokalisieren mit dem durch das Virus transduzierte EGFP. g-i: AAV-EGFP (40x Objektiv). g: THFärbung, h: EGFP-Reporter; i: Überlagerung. TH-positive Neurone kolokalisieren mit dem durch das Virus transduzierte EGFP.

Da der AAV-BAG1-EGFP-Vektor BAG1 und EGFP unter verschiedenen Promotoren exprimiert, wurde zusätzlich eine BAG1-Färbung durchgeführt. Da sowohl der BAG1 als auch der TH-Antikörper aus dem Kaninchen stammen, war hier keine Doppelfärbung möglich. Das EGFP-Reporter-Protein und BAG1 kolokalisieren (Abb. 19), sodass deutlich wird, dass beide Kassetten des Vektors aktiv sind. Zellen, die das virustransduzierte EGFP exprimieren, exprimieren auch das virustransduzierte BAG1. 

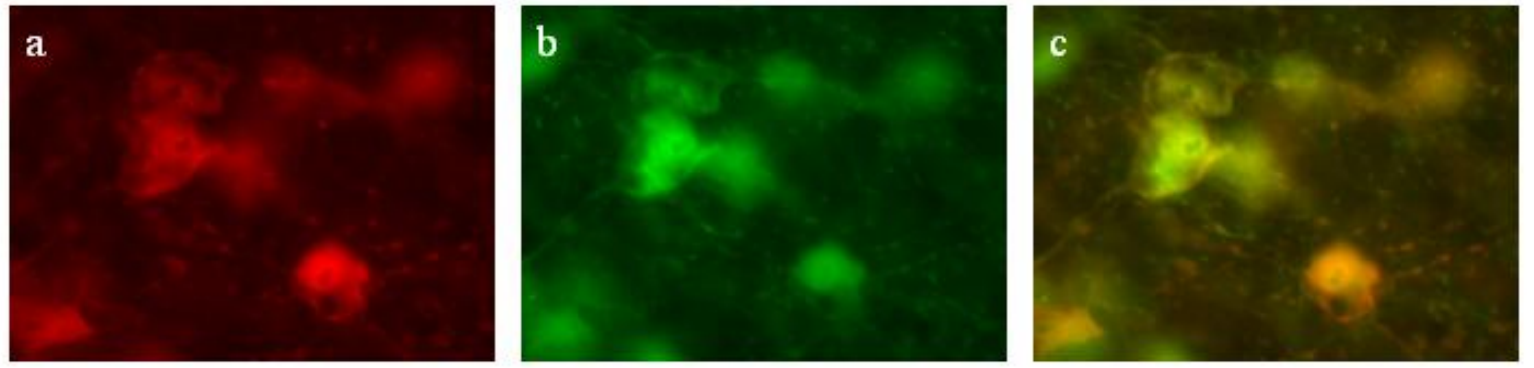

Abb. 19 BAG1 Färbung. AAV-BAG1-EGFP (40x Objektiv). a: BAG1-Färbung, b: EGFP-Reporter; c: Überlagerung. Das AAV-BAG1-EGFP exprimiert BAG1 und EGFP unter verschiedenen Promotoren. EGFP und BAG1 kolokalisieren, somit sind beide Promotoren aktiv.

\subsubsection{MPTP führt zu signifikantem Zelltod in der SNpc}

Durch das Auszählen der Neurone (TH- und Nissl-positive Zellen) im Bereich der SNpc wurde der durch die fünftägige MPTP-Applikation ausgelöste neuronale Zellverlust nachvollzogen. Ausgewertet wurden hierbei jeweils die nicht virusinjizierten SNpcs aller PBS-Tiere sowie die nicht virusinjizierten SNpcs aller MPTP-Tiere. In der Abb. 20 sind exemplarisch die SNpc eines PBS-Tieres (a) sowie eines MPTP-Tieres (b) dargestellt. Schon rein visuell ergibt sich hier ein deutlicher Zellverlust der TH-gefärbten Neurone durch die Behandlung mit MPTP.
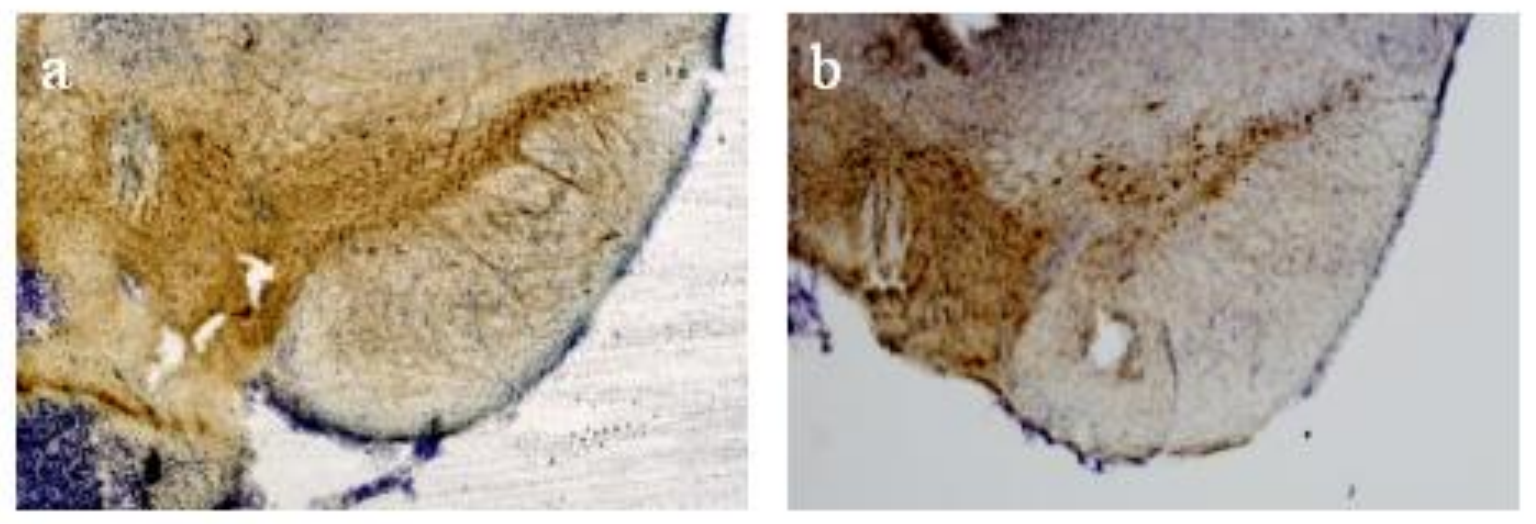

Abb. 20 Toxischer Effekt durch MPTP. SNpc ohne Virusinjektion (DAB+Nissl-Färbung). a: nicht virusinjizierte SNpc einer PBS-Maus, b: nicht virusinjizierte SNpc einer MPTP-Maus.

Nach stereologischem Auszählen ergibt sich dann anhand der ermittelten Zellzahlen eine signifikante Differenz der Zellanzahlen in den SNpcs von PBS- und MPTP-Tieren. Dies ist in der Abb. 21 dargestellt. Der durchschnittliche Zellverlust beträgt ca. $40 \%$. 


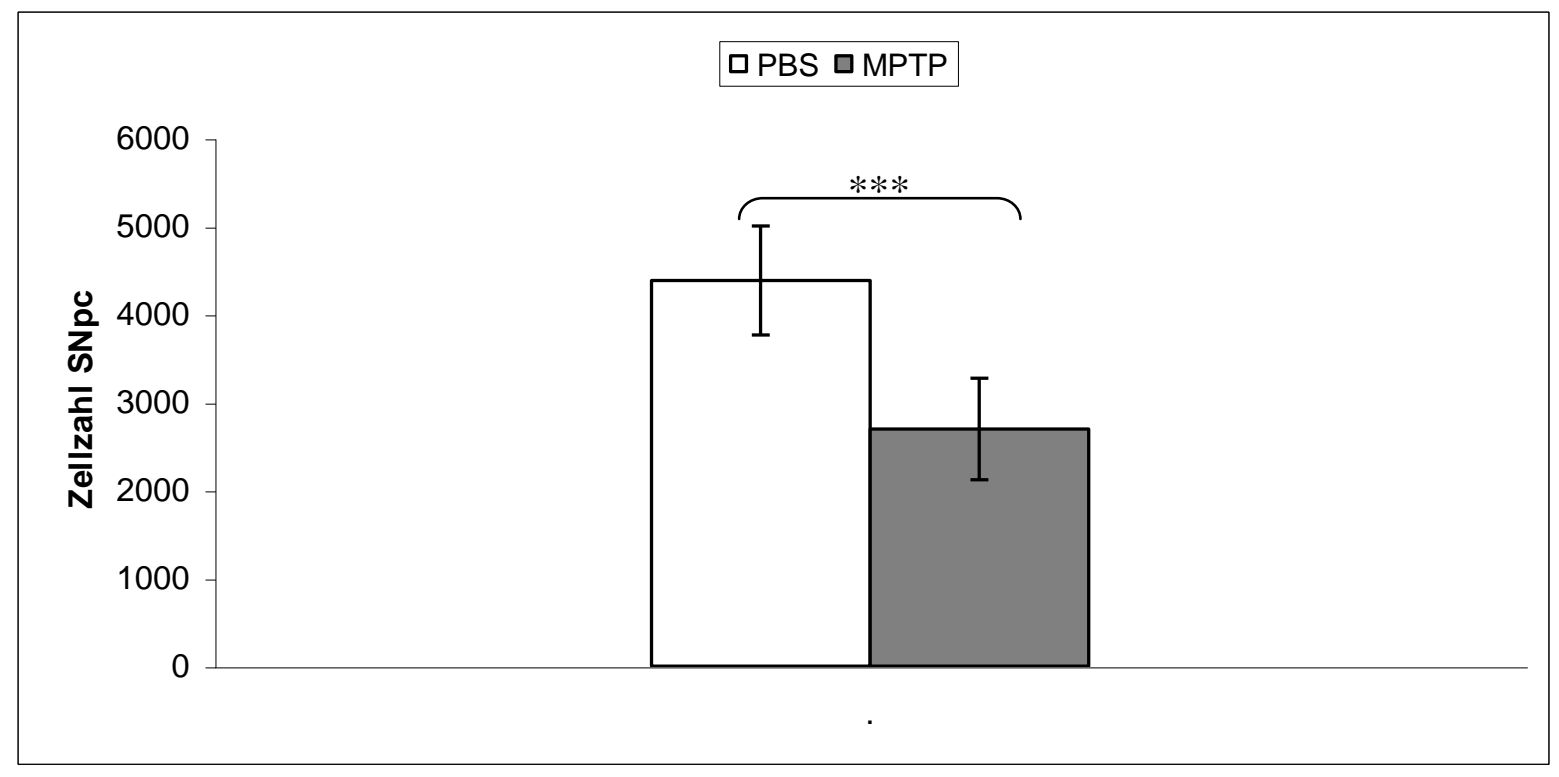

Abb. 21 Toxischer Effekt durch MPTP. Fehlerbalken: Standardabweichung. ***: p<0,001.

\subsubsection{Virus-Injektionen führen nicht zu signifikantem Zelltod in der SNpc}

Die Virusinjektion in die SNpc mittels einer Mikrokapillare stellt ein Trauma dar. In Abb. 22 ist die DAPI-Färbung einer AAV-BAG1-EGFP-injizierten Hemisphäre gezeigt. Der Stichkanal ist deutlich zu erkennen. Die höhere Dichte der durch die DAPI-Färbung sichtbar gemachten Zellkerne um den Injektionskanal gibt Hinweise auf das Einwandern von Zellen. Dabei handelt es sich höchstwahrscheinlich um Zellen des Immunsystems. Auch das Virus selbst führt wie alle AAV-2-Vektoren zu einer geringen Immunreaktion.

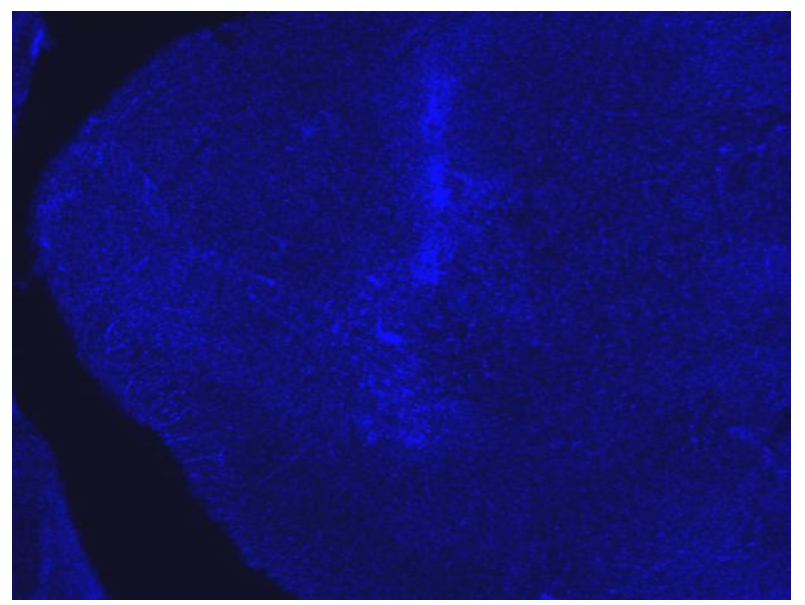

Abb. 22 DAPI-Färbung einer mit AAV-BAG1-EGFP injizierten Hemisphäre. Der Stichkanal ist deutlich zu erkennen.

In der Abb. 23 sind die virusinjizierten (a und c) sowie die nicht virusinjizierten Kontrollseiten ( $b$ und d) von PBS-Tieren gezeigt. Unterschiedliche Zellzahlen der beiden SNpcs sollten sich auf das Trauma der Virusinjektion zurückführen lassen. Im Vergleich der virusinjizierten und der nicht virusinjizierten Seiten scheint sich ein leichter Zellverlust in der 
SNpc sowohl durch die Injektion von AAV-BAG-EGFP (a und b) als auch durch Injektion von AAV-EGFP (c und d) abzuzeichnen.
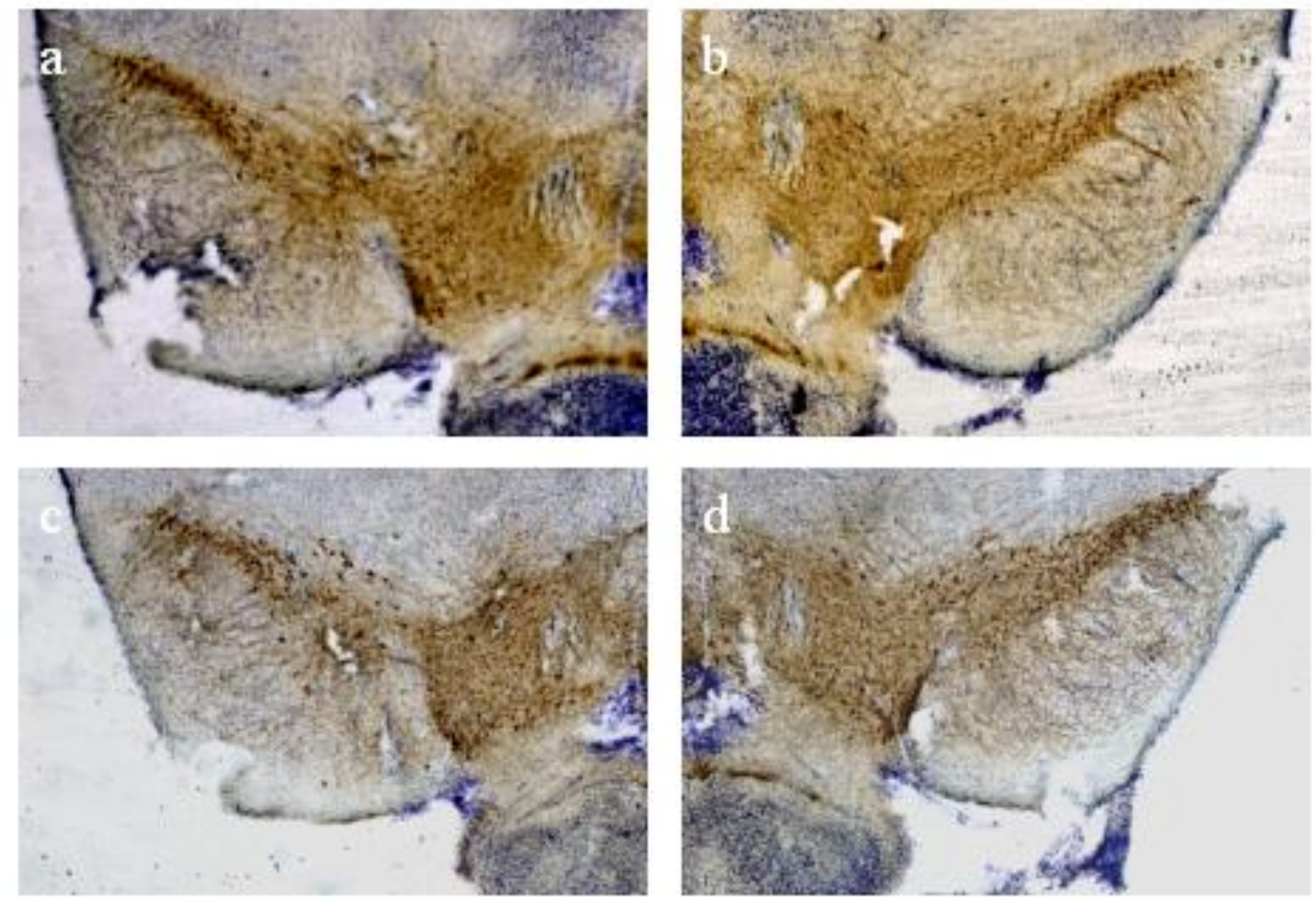

Abb. 23 Effekt durch Virusinjektion. Links SNpc mit Virusinjektion, rechts Hemisphären ohne Virusinjektion (DAB + Nissl-Färbung). a: Virusinjizierte SNpc einer AAV-BAG1-EGFP + PBSMaus, b: Nicht virusinjizierte SNpc einer AAV-BAG1-EGFP + PBS-Maus, c: Virusinjizierte SNpc einer AAV-EGFP + PBS-Maus, d: Nicht virusinjizierte SNpc einer AAV-EGFP + PBS-Maus.

In der erfolgten Auszählung der TH- und Nissl-positiven Zellen in der SNpc ergab sich allerdings weder durch das AAV-BAG1-EGFP noch durch das AAV-EGFP ein signifikanter Zellverlust gegenüber der nicht virusinjizierten Kontrollseite. Auch zwischen den AAVBAG1-EGFP- und den AAV-EGFP-injizierten SNpcs ergab sich kein signifikanter Unterschied. Ebenso ergab sich kein signifikanter Unterschied in den Zellzahlen der nicht virusinjizierten SNpcs. Damit haben die Injektionen von AAV-BAG1-EGFP und AAV-EGFP keine signifikanten Auswirkungen auf die Zellzahlen in der SNpc. 


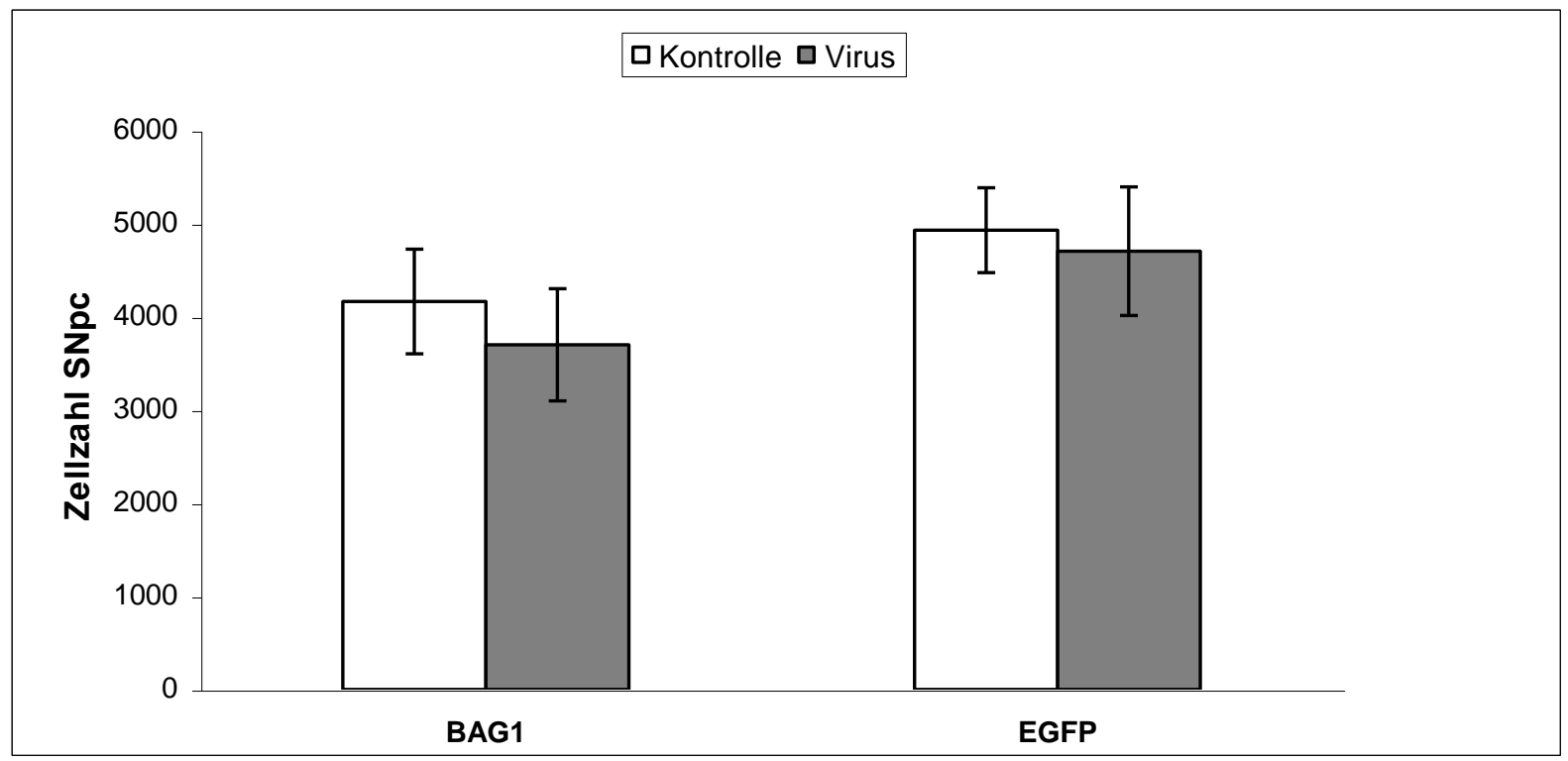

Abb. 24 Effekt durchVirusinjektion in die SNpc. PBS-Tiere. Fehlerbalken: Standardabweichung

\subsubsection{Kein protektiver Effekt durch BAG1 gegenüber der Kontroll-SNpc}

Wie oben gezeigt (3.2.2) ist durch die Applikation von MPTP mit einem Zellverlust von ca. $40 \%$ zu rechnen. Die Arbeitshypothese bestand darin, dass BAG1 gegen die durch MPTP induzierte Toxizität zu schützen vermag. In Abb. 25 sind die SNpcs einer MPTP-Maus gezeigt (a: virusinjizierte Seite, b: nicht virusinjizierte Seite). Damit konnte die nicht virusinjizierte Seite im selben Tier als Kontrolle dienen.
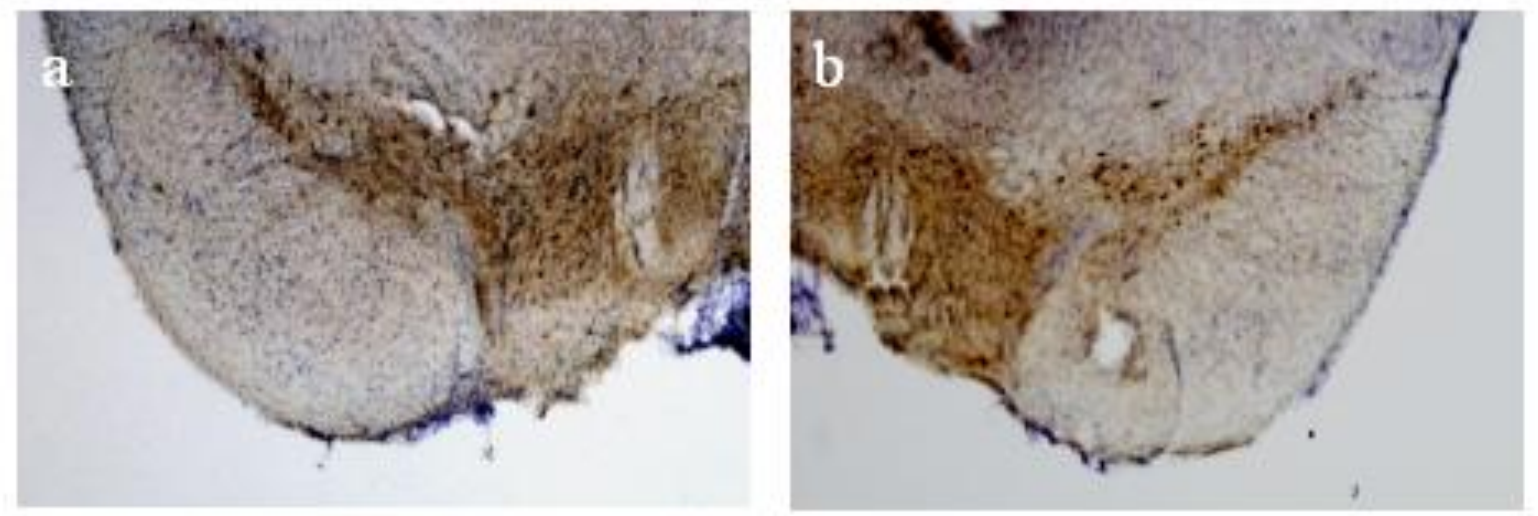

Abb. 25 Effekt durch BAG1 gegenüber der nicht virusinjizierten SNpc. MPTP-Maus (DAB + NisslFärbung). a: Virusinjizierte SNpc einer AAV-BAG1-EGFP + MPTP-Maus, b: Nicht virusinjizierte SNpc einer AAV-BAG1-EGFP + MPTP-Maus.

Es wurden deshalb die virusinjizierten und die nicht virusinjizierten SNpcs aller AAV-BAG1EGFP-injizierten MPTP-Tiere ausgezählt. Dabei ergab sich kein signifikanter Unterschied zwischen der virusinjizierten und der Kontrollseite (Abb. 26). 


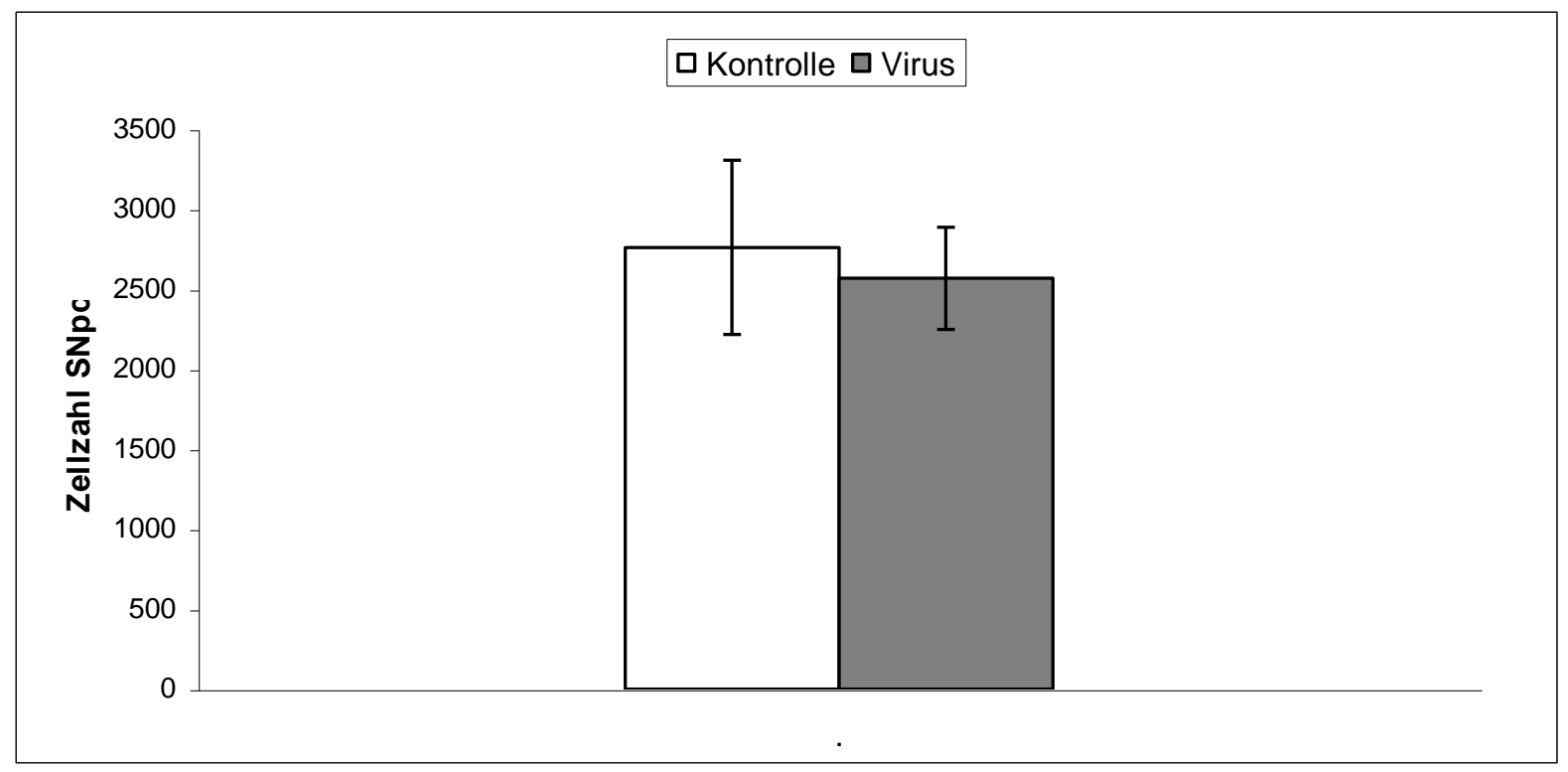

Abb. 26 Effekt durch Virusinjektion in die SNpc. MPTP-Mäuse. Fehlerbalken: Standardabweichung. Kein signifikanter Unterschied zwischen virusinjizierter und Kontrollseite.

\subsubsection{Protektiver Effekt durch BAG1 gegenüber dem Kontrollvirus}

Im Vergleich zur nicht virusinjizierten SNpc hatte sich kein protektiver Effekt von BAG1 zeigen können. Da mit erhöhtem Stress der Neurone durch die Virusinjektion gerechnet werden musste, sind die AAV-BAG1-EGFP-injizierten SNpcs außerdem mit AAV-EGFPinjizierten SNpcs verglichen worden. In Abb. 27 ist links (a) eine AAV-BAG1-EGFPinjizierte SNpc und rechts (b) eine AAV-EGFP-injizierte SNpcs von MPTP-Tieren dargestellt. Visuell ergibt sich hier ein protektiver Effekt des AAV-BAG1-EGFP-Vektors gegenüber dem AAV-EGFP-Kontrollvektor.
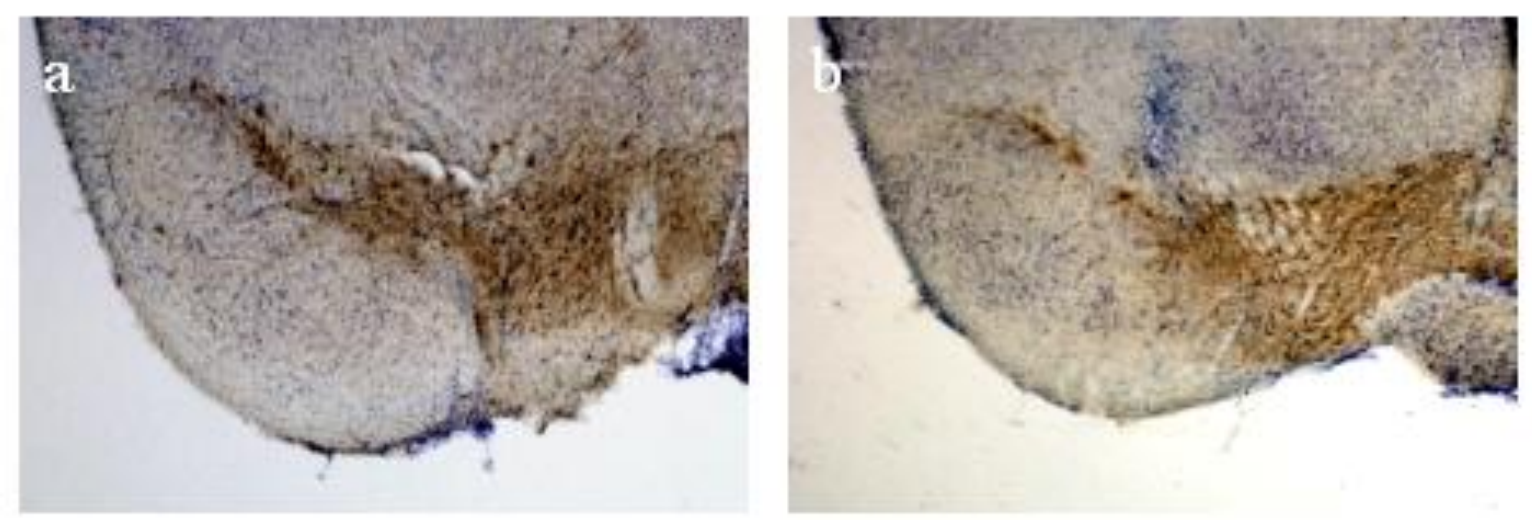

Abb. 27 Effekt von AAV-BAG1-EGFP versus AAV-EGFP. MPTP-Mäuse. Virusinjizierte SNpc (DAB + Nissl-Färbung). a: virusinjizierte SNpc einer AAV-BAG1-EGFP + MPTP-Maus, b: virusinjizierte SNpc einer AAV- EGFP + MPTP-Maus.

In der sterologischen Auswertung (Abb. 28) der SNpcs konnte dies bestätigt werden. Verglichen wurden die virusinjizierten SNpcs von AAV-BAG1-EGFP- bzw. AAV-EGFP- 
injizierten MPTP-Tieren. Hierbei ergibt sich ein signifikanter Unterschied ( $p<0,05 \mathrm{im}$ Student T-Test) zwischen den beiden Gruppen. Ebenso wurden die assoziierten, nicht virusinjizierten Kontrollseiten in denselben Tieren betrachtet. Hier fand sich kein signifikanter Unterschied zwischen den beiden Gruppen.

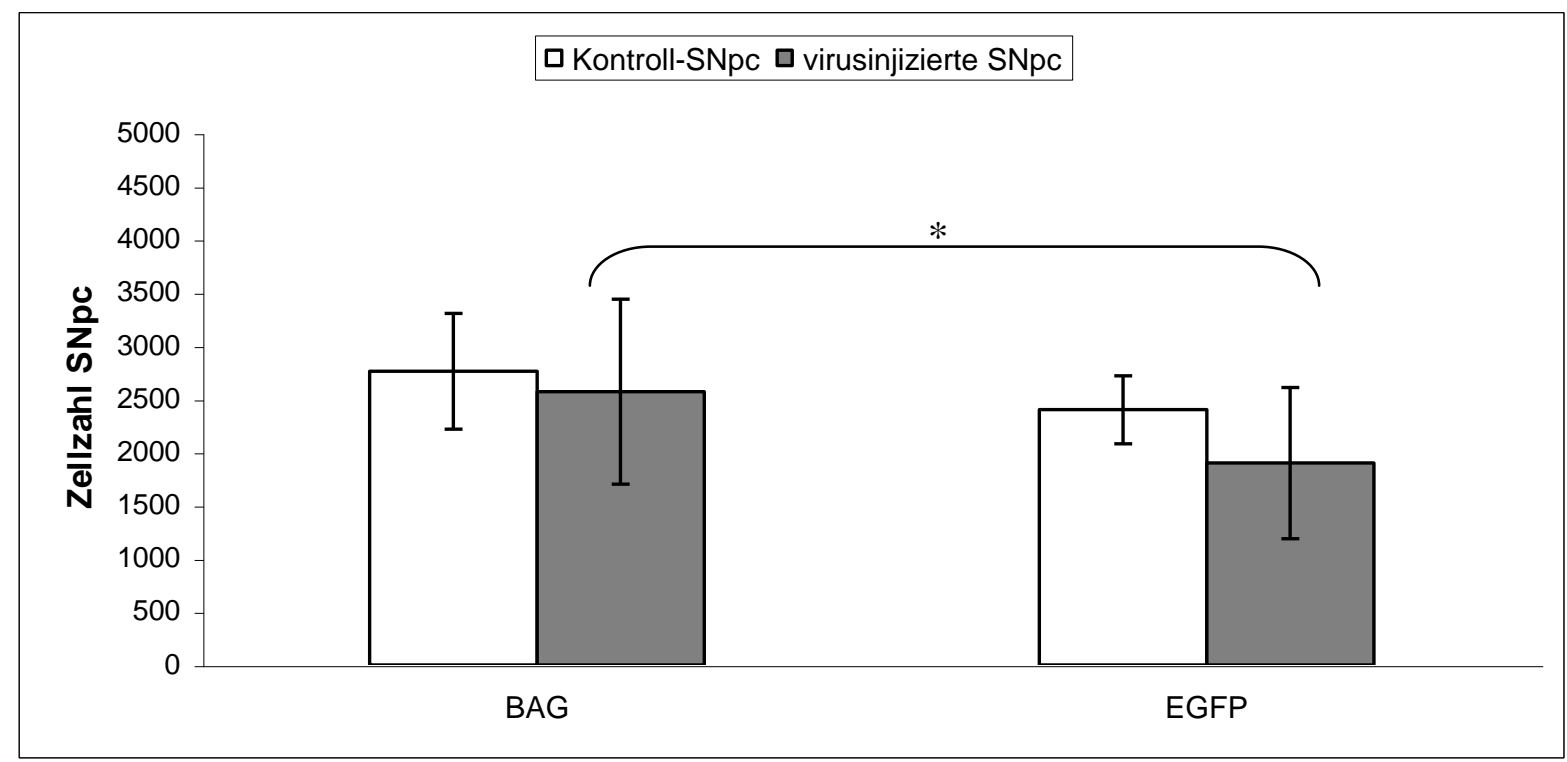

Abb. 28 Neuroprotektiver Effekt von AAV-BAG1-EGFP versus AAV-EGFP. MPTP-Mäuse. Fehlerbalken: Standardabweichung. *:p<0,05 


\section{DISKUSSION}

Was ist verantwortlich für den Untergang der dopaminergen Neurone beim IPS? Auf diese Frage gibt es bis jetzt keine zufriedenstellende Antwort. Diskutiert werden oxidativer Stress, mitochondriale Dysfunktion, proteasomale Dysfunkion und verminderte Autophagie. Eine wichtige Rolle in der Pathogenese des IPS scheint außerdem das Protein $\alpha$-Syn zu spielen. Den vielen unterschiedlichen neurodegenerativen Mechanismen entsprechend gibt es eine große Zahl unterschiedlicher Parkinson-Modelle, die alle einen Teil der möglichen Pathogenese abbilden. In der vorliegenden Arbeit wurde das Co-Chaperon BAG1 in drei verschiedenen in-vitro-Modellen und in einem in-vivo-Modell des IPS getestet, um ein möglichst umfassendes Bild zu generieren.

\subsection{BAG1 IN VITRO}

\subsubsection{Toxin-assoziierte Modelle: 6-Hydroxydopamin und Rotenon}

In der vorliegenden Arbeit ist das Co-Chaperon BAG1 als vielversprechendes neuroprotektives Target in zwei verschiedenen Toxin-assoziierten Zellkulturmodellen getestet worden. Dabei ergab sich kein schützender Effekt von BAG1 in Bezug auf 6-OHDAinduzierte Toxizität. Gegen das Neurotoxin Rotenon erwies sich BAG1 als protektiv, dies allerdings nur für geringe Rotenon-Konzentrationen $(0,25 \mu \mathrm{mol} / \mathrm{l})$. Bei höheren Konzentrationen konnte kein Unterschied zwischen den BAG1-überexprimierenden Zellen und der Kontrollgruppe ermittelt werden. Möglicherweise ist der durch BAG1 vermittelte Effekt nicht stark genug, um eine mit höheren Konzentrationen massiv aktivierte Apoptosekaskade aufzuhalten.

6-OHDA kann über verschiedene Mechanismen zum Zelltod führen. Durch Autooxidation von 6-OHDA entstehen freie Radikale und andere ROS (Bové et al. 2005), welche Zellbestandteile zerstören können. Daneben werden die Spiegel antioxidativer Proteine vermindert (Perumal et al. 1992), womit die Zelle ihren Schutz gegen freie Radikale verliert. Zuletzt hemmt 6-OHDA in isolierten Mitochondrien direkt den Komplex I der Atmungskette (Glinka et al. 1996), was über ATP-Mangel und den damit einhergehenden oxidativen Stress zum Zelltod führen könnte. Da sich der ATP-Mangel in mit 6-OHDA behandelten SH-SY5YZellen nicht nachweisen lässt (Storch et al. 2000, Wu et al. 1996), wird dies wahrscheinlich nicht der Hauptmechanismus sein (Blum et al. 2001). Rotenon wirkt dagegen vor allem über die Hemmung des Komplex I der Atmungskette (Sherer et al. 2003). Es beeinträchtigt hier die 
Funktion der Nikotinamid-Adenin-Dinukleotid-Ubiquinon-Reduktase, womit die oxidative Phosphorylierung gestört wird (Schuler und Casida 2001), und es in der Folge über den entstehenden zellulären Energiemangel zum Zelltod kommt. Daneben hemmt es die Bildung von Mikrotubuli, womit sich vermehrt Tubulin-Monomere ansammeln, welche toxisch wirken können (Burke et al. 1989). Zusammenfassend kann also gesagt werden, dass 6OHDA wahrscheinlich primär über die Formation von ROS und ihrer Auswirkungen auf die Zellen den Zelltod herbeiführt. Dies wird dadurch belegt, dass die Inkubation 6-OHDAbehandelter Zellen mit Katalasen, die unter anderem Wasserstoffperoxid spalten, was diesem seine toxische Potenz nimmt, die durch 6-OHDA-induzierte Toxizität aufzuheben vermag (Hanrott et al. 2006). Rotenon dagegen wirkt wohl primär über die Inhibierung der mitochondrialen Atmungskette und der darauf folgenden Induktion von Apoptosekaskaden toxisch. Demnach hätte BAG1 nur schützende Funktion bei durch mitochondriale Dysfunktion initiiertem Zelltod, nicht aber bei primär durch oxidativen Stress herbeigeführter Degeneration. $\mathrm{Zu}$ vermuten ist also, dass sich die durch 6-OHDA und Rotenon ausgelösten Zelltodkaskaden unterscheiden und BAG1 deshalb nur im Rotenon-Modell protektiv wirkt. Die genauen Zelltodmechanismen beider Toxine sind allerdings nicht vollständig geklärt. Es existeren aber zahlreiche Publikationen, die sich mit dieser Frage beschäftigen. 6-OHDA scheint die intrazellulären Level an Bax, einem proapoptotisch wirksamen Protein, zu erhöhen (Mladenovic et al. 2004). Ebenso erhöht auch Rotenon die intrazellulären Level an Bax (Gill und Perez-Polo 2009). Daneben aktivieren sowohl Rotenon als auch 6-OHDA den c-JnkSignalweg (Newhouse et al. 2004, Rodriguez-Blanco et al. 2008). Der effektive Zelltod scheint bei beiden Toxinen über die Aktivierung von verschiedenen Caspasen zu laufen, wobei zum Teil die gleichen, zum Teil aber auch unterschiedliche Caspasen aktiviert werden (Ahmadi et al. 2003, Hanrott et al. 2006, Kitamura et al. 2002). Es existieren widersprüchliche Arbeiten darüber, welche Typen von Caspasen bei den einzelnen Toxinen tatsächlich involviert sind (Ebert et al. 2008, Hanrott et al. 2006, Tanaka K et al. 2006). Auch das unterschiedliche Muster der Caspasen-Aktivierung ist mögliche Ursache für die verschiedene Wirkung von BAG1 in beiden Toxinmodellen. Zusammengenommen kann aber kein klarer, definitiver Unterschied der in die Zelltodkaskade involvierten Faktoren aufgezeigt werden, sodass unklar bleibt, warum BAG1 sich in Hinblick auf Rotenon-induzierte Toxizität als schützend erweist, nicht aber gegenüber 6-OHDA induzierter Toxizität.

Generell kann BAG1 auf verschiedene Arten neuroprotektiv wirken. Zuerst vermag BAG1 den antiapoptotischen Effekt von Bcl-2 zu unterstützen (Schulz et al. 1997, Takayama et al. 1995). So ist die Beinflussung von Bcl-2 ein möglicher Mechanismus wie BAG1 seine 
schützende Wirkung entfalten kann. Zur Wirkung von Bcl-2 auf die Toxizität von 6-OHDA liegen allerdings wiedersprüchliche Arbeiten vor. So schützt die Überexpression von Bcl-2 in Kulturen von primären kortikalen Neuronen und in der SNpc von Ratten gegen 6-OHDAinduzierten Zelltod (Yamada et al. 1999). Dagegen konnte in Kulturen mesencephaler Neurone aus Bcl-2 transgenen Mäusen kein schützender Effekt gegenüber 6-OHDA nachgewiesen werden (O'Malley et al. 2003). Auch Rotenon betreffend existieren sowohl Berichte über einen schützenden Effekt von Bcl-2 (Muscarella et al. 2003), als auch Arbeiten in denen ein solcher schützender Effekt nicht nachgewiesen werden konnte (Wolvetang et al. 1994). Daneben kann BAG1 auch über die Induktion der Hitzeschockproteine Hsc/Hsp70 den toxinbedingten oxidativen Schaden vermindern, was einen protektiven Effekt zur Folge hätte. Interessant ist weiterhin, dass in einem kürzlich publizierten Artikel von einer verminderten Rotenon-Toxizität durch die Induktion von Autophagie berichtet wurde (Dadakhujaev et al.), denn auch in diesem Bereich könnte BAG1, möglicherweise über CHIP, Einfluss nehmen und seine neuroprotektive Potenz entfalten.

\subsection{2 $\alpha$-Synuclein}

Die Überexpression von $\alpha$-Syn in der Zellkultur ist ein gängiges Parkinson-Modell. In der vorliegenden Arbeit wurden $\alpha$-Syn und seine Mutanten A30P und A53T in der nigralen Rattenzelllinie CSM14.1 und der Neuroblastomzelllinie SH-SY5Y transient überexprimiert. Anschließend wurden im Western Blot (CSM14.1) die Auswirkungen von BAG1 auf die Aggregationsneigung von $\alpha$-Syn und im Toxizitätsassay (SH-SY5Y) die potentielle neuroprotektive Wirkung von BAG1 untersucht. Hierbei zeigte sich, dass BAG1 zu vermehrter Aggregation von A30P und A53T, nicht aber von $\alpha$-Syn-WT führt. Weiterhin verhält es sich protektiv gegen die durch A30P und A53T induzierte Toxizität. Für $\alpha$-Syn-WT konnte ein solcher protektiver Effekt nicht nachgewiesen werden.

\subsubsection{Aggregate}

In der vorliegenden Arbeit erfolgte erstmalig die Überexpression von $\alpha$-Syn in CSM14.1Zellen, weshalb hierzu keine Vordaten existieren. Die $\alpha$-Syn Aggregate ließen sich in den Western Blots nur nach vorheriger Behandlung der Lysate mit einem Crosslinker, der die Aggregate stabilisiert, nachweisen. Es handelt sich somit um ein hochartifizielles Modell. Durch vorheriges Auszählen der Zellen wurde sichergestellt, dass in jedem Lysat die gleiche Menge Crosslinker pro Zelle appliziert wurde, sodass die einzelnen Lysate miteinander vergleichbar waren. Die CSM14.1-Zellen fanden in diesem Experiment Verwendung, da sie 
nicht sehr vulnerabel sind und somit eine große Proteinausbeute für den Western Blot erreicht werden konnte.

In der Literatur finden sich Angaben zur Überexpression von $\alpha$-Syn in SH-SY5Y-Zellen. Hier konnten bei Überexpression von WT- $\alpha$-Syn, der A30P- und A53T-Mutante in SHSY5Y-Zellen per Lipofektion ebenfalls Aggregate in den Zellen nachgewiesen werden (Pandey et al. 2006). Dabei fanden sich mehr Aggregate in den A53T-transfizierten Zellen als in den mit WT- $\alpha$-Syn-transfizierten Zellen. Die wenigsten Aggregate fanden sich in A30Ptransfizierten Zellen (Pandey et al. 2006), eine Entdeckung, die mit vorher durchgeführten Fibrillisationsstudien der mutierten Formen des $\alpha$-Syn im Einklang steht (Conway et al. 2000). Mit den hier erhobenen Daten konnte dies nicht bestätigt werden. In den CSM14.1WT-Zellen finden sich insgesamt kaum große Aggregate, am ausgeprägtesten sind diese noch in den mit SynWT transfizierten Zellen zu finden. Dieser Wiederspruch zur Literatur mag zum einen mit der verwendeten Zelllinie, zum anderen aber auch mit der Art der Lysate, die ja Crosslinker-stabilisiert sind, zusammenhängen. Auch in der Literatur existieren aber widersprüchliche Berichte zur Aggregationsneigung (Narhi et al. 1999, Pandey et al. 2006), insbesondere auch unter verschiedenen Zellkulturbedingungen (Hoyer et al. 2002).

Selbst wenn aber durch den verwendeten Crosslinker eine Vergleichbarkeit der Aggregation für die verschiedenen Formen des $\alpha$-Syn nicht sicher gegeben sein sollte, so sollten doch innerhalb einer $\alpha$-Syn-Kondition CSM14.1-WT- und CSM14.1-BAG1-Zellen vergleichbar sein. In den mit A30P und A53T transfizierten stabil BAG1-überexprimierenden Zellen fanden sich ausgeprägte, höhermolekulare Aggregate, die in den jeweiligen WT-Zellen nicht in dieser Ausprägung nachgewiesen werden konnten. Dieser proaggregatorische Effekt von BAG1 konnte in den mit $\alpha$-Syn-WT transfizierten Zellen nicht nachgewiesen werden. In der Literatur findet sich ein aggregationshemmender Effekt von BAG1 im Huntingtonmodell (Jana und Nukina 2005). In Alzheimer-Modellen dagegen erhöht BAG1 die Level an TauProtein. Zudem findet sich in Tau-Tangels enthaltenden Neuronen und in den Hippokampi von Alzheimer-Patienten eine Hochregulierung von BAG1, was Hinweise auf einen proaggregatorischen Effekt liefert (Elliott et al. 2007, Elliott et al. 2009).

\subsubsection{Toxizität}

Um Aussagen über einen neuroprotektiven Effekt von BAG1 machen zu können, wurden WT- $\alpha$-Syn, die A30P- und die A53T-Mutante in SH-SY5Y-pcDNA3.1- und SH-SY5Y-

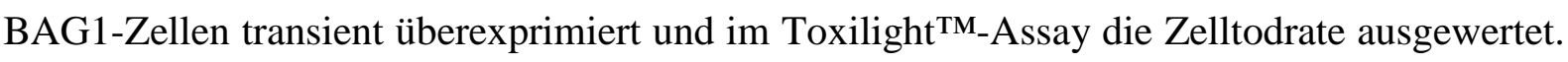
In diesem Fall fanden SH-SY5Y-Zellen Verwendung, da sie vulnerabler sind als CSM14.1 Zellen, in denen eine $\alpha$-Syn-induzierte Toxizität nicht zu detektieren war. In der vorliegenden 
Arbeit fand sich eine signifikant höhere Toxizität für die die A30P- und A53T-Mutante gegenüber WT- $\alpha-S y n$. Die Toxizität konnte für A30P und A53T durch BAG1 signifikant vermindert werden. Insgesamt wiesen diese Assays sehr hohe Standardabweichungen auf, was mit der insgesamt prozentual geringen Toxizitätsrate zusammenhängt. Verglichen mit einer ToxiLight ${ }^{\mathrm{TM}}$ 100\% Lysis Kontrolle, wie sie für die Toxin-assoziierten Assays (3.1.4.1, S. 58, 3.1.4.2, S. 59) verwendet wurde, konnte durch $\alpha$-Syn und seine Mutanten nur ein maximaler Zelltod von ca. $5 \%$ erreicht werden. Dies ist der Grund dafür, dass hier statt der prozentualen Auftragung der Daten eine absolute Darstellung gewählt wurde. Da der Assay auf der Feisetzung der Adenylatkinase aus zu Grunde gegangenen Zellen beruht, war es wichtig, auf gleiche Zelldichten zu achten (Abb. 16, S. 60). Während äquivalente Anzahlen an pcDNA3.1- oder auch BAG1-Zellen transfiziert worden sind, scheint die eigentliche $\alpha$ Syn-Expression (Abb. 16, S. 60) sogar in den BAG1-Zellen stärker zu sein. Dies sollte, auf Grund der höheren Menge an toxischem $\alpha$-Syn, sogar eher mit einer höheren Toxizität assozziert sein. Somit wird der protektive Effekt durch BAG1 in diesem Fall eventuell noch unterschätzt. Um die reine Transfektionstoxizität aus dem Assay zu eliminieren, wurde von jedem Wert eine mit dem Leervektor pcDNA3.1 transfizierte Kontrolle subtrahiert. Damit sollte auch eine mögliche stärkere Vulnerabilität von pcDNA3.1- oder auch BAG1-Zellen gegenüber dem Vorgang der Transfektion nicht mehr ins Gewicht fallen. In den durchgeführten Assays konnte somit ein neuroprotektiver Effekt durch BAG1 nachgewiesen werden. Direkte neuroprotektive Effekte von BAG1 finden sich in der Literatur beschrieben im Schlaganfall- (Kermer et al. 2003) und im Huntington-Modell (Orr et al. 2008, Sroka et al. 2009). Daneben hat BAG1 neuroregenerative Effekte (Planchamp et al. 2008). BAG1Knockout-Mäuse sterben schon in der Embryogenese durch eine fehlerhafte Entwicklung des Nervensystems (Götz et al. 2005), was auf eine wichtige Rolle von BAG1 für das neuronale Überleben schließen lässt.

\subsubsection{Aggregation und Toxizität}

Fraglich bleibt in diesem Kontext weiterhin, über welchen Mechanismus $\alpha$-Syn und seine Mutanten ihre toxische Wirkung entfalten. In der Literatur wird vor allem eine Toxizität durch $\alpha$-Syn-Oligomere postuliert. Sind es tatsächlich die Protofibrillen, die toxisch sind, ist anzunehmen, dass eine Blockierung der Fibrillenbildung ohne die Bildung der Protofibrillen zu inhibieren zu verstärkter Neurodegeneration führen könnte (Goldberg und Lansbury 2000), während eine Blockierung sowohl von Fibrillen- als auch von Protofibrillenbildung neuroprotekiv wirken müsste (Hashimoto et al. 2001). Rein theoretisch wäre es innerhalb dieses Konstruktes sogar möglich, dass das native, ungefaltetete $\alpha$-Syn die eigentlich toxische 
Struktur ist (Cookson 2009). Insgesamt bleibt also fraglich, was genau die toxische Spezies darstellt und noch viel mehr, was nun genau für die Toxizität und den Zelltod verantwortlich ist. Die Sequestrierung von $\alpha$-Syn durch die Bildung von Fibrillen könnte zu einem Funktionalitätsverlust führen, sodass $\alpha$-Syn nicht mehr seiner eigentlichen Funktion nachkommen kann: Dopamin würde dann vermehrt in die Zellen aufgenommen aber ungenügend in synaptischen Vesikeln gespeichert (Lotharius und Brundin 2002), wodurch es zur Auto-Oxidation des Dopamins mit nachfolgender Radikalbildung kommen kann, was Zellstress und Zelltod verursachen könnte. Frei im Zytoplasma kann Dopamin leicht oxidiert werden, was ROS produziert, die wiederum $\alpha$-Syn in seiner Konformation stören und zur Bildung von Protofibrillen anregen. Somit entsteht ein Teufelskreis in dem $\alpha$-Syn selbst Ereignisse initiiert, die zu seiner eigenen oxidativen Schädigung beitragen. Andererseits könnten die Ereignisse auch völlig unabhängig von der Funktion des $\alpha$-Syn sein. Ausreichen würde eine alleinige toxische Wirkung der Protofibrillen, welche über die Formation toxischer Membranporen gegeben sein könnte (Volles und Lansbury 2002).

Die Daten der vorliegenden Arbeit zeigen nun, dass BAG1 die Formation großer Aggregate fördert und sich neuroprotektiv gegen durch $\alpha$-Syn induzierte Toxizität zeigt. Sind tatsächlich die Protofibrillen das toxische Substrat, so kann vermutet werden, dass BAG1 die Konzentration der Protofibrillen zu mindern vermag. Sei es über die direkte Förderung ihres Abbaus oder über die Förderung ihrer Zusammenlagerung zu größeren Aggregaten, die weniger toxische Potenz aufweisen.

Ein nicht zu unterschätzender Anteil des Abbaus von $\alpha$-Syn erfolgt über den Weg der CVA (Lee HJ et al. 2004, Paxinou et al. 2001, Vogiatzi et al. 2008). So erhöht die Hemmung der CVA die $\alpha$-Syn-Plasmakonzentration (Cuervo et al. 2004). Die Überexpression von A53T- $\alpha-$ Syn und zum Teil auch die Überexpression von WT- $\alpha$-Syn führt dagegen zur Hemmung der CVA (Xilouri et al. 2009). Die Degradation von $\alpha$-Syn über die CVA scheint an CHIP gebunden zu sein (Shin et al. 2005), ein Protein mit dem auch BAG1 in Zusammenhang steht (Alberti et al. 2002). So stimuliert die Überexpression von BAG1 beispielsweise die CHIPabhängige Degradation des Glucocorticoid-Rezeptors (Demand et al. 2001). Ein ähnlicher Mechanismus wäre hier auch für $\alpha$-Syn möglich. So könnte BAG1 z. B. über die Stimulation der CHIP-abhängigen CVA von $\alpha$-Syn zum Abbau der toxischen $\alpha$-Syn-Oligomere beitragen. Da bekannt ist, dass insbesondere die $\alpha$-Syn-Mutanten die CVA hemmen (Xilouri et al. 2009), wäre es möglich, dass BAG1 dort die Hemmung der CVA zum Teil kompensieren kann, was die beobachtete Neuroprotektion erklären könnte. 
Weiterhin ist BAG1 als ein mit Hsc/Hsp70 interagierendes Protein beschrieben worden. Unklar ist in diesem Zusammenhang, ob die Überexpression von BAG1 generell die Funktion der Hitzeschockproteine unterstützt oder hemmt (Gässler et al. 2001) In der verwendeten BAG1-transgenen CSM14.1-Zelllinie konnte allerdings eine erhöhte Chaperonaktivität nachgewiesen werden (Liman et al. 2005). Möglicherweise führt die Überexpression von BAG1 in der vorliegenden Arbeit dazu, dass insbesondere die Oligomere vermehrt Hsc/Hsp70-abhängig degradiert werden können. Interessant ist, dass auch in AlzheimerModellen die Überexpression von BAG1 zu mehr Aggregaten führt (Elliott et al. 2007). Dort scheint dies zum einen durch die Inhibierung der proteasomalen Degradation von Tau durch BAG1 und zum anderen durch die Interaktion von BAG1 mit Hsc/Hsp70 zu stande zu kommen (Elliott et al. 2007). Weiterhin konnte die Überexpression von BAG1 sowohl in TauTangles enthaltenden Neuronen von Mäusen, als auch in den Hippokampi von AlzheimerPatienten nachgewiesen werden (Elliott et al. 2007, Elliott et al. 2009). Interessant wäre es also in der Zukunft die Frage zu klären, ob eine solche Assoziation auch für $\alpha$-Syn-Aggregate in der SNpc von IPS-Patienten existiert.

\subsubsection{Generelle Probleme der in-vitro-Modelle}

Die in-vitro-Experimente wurden an immortalisierten neuronalen Zelllinien durchgeführt. Es handelt sich also um homogene Kulturen von proliferierenden Neuronen, was ein extrem artifizielles und vereinfachtes Modell darstellt. Zum einen fehlen Gliazellen, in deren Umgebung neuronale Zellen sich anders verhalten können. So erweist sich L-Dopa als toxisch gegenüber reinen neuronalen Zellkulturen. Sind dagegen auch Gliazellen in der Kultur vorhanden, birgt es sogar neurotrophische Potenz. Außerdem sind Neurone eigentlich postmitotische Zellen, die sich nicht mehr teilen und somit auch nicht regenerieren können, was das besonders Dramatische an neuronaler Degeneration ausmacht, und zuletzt sind die undifferenzierten neuronalen Zellen in der Zellkultur nicht in der Lage, ihre typischen neuronalen Netzwerke auszubilden, was ebenfalls nicht die Realität widerspiegelt.

Zusammenfassend kann man deshalb also sagen, dass sich Zellkulturmodelle natürlich eignen, um neuroprotektive Substanzen zu testen und grundlegende intrazelluläre Prozesse aufzudecken, dass man aber nicht darauf verzichten sollte, positive Ergebnisse im Tiermodell zu bestätigen. 


\subsection{BAG1 IN VIVO}

\subsubsection{Virusexpression in der SNpc}

Der Sinn eines viralen Gentransfers in die SNpc liegt darin begründet, eine möglichst lang anhaltende und stabile Expression des Transgens in den dopaminergen Neuronen zu ermöglichen. Um dies sicherzustellen, wurde als viraler Vektor der AAV-2-Serotyp gewählt, welcher eine besonders hohe Affinität zu den dopaminergen Neuronen in der SNpc aufweist (Paterna et al. 2004). Die effiziente und selektive Transduktion der SNpc durch AAV-2Vektoren konnte mehrmals gezeigt werden (Paterna et al. 2004, Shevtsova et al. 2006). Daneben wurde der hSyn1-Promotor gewählt, welcher ebenfalls eine neuronale Spezifität gewährleistet (Schoch et al. 1996). Die Expression des Transgens in der SNpc wurde anschließend auf zwei Wegen kontrolliert. Zum einen konnte über die Kolokalisation von TH-positiven Neuronen und EGFP-positiven, und damit virustransduzierten, Zellen die Virusexpression in den dopaminergen Zellen der SNpc nachgewiesen werden. Zum anderen erfolgte ergänzend eine Färbung der Schnitte mit einem Anti-BAG1-Antikörper, um auch die Expression von BAG1, das in einer anderen Kassette exprimiert wurde, zu überprüfen. $\mathrm{Zu}$ diskutieren bleibt allerdings, ob die Dauer von 21 Tagen vor Beginn der MPTP-Injektionen ein ausreichendes Zeitintervall für die suffiziente Expression des Transgens darstellt. In der Literatur sind aber neuroprotektive Effekte durch Expression anderer Transgene mit Hilfe von AAV-Vektoren auch mit nur 14 Tagen Dauer zwischen Virusinjektion und MPTPApplikation nachgewiesen worden (Mochizuki et al. 2001). Daneben ließ sich auch in den Vorversuchen (Daten nicht gezeigt), in denen das reproduzierbare stereotaktische Injizieren in die SNpc validiert wurde, nach nur 21 Tagen eine starke EGFP-Fluoreszenz detektieren.

\subsubsection{MPTP-Mausmodelle}

MPTP ist ein synthetisches Neurotoxin, welches nach Umwandlung in $\mathrm{MPP}^{+}$und Aufnahme in Neurone über den DAT unter anderem über die Inhibierung des Komplex I der Atmungskette wirkt (Nicklas et al. 1985) und damit die oxidative Phosphorylierung blockiert. Dies führt zu einem Mangel an ATP, der im Striatum und dem ventralen Mittelhirn am ausgeprägtesten ist (Chan et al. 1991, Fabre et al. 1999). Daneben stimuliert MPTP die Produktion von ROS und induziert somit oxidativen Stress (Przedborski und Vila 2003). Im Rahmen der subakuten und chronischen MPTP-Modelle mit niedrigen bis mittleren Dosen an MPTP (Tabelle 8) führen diese Mechanismen zwar nicht unbedingt selbst zum Zelltod, sie initiieren aber Vorgänge (Mandir et al. 1999, Saporito et al. 2000, Vila et al. 2001), die im Endeffekt die Apoptose einleiten (Tatton und Kish 1997) und die dopaminergen Zellen 
absterben lassen. MPTP führt hier unter anderem zur Expressionssteigerung des proapoptotischen Bax und zur Herabregulation von Bcl-2 (Vila et al. 2001), welches antiapoptotisch wirksam ist. Weiterhin sind sowohl Bax-Knockout- als auch Bcl-2-transgeneMäuse resistent gegen die durch MPTP induzierte Neurotoxizität (Offen et al. 1998, Vila et al. 2001, Yang et al. 1998).

Für die Applikation von MPTP existieren die verschiedensten Modelle (Tabelle 8). Im Hinblick auf die Art des zu erreichenden Zelltodes erscheint es günstig, ein subakutes oder chronisches Modell zu wählen, in dem der apoptotische Zelltod über die gerade diskutierten Mechanismen eingeleitet wird, und damit besser die pathophysiologischen Vorgänge beim IPS widerspiegelt. In der vorliegenden Arbeit erfolgte die MPTP-Applikation im Rahmen eines subakuten Modells mit i.p. Injektionen von $30 \mathrm{mg} / \mathrm{kg}$ an fünf aufeinanderfolgenden Tagen. Um den Zelltod zu quantifizieren, wurden nicht nur die TH-positiven sondern alle Nissl-positiven Zellen in der SNpc gezählt, da es Berichte über die Herabregulation der TH durch MPTP gibt (Jackson-Lewis et al. 1995). Somit bestünde bei der alleinigen Berücksichtigung der sicher TH-positiv gefärbten Neurone die Gefahr, diejenigen Neurone zu übersehen, in denen die TH herunterreguliert wurde, die sich aber im Verlauf erholen und nicht apoptotisch sterben. Weiterhin kann diskutiert werden, wie aussagekräftig das Zählen der Neurone in der SNpc ist. Schließlich ist es vor allem die Verminderung der striatalen Dopamin-Konzentration, die für die Symptome beim IPS verantwortlich ist. Über die striatalen Projektionen der nigralen Neurone und ihren Dopamingehalt kann auf diesem Wege keine Aussage getroffen werden.

In den publizierten Daten zu den subakuten Modellen bei C57BL/6 Mäusen findet sich eine Zelltodrate in der SNpc von 17 - 50 \%, abhängig vom genauen Applikationsmodus und der Menge an appliziertem MPTP (Tabelle 8). Die in der vorliegenden Arbeit erreichten $40 \%$ Zelltod in der SNpc korrelieren also mit den publizierten Daten. Der Nachteil des gewählten subakuten Modells liegt darin, dass hier bekanntermaßen keine LK-ähnlichen Einschlusskörperchen auftreten (Tabelle 8), obwohl diese ja ein wichtiges Kennzeichen des IPS darstellen. Spannend wäre neben der reinen Neuroprotektion auch der in-vivo-Effekt von BAG1 auf die Formation von Aggregaten im chronischen MPTP-Modell gewesen, über den so leider keine Aussage getroffen werden kann.

Tabelle 8: MPTP in C57BL/6 Mäusen

\begin{tabular}{llllll}
\hline \multicolumn{1}{c}{ Modell } & \multicolumn{1}{c}{ Schema } & Dosis MPTP-HCl & LK & Zelltod in SNpc & \multicolumn{1}{c}{ Referenz } \\
\hline akut & 4 s.c. Injektionen an einem Tag & $\begin{array}{l}14 \mathrm{mg} / \mathrm{kg} \text { pro } \\
\text { im 2 Stunden Intervall }\end{array}$ & $-40 \%$ & (Jackson-Lewis und \\
& & & & Przedborski 2007)
\end{tabular}




\begin{tabular}{|c|c|c|c|c|c|}
\hline akut & $\begin{array}{l}4 \text { s.c. Injektionen an einem Tag } \\
\text { im } 2 \text { Stunden Intervall }\end{array}$ & $\begin{array}{l}20 \mathrm{mg} / \mathrm{kg} \text { pro } \\
\text { Injektion }\end{array}$ & - & $90 \%$ & $\begin{array}{l}\text { (Jackson-Lewis und } \\
\text { Przedborski 2007) }\end{array}$ \\
\hline subakut & $\begin{array}{l}\text { 2x tägl. s.c. Injektionen im } 4 \\
\text { Stunden-Intervall an } 4 \\
\text { aufeinander folgenden Tagen }\end{array}$ & $\begin{array}{l}20 \mathrm{mg} / \mathrm{kg} \text { pro } \\
\text { Injektion }\end{array}$ & - & $40 \%$ & $\begin{array}{l}\text { (Anderson et al. } \\
\text { 2006) }\end{array}$ \\
\hline subakut & $\begin{array}{l}\text { 1x tägl. i.p. Injektionen an } 5 \\
\text { aufeinanderfolgenden Tagen }\end{array}$ & $\begin{array}{l}30 \mathrm{mg} / \mathrm{kg} \text { pro } \\
\text { Injektion }\end{array}$ & - & $40-50 \%$ & $\begin{array}{l}\text { (Tatton und Kish } \\
\text { 1997) }\end{array}$ \\
\hline subakut & $\begin{array}{l}2 x \text { tägl. i.p. Injektionen an den } \\
\text { ersten beiden Tagen, } 1 x \text { tägl. } \\
\text { i.p. Injektionen an } 3 \text { weiteren } \\
\text { Tagen }\end{array}$ & $\begin{array}{l}20 \mathrm{mg} / \mathrm{kg} \text { pro } \\
\text { Injektion }\end{array}$ & - & $17 \%$ & (Gibrat et al. 2009) \\
\hline chronisch & $\begin{array}{l}\text { Kontinuierliche MPTP- } \\
\text { Infusion über i.p. implantierte } \\
\text { osmotische Minipumpen über } \\
28 \text { Tage }\end{array}$ & $30 \mathrm{mg} / \mathrm{kg}$ pro Tag & + & $80 \%$ & (Fornai et al. 2005) \\
\hline chronisch & $\begin{array}{l}\text { Kontinuierliche MPTP- } \\
\text { Infusion über s.c. implantierte } \\
\text { osmotische Minipumpen über } \\
28 \text { Tage }\end{array}$ & $23 \mathrm{mg} / \mathrm{kg}$ pro Tag & - & $\begin{array}{l}\text { Kein } \\
\text { signifikanter } \\
\text { Zelltod }\end{array}$ & (Gibrat et al. 2009) \\
\hline chronisch & $\begin{array}{l}\text { Kontinuierliche MPTP- } \\
\text { Infusion über s.c. implantierte } \\
\text { osmotische Minipumpen über } \\
14 \text { Tage }\end{array}$ & $46 \mathrm{mg} / \mathrm{kg}$ pro Tag & + & $45 \%$ & (Gibrat et al. 2009) \\
\hline
\end{tabular}

\subsubsection{BAG1 im MPTP-Mausmodell}

In der vorliegenden Arbeit wurden AAV-BAG1-EGFP-Vektoren in die SNpc von C57BL/6 Mäusen injiziert. Anschließend erfolgte die intraperitoneale Applikation von MPTP über fünf Tage. Als Kontrollgruppen dienten die nicht injizierten Hemisphären, sowie AAV-EGFPinjizierte Tiere. Es ergab sich kein schützender Effekt von BAG1 gegenüber der nicht injizierten Hemisphäre, dafür aber ein signifikanter protektiver Effekt gegenüber der Kontrollgruppe von AAV-EGFP-injizierten Tieren.

Aus diesen Daten lässt sich die Vermutung anstellen, dass die Virusinjektionen die Zellen vulnerabel machen, sodass das MPTP die quasi vorgeschädigten Zellen dann endgültig in die Apoptose treibt. Durch die alleinige Virusinjektion (PBS-Tiere) von AAV-BAG1-EGFP und AAV-EGFP hatte sich zwar kein signifikanter Zellverlust ergeben, in der DAPI-Färbung einer AAV-injizierten Hemisphäre (Abb. 22, S. 64) wird aber deutlich, dass zum einen die AAVInjektion selbst eine gewisse Läsion setzt und zum anderen auch eine gewisse Inflammation stattfindet. Daneben gibt es Hinweise in der Literatur, dass auch MPTP zu Inflammation und unter anderem zur Aktivierung von Mikroglia führt (Dehmer et al. 2004, Vazquez-Claverie et al. 2009). Möglicherweise wäre an dieser Stelle ein größerer zeitlicher Abstand zwischen 
Virusinjektion und MPTP-Applikation von Vorteil gewesen. Eine mögliche Inflammationsreaktion durch das Virus wäre $\mathrm{zu}$ einem späteren Zeitpunkt vielleicht abgeklungen gewesen. Im vorliegenden Experiment ist es aber möglich, dass die schon vorbestehende geringe Inflammationsreaktion in der Region der SNpc diese Region besonders vulnerabel für die MPTP-Toxizität gemacht hat.

Die Injektion von AAV-BAG1-EGFP führt aber gegenüber AAV-EGFP zu signifikanter Protektion von Neuronen. Der Mechanismus, über den BAG1 diesen Schutz vermittelt, bleibt unklar. BAG1 ist ursprünglich als Bcl-2 bindendes Protein beschrieben worden, welches den antiapoptotischen Effekt von Bcl-2 zu unterstützen vermag (Takayama et al. 1995). Wie oben erläutert (4.2.2) wirkt MPTP unter anderem über die Induktion von Bax und die Herabregulierung von Bcl-2. Möglich wäre hier also eine Interaktion, in der BAG1 die Herabregulierung von Bcl-2 vermindert, was einen Apoptoseschutz induzieren könnte. Ein weiterer möglicher Mechanismus ist die Verminderung der Konzentration von Siah1 (Seven in absentia Homolog 1), einem anderen proapoptotischen Protein, durch BAG1 (Sroka et al. 2009). Daneben ist auch in diesem Modell fraglich wie BAG1 mit den Hitzeschockproteinen Hsc/Hsp70 in Interaktion tritt und ob auf diesem Weg ein Teil des durch MPTP induzierten oxidativen Schadens abgemildert werden kann. Auch könnte es möglich sein, dass über die Interaktion von BAG1 und CHIP ein Teil der oxidativ geschädigten Proteine besser abgebaut werden kann.

\subsection{ANWENDUNG UND AUSBLICK}

Die Pathomechanismen, die dem IPS und auch anderen neurodegenerativen Erkrankungen zu Grunde liegen, sind unklar. Es kann postuliert werden, dass es sich um eine multifaktorielle Ätiologie, also eine Mischung aus sowohl genetischen wie auch umweltbedingten Ursachen handelt. Eine mögliche Therapie sollte also idealerweise frühestmöglich an mehreren dieser Punkte angreifen, um möglichst effektiv sein zu können.

Das IPS wird oft erst in höherem Alter diagnostiziert und zum Zeitpunkt, zu dem die ersten Symptome auftreten, sind schon ein Großteil der Neurone unwiederbringlich zu Grunde gegangen. Im Verlauf der nächsten Jahre und Jahrzehnte kommt es dann zu fortwährender Neurodegenertion und zur Verschlimmerung der Symptome. Ziel einer möglichen Behandlung sollte es also sein, die Neurodenegeneration $\mathrm{zu}$ stoppen oder zumindest entscheidend zu verlangsamen. Die neuroprotektive Gentherapie bietet hier einen möglichen therapeutischen Ansatz. Die Überexpression neuroprotektiver Proteine in der SNpc durch viralen Gentransfer kann die dopaminergen Neurone möglicherweise vor dem Untergang 
bewahren und damit die Progression des IPS stoppen oder zumindest verlangsamen. Eine solche Therapie kann aber maximal einen Status halten - die bereits degenerierten Neurone werden hierdurch funktionell nicht ersetzt. Problematisch ist außerdem, dass neben den Neuronen der SNpc, in die man auf Grund ihrer relativ geringen Größe gezielt ein Virus einbringen könnte, beim IPS auch andere Neurone degenerieren. Gerade für die oft so belastenden vegetativen Symptome der IPS-Patienten ist wohl die Degeneration von Neuronen im Nucleus dorsalis nervi vagi verantwortlich. Diese Neurone werden durch eine Virusinjektion in die SNpc nicht therapiert. Ganz davon abgesehen, dass man ein Virus für die SNpc höchstwahrscheinlich so konstruieren würde, dass es recht selektiv dopaminerge Neurone transduziert. Die Neurone des Nucleus dorsalis nervi vagi sind aber nicht dopaminerg, sondern cholinerg (Gai et al. 1992). Um eine umfassende Therapie zu gewährleisten, müssten im Idealfall alle betroffenen Neurone behandelt werden können. Dies ist aber mit einer punktuellen Virusinjektion nicht zu erreichen. Vielversprechend sind in diesem Zusammenhang auch andere Transfer-Werkzeuge neben viralen Vektoren, wie z. B. die sogenannten „,trojanischen Peptide“, die ein Transgen in alle Zellen einbringen können, da sie systemisch verabreicht werden. Hier sind aber systemische Nebenwirkungen zu erwarten, welche zum jetzigen Zeitpunkt eine klinische Evaluation dieser Peptide verbieten. Unanhängig vom Transfer-Werkzeug ist aber BAG1 im Rahmen einer möglichen therapeutischen Intervention als vielversprechendes Target anzusehen, da es mehrere positive Eigenschaften vereint. Es vermittelt seine neuroprotektive Wirkung höchstwahrscheinlich durch Interaktionen an verschiedenen Stellen, was im Rahmen einer Erkrankung, der höchstwahrscheinlich eine multifaktorielle Genese zu Grunde liegt, vielversprechend erscheint. So wirkt es möglicherweise über Interaktionen mit Hsp70, CHIP und Bcl-2, die sich, schon allein genommen, alle als neuroprotektiv erwiesen haben. Besonders interessant ist, dass BAG1 neben dem neuroprotektiven Effekt auch einen neuroregenerativen Effekt besitzt (Planchamp et al. 2008), womit es eventuell auch schon bestehende neuronale Schäden $\mathrm{zu}$ verbessern vermag. Insbesondere diese Kombination von Ansatzpunkten macht BAG1 auch weiterhin zu einem vielversprechenden Target in Bezug auf die Behandlung neurodegenerativer Erkrankungen. 


\section{ZUSAMMENFASSUNG}

In dieser Arbeit wurden die Effekte des neuroprotektiven Co-Chaperons BAG1 (Bcl-2assoziiertes Athanogen-1) in verschiedenen Modellen des IPS untersucht.

In Zellkultur mit SH-SY5Y-Neuroblastomzellen zeigte sich BAG1 protektiv gegenüber Rotenon-, nicht aber gegenüber 6-Hydroxydopamin-induzierter Neurotoxizität. Weiterhin konnte ein protektiver Effekt von BAG1 gegenüber der Toxizität verschiedener $\alpha$-SynucleinMutanten nachgewiesen werden. In Proteinaggregationsstudien mit Lysaten aus CSM14.1Zellen konnte entgegen der ursprünglichen Arbeitshypothese ein proaggregatorischer Effekt von BAG1 gegenüber $\alpha$-Synuclein-Mutanten nachgewiesen werden, was aber nicht im Widerspruch zu den Toxizitätsexperimenten steht, da höchstwahrscheinlich oligomere $\alpha$ Synuclein-Strukturen und nicht höhermolekulare Aggregate für die Toxizität von $\alpha$-Synuclein verantwortlich sind.

In den durchgeführten in-vivo-Experminenten konnte gezeigt werden, dass die Überexpression von BAG1 in der SNpc von C57BL/6-Mäusen durch AAV-mediierten Gentransfer zu einer Protektion der SNpc-Neurone im MPTP-Parkinson-Modell führt.

Zusammenfassend präsentiert sich BAG1 damit als neuroprotektiv in verschiedenen in-vitroParkinson-Modellen und in einem in-vivo-Parkinson-Modell. In Hinblick auf die multifaktorielle Genese des IPS ist hervorzuheben, dass BAG1 über die Interaktionen mit Hsp70, CHIP und Bcl-2 funktionell verschiedene Interaktionsstellen in der Pathogenese des IPS besitzt und sowohl neuroprotektive als auch neuroregenerative Eigenschaften vereint, womit es ein besonders vielversprechendes Target für zukünftige antineurodegenerative Therapien darstellt.

Weitere Studien sollten sich mit den genauen neuroprotektiven Mechanismen von BAG1 beschäftigen, um zukünftig tatsächlich den Einsatz von BAG1 im Rahmen antineurodegenerativer Therapieansätze zu ermöglichen. 


\section{LITERATURVERZEICHNIS}

1. Abeliovich A, Schmitz Y, Farinas I, Choi-Lundberg D, Ho WH, Castillo PE, Shinsky N, Verdugo JM, Armanini M, Ryan A, et al. (2000): Mice lacking alpha-synuclein display functional deficits in the nigrostriatal dopamine system. Neuron $\underline{25}, 239-252$

2. Ahmadi FA, Linseman DA, Grammatopoulos TN, Jones SM, Bouchard RJ, Freed CR, Heidenreich KA, Zawada WM (2003): The pesticide rotenone induces caspase-3mediated apoptosis in ventral mesencephalic dopaminergic neurons. J Neurochem $\underline{87}$, 914-921

3. Alberti S, Demand J, Esser C, Emmerich N, Schild H, Hohfeld J (2002): Ubiquitylation of BAG-1 suggests a novel regulatory mechanism during the sorting of chaperone substrates to the proteasome. J Biol Chem 277, 45920-45927

4. Alberti S, Esser C, Hohfeld J (2003): BAG-1 - a nucleotide exchange factor of Hsc70 with multiple cellular functions. Cell Stress Chaperones $\underline{8}, 225-231$

5. Andersen JK (2004): Oxidative stress in neurodegeneration: cause or consequence? Nat Med 10 Suppl, S18-25

6. Anderson DW, Bradbury KA, Schneider JS (2006): Neuroprotection in Parkinson models varies with toxin administration protocol. Eur J Neurosci 24, 3174-3182

7. Andrew R, Watson DG, Best SA, Midgley JM, Wenlong H, Petty RK (1993): The determination of hydroxydopamines and other trace amines in the urine of parkinsonian patients and normal controls. Neurochem Res $\underline{18}, 1175-1177$

8. Azzouz M, Hottinger A, Paterna JC, Zurn AD, Aebischer P, Bueler H (2000): Increased motoneuron survival and improved neuromuscular function in transgenic ALS mice after intraspinal injection of an adeno-associated virus encoding Bcl-2. Hum Mol Genet $\underline{9}$, 803-811

9. Bardelli A, Longati P, Albero D, Goruppi S, Schneider C, Ponzetto C, Comoglio PM (1996): HGF receptor associates with the anti-apoptotic protein BAG-1 and prevents cell death. EMBO J $\underline{15}, 6205-6212$

10. Baron JA (1986): Cigarette smoking and Parkinson's disease. Neurology $\underline{36}, 1490-$ 1496

11. Bensadoun JC, Deglon N, Tseng JL, Ridet JL, Zurn AD, Aebischer P (2000): Lentiviral vectors as a gene delivery system in the mouse midbrain: cellular and behavioral improvements in a 6-OHDA model of Parkinson's disease using GDNF. Exp Neurol 164, 15-24

12. Berg D, Niwar M, Maass S, Zimprich A, Moller JC, Wuellner U, Schmitz-Hubsch T, Klein C, Tan EK, Schols L, et al. (2005): Alpha-synuclein and Parkinson's disease: implications from the screening of more than 1,900 patients. Mov Disord 20, 11911194 
13. Berman SB, Hastings TG (1999): Dopamine oxidation alters mitochondrial respiration and induces permeability transition in brain mitochondria: implications for Parkinson's disease. J Neurochem $\underline{73}, 1127-1137$

14. Betarbet R, Sherer TB, MacKenzie G, Garcia-Osuna M, Panov AV, Greenamyre JT (2000): Chronic systemic pesticide exposure reproduces features of Parkinson's disease. Nat Neurosci $\underline{3}, 1301-1306$

15. Biedler JL, Helson L, Spengler BA (1973): Morphology and growth, tumorigenicity, and cytogenetics of human neuroblastoma cells in continuous culture. Cancer Res $\underline{33}$, 2643-2652

16. Bimston D, Song J, Winchester D, Takayama S, Reed JC, Morimoto RI (1998): BAG1, a negative regulator of Hsp70 chaperone activity, uncouples nucleotide hydrolysis from substrate release. EMBO J $\underline{17}$, 6871-6878

17. Björklund A, Kirik D, Rosenblad C, Georgievska B, Lundberg C, Mandel RJ (2000): Towards a neuroprotective gene therapy for Parkinson's disease: use of adenovirus, AAV and lentivirus vectors for gene transfer of GDNF to the nigrostriatal system in the rat Parkinson model. Brain Res $\underline{886}, 82-98$

18. Blaszczyk JW (1998): Motor deficiency in Parkinson's disease. Acta Neurobiol Exp (Wars) $\underline{58}, 79-93$

19. Bloem BR, Van Dijk JG, Beckley DJ, Roos RA, Remler MP, Bruyn GW (1992): Altered postural reflexes in Parkinson's disease: a reverse hypothesis. Med Hypotheses 39, 243-247

20. Blum D, Torch S, Lambeng N, Nissou M, Benabid AL, Sadoul R, Verna JM (2001): Molecular pathways involved in the neurotoxicity of 6-OHDA, dopamine and MPTP: contribution to the apoptotic theory in Parkinson's disease. Prog Neurobiol $\underline{65}, 135-$ 172

21. Bodis-Wollner I, Tagliati M (1993): The visual system in Parkinson's disease. Adv Neurol 60, 390-394

22. Bonifati V, Rizzu P, van Baren MJ, Schaap O, Breedveld GJ, Krieger E, Dekker MC, Squitieri F, Ibanez P, Joosse M, et al. (2003): Mutations in the DJ-1 gene associated with autosomal recessive early-onset parkinsonism. Science 299, 256-259

23. Bossy-Wetzel E, Schwarzenbacher R, Lipton SA (2004): Molecular pathways to neurodegeneration. Nat Med 10 Suppl, S2-9

24. Bové J, Prou D, Perier C, Przedborski S (2005): Toxin-induced models of Parkinson's disease. NeuroRx $\underline{2}, 484-494$

25. Braak H, Del Tredici K (2008): Invited Article: Nervous system pathology in sporadic Parkinson disease. Neurology $\underline{70}, 1916-1925$

26. Braak H, Muller CM, Rub U, Ackermann H, Bratzke H, de Vos RA, Del Tredici K (2006): Pathology associated with sporadic Parkinson's disease--where does it end? J 
Neural Transm Suppl, 89-97

27. Brooks DJ (1998): The early diagnosis of Parkinson's disease. Ann Neurol $\underline{44}$, S10-18

28. Buller RM, Janik JE, Sebring ED, Rose JA (1981): Herpes simplex virus types 1 and 2 completely help adenovirus-associated virus replication. J Virol $\underline{40}, 241-247$

29. Burke D, Gasdaska P, Hartwell L (1989): Dominant effects of tubulin overexpression in Saccharomyces cerevisiae. Mol Cell Biol $\underline{9}, 1049-1059$

30. Burns RS, Chiueh CC, Markey SP, Ebert MH, Jacobowitz DM, Kopin IJ (1983): A primate model of parkinsonism: selective destruction of dopaminergic neurons in the pars compacta of the substantia nigra by N-methyl-4-phenyl-1,2,3,6tetrahydropyridine. Proc Natl Acad Sci U S A $\underline{80}, 4546-4550$

31. Cannon JR, Tapias V, Na HM, Honick AS, Drolet RE, Greenamyre JT (2009): A highly reproducible rotenone model of Parkinson's disease. Neurobiol Dis 34, 279-290

32. Cearley CN, Wolfe JH (2006): Transduction characteristics of adeno-associated virus vectors expressing cap serotypes 7, 8, 9, and Rh10 in the mouse brain. Mol Ther $\underline{13}$, 528-537

33. Chan P, DeLanney LE, Irwin I, Langston JW, Di Monte D (1991): Rapid ATP loss caused by 1-methyl-4-phenyl-1,2,3,6-tetrahydropyridine in mouse brain. J Neurochem 57, 348-351

34. Chandra S, Gallardo G, Fernandez-Chacon R, Schluter OM, Sudhof TC (2005): Alpha-synuclein cooperates with CSPalpha in preventing neurodegeneration. Cell $\underline{123}$, 383-396

35. Chartier-Harlin MC, Kachergus J, Roumier C, Mouroux V, Douay X, Lincoln S, Levecque C, Larvor L, Andrieux J, Hulihan M, et al. (2004): Alpha-synuclein locus duplication as a cause of familial Parkinson's disease. Lancet $\underline{364}, 1167-1169$

36. Chaudhuri KR, Schapira AH (2009): Non-motor symptoms of Parkinson's disease: dopaminergic pathophysiology and treatment. Lancet Neurol $\underline{8}, 464-474$

37. Chen L, Feany MB (2005): Alpha-synuclein phosphorylation controls neurotoxicity and inclusion formation in a Drosophila model of Parkinson disease. Nat Neurosci $\underline{8}$, 657-663

38. Choi HS, Lee SH, Kim SY, An JJ, Hwang SI, Kim DW, Yoo KY, Won MH, Kang TC, Kwon HJ, et al. (2006): Transduced Tat-alpha-synuclein protects against oxidative stress in vitro and in vivo. J Biochem Mol Biol 39, 253-262

39. Chu Y, Kordower JH (2007): Age-associated increases of alpha-synuclein in monkeys and humans are associated with nigrostriatal dopamine depletion: Is this the target for Parkinson's disease? Neurobiol Dis $\underline{25}, 134-149$

40. Clevenger CV, Thickman K, Ngo W, Chang WP, Takayama S, Reed JC (1997): Role of Bag-1 in the survival and proliferation of the cytokine-dependent lymphocyte lines, 
$\mathrm{Ba} / \mathrm{F} 3$ and $\mathrm{Nb} 2$. Mol Endocrinol 11, 608-618

41. Cohen G, Pasik P, Cohen B, Leist A, Mytilineou C, Yahr MD (1984): Pargyline and deprenyl prevent the neurotoxicity of 1-methyl-4-phenyl-1,2,3,6-tetrahydropyridine (MPTP) in monkeys. Eur J Pharmacol 106, 209-210

42. Colapinto M, Mila S, Giraudo S, Stefanazzi P, Molteni M, Rossetti C, Bergamasco B, Lopiano L, Fasano M (2006): alpha-Synuclein protects SH-SY5Y cells from dopamine toxicity. Biochem Biophys Res Commun $\underline{349}$, 1294-1300

43. Conway KA, Harper JD, Lansbury PT (1998): Accelerated in vitro fibril formation by a mutant alpha-synuclein linked to early-onset Parkinson disease. Nat Med $\underline{4}, 1318-$ 1320

44. Conway KA, Lee SJ, Rochet JC, Ding TT, Williamson RE, Lansbury PT, Jr. (2000): Acceleration of oligomerization, not fibrillization, is a shared property of both alphasynuclein mutations linked to early-onset Parkinson's disease: implications for pathogenesis and therapy. Proc Natl Acad Sci U S A 97, 571-576

45. Conway KA, Rochet JC, Bieganski RM, Lansbury PT, Jr. (2001): Kinetic stabilization of the alpha-synuclein protofibril by a dopamine-alpha-synuclein adduct. Science 294, 1346-1349

46. Cookson MR (2009): alpha-Synuclein and neuronal cell death. Mol Neurodegener $\underline{4}, 9$

47. Cooper AA, Gitler AD, Cashikar A, Haynes CM, Hill KJ, Bhullar B, Liu K, Xu K, Strathearn KE, Liu F, et al. (2006): Alpha-synuclein blocks ER-Golgi traffic and Rab1 rescues neuron loss in Parkinson's models. Science $\underline{313}$, 324-328

48. Cooper JM, Daniel SE, Marsden CD, Schapira AH (1995): L-dihydroxyphenylalanine and complex I deficiency in Parkinson's disease brain. Mov Disord 10, 295-297

49. Cuervo AM, Stefanis L, Fredenburg R, Lansbury PT, Sulzer D (2004): Impaired degradation of mutant alpha-synuclein by chaperone-mediated autophagy. Science $\underline{305}, 1292-1295$

50. Cuervo AM, Bergamini E, Brunk UT, Droge W, Ffrench M, Terman A (2005):

Autophagy and aging: the importance of maintaining "clean" cells. Autophagy $1,131-$ 140

51. Curtius HC, Wolfensberger M, Steinmann B, Redweik U, Siegfried J (1974): Mass fragmentography of dopamine and 6-hydroxydopamine. Application to the determination of dopamine in human brain biopsies from the caudate nucleus. $\mathbf{J}$ Chromatogr 99, 529-540

52. Dadakhujaev S, Noh HS, Jung EJ, Cha JY, Baek SM, Ha JH, Kim DR (2010): Autophagy protects the rotenone-induced cell death in alpha-synuclein overexpressing SH-SY5Y cells. Neurosci Lett $\underline{472}, 47-52$

53. Dauer W, Przedborski S (2003): Parkinson's disease: mechanisms and models. Neuron 39, 889-909 
54. Dauer W, Kholodilov N, Vila M, Trillat AC, Goodchild R, Larsen KE, Staal R, Tieu K, Schmitz Y, Yuan CA, et al. (2002): Resistance of alpha -synuclein null mice to the parkinsonian neurotoxin MPTP. Proc Natl Acad Sci U S A 99, 14524-14529

55. Davis GC, Williams AC, Markey SP, Ebert MH, Caine ED, Reichert CM, Kopin IJ (1979): Chronic Parkinsonism secondary to intravenous injection of meperidine analogues. Psychiatry Res $\underline{1}, 249-254$

56. Dehmer T, Heneka MT, Sastre M, Dichgans J, Schulz JB (2004): Protection by pioglitazone in the MPTP model of Parkinson's disease correlates with I kappa B alpha induction and block of NF kappa B and iNOS activation. J Neurochem $\underline{88}$, 494501

57. Demand J, Alberti S, Patterson C, Hohfeld J (2001): Cooperation of a ubiquitin domain protein and an E3 ubiquitin ligase during chaperone/proteasome coupling. Curr Biol 11, 1569-1577

58. de Rijk MC, Launer LJ, Berger K, Breteler MM, Dartigues JF, Baldereschi M, Fratiglioni L, Lobo A, Martinez-Lage J, Trenkwalder C, et al. (2000): Prevalence of Parkinson's disease in Europe: A collaborative study of population-based cohorts. Neurologic Diseases in the Elderly Research Group. Neurology 54, S21-23

59. Desplats P, Lee HJ, Bae EJ, Patrick C, Rockenstein E, Crews L, Spencer B, Masliah E, Lee SJ (2009): Inclusion formation and neuronal cell death through neuron-toneuron transmission of $\{$ alpha $\}$-synuclein. Proc Natl Acad Sci U S A $\underline{106}, 13010$ 13015

60. Dexter DT, Carter CJ, Wells FR, Javoy-Agid F, Agid Y, Lees A, Jenner P, Marsden CD (1989): Basal lipid peroxidation in substantia nigra is increased in Parkinson's disease. J Neurochem $\underline{52}$, 381-389

61. Di Fonzo A, Dekker MC, Montagna P, Baruzzi A, Yonova EH, Correia Guedes L, Szczerbinska A, Zhao T, Dubbel-Hulsman LO, Wouters CH, et al. (2009): FBXO7 mutations cause autosomal recessive, early-onset parkinsonian-pyramidal syndrome. Neurology $\underline{72}, 240-245$

62. Dice JF (1990): Peptide sequences that target cytosolic proteins for lysosomal proteolysis. Trends Biochem Sci 15, 305-309

63. Dohm CP, Kermer P, Bahr M (2008): Aggregopathy in neurodegenerative diseases: mechanisms and therapeutic implication. Neurodegener Dis $\underline{5}, 321-338$

64. Dong JY, Fan PD, Frizzell RA (1996): Quantitative analysis of the packaging capacity of recombinant adeno-associated virus. Hum Gene Ther $\underline{7}, 2101-2112$

65. Dong Z, Wolfer DP, Lipp HP, Bueler H (2005): Hsp70 gene transfer by adeno associated virus inhibits MPTP-induced nigrostriatal degeneration in the mouse model of Parkinson disease. Mol Ther $\underline{11}, 80-88$

66. Dorsey ER, Constantinescu R, Thompson JP, Biglan KM, Holloway RG, Kieburtz K, 
Marshall FJ, Ravina BM, Schifitto G, Siderowf A, et al. (2007): Projected number of people with Parkinson disease in the most populous nations, 2005 through 2030.

Neurology $\underline{68}, 384-386$

67. Driver JA, Logroscino G, Gaziano JM, Kurth T (2009): Incidence and remaining lifetime risk of Parkinson disease in advanced age. Neurology $\underline{72}, 432-438$

68. Duan D, Sharma P, Yang J, Yue Y, Dudus L, Zhang Y, Fisher KJ, Engelhardt JF (1998): Circular intermediates of recombinant adeno-associated virus have defined structural characteristics responsible for long-term episomal persistence in muscle tissue. J Virol $\underline{72}$, 8568-8577

69. Eberling JL, Jagust WJ, Christine CW, Starr P, Larson P, Bankiewicz KS, Aminoff MJ (2008): Results from a phase I safety trial of hAADC gene therapy for Parkinson disease. Neurology $\underline{70}$, 1980-1983

70. Ebert AD, Hann HJ, Bohn MC (2008): Progressive degeneration of dopamine neurons in 6-hydroxydopamine rat model of Parkinson's disease does not involve activation of caspase-9 and caspase-3. J Neurosci Res $\underline{86}$, 317-325

71. Eggert KM, Oertel WH, Reichmann H, Arnold G, Baas H, Berg D, Braune S, Deuschl G, Dodel R, Gasser T, et al.: Parkinson-Syndrome Diagnostik und Therapie; in: Leitlinien für Diagnostik und Therapie in der Neurologie, 4. Auflage; hrsg. v. Diener HC, Putzki N u.a.; Georg Thieme Verlag, Stuttgart 2008, 82-112

72. Elliott E, Tsvetkov P, Ginzburg I (2007): BAG-1 associates with Hsc70.Tau complex and regulates the proteasomal degradation of Tau protein. J Biol Chem $\underline{282}$, 3727637284

73. Elliott E, Laufer O, Ginzburg I (2009): BAG-1M is up-regulated in hippocampus of Alzheimer's disease patients and associates with tau and APP proteins. J Neurochem $\underline{109}, 1168-1178$

74. Encinas M, Iglesias M, Liu Y, Wang H, Muhaisen A, Cena V, Gallego C, Comella JX (2000): Sequential treatment of SH-SY5Y cells with retinoic acid and brain-derived neurotrophic factor gives rise to fully differentiated, neurotrophic factor-dependent, human neuron-like cells. J Neurochem $\underline{75}$, 991-1003

75. Eversole-Cire P, Concepcion FA, Simon MI, Takayama S, Reed JC, Chen J (2000): Synergistic effect of Bcl-2 and BAG-1 on the prevention of photoreceptor cell death. Invest Ophthalmol Vis Sci $\underline{41}, 1953-1961$

76. Fabre E, Monserrat J, Herrero A, Barja G, Leret ML (1999): Effect of MPTP on brain mitochondrial $\mathrm{H} 2 \mathrm{O} 2$ and ATP production and on dopamine and DOPAC in the striatum. J Physiol Biochem 55, 325-331

77. Fasano M, Bergamasco B, Lopiano L (2006): Modifications of the iron-neuromelanin system in Parkinson's disease. J Neurochem $\underline{96}$, 909-916

78. Feany MB, Bender WW (2000): A Drosophila model of Parkinson's disease. Nature 404, 394-398 
79. Fearnley JM, Lees AJ (1991): Ageing and Parkinson's disease: substantia nigra regional selectivity. Brain $\underline{114(\mathrm{Pt} 5)}, 2283-2301$

80. Fiandaca M, Forsayeth J, Bankiewicz K (2008): Current status of gene therapy trials for Parkinson's disease. Exp Neurol 209, 51-57

81. Fiske BK, Frasier MA, Sherer TB (2008): Special focus section: gene therapy for Parkinson's disease. Exp Neurol 209, 28-29

82. Florence TM, Stauber JL (1988): Neurotoxicity of manganese. Lancet 1988,1, 363

83. Flotte TR, Solow R, Owens RA, Afione S, Zeitlin PL, Carter BJ (1992): Gene expression from adeno-associated virus vectors in airway epithelial cells. Am J Respir Cell Mol Biol 7, 349-356

84. Flotte TR, Afione SA, Zeitlin PL (1994): Adeno-associated virus vector gene expression occurs in nondividing cells in the absence of vector DNA integration. Am J Respir Cell Mol Biol 11, 517-521

85. Fornai F, Schluter OM, Lenzi P, Gesi M, Ruffoli R, Ferrucci M, Lazzeri G, Busceti CL, Pontarelli F, Battaglia G, et al. (2005): Parkinson-like syndrome induced by continuous MPTP infusion: convergent roles of the ubiquitin-proteasome system and alpha-synuclein. Proc Natl Acad Sci U S A $\underline{102}$, 3413-3418

86. Forno LS, Langston JW, DeLanney LE, Irwin I, Ricaurte GA (1986): Locus ceruleus lesions and eosinophilic inclusions in MPTP-treated monkeys. Ann Neurol 20, 449455

87. Frank KM, Hogarth DK, Miller JL, Mandal S, Mease PJ, Samulski RJ, Weisgerber GA, Hart J (2009): Investigation of the cause of death in a gene-therapy trial. N Engl J Med $\underline{361}, 161-169$

88. Friguet B, Szweda LI (1997): Inhibition of the multicatalytic proteinase (proteasome) by 4-hydroxy-2-nonenal cross-linked protein. FEBS Lett $\underline{405}$, 21-25

89. Fujiwara H, Hasegawa M, Dohmae N, Kawashima A, Masliah E, Goldberg MS, Shen J, Takio K, Iwatsubo T (2002): alpha-Synuclein is phosphorylated in synucleinopathy lesions. Nat Cell Biol $\underline{4}, 160-164$

90. Fuxe K, Chadi G, Tinner B, Agnati LF, Pettersson R, David G (1994): On the regional distribution of heparan sulfate proteoglycan immunoreactivity in the rat brain. Brain Res $\underline{636}, 131-138$

91. Gai WP, Blumbergs PC, Geffen LB, Blessing WW (1992): Age-related loss of dorsal vagal neurons in Parkinson's disease. Neurology $\underline{42}, 2106-2111$

92. Gasser T (2001): Genetics of Parkinson's disease. J Neurol 248, 833-840

93. Gässler CS, Wiederkehr T, Brehmer D, Bukau B, Mayer MP (2001): Bag-1M 
accelerates nucleotide release for human Hsc70 and Hsp70 and can act concentrationdependent as positive and negative cofactor. J Biol Chem 276, 32538-32544

94. Gehring U (2004): Biological activities of HAP46/BAG-1. The HAP46/BAG-1 protein: regulator of HSP70 chaperones, DNA-binding protein and stimulator of transcription. EMBO Rep $\underline{5}, 148-153$

95. George JM (2002): The synucleins. Genome Biol $\underline{3}$, REVIEWS3002

96. Gibrat C, Saint-Pierre M, Bousquet M, Levesque D, Rouillard C, Cicchetti F (2009): Differences between subacute and chronic MPTP mice models: investigation of dopaminergic neuronal degeneration and alpha-synuclein inclusions. J Neurochem $\underline{109}, 1469-1482$

97. Gill MB, Perez-Polo JR (2009): Bax shuttling after rotenone treatment of neuronal

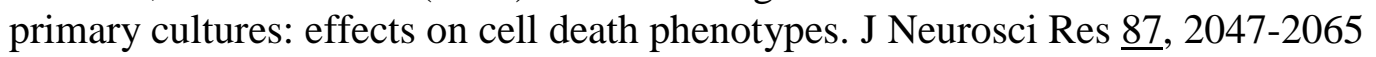

98. Glickman MH, Ciechanover A (2002): The ubiquitin-proteasome proteolytic pathway: destruction for the sake of construction. Physiol Rev $\underline{82}, 373-428$

99. Glinka Y, Tipton KF, Youdim MB (1996): Nature of inhibition of mitochondrial respiratory complex I by 6-Hydroxydopamine. J Neurochem $\underline{66}, 2004-2010$

100. Golbe LI, Di Iorio G, Sanges G, Lazzarini AM, La Sala S, Bonavita V, Duvoisin RC (1996): Clinical genetic analysis of Parkinson's disease in the Contursi kindred. Ann Neurol $\underline{40}, 767-775$

101. Goldberg MS, Lansbury PT, Jr. (2000): Is there a cause-and-effect relationship between alpha-synuclein fibrillization and Parkinson's disease? Nat Cell Biol 2, E115119

102. Gomez-Santos C, Ferrer I, Reiriz J, Vinals F, Barrachina M, Ambrosio S (2002): MPP+ increases alpha-synuclein expression and ERK/MAP-kinase phosphorylation in human neuroblastoma SH-SY5Y cells. Brain Res $\underline{935}$, 32-39

103. Good PF, Hsu A, Werner P, Perl DP, Olanow CW (1998): Protein nitration in Parkinson's disease. J Neuropathol Exp Neurol 57, 338-342

104. Gorell JM, Johnson CC, Rybicki BA, Peterson EL, Kortsha GX, Brown GG, Richardson RJ (1999): Occupational exposure to manganese, copper, lead, iron, mercury and zinc and the risk of Parkinson's disease. Neurotoxicology 20, 239-247

105. Götz R, Wiese S, Takayama S, Camarero GC, Rossoll W, Schweizer U, Troppmair J, Jablonka S, Holtmann B, Reed JC, et al. (2005): Bag1 is essential for differentiation and survival of hematopoietic and neuronal cells. Nat Neurosci $\underline{8}, 1169-1178$

106. Greene P (2009): Cell-based therapies in Parkinson's disease. Curr Neurol Neurosci Rep $\underline{9}$, 292-297

107. Haas SJ, Wree A (2002): Dopaminergic differentiation of the Nurr1-expressing immortalized mesencephalic cell line CSM14.1 in vitro. J Anat 201, 61-69 
108. Hadjigeorgiou GM, Xiromerisiou G, Gourbali V, Aggelakis K, Scarmeas N, Papadimitriou A, Singleton A (2006): Association of alpha-synuclein Rep1 polymorphism and Parkinson's disease: influence of Rep1 on age at onset. Mov Disord 21, 534-539

109. Hanrott K, Gudmunsen L, O'Neill MJ, Wonnacott S (2006): 6-hydroxydopamineinduced apoptosis is mediated via extracellular auto-oxidation and caspase 3dependent activation of protein kinase Cdelta. J Biol Chem 281, 5373-5382

110. Hashimoto M, Rockenstein E, Mante M, Mallory M, Masliah E (2001): betaSynuclein inhibits alpha-synuclein aggregation: a possible role as an anti-parkinsonian factor. Neuron $\underline{32}, 213-223$

111. Hashimoto M, Hsu LJ, Rockenstein E, Takenouchi T, Mallory M, Masliah E (2002): alpha-Synuclein protects against oxidative stress via inactivation of the c-Jun Nterminal kinase stress-signaling pathway in neuronal cells. J Biol Chem $\underline{277}, 11465$ 11472

112. Heikkila RE, Hess A, Duvoisin RC (1984): Dopaminergic neurotoxicity of 1-methyl4-phenyl-1,2,5,6-tetrahydropyridine in mice. Science 224, 1451-1453

113. Heikkila RE, Nicklas WJ, Vyas I, Duvoisin RC (1985): Dopaminergic toxicity of rotenone and the 1-methyl-4-phenylpyridinium ion after their stereotaxic administration to rats: implication for the mechanism of 1-methyl-4-phenyl-1,2,3,6tetrahydropyridine toxicity. Neurosci Lett $\underline{62}, 389-394$

114. Herting B, Bietenbeck S, Scholz K, Hahner A, Hummel T, Reichmann H (2008): [Olfactory dysfunction in Parkinson's disease: its role as a new cardinal sign in early and differential diagnosis]. Nervenarzt $\underline{79}, 175-184$

115. Hicks AA, Petursson H, Jonsson T, Stefansson H, Johannsdottir HS, Sainz J, Frigge ML, Kong A, Gulcher JR, Stefansson K, et al. (2002): A susceptibility gene for lateonset idiopathic Parkinson's disease. Ann Neurol 52, 549-555

116. Höhfeld J, Jentsch S (1997): GrpE-like regulation of the hsc70 chaperone by the antiapoptotic protein BAG-1. EMBO J $\underline{16}, 6209-6216$

117. Hong M, Mukhida K, Mendez I (2008): GDNF therapy for Parkinson's disease. Expert Rev Neurother $\underline{8}, 1125-1139$

118. Hoyer W, Antony T, Cherny D, Heim G, Jovin TM, Subramaniam V (2002): Dependence of alpha-synuclein aggregate morphology on solution conditions. J Mol Biol $\underline{322}$, 383-393

119. Irwin I, DeLanney LE, Langston JW (1993): MPTP and aging. Studies in the C57BL/6 mouse. Adv Neurol $\underline{60}, 197-206$

120. Jackson-Lewis V, Przedborski S (2007): Protocol for the MPTP mouse model of Parkinson's disease. Nat Protoc $\underline{2}, 141-151$

121. Jackson-Lewis V, Jakowec M, Burke RE, Przedborski S (1995): Time course and 
morphology of dopaminergic neuronal death caused by the neurotoxin 1-methyl-4phenyl-1,2,3,6-tetrahydropyridine. Neurodegeneration $\underline{4}$, 257-269

122. Jana NR, Nukina N (2005): BAG-1 associates with the polyglutamine-expanded huntingtin aggregates. Neurosci Lett $\underline{378}, 171-175$

123. Javitch JA, D'Amato RJ, Strittmatter SM, Snyder SH (1985): Parkinsonism-inducing neurotoxin, N-methyl-4-phenyl-1,2,3,6 -tetrahydropyridine: uptake of the metabolite $\mathrm{N}$-methyl-4-phenylpyridine by dopamine neurons explains selective toxicity. Proc Natl Acad Sci U S A $\underline{82}, 2173-2177$

124. Javoy F, Sotelo C, Herbet A, Agid Y (1976): Specificity of dopaminergic neuronal degeneration induced by intracerebral injection of 6-hydroxydopamine in the nigrostriatal dopamine system. Brain Res $\underline{102}$, 201-215

125. Jensen PJ, Alter BJ, O'Malley KL (2003): Alpha-synuclein protects naive but not dbcAMP-treated dopaminergic cell types from 1-methyl-4-phenylpyridinium toxicity. J Neurochem $\underline{86}, 196-209$

126. Jha N, Jurma O, Lalli G, Liu Y, Pettus EH, Greenamyre JT, Liu RM, Forman HJ, Andersen JK (2000): Glutathione depletion in PC12 results in selective inhibition of mitochondrial complex I activity. Implications for Parkinson's disease. J Biol Chem $\underline{275}, 26096-26101$

127. Jha N, Kumar MJ, Boonplueang R, Andersen JK (2002): Glutathione decreases in dopaminergic PC12 cells interfere with the ubiquitin protein degradation pathway: relevance for Parkinson's disease? J Neurochem $\underline{80}, 555-561$

128. Kahle PJ, Neumann M, Ozmen L, Haass C (2000): Physiology and pathophysiology of alpha-synuclein. Cell culture and transgenic animal models based on a Parkinson's disease-associated protein. Ann N Y Acad Sci 920, 33-41

129. Kamel F, Hoppin JA (2004): Association of pesticide exposure with neurologic dysfunction and disease. Environ Health Perspect 112, 950-958

130. Kaplitt MG, Feigin A, Tang C, Fitzsimons HL, Mattis P, Lawlor PA, Bland RJ, Young D, Strybing K, Eidelberg D, et al. (2007): Safety and tolerability of gene therapy with an adeno-associated virus (AAV) borne GAD gene for Parkinson's disease: an open label, phase I trial. Lancet 369, 2097-2105

131. Karpinar DP, Balija MB, Kugler S, Opazo F, Rezaei-Ghaleh N, Wender N, Kim HY, Taschenberger G, Falkenburger BH, Heise H, et al. (2009): Pre-fibrillar alphasynuclein variants with impaired beta-structure increase neurotoxicity in Parkinson's disease models. EMBO J 28, 3256-3268

132. Kaur D, Yantiri F, Rajagopalan S, Kumar J, Mo JQ, Boonplueang R, Viswanath V, Jacobs R, Yang L, Beal MF, et al. (2003): Genetic or pharmacological iron chelation prevents MPTP-induced neurotoxicity in vivo: a novel therapy for Parkinson's disease. Neuron $\underline{37}, 899-909$

133. Keeney PM, Xie J, Capaldi RA, Bennett JP, Jr. (2006): Parkinson's disease brain 
mitochondrial complex I has oxidatively damaged subunits and is functionally impaired and misassembled. J Neurosci 26, 5256-5264

134. Kermer P, Krajewska M, Zapata JM, Takayama S, Mai J, Krajewski S, Reed JC (2002): Bag1 is a regulator and marker of neuronal differentiation. Cell Death Differ $\underline{9}, 405-413$

135. Kermer P, Digicaylioglu MH, Kaul M, Zapata JM, Krajewska M, Stenner-Liewen F, Takayama S, Krajewski S, Lipton SA, Reed JC (2003): BAG1 over-expression in brain protects against stroke. Brain Pathol 13, 495-506

136. Kim HY, Cho MK, Kumar A, Maier E, Siebenhaar C, Becker S, Fernandez CO, Lashuel HA, Benz R, Lange A, et al. (2009): Structural properties of pore-forming oligomers of alpha-synuclein. J Am Chem Soc 131, 17482-17489

137. Kirby J, Menzies FM, Cookson MR, Bushby K, Shaw PJ (2002): Differential gene expression in a cell culture model of SOD1-related familial motor neurone disease. Hum Mol Genet 11, 2061-2075

138. Kirik D, Rosenblad C, Burger C, Lundberg C, Johansen TE, Muzyczka N, Mandel RJ, Bjorklund A (2002): Parkinson-like neurodegeneration induced by targeted overexpression of alpha-synuclein in the nigrostriatal system. J Neurosci $\underline{22}$, 27802791

139. Kitada T, Asakawa S, Hattori N, Matsumine H, Yamamura Y, Minoshima S, Yokochi M, Mizuno Y, Shimizu N (1998): Mutations in the parkin gene cause autosomal recessive juvenile parkinsonism. Nature $\underline{392}$, 605-608

140. Kitamura Y, Inden M, Miyamura A, Kakimura J, Taniguchi T, Shimohama S (2002): Possible involvement of both mitochondria- and endoplasmic reticulum-dependent caspase pathways in rotenone-induced apoptosis in human neuroblastoma SH-SY5Y cells. Neurosci Lett $\underline{333}, 25-28$

141. Klucken J, Shin Y, Masliah E, Hyman BT, McLean PJ (2004): Hsp70 Reduces alphaSynuclein Aggregation and Toxicity. J Biol Chem 279, 25497-25502

142. Kotzbauer PT, Giasson BI, Kravitz AV, Golbe LI, Mark MH, Trojanowski JQ, Lee VM (2004): Fibrillization of alpha-synuclein and tau in familial Parkinson's disease caused by the A53T alpha-synuclein mutation. Exp Neurol 187, 279-288

143. Krüger R, Kuhn W, Muller T, Woitalla D, Graeber M, Kosel S, Przuntek H, Epplen JT, Schols L, Riess O (1998): Ala30Pro mutation in the gene encoding alphasynuclein in Parkinson's disease. Nat Genet $\underline{18}, 106-108$

144. Kullmann M, Schneikert J, Moll J, Heck S, Zeiner M, Gehring U, Cato AC (1998): RAP46 is a negative regulator of glucocorticoid receptor action and hormone-induced apoptosis. J Biol Chem $\underline{273}$, 14620-14625

145. Kuwahara T, Koyama A, Gengyo-Ando K, Masuda M, Kowa H, Tsunoda M, Mitani S, Iwatsubo T (2006): Familial Parkinson mutant alpha-synuclein causes dopamine neuron dysfunction in transgenic Caenorhabditis elegans. J Biol Chem 281, 334-340 
146. Lakso M, Vartiainen S, Moilanen AM, Sirvio J, Thomas JH, Nass R, Blakely RD, Wong G (2003): Dopaminergic neuronal loss and motor deficits in Caenorhabditis elegans overexpressing human alpha-synuclein. J Neurochem $\underline{86}, 165-172$

147. Langston JW, Ballard PA, Jr. (1983): Parkinson's disease in a chemist working with 1methyl-4-phenyl-1,2,5,6-tetrahydropyridine. N Engl J Med 309, 310

148. Lautier C, Goldwurm S, Durr A, Giovannone B, Tsiaras WG, Pezzoli G, Brice A, Smith RJ (2008): Mutations in the GIGYF2 (TNRC15) gene at the PARK11 locus in familial Parkinson disease. Am J Hum Genet $\underline{82}$, 822-833

149. Lauwers E, Debyser Z, Van Dorpe J, De Strooper B, Nuttin B, Baekelandt V (2003): Neuropathology and neurodegeneration in rodent brain induced by lentiviral vectormediated overexpression of alpha-synuclein. Brain Pathol 13, 364-372

150. Lee HJ, Shin SY, Choi C, Lee YH, Lee SJ (2002): Formation and removal of alphasynuclein aggregates in cells exposed to mitochondrial inhibitors. J Biol Chem $\underline{277}$, 5411-5417

151. Lee HJ, Khoshaghideh F, Patel S, Lee SJ (2004): Clearance of alpha-synuclein oligomeric intermediates via the lysosomal degradation pathway. J Neurosci $\underline{24}$, 18881896

152. Lee HJ, Suk JE, Bae EJ, Lee SJ (2008): Clearance and deposition of extracellular alpha-synuclein aggregates in microglia. Biochem Biophys Res Commun $\underline{372}$, 423428

153. Lee MK, Stirling W, Xu Y, Xu X, Qui D, Mandir AS, Dawson TM, Copeland NG, Jenkins NA, Price DL (2002): Human alpha-synuclein-harboring familial Parkinson's disease-linked Ala-53 --> Thr mutation causes neurodegenerative disease with alphasynuclein aggregation in transgenic mice. Proc Natl Acad Sci U S A 99, 8968-8973

154. Leroy E, Boyer R, Polymeropoulos MH (1998): Intron-exon structure of ubiquitin cterminal hydrolase-L1. DNA Res $\underline{5}, 397-400$

155. Li JY, Englund E, Holton JL, Soulet D, Hagell P, Lees AJ, Lashley T, Quinn NP, Rehncrona S, Bjorklund A, et al. (2008): Lewy bodies in grafted neurons in subjects with Parkinson's disease suggest host-to-graft disease propagation. Nat Med $\underline{14}, 501-$ 503

156. Li W, West N, Colla E, Pletnikova O, Troncoso JC, Marsh L, Dawson TM, Jakala P, Hartmann T, Price DL, et al. (2005): Aggregation promoting C-terminal truncation of alpha-synuclein is a normal cellular process and is enhanced by the familial Parkinson's disease-linked mutations. Proc Natl Acad Sci U S A $\underline{102,2162-2167}$

157. Liebetanz D, Baier PC, Paulus W, Meuer K, Bahr M, Weishaupt JH (2007): A highly sensitive automated complex running wheel test to detect latent motor deficits in the mouse MPTP model of Parkinson's disease. Exp Neurol 205, 207-213

158. Liman J, Ganesan S, Dohm CP, Krajewski S, Reed JC, Bahr M, Wouters FS, Kermer P (2005): Interaction of BAG1 and Hsp70 mediates neuroprotectivity and increases 
chaperone activity. Mol Cell Biol 25, 3715-3725

159. Liman J, Faida L, Dohm CP, Reed JC, Bahr M, Kermer P (2008): Subcellular distribution affects BAG1 function. Brain Res $\underline{1198}, 21-26$

160. Lindersson E, Beedholm R, Hojrup P, Moos T, Gai W, Hendil KB, Jensen PH (2004): Proteasomal inhibition by alpha-synuclein filaments and oligomers. J Biol Chem $\underline{279}$, 12924-12934

161. Lindvall O, Wahlberg LU (2008): Encapsulated cell biodelivery of GDNF: a novel clinical strategy for neuroprotection and neuroregeneration in Parkinson's disease? Exp Neurol 209, 82-88

162. Liu R, Takayama S, Zheng Y, Froesch B, Chen GQ, Zhang X, Reed JC, Zhang XK (1998): Interaction of BAG-1 with retinoic acid receptor and its inhibition of retinoic acid-induced apoptosis in cancer cells. J Biol Chem $\underline{273}$, 16985-16992

163. Lo Bianco C, Ridet JL, Schneider BL, Deglon N, Aebischer P (2002): alpha Synucleinopathy and selective dopaminergic neuron loss in a rat lentiviral-based model of Parkinson's disease. Proc Natl Acad Sci U S A 9ㅜ, 10813-10818

164. Lotharius J, Brundin P (2002): Impaired dopamine storage resulting from alphasynuclein mutations may contribute to the pathogenesis of Parkinson's disease. Hum Mol Genet $\underline{11}, 2395-2407$

165. Lüders J, Demand J, Hohfeld J (2000): The ubiquitin-related BAG-1 provides a link between the molecular chaperones Hsc70/Hsp70 and the proteasome. J Biol Chem $\underline{275}, 4613-4617$

166. Malik JM, Shevtsova Z, Bahr M, Kugler S (2005): Long-term in vivo inhibition of CNS neurodegeneration by Bcl-XL gene transfer. Mol Ther 11, 373-381

167. Mandir AS, Przedborski S, Jackson-Lewis V, Wang ZQ, Simbulan-Rosenthal CM, Smulson ME, Hoffman BE, Guastella DB, Dawson VL, Dawson TM (1999): Poly(ADP-ribose) polymerase activation mediates 1-methyl-4-phenyl-1, 2,3,6tetrahydropyridine (MPTP)-induced parkinsonism. Proc Natl Acad Sci U S A $\underline{96}$, 5774-5779

168. Maries E, Dass B, Collier TJ, Kordower JH, Steece-Collier K (2003): The role of alpha-synuclein in Parkinson's disease: insights from animal models. Nat Rev Neurosci $\underline{4}, 727-738$

169. Marshall LE, Himes RH (1978): Rotenone inhibition of tubulin self-assembly. Biochim Biophys Acta 543, 590-594

170. Martinez-Vicente M, Talloczy Z, Kaushik S, Massey AC, Mazzulli J, Mosharov EV, Hodara R, Fredenburg R, Wu DC, Follenzi A, et al. (2008): Dopamine-modified alpha-synuclein blocks chaperone-mediated autophagy. J Clin Invest $\underline{118}$, 777-788

171. Masliah E, Rockenstein E, Veinbergs I, Mallory M, Hashimoto M, Takeda A, Sagara Y, Sisk A, Mucke L (2000): Dopaminergic loss and inclusion body formation in 
alpha-synuclein mice: implications for neurodegenerative disorders. Science 287, 1265-1269

172. Mastakov MY, Baer K, Symes CW, Leichtlein CB, Kotin RM, During MJ (2002): Immunological aspects of recombinant adeno-associated virus delivery to the mammalian brain. J Virol $\underline{76}, 8446-8454$

173. Mladenovic A, Perovic M, Raicevic N, Kanazir S, Rakic L, Ruzdijic S (2004): 6Hydroxydopamine increases the level of TNFalpha and bax mRNA in the striatum and induces apoptosis of dopaminergic neurons in hemiparkinsonian rats. Brain Res $\underline{996}$, 237-245

174. Mochizuki H, Hayakawa H, Migita M, Shibata M, Tanaka R, Suzuki A, ShimoNakanishi Y, Urabe T, Yamada M, Tamayose K, et al. (2001): An AAV-derived Apaf-1 dominant negative inhibitor prevents MPTP toxicity as antiapoptotic gene therapy for Parkinson's disease. Proc Natl Acad Sci U S A $\underline{98}$, 10918-10923

175. Modler AJ, Gast K, Lutsch G, Damaschun G (2003): Assembly of amyloid protofibrils via critical oligomers--a novel pathway of amyloid formation. J Mol Biol $\underline{325}, 135-148$

176. Monti B, Polazzi E, Batti L, Crochemore C, Virgili M, Contestabile A (2007): Alphasynuclein protects cerebellar granule neurons against 6-hydroxydopamine-induced death. J Neurochem $\underline{103}$, 518-530

177. Moskalenko M, Chen L, van Roey M, Donahue BA, Snyder RO, McArthur JG, Patel SD (2000): Epitope mapping of human anti-adeno-associated virus type 2 neutralizing antibodies: implications for gene therapy and virus structure. J Virol $\underline{74}, 1761-1766$

178. Moussa CE, Wersinger C, Tomita Y, Sidhu A (2004): Differential cytotoxicity of human wild type and mutant alpha-synuclein in human neuroblastoma SH-SY5Y cells in the presence of dopamine. Biochemistry $\underline{43}, 5539-5550$

179. Murphy DD, Rueter SM, Trojanowski JQ, Lee VM (2000): Synucleins are developmentally expressed, and alpha-synuclein regulates the size of the presynaptic vesicular pool in primary hippocampal neurons. J Neurosci 20, 3214-3220

180. Muscarella DE, O'Brien KA, Lemley AT, Bloom SE (2003): Reversal of Bcl-2mediated resistance of the EW36 human B-cell lymphoma cell line to arsenite- and pesticide-induced apoptosis by PK11195, a ligand of the mitochondrial benzodiazepine receptor. Toxicol Sci $\underline{74}, 66-73$

181. Naishiro Y, Adachi M, Okuda H, Yawata A, Mitaka T, Takayama S, Reed JC, Hinoda Y, Imai K (1999): BAG-1 accelerates cell motility of human gastric cancer cells. Oncogene $\underline{18}, 3244-3251$

182. Narhi L, Wood SJ, Steavenson S, Jiang Y, Wu GM, Anafi D, Kaufman SA, Martin F, Sitney K, Denis P, et al. (1999): Both familial Parkinson's disease mutations accelerate alpha-synuclein aggregation. J Biol Chem $\underline{274}$, 9843-9846

183. Newhouse K, Hsuan SL, Chang SH, Cai B, Wang Y, Xia Z (2004): Rotenone-induced 
apoptosis is mediated by $\mathrm{p} 38$ and JNK MAP kinases in human dopaminergic SHSY5Y cells. Toxicol Sci $\underline{79}$, 137-146

184. Nicklas WJ, Vyas I, Heikkila RE (1985): Inhibition of NADH-linked oxidation in brain mitochondria by 1-methyl-4-phenyl-pyridine, a metabolite of the neurotoxin, 1methyl-4-phenyl-1,2,5,6-tetrahydropyridine. Life Sci $\underline{36}$, 2503-2508

185. Nollen EA, Kabakov AE, Brunsting JF, Kanon B, Hohfeld J, Kampinga HH (2001): Modulation of in vivo HSP70 chaperone activity by Hip and Bag-1. J Biol Chem 276 , 4677-4682

186. Offen D, Beart PM, Cheung NS, Pascoe CJ, Hochman A, Gorodin S, Melamed E, Bernard R, Bernard O (1998): Transgenic mice expressing human Bcl-2 in their neurons are resistant to 6-hydroxydopamine and 1-methyl-4-phenyl-1,2,3,6tetrahydropyridine neurotoxicity. Proc Natl Acad Sci U S A $\underline{95}, 5789-5794$

187. Okada K, Wangpoengtrakul C, Osawa T, Toyokuni S, Tanaka K, Uchida K (1999): 4Hydroxy-2-nonenal-mediated impairment of intracellular proteolysis during oxidative stress. Identification of proteasomes as target molecules. J Biol Chem $\underline{274}$, 2378723793

188. O'Malley KL, Liu J, Lotharius J, Holtz W (2003): Targeted expression of BCL-2 attenuates MPP+ but not 6-OHDA induced cell death in dopaminergic neurons. Neurobiol Dis $\underline{14}, 43-51$

189. Orr AL, Huang S, Roberts MA, Reed JC, Li S, Li XJ (2008): Sex-dependent effect of BAG1 in ameliorating motor deficits of Huntington disease transgenic mice. J Biol Chem $\underline{283}, 16027-16036$

190. Ostrerova-Golts N, Petrucelli L, Hardy J, Lee JM, Farer M, Wolozin B (2000): The A53T alpha-synuclein mutation increases iron-dependent aggregation and toxicity. $\mathrm{J}$ Neurosci 20, 6048-6054

191. Paisan-Ruiz C, Jain S, Evans EW, Gilks WP, Simon J, van der Brug M, Lopez de Munain A, Aparicio S, Gil AM, Khan N, et al. (2004): Cloning of the gene containing mutations that cause PARK8-linked Parkinson's disease. Neuron $\underline{44}, 595-600$

192. Paisan-Ruiz C, Bhatia KP, Li A, Hernandez D, Davis M, Wood NW, Hardy J, Houlden H, Singleton A, Schneider SA (2009): Characterization of PLA2G6 as a locus for dystonia-parkinsonism. Ann Neurol 65, 19-23

193. Pandey N, Schmidt RE, Galvin JE (2006): The alpha-synuclein mutation E46K promotes aggregation in cultured cells. Exp Neurol 197, 515-520

194. Pankratz N, Nichols WC, Uniacke SK, Halter C, Murrell J, Rudolph A, Shults CW, Conneally PM, Foroud T, Parkinson Study G (2003): Genome-wide linkage analysis and evidence of gene-by-gene interactions in a sample of 362 multiplex Parkinson disease families. Hum Mol Genet 12, 2599-2608

195. Parkinson J (2002): An essay on the shaking palsy. 1817. J Neuropsychiatry Clin Neurosci 14, 223-236; discussion 222 
196. Paterna JC, Feldon J, Bueler H (2004): Transduction profiles of recombinant adenoassociated virus vectors derived from serotypes 2 and 5 in the nigrostriatal system of rats. J Virol $\underline{78}, 6808-6817$

197. Paxinou E, Chen Q, Weisse M, Giasson BI, Norris EH, Rueter SM, Trojanowski JQ, Lee VM, Ischiropoulos H (2001): Induction of alpha-synuclein aggregation by intracellular nitrative insult. J Neurosci $\underline{21}$, 8053-8061

198. Pearce RK, Owen A, Daniel S, Jenner P, Marsden CD (1997): Alterations in the distribution of glutathione in the substantia nigra in Parkinson's disease. J Neural Transm $\underline{104}, 661-677$

199. Perry TL, Godin DV, Hansen S (1982): Parkinson's disease: a disorder due to nigral glutathione deficiency? Neurosci Lett $\underline{33}, 305-310$

200. Perumal AS, Gopal VB, Tordzro WK, Cooper TB, Cadet JL (1992): Vitamin E attenuates the toxic effects of 6-hydroxydopamine on free radical scavenging systems in rat brain. Brain Res Bull 29, 699-701

201. Planchamp V, Bermel C, Tonges L, Ostendorf T, Kugler S, Reed JC, Kermer P, Bahr M, Lingor P (2008): BAG1 promotes axonal outgrowth and regeneration in vivo via Raf-1 and reduction of ROCK activity. Brain $\underline{131}$, 2606-2619

202. Polymeropoulos MH, Lavedan C, Leroy E, Ide SE, Dehejia A, Dutra A, Pike B, Root H, Rubenstein J, Boyer R, et al. (1997): Mutation in the alpha-synuclein gene identified in families with Parkinson's disease. Science 276, 2045-2047

203. Powers KM, Kay DM, Factor SA, Zabetian CP, Higgins DS, Samii A, Nutt JG, Griffith A, Leis B, Roberts JW, et al. (2008): Combined effects of smoking, coffee, and NSAIDs on Parkinson's disease risk. Mov Disord 23, 88-95

204. Priyadarshi A, Khuder SA, Schaub EA, Priyadarshi SS (2001): Environmental risk factors and Parkinson's disease: a metaanalysis. Environ Res $\underline{86}, 122-127$

205. Przedborski S, Vila M (2003): The 1-methyl-4-phenyl-1,2,3,6-tetrahydropyridine mouse model: a tool to explore the pathogenesis of Parkinson's disease. Ann N Y Acad Sci 991, 189-198

206. Przedborski S, Kostic V, Jackson-Lewis V, Naini AB, Simonetti S, Fahn S, Carlson E, Epstein CJ, Cadet JL (1992): Transgenic mice with increased Cu/Zn-superoxide dismutase activity are resistant to N-methyl-4-phenyl-1,2,3,6-tetrahydropyridine induced neurotoxicity. J Neurosci $\underline{12}, 1658-1667$

207. Przedborski S, Tieu K, Perier C, Vila M (2004): MPTP as a mitochondrial neurotoxic model of Parkinson's disease. J Bioenerg Biomembr 36, 375-379

208. Puschmann A, Ross OA, Vilarino-Guell C, Lincoln SJ, Kachergus JM, Cobb SA, Lindquist SG, Nielsen JE, Wszolek ZK, Farrer M, et al. (2009): A Swedish family with de novo alpha-synuclein A53T mutation: Evidence for early cortical dysfunction. Parkinsonism Relat Disord 15, 627-632 
209. Quik M, O'Leary K, Tanner CM (2008): Nicotine and Parkinson's disease: implications for therapy. Mov Disord 23, 1641-1652

210. Ramirez A, Heimbach A, Grundemann J, Stiller B, Hampshire D, Cid LP, Goebel I, Mubaidin AF, Wriekat AL, Roeper J, et al. (2006): Hereditary parkinsonism with dementia is caused by mutations in ATP13A2, encoding a lysosomal type 5 P-type ATPase. Nat Genet $\underline{38}, 1184-1191$

211. Riachi NJ, LaManna JC, Harik SI (1989): Entry of 1-methyl-4-phenyl-1,2,3,6tetrahydropyridine into the rat brain. J Pharmacol Exp Ther 249, 744-748

212. Rideout HJ, Larsen KE, Sulzer D, Stefanis L (2001): Proteasomal inhibition leads to formation of ubiquitin/alpha-synuclein-immunoreactive inclusions in PC12 cells. $\mathrm{J}$ Neurochem $\underline{78}, 899-908$

213. Riederer P, Sofic E, Rausch WD, Schmidt B, Reynolds GP, Jellinger K, Youdim MB (1989): Transition metals, ferritin, glutathione, and ascorbic acid in parkinsonian brains. J Neurochem $\underline{52}, 515-520$

214. Roberts DC, Zis AP, Fibiger HC (1975): Ascending catecholamine pathways and amphetamine-induced locomotor activity: importance of dopamine and apparent noninvolvement of norepinephrine. Brain Res $\underline{93}$, 441-454

215. Rodriguez-Blanco J, Martin V, Herrera F, Garcia-Santos G, Antolin I, Rodriguez C (2008): Intracellular signaling pathways involved in post-mitotic dopaminergic PC12 cell death induced by 6-hydroxydopamine. J Neurochem 107, 127-140

216. Rohde G, Kermer P, Reed JC, Bahr M, Weishaupt JH (2008): Neuron-specific overexpression of the co-chaperone Bcl-2-associated athanogene-1 in superoxide dismutase 1(G93A)-transgenic mice. Neuroscience 157, 844-849

217. Samulski RJ, Chang LS, Shenk T (1989): Helper-free stocks of recombinant adenoassociated viruses: normal integration does not require viral gene expression. J Virol $\underline{63}, 3822-3828$

218. Saporito MS, Thomas BA, Scott RW (2000): MPTP activates c-Jun NH(2)-terminal kinase (JNK) and its upstream regulatory kinase MKK4 in nigrostriatal neurons in vivo. J Neurochem $\underline{75}, 1200-1208$

219. Satake W, Nakabayashi Y, Mizuta I, Hirota Y, Ito C, Kubo M, Kawaguchi T, Tsunoda T, Watanabe M, Takeda A, et al. (2009): Genome-wide association study identifies common variants at four loci as genetic risk factors for Parkinson's disease. Nat Genet $\underline{41}, 1303-1307$

220. Schoch S, Cibelli G, Thiel G (1996): Neuron-specific gene expression of synapsin I. Major role of a negative regulatory mechanism. J Biol Chem 271, 3317-3323

221. Schuler F, Casida JE (2001): Functional coupling of PSST and ND1 subunits in NADH:ubiquinone oxidoreductase established by photoaffinity labeling. Biochim Biophys Acta 1506, 79-87 
222. Schulz JB, Bremen D, Reed JC, Lommatzsch J, Takayama S, Wullner U, Loschmann PA, Klockgether T, Weller M (1997): Cooperative interception of neuronal apoptosis by BCL-2 and BAG-1 expression: prevention of caspase activation and reduced production of reactive oxygen species. J Neurochem $\underline{69}$, 2075-2086

223. Scott IG, Akerman KE, Heikkila JE, Kaila K, Andersson LC (1986): Development of a neural phenotype in differentiating ganglion cell-derived human neuroblastoma cells. J Cell Physiol 128, 285-292

224. Sherer TB, Betarbet R, Testa CM, Seo BB, Richardson JR, Kim JH, Miller GW, Yagi T, Matsuno-Yagi A, Greenamyre JT (2003): Mechanism of toxicity in rotenone models of Parkinson's disease. J Neurosci 23, 10756-10764

225. Shevtsova Z, Malik I, Garrido M, Scholl U, Bahr M, Kugler S (2006): Potentiation of in vivo neuroprotection by $\mathrm{BclX}(\mathrm{L})$ and GDNF co-expression depends on post-lesion time in deafferentiated CNS neurons. Gene Ther $\underline{13}$, 1569-1578

226. Shin Y, Klucken J, Patterson C, Hyman BT, McLean PJ (2005): The co-chaperone carboxyl terminus of Hsp70-interacting protein (CHIP) mediates alpha-synuclein degradation decisions between proteasomal and lysosomal pathways. J Biol Chem $\underline{280}, 23727-23734$

227. Singleton AB, Farrer M, Johnson J, Singleton A, Hague S, Kachergus J, Hulihan M, Peuralinna T, Dutra A, Nussbaum R, et al. (2003): alpha-Synuclein locus triplication causes Parkinson's disease. Science $\underline{302}, 841$

228. Smith PK, Krohn RI, Hermanson GT, Mallia AK, Gartner FH, Provenzano MD, Fujimoto EK, Goeke NM, Olson BJ, Klenk DC (1985): Measurement of protein using bicinchoninic acid. Anal Biochem 150, 76-85

229. Smith WW, Jiang H, Pei Z, Tanaka Y, Morita H, Sawa A, Dawson VL, Dawson TM, Ross CA (2005): Endoplasmic reticulum stress and mitochondrial cell death pathways mediate A53T mutant alpha-synuclein-induced toxicity. Hum Mol Genet 14, 38013811

230. Snyder H, Mensah K, Theisler C, Lee J, Matouschek A, Wolozin B (2003): Aggregated and monomeric alpha-synuclein bind to the S6' proteasomal protein and inhibit proteasomal function. J Biol Chem 278, 11753-11759

231. Sondermann H, Scheufler C, Schneider C, Hohfeld J, Hartl FU, Moarefi I (2001): Structure of a Bag/Hsc70 complex: convergent functional evolution of Hsp70 nucleotide exchange factors. Science $\underline{291}, 1553-1557$

232. Song J, Takeda M, Morimoto RI (2001): Bag1-Hsp70 mediates a physiological stress signalling pathway that regulates Raf-1/ERK and cell growth. Nat Cell Biol $\underline{3}$, 276282

233. Spencer JP, Jenner P, Daniel SE, Lees AJ, Marsden DC, Halliwell B (1998):

Conjugates of catecholamines with cysteine and GSH in Parkinson's disease: possible mechanisms of formation involving reactive oxygen species. J Neurochem $\underline{71}, 2112$ - 
234. Spillantini MG, Schmidt ML, Lee VM, Trojanowski JQ, Jakes R, Goedert M (1997): Alpha-synuclein in Lewy bodies. Nature $\underline{388}, 839-840$

235. Srivastava A, Lusby EW, Berns KI (1983): Nucleotide sequence and organization of the adeno-associated virus 2 genome. J Virol $\underline{45}, 555-564$

236. Sroka K, Voigt A, Deeg S, Reed JC, Schulz JB, Bahr M, Kermer P (2009): BAG1 modulates huntingtin toxicity, aggregation, degradation, and subcellular distribution. J Neurochem 111, 801-807

237. Stefanis L, Larsen KE, Rideout HJ, Sulzer D, Greene LA (2001): Expression of A53T mutant but not wild-type alpha-synuclein in PC12 cells induces alterations of the ubiquitin-dependent degradation system, loss of dopamine release, and autophagic cell death. J Neurosci 21, 9549-9560

238. Stieger K, Le Meur G, Lasne F, Weber M, Deschamps JY, Nivard D, MendesMadeira A, Provost N, Martin L, Moullier P, et al. (2006): Long-term doxycyclineregulated transgene expression in the retina of nonhuman primates following subretinal injection of recombinant AAV vectors. Mol Ther $\underline{13}$, 967-975

239. Storch A, Kaftan A, Burkhardt K, Schwarz J (2000): 6-Hydroxydopamine toxicity towards human SH-SY5Y dopaminergic neuroblastoma cells: independent of mitochondrial energy metabolism. J Neural Transm 107, 281-293

240. Strauss KM, Martins LM, Plun-Favreau H, Marx FP, Kautzmann S, Berg D, Gasser T, Wszolek Z, Muller T, Bornemann A, et al. (2005): Loss of function mutations in the gene encoding Omi/HtrA2 in Parkinson's disease. Hum Mol Genet 14, 2099-2111

241. Takayama S, Reed JC (2001): Molecular chaperone targeting and regulation by BAG family proteins. Nat Cell Biol $\underline{3}$, E237-241

242. Takayama S, Sato T, Krajewski S, Kochel K, Irie S, Millan JA, Reed JC (1995): Cloning and functional analysis of BAG-1: a novel Bcl-2-binding protein with anticell death activity. Cell $\underline{80}, 279-284$

243. Takayama S, Kochel K, Irie S, Inazawa J, Abe T, Sato T, Druck T, Huebner K, Reed JC (1996): Cloning of cDNAs encoding the human BAG1 protein and localization of the human BAG1 gene to chromosome 9p12. Genomics $\underline{35}$, 494-498

244. Takayama S, Bimston DN, Matsuzawa S, Freeman BC, Aime-Sempe C, Xie Z, Morimoto RI, Reed JC (1997): BAG-1 modulates the chaperone activity of Hsp70/Hsc70. EMBO J 16, 4887-4896

245. Takeda A, Mallory M, Sundsmo M, Honer W, Hansen L, Masliah E (1998): Abnormal accumulation of NACP/alpha-synuclein in neurodegenerative disorders. Am J Pathol $\underline{152}, 367-372$

246. Tan EK, Tan C, Shen H, Chai A, Lum SY, Teoh ML, Yih Y, Wong MC, Zhao Y (2003): Alpha synuclein promoter and risk of Parkinson's disease: microsatellite and 
allelic size variability. Neurosci Lett $\underline{336}, 70-72$

247. Tanaka K, Ogawa N, Asanuma M (2006): Molecular basis of 6-hydroxydopamineinduced caspase activations due to increases in oxidative stress in the mouse striatum. Neurosci Lett $\underline{410}, 85-89$

248. Tanaka Y, Engelender S, Igarashi S, Rao RK, Wanner T, Tanzi RE, Sawa A, V LD, Dawson TM, Ross CA (2001): Inducible expression of mutant alpha-synuclein decreases proteasome activity and increases sensitivity to mitochondria-dependent apoptosis. Hum Mol Genet 10, 919-926

249. Tang SC (2002): BAG-1, an anti-apoptotic tumour marker. IUBMB Life $\underline{53}$, 99-105

250. Tanner CM, Ottman R, Goldman SM, Ellenberg J, Chan P, Mayeux R, Langston JW (1999): Parkinson disease in twins: an etiologic study. JAMA 281, 341-346

251. Tatton NA, Kish SJ (1997): In situ detection of apoptotic nuclei in the substantia nigra compacta of 1-methyl-4-phenyl-1,2,3,6-tetrahydropyridine-treated mice using terminal deoxynucleotidyl transferase labelling and acridine orange staining. Neuroscience $\underline{77}$, $1037-1048$

252. Terada K, Mori M (2000): Human DnaJ homologs dj2 and dj3, and bag-1 are positive cochaperones of hsc70. J Biol Chem $\underline{275}$, 24728-24734

253. Tetzlaff JE, Putcha P, Outeiro TF, Ivanov A, Berezovska O, Hyman BT, McLean PJ (2008): CHIP targets toxic alpha-Synuclein oligomers for degradation. J Biol Chem $\underline{283}, 17962-17968$

254. Thal DR, Del Tredici K, Braak H (2004): Neurodegeneration in normal brain aging and disease. Sci Aging Knowledge Environ 2004, pe26

255. Thomas B, Beal MF (2007): Parkinson's disease. Hum Mol Genet 16 Spec No. 2 , R183-194

256. Townsend PA, Cutress RI, Sharp A, Brimmell M, Packham G (2003): BAG-1: a multifunctional regulator of cell growth and survival. Biochim Biophys Acta 1603, 83-98

257. Ungerstedt U (1968): 6-Hydroxy-dopamine induced degeneration of central monoamine neurons. Eur J Pharmacol 5, 107-110

258. Ungerstedt U, Arbuthnott GW (1970): Quantitative recording of rotational behavior in rats after 6-hydroxy-dopamine lesions of the nigrostriatal dopamine system. Brain Res $\underline{24}, 485-493$

259. Uversky VN, Li J, Fink AL (2001): Metal-triggered structural transformations, aggregation, and fibrillation of human alpha-synuclein. A possible molecular NK between Parkinson's disease and heavy metal exposure. J Biol Chem $\underline{276}$, 4428444296

260. Valente EM, Salvi S, Ialongo T, Marongiu R, Elia AE, Caputo V, Romito L, Albanese 
A, Dallapiccola B, Bentivoglio AR (2004): PINK1 mutations are associated with sporadic early-onset parkinsonism. Ann Neurol 56, 336-341

261. van der Putten H, Wiederhold KH, Probst A, Barbieri S, Mistl C, Danner S, Kauffmann S, Hofele K, Spooren WP, Ruegg MA, et al. (2000): Neuropathology in mice expressing human alpha-synuclein. J Neurosci 20, 6021-6029

262. Vazquez-Claverie M, Garrido-Gil P, San Sebastian W, Izal-Azcarate A, Belzunegui S, Marcilla I, Lopez B, Luquin MR (2009): Acute and chronic 1-methyl-4-phenyl1,2,3,6-tetrahydropyridine administrations elicit similar microglial activation in the substantia nigra of monkeys. J Neuropathol Exp Neurol $\underline{68}$, 977-984

263. Vila M, Vukosavic S, Jackson-Lewis V, Neystat M, Jakowec M, Przedborski S (2000): Alpha-synuclein up-regulation in substantia nigra dopaminergic neurons following administration of the parkinsonian toxin MPTP. J Neurochem $\underline{74}$, 721-729

264. Vila M, Jackson-Lewis V, Vukosavic S, Djaldetti R, Liberatore G, Offen D, Korsmeyer SJ, Przedborski S (2001): Bax ablation prevents dopaminergic neurodegeneration in the 1-methyl- 4-phenyl-1,2,3,6-tetrahydropyridine mouse model of Parkinson's disease. Proc Natl Acad Sci U S A $\underline{98}$, 2837-2842

265. Vogiatzi T, Xilouri M, Vekrellis K, Stefanis L (2008): Wild type alpha-synuclein is degraded by chaperone-mediated autophagy and macroautophagy in neuronal cells. J Biol Chem $\underline{283}, 23542-23556$

266. Volles MJ, Lansbury PT, Jr. (2002): Vesicle permeabilization by protofibrillar alphasynuclein is sensitive to Parkinson's disease-linked mutations and occurs by a porelike mechanism. Biochemistry $\underline{41}, 4595-4602$

267. Vyas I, Heikkila RE, Nicklas WJ (1986): Studies on the neurotoxicity of 1-methyl-4phenyl-1,2,3,6-tetrahydropyridine: inhibition of NAD-linked substrate oxidation by its metabolite, 1-methyl-4-phenylpyridinium. J Neurochem $\underline{46}, 1501-1507$

268. Wang HG, Takayama S, Rapp UR, Reed JC (1996): Bcl-2 interacting protein, BAG-1, binds to and activates the kinase Raf-1. Proc Natl Acad Sci U S A 93, 7063-7068

269. Wersinger C, Sidhu A (2003): Attenuation of dopamine transporter activity by alphasynuclein. Neurosci Lett $\underline{340}, 189-192$

270. Wider C, Wszolek ZK (2008): Etiology and pathophysiology of frontotemporal dementia, Parkinson disease and Alzheimer disease: lessons from genetic studies. Neurodegener Dis $\underline{5}, 122-125$

271. Wolvetang EJ, Johnson KL, Krauer K, Ralph SJ, Linnane AW (1994): Mitochondrial respiratory chain inhibitors induce apoptosis. FEBS Lett $\underline{339}$, 40-44

272. Wong LF, Ralph GS, Walmsley LE, Bienemann AS, Parham S, Kingsman SM, Uney JB, Mazarakis ND (2005): Lentiviral-mediated delivery of Bcl-2 or GDNF protects against excitotoxicity in the rat hippocampus. Mol Ther $\underline{11}, 89-95$

273. Woo YJ, Zhang JC, Taylor MD, Cohen JE, Hsu VM, Sweeney HL (2005): One year 
transgene expression with adeno-associated virus cardiac gene transfer. Int J Cardiol $\underline{100}, 421-426$

274. Wu Y, Blum D, Nissou MF, Benabid AL, Verna JM (1996): Unlike MPP+, apoptosis induced by 6-OHDA in PC12 cells is independent of mitochondrial inhibition. Neurosci Lett 221, 69-71

275. Xilouri M, Vogiatzi T, Vekrellis K, Park D, Stefanis L (2009): Abberant alphasynuclein confers toxicity to neurons in part through inhibition of chaperone-mediated autophagy. PLoS One $\underline{4}$, e5515

276. Yamada M, Oligino T, Mata M, Goss JR, Glorioso JC, Fink DJ (1999): Herpes simplex virus vector-mediated expression of Bcl-2 prevents 6-hydroxydopamineinduced degeneration of neurons in the substantia nigra in vivo. Proc Natl Acad Sci U S A $\underline{96}, 4078-4083$

277. Yang L, Matthews RT, Schulz JB, Klockgether T, Liao AW, Martinou JC, Penney JB, Jr., Hyman BT, Beal MF (1998): 1-Methyl-4-phenyl-1,2,3,6-tetrahydropyride neurotoxicity is attenuated in mice overexpressing Bcl-2. J Neurosci $\underline{18}, 8145-8152$

278. Zach S, Bueler H, Hengerer B, Gillardon F (2007): Predominant neuritic pathology induced by viral overexpression of alpha-synuclein in cell culture. Cell Mol Neurobiol $\underline{27}, 505-515$

279. Zarranz JJ, Alegre J, Gomez-Esteban JC, Lezcano E, Ros R, Ampuero I, Vidal L, Hoenicka J, Rodriguez O, Atares B, et al. (2004): The new mutation, E46K, of alphasynuclein causes Parkinson and Lewy body dementia. Ann Neurol 55, 164-173

280. Zeiner M, Gehring U (1995): A protein that interacts with members of the nuclear hormone receptor family: identification and cDNA cloning. Proc Natl Acad Sci U S A $\underline{92}, 11465-11469$

281. Zeiner M, Gebauer M, Gehring U (1997): Mammalian protein RAP46: an interaction partner and modulator of $70 \mathrm{kDa}$ heat shock proteins. EMBO J $\underline{16}, 5483-5490$

282. Zeng BY, Medhurst AD, Jackson M, Rose S, Jenner P (2005): Proteasomal activity in brain differs between species and brain regions and changes with age. Mech Ageing Dev 126, 760-766

283. Zhang J, Graham DG, Montine TJ, Ho YS (2000): Enhanced N-methyl-4-phenyl1,2,3,6-tetrahydropyridine toxicity in mice deficient in CuZn-superoxide dismutase or glutathione peroxidase. J Neuropathol Exp Neurol 모, 53-61

284. Zhang NY, Tang Z, Liu CW (2008): alpha-Synuclein protofibrils inhibit 26 S proteasome-mediated protein degradation: understanding the cytotoxicity of protein protofibrils in neurodegenerative disease pathogenesis. J Biol Chem $\underline{283}$, 2028820298

285. Zhong LT, Sarafian T, Kane DJ, Charles AC, Mah SP, Edwards RH, Bredesen DE (1993): bcl-2 inhibits death of central neural cells induced by multiple agents. Proc Natl Acad Sci U S A $\underline{90}$, 4533-4537 
286. Zimprich A, Biskup S, Leitner P, Lichtner P, Farrer M, Lincoln S, Kachergus J, Hulihan M, Uitti RJ, Calne DB, et al. (2004): Mutations in LRRK2 cause autosomaldominant parkinsonism with pleomorphic pathology. Neuron $\underline{44}$, 601-6 
Teile dieser Arbeit wurden in folgendem Beitrag vorab veröffentlicht:

\section{Poster:}

Dohm CP, Baumann A, Schnieder M, Liman J, Reed, JC, Bähr M, Kermer P: BAG1 mediated neuroprotection in in vivo and in vitro models of Parkinson's disease. $32^{\text {th }}$ Göttingen Neurobiology Conference, 8th Meeting of the Neuroscience Society, 25. bis 29. März 2009 in Göttingen 


\section{DANKSAGUNG}

Zuerst möchte ich mich bei Prof. M. Bähr für die freundliche Aufnahme in seine Arbeitsgruppe und für die Ermöglichung zur Durchführung dieser Arbeit bedanken.

Mein ganz besonderer Dank gilt meinem Betreuer Dr. Christoph Dohm für die wunderbare Zusammenarbeit. Er hat dafür gesorgt, dass ich während der vielen Rückschläge und Frustrationen, welche die Laborarbeit mit sich bringt, nie die Motivation verloren habe. Jedes Gespräch mit ihm hat mir neue Perspektiven aufgezeigt, für die ich mich wieder begeistern konnte. Ihm danke ich insbesondere auch für die Hilfe bei den statistischen Auswertungen und natürlich für seine Freundschaft und das offene Ohr für jedes Problem während der gesamten Zeit meiner Dissertation.

Mein Dank gilt weiterhin insbesondere meinem Doktorvater Prof. Dr. P. Kermer für die Bereitstellung dieses spannenden Themas, für seine Hilfsbereitschaft während der gesamten Zeit meiner Dissertation und insbesondere für die unglaublich schnellen Korrekturen an meiner Arbeit.

Weiterhin bedanken möchte ich mich bei allen Mitgliedern der Arbeitsgruppe von Prof. M. Bähr, insbesondere aber bei der AG Kermer, die mir immer mit Rat und Tat zur Seite standen. Großen Dank schulde ich hier insbesondere Beate Veith für die Einführung in die praktische Laborarbeit zu Beginn meiner Dissertation und Sandra Gerke für die große Hilfe bei vielen Techniken der praktischen Laborarbeit. Weiterhin gilt mein Dank Gunnar Dietz für die theoretische Einführung in verschiedenste wissenschaftliche Methoden im Rahmen seines Doktorandenseminars, was mir immer wieder neue Denkanstöße beschert hat. Besonders danken möchte ich außerdem Florian Nagel für die Hilfe meim Tier-Handling sowie den stereologischen Auszählungen, Sebastian Kügler für die Bereitstellung der Viren, und Zinayida Shevtsova für die geduldige Anleitung zur Virusinjektion. Mein ganz besonderer Dank gilt auch Marlena Schnieder, meiner Mitdoktorandin und Freundin, ohne welche die Fertigstellung dieser Arbeit nicht möglich gewesen wäre. 
Ich danke weiterhin dem Team der Arbeitsgruppe von Prof. J.B. Schulz in Göttingen für die Einarbeitung in die Stereologie-Software sowie J. C. Reed vom Burnham Institute, La Jolla, USA für die freundliche Bereitstellung des BAG1-Konstruktes. 


\section{LEBENSLAUF}

Ich, Anja Friederike Baumann, wurde am 03.01.1984 als erstes Kind der Diplom-Volkswirtin Birgit Baumann (geb. 09.07.1955), geborene Koltzau, und des Diplom-Mathematikers Bernd Alfons Baumann (geb 02.10.1954) in Hamburg geboren. Mein Bruder Christoph Baumann wurde am 14.01.1987 in Hamburg geboren.

In den Jahren 1990 bis 1994 besuchte ich die Grundschule Sengelmannstraße in Hamburg. Von dort wechselte ich anschließend auf das Gymnasium Süderelbe. Im Juli 2003 erwarb ich dort die Allgemeine Hochschulreife. Parallel zur gymnasialen Oberstufe habe ich eine Ausbildung zur Chemisch Technischen Assistentin (CTA) am Gymnasium Altona und der Gewerbeschule in Bergedorf begonnen, die ich im Januar 2004 abschloss.

Im April 2004 begann ich das Studium der Humanmedizin an der Georg-August-Universität in Göttingen, wo ich im April 2006 den ersten Teil der ärztlichen Prüfung ablegte. Im November 2006 wurde ich als Stipendiatin in die Studienstiftung des Deutschen Volkes aufgenommen. Die wissenschaftliche Arbeit für meine Promotion in der Arbeitsgruppe von Prof. P. Kermer (Abteilung Neurologie, Universitätsmedizin Göttingen) begann ich im Dezember 2006. Im Sommersemster 2007 erhielt ich ein Förderstipendium der Universitätsmedizin Göttingen für ein Forschungsfreisemester.

Das Praktische Jahr absolvierte ich von August 2009 bis Juli 2010 am Universitätsklinikum Göttingen im Fach Pädiatrie, am Inselspital in Bern im Fach Innere Medizin (Abteilung Nephrologie) und am Western Hospital in Melbourne sowie am Städtischen Klinikum Lüneburg im Fach Chirurgie. Im Herbst 2010 werde ich voraussichtlich den zweiten Teil der ärztlichen Prüfung ablegen. 